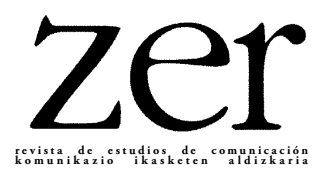

\title{
Propuesta metodológica para el análisis del videojuego desde la perspectiva del paradigma clásico del guión cinematográfico y su aplicación a Assassin's Creed IV: Black Flag
}

Bideo-jokoaren analisia egiteko proposamen metodologikoa gidoi zinematografikoaren paradigma klasikoaren ikuspegitik eta horren aplikazioa Assassin's Creed IV: Black Flag jokoan

Methodological Proposal for the Videogames analysis using as perspective the classic screenplay paradigm and its application to the study of Assassin's Creed IV: Black Flag

Germán Esteban Espinosa

Doctor en Ciencias de la Comunicación especializado en la narrativa de los videojuegos

Antonio Malalana-Ureña

Fundación Universitaria CEU

RESUMEN: el presente artículo propone una nueva metodología para comprobar si existen semejanzas estructurales entre la narración en el videojuego y las estructuras clásicas del guión cinematográfico, y prueba su utilidad empleándola en el análisis del argumento de un videojuego.

PALABRAS CLAVE: Videojuego; narrativa audiovisual; cine; guión; metodología.

LABURPENA: artikulu honen bidez metodologia berri bat proposatzen da bideojokoaren narrazioaren eta gidoi zinematografikoaren egitura klasikoen artean egiturazko antzekotasunak dauden egiaztatzeko, eta erabilgarria dela frogatzeko, bideojoko baten argumentua aztertzeko erabiltzen da.

HITZ-GAKOAK: Bideo-jokoa; ikus-entzunezko narratiba; zinema; gidoia; metodologia. 
ABSTRACT: This paper proposes a new methodology created to check the existence of structural similarities between videogame narrative and classic screenplay structures. Once it is developed, it is applied to analyze a videogame's plot.

KEYWORDS: Videogame, audiovisual narrative; cinema; screenplay; methodology.

* Correspondencia a: Germán Esteban Espinosa. Universidad CEU San Pablo, P. Juan XXIII 6 (28040 Madrid).vohzd2@gmail.com https://orcid.org/0000-0001-8647-8862

Cómo citar: Esteban Espinosa, Germán; Malalana-Ureña, Antonio. 2018. Propuesta metodológica para el análisis del videojuego desde la perspectiva del paradigma clásico del guión cinematográfico y su aplicación a Assassin's Creed IV: Black Flag. Zer. 23(45). 117-138.

https://doi.org/10.1387/zer.20179

Recibido: 13 setiembre 2018; aceptado: 17 octubre 2018

1137-1102 y 1989-631X / C 2018 UPV/EHU 


\section{Introducción}

Cuando jugamos a muchos de los productos de la industria cultural del videojuego (Morales, 2012: 20), tenemos la sensación de estar consumiendo ficciones audiovisuales que guardan una enorme semejanza con las obras cinematográficas. Sin embargo, a la hora de querer comprobar si nuestra intuición es acertada o no, nos encontramos ante la ausencia de metodologías que sirvan para nuestros objetivos, por lo que nos proponemos elaborar un método de análisis de la narración en el videojuego que nos permita, además de localizar claramente todo lo que suceda en su argumento, comparar su estructura narrativa con la descrita en las teorías clásicas del guión cinematográfico.

El estudio del videojuego desde las perspectivas de las humanidades y la comunicación se ha desarrollado notablemente desde mediados de los años 90 del siglo pasado (Wolf, Perrón, 2005; Planells, 2015), respondiendo al gran crecimiento que ha experimentado este producto en nuestra sociedad, con un incremento en su facturación global del 320,74\% entre 2005 y 2015, pasando de los 25.000 a los 80.186 millones de euros (Benito, 2006: 38; Aevi, 2016: 29). De la cifra del 2015, España aportó 1.083 millones de euros, pagados por los aproximadamente 15 millones de jugadores con los que cuenta nuestro país, de los que el $47 \%$ son mujeres y el resto hombres (2016: 6, 33). Este crecimiento parece, además, tener una marcadísima tendencia al alza, como demuestra el incremento de la facturación en 2017 hasta llegar a los 1.350 millones de euros, un 24,6\% más que dos años atrás, cifra que supera con holgura la facturación del cine (597 millones) y de la música grabada (474 millones). También se aprecia un aumento en el número de jugadores, que sube hasta los 15,8 millones, de los cuales un 44\% son mujeres (Aevi, 2018: 32).

El videojuego es, además, un producto heterogéneo, que mezcla en proporciones muy variables superación de retos, juego, creación y narración, lo que dificulta que exista un único método válido para su investigación, hecho que a su vez provoca la creación de numerosas propuestas de análisis, algunas de las cuales se oponen frontalmente. En este artículo vamos a explorar primero la teoría sobre el videojuego, a ver si podemos constatar la existencia de su dimensión narrativa; para a continuación analizar la existencia o no de metodologías que aproximen el cine al videojuego y las teorías principales del paradigma clásico cinematográfico. A continuación, describiremos en qué consiste nuestra metodología y la ficha de análisis, y la aplicaremos al estudio del videojuego Assassin's Creed IV: Black Flag.

\section{Definiendo el videojuego: jugar con reglas o vivir una narración}

Aunque se hayan desarrollado múltiples teorías desde que en 1997 Espen Aarseth y Janet H. Murray comenzaran a analizar el videojuego desde la perspectiva de las $\mathrm{Hu}-$ 
manidades y la Comunicación, todas se pueden clasificar en función de si apuestan por entender el videojuego como una simulación con un conjunto de reglas definidas con las que el usuario juega, o como una ficción interactiva en la que el jugador recibe una historia. Aunque en el año 2004 Henry Jenkins propusiera una teoría intermedia que analiza los videojuegos como mundos con capacidad de contar historias (Jenkins, 2004: 118-130), y recientemente en España Planells propusiera, inspirado por Ryan, analizarlos como un universo de mundos posibles que se actualizan en función de las acciones del jugador (2015), todas las teorías son herederas de los principios que sembraron la oposición entre la Ludología de Dinamarca y países europeos y la Narratología de Norteamérica ${ }^{1}$.

Podemos situar la consolidación oficial de la Ludología en el año 2001, con la fundación de la revista Game Studies en la Universidad de Copenhague de la mano de Jesper Juul y Espen Aarseth, quien años atrás, en 1997, había definido al videojuego como un "cibertexto», un texto que para ser leído por el lector, requería de un esfuerzo no trivial por parte de éste, por ser este texto una especie de «literatura ergódica» (Aarseth, 2004:117-145). Aunque sea Gonzalo Frasca quien adelantó una definición en 1999 de Ludología y la completó en 2003, señalándola como una disciplina que estudia los juegos en general y los videojuegos en particular, y que no se usa solo para el estudio de los videojuegos sino también para otros como los juegos de mesa (2003), es el artículo inaugural de Jesper Juul en Game Studies el que asienta los principales argumentos para calificar la narración en los videojuegos como un accesorio meramente secundario.

Jesper Juul argumenta que un videojuego no puede ser tratado como una narración por no pertenecer al ecosistema formado por la novela, el cine y el teatro; por tener un tiempo diferente al que opera en las narraciones tradicionales, pues en estas los eventos suceden en pasado, mientras que en el juego lo hacen en el presente a través de la interacción del jugador, amén de no tener ni flashbacks ni flashforwards (afirmación muy discutible); y porque la relación entre el jugador y el mundo del juego es diferente a la del lector/espectador con la novela/película, pues en el segundo caso el receptor del mensaje es pasivo, o al menos, más pasivo que en el primero. Aunque opina que los videojuegos y las narrativas comparten ciertas semejanzas estructurales, defiende sus diferencias argumentando que no se puede tener interacción y narración a la vez y que, en consecuencia, nuestra experiencia es distinta si jugamos que si leemos, además de sostener que mientras la narración es lineal y fija, el videojuego permite una narración emergente única y distinta en cada partida (2001).

${ }^{1}$ Para conocer una visión estructurada de todos los posibles acercamientos teóricos al videojuego, recomendamos la consulta del artículo firmado por Navarrete Cardero y otros que indicamos en las referencias bibliográficas (Navarrete, Gómez y Pérez, 2014b). 
Estos argumentos son respondidos enérgicamente por Marie-Laure Ryan, quien recoge el testigo de la mayor impulsora de la narratología en el videojuego, Janet H. Murray, que definió a éste como un «drama simbólico» que permitía una inmersión mucho mayor que la novela o la película (1999: 110). Ryan contesta a los argumentos de Juul alegando que en el caso del videojuego, la interacción no interrumpe a la narración, ya que al jugar, el jugador ve el efecto inmediato de sus acciones en el mundo del videojuego, con lo que a la vez que interactúa, recibe una narración, pudiendo darse ambos fenómenos simultáneamente.

También critica que el hecho de que el videojuego presente una narración diferente al cine, el teatro o la novela, no implica que por ello tenga que dejar de ser narrativo; que hay videojuegos que contienen recursos que interrumpen la narración lineal como el flashback y que, aunque la narración escrita use tiempos verbales para expresar el paso del tiempo, los lectores son transportados al pasado de lo narrado, viviendo los hechos en presente, al igual que en el videojuego. También comenta que aunque se deje al videojugador cierta libertad de acción, esta siempre está sujeta a una estructura macro prefijada por los diseñadores del videojuego, que además de buscar la limitación de las posibilidades del usuario, establece una relación causal entre los hechos pasados y los presentes del argumento.

Así, la autora concluye proponiendo una definición del videojuego como producto narrativo: «apelando en proporciones variables a la capacidad estratégica de la mente y a la imaginación, los videojuegos son un arte de compromiso entre la narración y el gameplay»² (Ryan, 2006: 185-198).

A estos argumentos a favor de la narración en el videojuego podemos sumarles otros de la producción académica española, tales como la propuesta de definirlo como una narración caleidoscópica que se construye a partir de la fragmentación en la superficie discursiva, que dota al jugador del triple papel de lector, jugador y autor, pues juega con las reglas del juego y, al hacerlo, crea una nueva ficción dentro del mismo que a la vez lee (Esnaola, 2008). También podemos tomar la definición de «narrativas interactivas electivas regladas» (Marín, 2015: 98), o de un modo más próximo a nuestro objetivo, definir al videojuego como un tipo de «narración audiovisual interactiva, que parte de la estructura cinematográfica pero va más allá, [y] cuyo argumento necesita de la actividad ergódica del usuario para ser completado» («Primer autor», 2017: 340).

Una vez que hemos constatado la presencia de teorías que sostienen que la narración existe en los videojuegos y que puede tener peso suficiente como para fundamentar su misma definición, veamos ahora desde qué perspectivas se afronta

\footnotetext{
2 Traducción del inglés realizada por el autor.
} 
el estudio de los contactos entre videojuegos y cine, y si ya existen metodologías próximas a nuestros objetivos.

\section{Videojuegos y cine: en busca de una metodología de análisis}

Ante nuestra sorpresa, el enfoque que sostenemos sobre las semejanzas de estructura narrativa entre cine y videojuegos está escasamente representado en la bibliografía científica. Al repasar tanto la española como la internacional, vemos en primer lugar una serie de voces en contra de una supuesta semejanza entre ambos medios.

Así, por ejemplo, tenemos en España las opiniones de Navarrete Cardero y otros (2014a), que aluden a que cine y videojuegos son dos medios diferentes porque en el primero el espectador pone en práctica el pensamiento deductivo e inductivo para adivinar qué va a aparecer a continuación en la trama, mientras que en el segundo lo que opera es el pensamiento abductivo de generación de hipótesis y verificación de las mismas. Gómez Tarín y otros (2012) sostienen que ambos medios se diferencian insalvablemente porque para ver una película, el espectador establece un vínculo semiótico, empático o cultural con la misma; mientras que esto no es necesario para jugar al videojuego ${ }^{3}$. Afirman también que el cine es contemplativo mientras que el videojuego es participativo, aunque tal como sostenía Ryan, vemos cómo esa participación a la vez se convierte en contemplación al ser observados sus efectos en el mundo del videojuego y, por tanto, incorporados a la narración.

Siguiendo en la perspectiva de negar la relación de semejanza entre cine y videojuegos, encontramos a Geoff King, quien defiende que la repetición de partidas hasta que el jugador consigue la superación de su misión es el fundamento narrativo del videojuego, por lo que, si el cine se pareciera a este medio de entretenimiento, sería necesario ver cómo los protagonistas mueren y resucitan una y otra vez hasta que tienen éxito en sus objetivos (aunque también podríamos interpretar que este sistema de repeticiones se produce cuando el jugador no ha sido capaz de completar la narración como está prevista en la trama, por lo que más que un recurso narrativo del videojuego sería más bien un recurso de su jugabilidad). También alude a que si en la película existen tres actos, en el videojuego, en realidad, el jugador solo juega a un segundo acto muy ampliado (King, Krzywinska, 2002: 19). En la misma monografia, Andrew MacTavish señala las diferencias entre ambos, indicando que, por encima de la trama, en el videojuego la importancia radica en la resolución de con-

${ }^{3}$ Afirmación de la que podemos discrepar, ya que al jugar al videojuego también establecemos un vínculo semiótico y cultural con él, como demuestra la necesidad de traducir y hasta localizar videojuegos extranjeros cuando llegan a España, como informa Lucila María Pérez en su tesis doctoral (2010). 
flictos de dificultad creciente (2002: 39) (Sin embargo, la resolución de conflictos de dificultad creciente es, precisamente, el principio básico que guía la acción de muchas películas).

Cambiando de perspectiva, encontramos a aquellos investigadores que buscan establecer una aproximación entre ambos medios, denotando las influencias entre uno y otro. Así, vemos cómo Planells de la Maza selecciona el videojuego Max Payne para indicar cómo su equipo de desarrollo tomó fotos de calles de Nueva York y se inspiró en el cine de John Woo para crear la ambientación del título, la importancia de la escenografia para crear el espacio de juego o el carácter puramente cinematográfico de las cinemáticas (partes no interactivas del videojuego), definiendo a este título como una mezcla «entre tres formas de contar un relato: la narrativa emergente del medio interactivo, la continuidad cinematográfica y la discontinuidad del cómic» (2010: 4-12).

Iván Bort Gual intenta algo semejante con el videojuego Silent Hill, señalando la presencia en este título de numerosos recursos del cine de terror (2012). Por su parte, Eric Zimmerman constata que los videojuegos están tomando prestados más y más recursos cinematográficos, transformándose en una especie de cine mutante (2004: 154-163).

Es interesante la perspectiva que Planells establece al analizar la evolución narrativa de los videojuegos y la de los modelos de representación en el celuloide, estableciendo una comparativa entre los primeros videojuegos y los modelos de representación del cine de los pioneros, aludiendo a que los inventores de ambos medios eran científicos, al paso del encuadre centrípeto a la concepción centrífuga para crear mundos de ficción completos que se desarrollan más allá de lo que vemos en pantalla y el consecuente fin de la autarquía del plano, e incluso al progresivo establecimiento de un Star System del videojuego con personajes como Mario (2011: 46-57).

Jason W. Buel ve la influencia del cine en el videojuego en la manera en que géneros clásicos del Séptimo Arte se instalan en las historias interactivas, centrándose en este caso en el Western dentro del título Red Dead Redemption (2013: 48). Audrey Anable añade que el videojuego consigue expandir aspectos de la trama cinematográfica tales como las líneas narrativas secundarias, los personajes y el atrezo (2013: 86-100).

También existen aquellos que enfocan el estudio de la relación entre cine y videojuegos a la inversa, viendo la influencia de los segundos en el primero. Coincidiendo con las afirmaciones de Geoff King sobre la dinámica de repeticiones de vidas hasta la consecución del objetivo principal, José Manuel Marín indica que Al filo del mañana ejemplifica la influencia del videojuego al consistir su premisa en que el protagonista muere cada vez que fracasa en su misión, para volver a empezarla desde el principio (2014: 98). 
De un modo distinto, destaca la aportación de Juan Enrique Gonzálvez y José Rodríguez, en la que buscan identificar elementos del videojuego en la película Scott Pilgrim contra el mundo, además de aportar una reflexión interesante sobre la proximidad entre el cine y el videojuego: "visionar un filme es como asistir a la proyección de un videojuego sin la parte lúdico-interactiva, al menos para quien hace las veces de espectador, pues evidentemente habrá alguien jugando la partida» (2015: 202).

Otras líneas de investigación más próximas a nuestros objetivos indican cómo la narración en el videojuego se aproxima a la cinematográfica y, aunque se diferencian en varios aspectos, la del primero no tiene nada que envidiarle a la del segundo, pudiendo construir narraciones audiovisuales tan complejas como las del videojuego Alan Wake, en el que la jugabilidad es bastante simple y lo que importa es avanzar por la trama, en la que:

«los eventos que se desarrollan frente a los ojos de Alan Wake están basados en una novela escrita por Alan Wake, que sin embargo, es un personaje de ficción de una historia escrita por Thomas Zane (quien es, por supuesto, un personaje de ficción del videojuego)» (Fuchs, 2013: 145.-153).

En España, Alberto Carlier y Juan Luis Carrillo abordan el estudio de un género particular de videojuegos que los transforma en prácticamente una película de cine interactivo, el género de las "películas interactivas», caracterizadas por la inclusión de extensas cinemáticas con frecuentes Quick Time Events ${ }^{5}$ que difuminan aún más la frontera entre interacción y narración. Encontramos los máximos exponentes de este tipo de videojuegos en los creados por el estudio Quantic Dreams, como Heavy Rain o Beyond: Two Souls, que además está protagonizado por Ellen Page y Willem Dafoe (2015: 51-67).

Destaca el artículo de Águeda Delgado y Francisco A. Granados porque, aunque sostengan que cine y videojuegos son medios con unas diferencias insalvables, son de los únicos que proponen una metodología de análisis de la narración del videojuego en comparación con la cinematográfica, comparando de este modo varios títulos del medio con sus correspondientes adaptaciones. Así, los autores ofrecen estudiar el videojuego mediante una triple perspectiva precedida de una ficha técnica que ayude a localizar el objeto de la investigación: en primer lugar, habría que estudiar «la estructura narrativa que permite conocer los personajes, acciones y tramas de la historia», para después analizar todos los recursos narrativos (propios del cine), ta-

4 Traducido del inglés por el autor.

5 El Quick Time Event, en adelante QTE, es un evento propio del videojuego que combina cinemática e interactividad, interrumpiendo una secuencia de vídeo para que el jugador interactúe rápidamente siguiendo una serie de indicaciones dadas por el videojuego. 
les como la iluminación, el color, la música, los silencios... Por último, se completaría el análisis con el estudio de la recepción del videojuego, tomando en consideración tanto la crítica especializada como la opinión de los usuarios (2012: 63-71).

Aparte de este artículo, es interesante el firmado por Ángel Colón y Lluís Anyó, pues en él exponen unas conclusiones parecidas a las que queremos llegar nosotros, aunque sin proponer ninguna metodología. Estos autores señalan las semejanzas entre la narración en cine y videojuegos señalando los nudos de la trama estructurales del paradigma clásico del guión cinematográfico en el videojuego The Last Of $U s$, señalando que el papel del jugador es construir con sus acciones relatos variables en los nudos no estructurales (2015: 69-85).

Para que podamos comprender mejor esta terminología del guión y armar nuestra propuesta metodológica, vamos a dedicar el siguiente epígrafe a resumir la teoría del análisis del guión cinematográfico.

\section{Teoría del guión cinematográfico}

Dentro del guión cinematográfico ${ }^{6}$ podemos distinguir dos conceptos fundamentales, la trama y el tema. La trama es la estructura de acontecimientos que guía la narración desde el principio hasta el final, «una disposición lineal de incidentes [...] relacionados entre sí que conducen a una resolución dramática» (Field, 1999: 15), "una cadena de relaciones de causa y efecto que crea constantemente un patrón de acción y conducta unificadas» (Tobías, 1999: 24).

De manera histórica, como cita Linda Seger, la trama se ha dividido en tres actos: planteamiento, desarrollo y desenlace (2011: 13). Sobre esta estructura en tres actos, primero Syd Field y después Seger teorizaron sobre el paradigma estructural que seguían la mayoría de las películas de Hollywood. Syd Field lo definió como un esquema que divide la trama en tres actos, situándose en la frontera de cada acto un «nudo de la trama», que es «un incidente o acontecimiento que se engancha a la acción y la obliga a describir un giro en otra dirección». Así, si una película dura 120 minutos o páginas de guión, se mantiene una proporción de actos según la cual el segundo dura la suma del primero más el tercero (1999: 14-15). En un trabajo posterior, el autor completa el paradigma introduciendo el "Midpoint», un nudo de la trama situado justo en la mitad del segundo acto y encargado de centrar la línea argumental en una línea de acción concreta (1995: 102-117).

\footnotetext{
${ }^{6}$ Debemos aclarar que el acercamiento que hemos elegido al estudio del guión cinematográfico se limita a las perspectivas más clásicas del mismo, desarrolladas por autores como Syd Field, Linda Seger, Christopher Vogler o Ronald B. Tobías.
} 
Seger ahonda en este modelo y, además de desplazar los nudos de la trama o, como ella los llama, puntos de giro, a un poco antes de las fronteras entre actos, introduce nuevos elementos en el paradigma denominados "puntos de acción». Así, introduce una «imagen inicial» que presenta la película y un «detonante» que arranca la acción de la historia. Afirma que el segundo punto de acción inicia una cuenta atrás hacia el clímax, que es el momento cumbre del argumento y que puede introducir la resolución del conflicto que guía la trama.

También indica que este segundo punto de giro puede dividirse en dos momentos: un instante oscuro de máximo peligro para el protagonista y otro de estímulo en el que el protagonista sale victorioso de su odisea. También introduce otros, como las barreras, que son dificultades normalmente fisicas que ha de superar el protagonista para lograr su meta; el revés, que es un incidente que da un giro de 180 grados a la trama; la complicación, que es un problema cuyos efectos tardan en hacerse visibles; y la secuencia de escenas, que compone una pequeña línea argumental, como una persecución de coches. Del mismo modo, habla de la presencia de anticipaciones y cumplimientos que ayudan a cohesionar y dar coherencia a los hechos de la trama, sedimentando la causalidad necesaria para el mantenimiento de la lógica interna del argumento (2011: 41-113).

Sánchez-Escalonilla reúne las aportaciones de ambos y propone un paradigma en el que distingue los nudos de acción estructurales de los no estructurales, siendo los primeros aquellos esenciales para la estructura del paradigma, y los segundos, aquellos que son accesorios u opcionales. Todos los nudos de acción pueden ser peripecias o anagnórisis. La peripecia es una acción determinada, mientras que la anagnórisis es un momento de descubrimiento de información importante para el argumento. La trama avanza a través de estos nudos de acción. Así, para SánchezEscalonilla, la estructura se divide en tres actos con dos puntos de giro en la frontera de cada acto. En el primer acto se sitúa un detonante, que es la peripecia que marca el inicio de la acción; y en el tercero, un clímax, donde se da tanto el desenlace definitivo como el momento de mayor tensión dramática. Estos serían los nudos estructurales.

Además de los anteriores, el paradigma puede incluir una imagen inicial que coincide con la de Linda Seger; un midpoint, que a diferencia del de Field queda marcado como opcional; una serie de anticipaciones y cumplimientos, barreras, reveses y complicaciones ${ }^{7}$; anticlímax, que es un revés que parece frustrar todo el trabajo realizado por el protagonista; secuencia de acciones (equivalentes a las secuencias de escenas de Seger) y resolución, situada después del clímax para «añadir una

7 Sánchez-Escalonilla añade a la información de Seger que las complicaciones suelen producirse en el interior de los personajes, a causa de su manera de comportarse. 
última información [...] o hacer referencia al tema que ha sido objeto de reflexión» (2014: 188-310).

De esta manera, el paradigma quedaría del siguiente modo:

\section{Paradigma combinado según Sánchez-Escalonilla:}

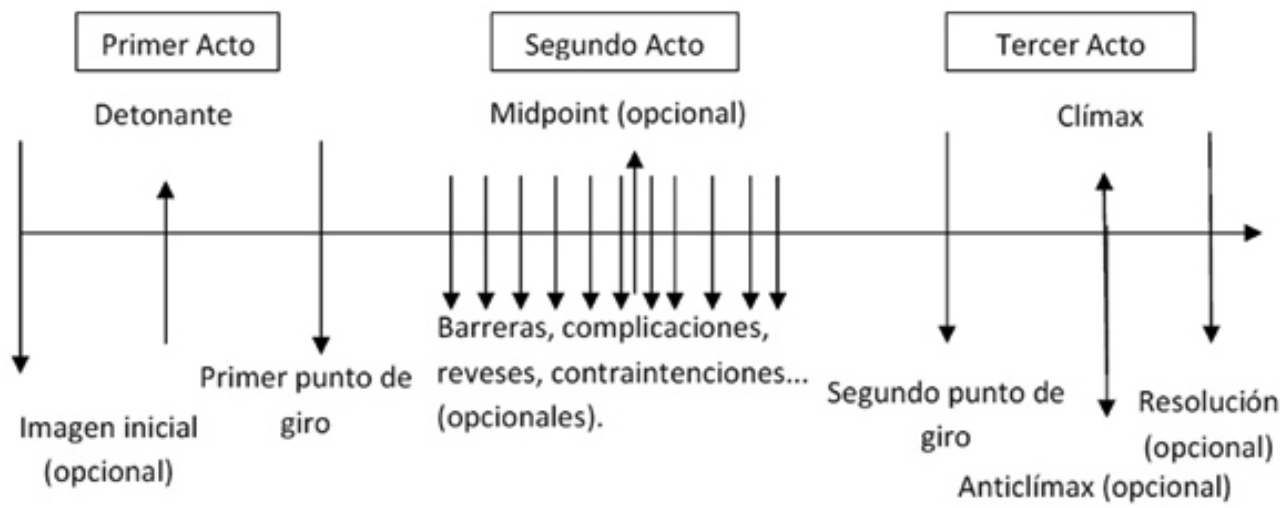

Fuente: Elaboración propia.

\section{ILUSTRACIÓN I}

Resumen del paradigma según Antonio Sánchez-Escalonilla

Las tramas suelen inspirarse para su construcción en premisas dramáticas, que son los patrones comunes de las historias. Ronald Tobías propone hasta 20 tramas maestras (1999), a las que Sánchez-Escalonilla suma algunas más. La que más nos interesa es la que propone Christopher Vogler, por considerar que es la que mejor puede encajar en los videojuegos, la premisa dramática del viaje del héroe.

Vogler afirma que la mayoría de las películas sobre héroes se articulan en torno a esta premisa dramática, que encaja perfectamente dentro de la estructura en tres actos del argumento y que nace de la aplicación al guión cinematográfico de las etapas del viaje del héroe descritas por Joseph Campbell en El héroe de las mil caras. Según Vogler, el protagonista vive en un mundo ordinario y tranquilo, sin saber que es un héroe, hasta que llega un detonante, una llamada a la aventura. Tras esta llamada, el héroe suele ser reacio a abandonar su mundo, por lo que rechaza la llamada. En esos momentos suele aparecer un mentor, que guía al héroe hasta que finalmente acepta la llamada y cruza el primer umbral, introduciéndose en el mundo extraordinario (umbral que coincide en el paradigma con el primer punto de giro). 
En el segundo acto, la aparición de aliados, pruebas y enemigos aumenta enormemente, hasta que llega un punto en el que el héroe se aproxima a la caverna más profunda, donde espera encontrar el objeto de su búsqueda. Allí se enfrenta a un momento muy oscuro, una odisea, un momento cercano a la muerte, para superarlo y conseguir la recompensa a sus acciones ${ }^{8}$. Ya en el tercer acto, comienza el camino de regreso, en el que el héroe reflexiona sobre qué hacer a continuación, si es hora de volver a casa o si es mejor seguir adelante. Después llega la resurrección, que equivale al clímax: el héroe se enfrenta al mayor peligro de todos y está a punto de morir (o muere), pero al final tiene éxito, resucita, logra su objetivo, vence al rival (o se sacrifica). Por último, tenemos el retorno con el elixir, que cierra la premisa y equivale a la resolución de Sánchez-Escalonilla (2002: 31-261).

Además de la trama, el guión presenta también una propuesta temática que podemos definir como la «reflexión que subyace bajo la tesis argumental» (Sánchez-Escalonilla, 2014: 130). Una trama puede tener una o varias propuestas temáticas con mayor o menor relevancia en el argumento. Este tema es la reflexión ideológica o moral que ofrece una historia. Si tomamos como ejemplo una película como Trascendence, la trama sería el devenir de las acciones y los sucesos, mientras que el tema sería la dialéctica entre una libertad tendiente al caos y un orden muy próximo a la anulación del libre albedrío.

Es muy común que el tema se explore con la ayuda de subtramas o tramas secundarias que acompañan a la principal, y que suelen formarse a partir de las relaciones que establecen los personajes entre sí. Estas tramas secundarias pueden tener también una estructura paradigmática, con presentaciones, desarrollos y desenlaces propios (Seger, 2011: 60-62; Aranda, Pujol, 2015: 40-41).

\section{Propuesta metodológica}

Teniendo en cuenta la falta de metodologías que nos sirvan para comparar las semejanzas estructurales entre la narración en videojuegos y las estructuras clásicas del guión cinematográfico, tenemos que proponer una metodología de elaboración propia, para lo que vamos en primer lugar a definir las propiedades que ha de reunir un videojuego para poder ser objeto de estudio de nuestra metodología, para a continuación describir nuestro método de trabajo y su aplicación al estudio de videojuegos mediante la confección de una ficha de análisis.

${ }^{8}$ Vemos cómo esto equivale a las dos partes en las que se puede dividir, según Linda Seger, el segundo punto de giro. 
Como vimos en el primer epígrafe, el videojuego es un producto con una naturaleza muy heterogénea que ocasiona que pueda ser analizado desde perspectivas dispares e incluso opuestas sin que esto provoque la anulación instrumental de ningún punto de vista. Por esto mismo, porque no hay un mismo tipo de videojuego sino muchos, una metodología enfocada en el análisis de las semejanzas entre la narración videolúdica y el guión cinematográfico solo puede aplicarse a un tipo de juego que esté centrado en la transmisión de una narración y posea unas características determinadas.

De este modo, para que un título pueda ser estudiado por nuestro método, tiene que tener, en primer lugar, una campaña para un jugador sólidamente guionizada, con unos personajes definidos que tengan un objetivo que cumplir en una historia predefinida. Así pues, el análisis del modo multijugador y de aquellos videojuegos que se basen en simulaciones o abstracciones (como Los Sims o el Tetris) quedará fuera del alcance de nuestra metodología.

En segundo lugar, tiene que tratarse un videojuego que no ofrezca múltiples opciones de caminos narrativos al jugador, ya que en ese caso, no estaríamos analizando una trama, sino tantas como opciones tenga el jugador, con lo que incrementaría enormemente su complejidad y, en lugar de analizar un elemento, analizaríamos tantos como elecciones existan. En tercer lugar, establecemos una regla no estrictamente necesaria para este método, pero sí útil para reforzar los resultados de nuestro análisis y evitar acusaciones de detractores de nuestra perspectiva: el videojuego tiene que narrar un argumento original del propio videojuego y no ser una adaptación de otros medios como el cine o la novela, para evitar así acusaciones de que su semejanza con la estructura narrativa de una película se deba a su naturaleza de adaptación en lugar de algo propio del videojuego.

Con estas reglas tan sencillas serían muchos los títulos que podrían ser analizados por esta metodología, como por ejemplo Mortal Kombat 9, Mortal Kombat X, Battlefield 4, Bioshock Infinite, los Call Of Duty, Tomb Raider Definitive Edition, etc. Para este artículo, vamos a elegir el Assassin's Creed IV: Black Flag, por presentar una historia para un jugador sin opciones y bien guionizada, y pertenecer a una saga cuyo origen está en los propios videojuegos. Aunque este videojuego presente la peculiaridad de combinar dos tramas entre sí, para este artículo nos centraremos en el análisis de su trama del pasado?

La primera y más compleja dificultad que tenemos que resolver con nuestra metodología es la ausencia de coordenadas que nos permitan tanto localizar con pre-

\footnotetext{
9 El argumento de los títulos de esta saga giran en torno a la exploración de recuerdos de los antepasados, con lo que en todo título hay una trama del presente y una del pasado. Por cuestión de espacio, nos limitaremos a analizar solo una de ellas.
} 
cisión en el argumento los aspectos de los que hablemos en nuestra ficha de análisis como presentar de forma directa a otros investigadores el trabajo de campo que hemos realizado para llegar a los resultados presentados.

El establecimiento de estas coordenadas resulta complicado debido a que el videojuego, a diferencia de la película o del libro, carece de este sistema, más allá de su estructura macro de niveles, pantallas o misiones que, no obstante, no nos permite localizar un instante concreto de una manera sencilla, ni facilita al lector o investigador una manera de poder contrastar nuestro análisis con el objeto de estudio original. El videojuego no tiene páginas, ni línea temporal de reproducción, por lo que hemos de fabricar dichas coordenadas.

Para ello, proponemos llevar a cabo la transcripción del videojuego. Para hacerlo, tendremos que plasmar por un lado la estructura de la trama principal, con las misiones o niveles principales, y por el otro, la sucesión de misiones secundarias, coleccionables y textos opcionales. Para ello, proponemos la transcripción en negrita del número de pantalla/nivel y el texto, en caso de que lo haya, que describa dicho nivel. Después, indicaremos qué acción es la principal para realizar en esa pantalla, que resumirá su objetivo. A continuación, señalaremos las acciones que podemos hacer como jugador para, por último, transcribir el desarrollo del argumento.

Esta narración del argumento se realizará en primera persona del singular, porque al jugar tenemos la impresión de ser nosotros, a través del personaje, los que completamos la narración, y opinamos que es la forma más adecuada de transmitir el modo en que el jugador recibe la narración. También diferenciaremos con los términos «cinemática» y "parte jugable» las partes en las que el jugador pueda o no interactuar con el juego, para constatar la participación del usuario en los distintos actos. Por supuesto, si estos niveles se agrupan a su vez en otras estructuras tales como 'mundos' o 'secuencias', se presentarán agrupados dentro de dichos elementos y presentados en orden cronológico de aparición en el argumento del videojuego. Será necesario jugar cada título dos veces, la primera para empaparnos de toda su historia y argumento y la segunda para transcribirlo. Así, tomando como ejemplo uno de los niveles del videojuego analizado, obtendríamos una estructura similar a la siguiente $^{10}$ :

${ }^{10}$ Debido a la enorme extensión de este título (extensión común a muchos otros videojuegos), en este artículo solo podemos replicar esta pequeña muestra, ya que la transcripción completa ocupa 104 páginas. 
Memoria $3^{\star}$. «El secreto enterrado del Sabio».

«Edward y James exploran el templo maya en busca de pistas de la identidad del Sabio»

Acción: descubrir el tesoro del templo subterráneo.

Cosas para hacer: movimiento libre, escalar, resolver el puzle.

Desarrollo del argumento: parte jugable: estamos en una cueva oscura. James Kidd avanza por las vigas y plataformas y yo voy detrás. Mientras, vamos hablando. Le digo que me ha metido en este embrollo a sabiendas: «¿Quién demonios era ese bufón de antes?», me responde: "Ah Tabai, asesino y mentor». Exclamo: «así que formas parte de un culto de lunáticos». Responde: «somos asesinos y seguimos un credo, en efecto, pero no nos impele a actuar o a someternos, solo a ser sabios». Comento, irónico, que me encantaría oír más. Accede a mis deseos: «nada es cierto, todo está permitido. Es la única certeza». Observo que me encanta eso: "pensar como quiera y actuar como me plazca». Va a decirme algo, pero justo en ese momento el puente sobre el que está se derrumba, aunque dándole tiempo a cruzar al otro lado.

* Las memorias en este título equivalen a las misiones principales, y están englobadas en varias secuencias, en este caso, doce. Esta, en concreto, pertenece a la secuencia 4.

Una vez que tenemos transcrito el argumento del videojuego, el siguiente paso en nuestra metodología es la elaboración de una ficha de análisis que nos permita comprobar la existencia en dicho argumento de los nudos estructurales y no estructurales del paradigma cinematográfico, así como la presencia o no de la premisa del viaje del héroe. De esta forma y para facilitar su presentación y rápida asimilación, generaremos una tabla con cuatro columnas. En la primera aparecerá el elemento investigado («detonante», "clímax», etc.). La segunda columna contendrá información sobre si dicho elemento existe o no en el videojuego. En la tercera, su localización o, si el elemento es más abstracto, como en el caso del «tema» o "propuesta temática», la cantidad de estos elementos que posee el argumento. Por último, la cuarta columna se reserva a comentarios sobre la forma que toman estos elementos en la narración.

De esta manera, podremos analizar el argumento del videojuego y comprobar sus semejanzas o diferencias estructurales con las estructuras clásicas del guión cinematográfico. En el caso del análisis de Assassin's Creed IV: Black Flag, hemos obtenido los siguientes resultados: 


\section{TABla I}

Comprobación de la existencia de nudos estructurales de la trama y del tema en el videojuego analizado

\begin{tabular}{|c|c|c|c|}
\hline \multicolumn{4}{|c|}{ Paradigma - Nudos estructurales de la trama - Propuesta temática } \\
\hline $\begin{array}{l}\text { Elemento } \\
\text { investigado }\end{array}$ & $\begin{array}{l}\text { Presencia } \\
\text { en el } \\
\text { videojuego }\end{array}$ & Localización / Cantidad & Comentarios \\
\hline Tres actos & Sí & - & - \\
\hline Primer Acto & Sí & Secuencias 1-2 & - \\
\hline Segundo Acto & Sí & Secuencias 3-10 & - \\
\hline Tercer Acto & Sí & Secuencias 11-12 & - \\
\hline Detonante & Sí & Memoria 3 de Secuencia 2 & $\begin{array}{l}\text { Edward descubre la existencia del } \\
\text { Observatorio. }\end{array}$ \\
\hline $\begin{array}{c}\text { Primer punto } \\
\text { de giro }\end{array}$ & Sí & Memoria 6 de Secuencia 2 & $\begin{array}{l}\text { Edward es apresado, escapa y roba un } \\
\text { barco. }\end{array}$ \\
\hline $\begin{array}{l}\text { Segundo punto } \\
\text { de giro }\end{array}$ & Sí & $\begin{array}{l}\text { Final Secuencia } 10 \text { - Princi- } \\
\text { pio Secuencia } 11\end{array}$ & $\begin{array}{l}\text { Edward en prisión, traicionado, crisis } \\
\text { existencial, transformación. }\end{array}$ \\
\hline Clímax & Sí & Memoria 4 de Secuencia 12 & $\begin{array}{l}\text { Edward asesina al líder enemigo y res- } \\
\text { taura el Observatorio }\end{array}$ \\
\hline $\begin{array}{l}\text { Todos los actos } \\
\text { son jugables }\end{array}$ & Sí & - & Todos son jugables \\
\hline $\begin{array}{l}\text { Propuesta } \\
\text { temática }\end{array}$ & Sí & Varias & $\begin{array}{l}\text { Orden y control frente a libertad y } \\
\text { caos en dos enfrentamientos: piratas } \\
\text { contra gobernantes y asesinos contra } \\
\text { templarios; el egoísmo y la ambición } \\
\text { como elementos destructivos. }\end{array}$ \\
\hline
\end{tabular}




\section{TABLA II}

Comprobación de la existencia de nudos no estructurales de la trama en el videojuego analizado

\begin{tabular}{|c|c|c|c|}
\hline \multicolumn{4}{|c|}{ Nudos no estructurales de la trama } \\
\hline $\begin{array}{l}\text { Elemento } \\
\text { investigado }\end{array}$ & $\begin{array}{l}\text { Presencia } \\
\text { en el } \\
\text { videojuego }\end{array}$ & Localización / Cantidad & Comentarios \\
\hline Imagen inicial & Sí & Secuencia 1 & $\begin{array}{l}\text { Barcos, naufragio, isla tropical, piratas, } \\
\text { La Habana }\end{array}$ \\
\hline Midpoint & Sí & Secuencia 7 & $\begin{array}{l}\text { Inicio de la debacle del mundo del } \\
\text { protagonista }\end{array}$ \\
\hline Anticlímax & No & - & - \\
\hline Resolución & Sí & Epílogo & $\begin{array}{l}\text { Edward se despide, le dicen adiós las } \\
\text { almas de sus compañeros muertos. } \\
\text { Regresa a Inglaterra con su hija }\end{array}$ \\
\hline $\begin{array}{l}\text { Anticipaciones } \\
\text { y } \\
\text { cumplimientos }\end{array}$ & Sí & Abundantes & Todas tienen cumplimiento \\
\hline Anagnórisis & Sí & Abundantes & \\
\hline Barreras & Sí & Abundantísimas & $\begin{array}{l}\text { Su superación guía el desarrollo de la } \\
\text { trama }\end{array}$ \\
\hline Complicaciones & Sí & $\begin{array}{l}\text { Una, la personalidad de Ed- } \\
\text { ward }\end{array}$ & $\begin{array}{l}\text { Guía al personaje hasta el segundo } \\
\text { punto de giro }\end{array}$ \\
\hline Reveses & Sí & Varios & $\begin{array}{l}\text { Construyen la base para los puntos } \\
\text { de giro }\end{array}$ \\
\hline
\end{tabular}




\section{TABLA III}

\section{Comprobación de la existencia de las fases de la premisa del viaje del héroe en el videojuego analizado}

\begin{tabular}{|c|c|c|c|}
\hline \multicolumn{4}{|c|}{ Premisa del viaje del héroe } \\
\hline $\begin{array}{l}\text { Elemento } \\
\text { investigado }\end{array}$ & $\begin{array}{c}\text { Presencia } \\
\text { en el } \\
\text { videojuego }\end{array}$ & Localización / Cantidad & Comentarios \\
\hline $\begin{array}{l}\text { Mundo } \\
\text { ordinario }\end{array}$ & Sí & $\begin{array}{l}\text { Secuencia } 1 \text { - Principio Se- } \\
\text { cuencia } 2\end{array}$ & Coincide con la Imagen inicial \\
\hline $\begin{array}{l}\text { Llamada a la } \\
\text { aventura }\end{array}$ & Sí & Memoria 3 de Secuencia 2 & Coincide con el detonante \\
\hline $\begin{array}{l}\text { Rechazo de la } \\
\text { llamada }\end{array}$ & No & - & - \\
\hline $\begin{array}{l}\text { Encuentro con } \\
\text { el mentor }\end{array}$ & Sí & Memoria 2 de Secuencia 3 & $\begin{array}{l}\text { Sucede después de la travesía del pri- } \\
\text { mer umbral. Varios mentores }\end{array}$ \\
\hline $\begin{array}{l}\text { Travesía del } \\
\text { primer umbral }\end{array}$ & Sí & Memoria 6 de Secuencia 2 & Coincide con el primer punto de giro \\
\hline $\begin{array}{l}\text { Pruebas, } \\
\text { Aliados, } \\
\text { Enemigos }\end{array}$ & Sí & Abundantes & $\begin{array}{l}\text { Algunos aliados se convierten en ene- } \\
\text { migos }\end{array}$ \\
\hline $\begin{array}{l}\text { Aproximación } \\
\text { a la caverna } \\
\text { más profunda }\end{array}$ & Sí & Memoria 3 de Secuencia 10 & $\begin{array}{l}\text { Literal, Edward se adentra con Ro- } \\
\text { berts en la caverna donde está El Ob- } \\
\text { servatorio }\end{array}$ \\
\hline Odisea & Sí & $\begin{array}{l}\text { Final secuencia } 10-\text { Memo- } \\
\text { ria } 2 \text { de secuencia } 11\end{array}$ & $\begin{array}{l}\text { Coincide con el segundo punto de } \\
\text { giro }\end{array}$ \\
\hline Recompensa & Sí & Memoria 3 de secuencia 11 & Fin de la complicación \\
\hline $\begin{array}{l}\text { Camino de } \\
\text { regreso }\end{array}$ & Sí & $\begin{array}{l}\text { Primeras memorias de se- } \\
\text { cuencia } 12\end{array}$ & \\
\hline Resurrección & Sí & Memoria 4 de secuencia 12 & Coincide con el clímax \\
\hline $\begin{array}{l}\text { Retorno con el } \\
\text { elixir }\end{array}$ & Sí & Epílogo & Coincide con la resolución \\
\hline
\end{tabular}




\section{Conclusiones}

Vemos cómo, al menos en el título analizado, sí podemos observar una serie de semejanzas estructurales entre la narración del videojuego y las estructuras clásicas del guión cinematográfico, aunque la primera presenta unas características propias, como el alargamiento del segundo acto hasta superar la proporción descrita por Syd Field, o la multiplicidad de barreras y reveses para ampliar la cantidad de acciones y sucesos que ocurren en el videojuego.

Observamos que en la trama de este videojuego se aprecia la existencia de una estructura muy próxima al paradigma cinematográfico, con tres actos jugables definidos por los nudos estructurales establecidos en el paradigma de Sánchez-Escalonilla, que además posee una buena cantidad de nudos no estructurales y una amplia gama de anticipaciones con cumplimiento, que denotan la preocupación de este videojuego por afianzar la causalidad del argumento. También vemos cómo se cumplen la mayoría de las etapas de la premisa del viaje del héroe y cómo estas coinciden con la mayoría de los nudos de la trama.

Hemos anotado cómo en la comunidad científica dedicada al estudio del videojuego existe una necesidad urgente de propuestas metodológicas que faciliten el estudio del videojuego, sobre todo desde perspectivas narratológicas, lo que nos ha llevado a la elaboración de una metodología propia que ha demostrado ser útil para comprobar la veracidad o error de nuestra intuición sobre la semejanza entre la narración videolúdica y la cinematográfica. Sin embargo, como el videojuego posee una naturaleza altamente heterogénea, nuestro método solo puede ocuparse de una porción de los títulos interactivos, siendo necesaria la aparición de más metodologías que puedan abarcar una cantidad mayor de productos de esta industria.

Las mayores ventajas de esta metodología son tanto el nivel de exactitud analítica que permite alcanzar como su capacidad para facilitar la investigación a futuros analistas, que puedan recurrir directamente a una transcripción del videojuego, realizada de tal forma que se puede aprovechar para multitud de estudios sobre la forma en la que está construida su narración. Además, permitiría la incorporación modular de otros aspectos en función del objetivo del estudio, como la inclusión de referencias a la narrativa audiovisual del videojuego, como por ejemplo notas sobre la iluminación, la planificación o el atrezo, según la comparación que quisiéramos observar entre el videojuego y el cine.

Por otra parte, la gran extensión argumental de muchos videojuegos trae consigo la mayor desventaja de esta metodología: la cantidad de tiempo necesaria para la correcta transcripción de cada título y la enorme extensión de páginas que ocupa, oscilando entre las 50 y las 120 en función de la complejidad del título analizado, 
por lo que se abre la posibilidad de crear propuestas que agilicen esta metodología sin que ello conlleve la pérdida de datos o su capacidad analítica. Continuaremos explorando la proximidad entre cine y videojuegos, así como la utilidad de la metodología propuesta en futuros artículos.

\section{Referencias bibliográficas}

Aarseth, Espen (2004) ${ }^{11}$. La literatura ergódica. En D. Sánchez-Mesa (Comp.) (2004). Literatura y cibercultura (pp. 117-145). Madrid, Arco/libros.

AEVI (2016). 15 Anuario del videojuego. Madrid: Asociación Española de Videojuegos. Recuperado de: http://www.aevi.org.es/web/wp-content/uploads/2016/06/MEMORIAANUAL_2015_AEVI_-definitivo.pdf.

AEVI (2018). Anuario 2017. Anuario de la industria del videojuego. Madrid: Asociación Española de Videojuegos. Recuperado de: http://www.aevi.org.es/web/wp-content/ uploads/2018/07/AEVI_Anuario2017.pdf

Anable, A. (2013). Playing (with) the City: The Warriors and images of Urban Disorder. En G. Papazian y J. M. Sommers (Eds.), Game On, Hollywood! Essays on the Instersection of Video Games and Cinema (pp. 86-100). Jefferson, Carolina del Norte y Londres: McFarland.

Aranda, D. y Pujol, C. (2015). ¿Cómo se estructura la trama de un guión audiovisual?. Barcelona: Editorial UOC.

Benito, J.M. (junio 2006). El mercado del videojuego: unas cifras. Icono 14, 4(1), 36-47.

Bort, I. (2012). Antes [de] que el videojuego sepa que has muerto. En Sociedad Latina de Comunicación Social, Actas IV Congreso Internacional Latina de Comunicación Social: Comunicación, control y resistencias. Recuperado de: http://www.revistalatinacs. org/12SLCS/2012_actas/063_Gual.pdf

Buel, J.W. (2013). Playing (with) the Western: Classical Hollywood Genres in Modern Videogames. En G. Papazian y J. M. Sommers (Eds.), Game On, Hollywood! Essays on the Instersection of Video Games and Cinema (pp. 47-57). Jefferson, Carolina del Norte y Londres: McFarland.

Carlier, A. y Carrillo, J.L. (2015). El videojuego como cine interactivo: buscando la experiencia cinematográfica definitiva. En J. Cuesta y J. Sierra (Eds.), Videojuegos: arte y narrativa audiovisual (pp. 51-67). Madrid: ESNE.

Colón, A. y Anyó, L. (2015). Argumentos para el clímax: estrategias narrativas en el videojuego de acción y aventuras. En J. Cuesta y J. Sierra (Eds.), Videojuegos: arte y narrativa audiovisual (pp. 69-85). Madrid: ESNE.

${ }^{11}$ La publicación original procede de la introducción de: Aarseth, A. (1997). Cybertext. Perspectives on Ergodic Literature (pp. 1-23). Baltimore/Londres: John Hopkins University Press. 
Delgado, A. y Granados, F.A. (2012). Videojuegos trasladados al cine: análisis y caracterización de la narrativa audiovisual en ambos medios. Comunicación: revista Internacional de Comunicación Audiovisual, Publicidad y Estudios Culturales, 1(10), 63-77.

Esnaola, G.A. y Levis, D.S. (2008). La narrativa en los videojuegos: un espacio cultural de aprendizaje socioemocional. Teoría de la Educación: Educación y cultura en la Sociedad de la información, 9(3). Recuperado de: http://revistas.usal.es/index.php/revistatesi/article/ view/16789

«Primer Autor». (2017). «Título».

Field, S. (1995). El manual del guionista. Ejercicios e instrucciones para escribir un buen guión paso a paso. Madrid: Plot.

Field, S. (1999). El libro del guión. Fundamentos de la escritura de guiones. Madrid: Plot.

Frasca, G. (2003). Simulation versus Narrative: Introduction to Ludology. En M.J.P. Wolf, y B. Perron (Eds.), Video/Game/Theory. Oxford: Routledge. Recuperado de: http:// www.ludology.org/articles/VGT_final.pdf

Fuchs, M. (2013). 'My name is Alan Wake. I'm a Writer'. Crafting narrative complexity in the Age of Transmedia Storytelling. En G. Papazian y J. M. Sommers (Eds.), Game On, Hollywood! Essays on the Instersection of Video Games and Cinema (pp. 144-155). Jefferson, Carolina del Norte y Londres: McFarland.

Garin, M. y Pérez, O. (2009). Entre mundos e historias: ciencia ficción y experiencia de juego. Formats: revista de comunicació audiovisual, 5. Recuperado de: http://www.raco. cat/index.php/Formats/article/view/136946/343854

Gómez, F.J., Rubio A. y Tomás, A. (2012): Punto de vista y videojuego. Un acercamiento multidisciplinar. En Sociedad Latina de Comunicación Social, Actas IV Congreso Internacional Latina de Comunicación Social: Comunicación, control y resistencias. Recuperado de: http://www.revistalatinacs.org/12SLCS/2012_actas/124_Gomez_Tarin.pdf

Gonzálvez, J.E. y Rodríguez, J. (2015). Cine y videojuegos. En J. Cuesta y J. Sierra (Eds.), Videojuegos: arte y narrativa audiovisual (pp. 197-209). Madrid: ESNE.

Jenkins, H. (2004). Games Design as Narrative Architecture. En Wardrip-Fruin, N. y P. Harrigan (Eds.), First Person. New Media as Story, Performance and Game (pp. 118-130). Cambridge: MIT Press.

Juul, J. (2001): Games telling stories? A brief note on games and narratives. Game Studies, 1(1). Recuperado de: http://www.gamestudies.org/0101/juul-gts/

King, G. y Krzywinska, T. (Eds.) (2002). ScreenPlay: cinema/videogames/interfaces. Londres y Nueva York: Wallflower Press.

Mactavish, A. (2002). Technological Pleasure: The Performance and Narrative of Technology in Half-Life and other High-Tech Computer Games. En G. King y T. Krzywinska (Eds.), ScreenPlay: cinema/videogames/interfaces (pp. 33-49). Londres y Nueva York: Wallflower Press.

Marín, J.M. (2015). Intermedialidad narrativa, modelos estructurales de videojuegos en cine: el caso de Al filo del mañana (2014), de Doug Liman. Espéculo: Revista de Estudios Literarios, (54), 93-110. 
Morales, E. (2012). El reconocimiento institucional español de los videojuegos como industria cultural: propuestas para crear industria. Derecom, (11), 17-33.

Murray, J.H. (1999). Hamlet en la holocubierta. El futuro de la narrativa en el ciberespacio. Barcelona: Paidós.

Navarrete, J.L., Pérez, J. P. y Gómez, F.J. (2014a). El pensamiento abductivo como funcionamiento ontológico de los videojuegos. Icono14, 12(2), 416-440.

Navarrete, J.L., Pérez, J. P. y Gómez, F.J. (2014b). Una aproximación a los paradigmas de la Teoría del Videojuego. ZER-Revista de Estudios de Comunicación, 19(37), 107-121. Recuperado de: http://www.ehu.eus/ojs/index.php/Zer/article/view/13528/12110

Pérez, L.M. (2010). La localización de videojuegos (inglés-español): aspectos técnicos, metodológicos y profesionales. Málaga: Universidad de Málaga (tesis doctoral inédita).

Planells, A.J. (2010). Max Payne: cine negro y pesadillas en el medio interactivo. Razón y palabra, (72). Recuperado de: http://www.razonypalabra.org.mx/N/N72/Varia_72/35_ Planells\%20_72.pdf

Planells, A.J. (2011). Usos sociales y analogías estéticas: el cine primitivo y el nacimiento de los videojuegos. Telos: Cuadernos de comunicación e innovación, (88) 46-57.

Planells, A.J. (2015). Videojuegos y mundos de ficción. De Super Mario a Portal. Madrid: Cátedra.

Ryan, M.-L. (2006). Avatars of Story. Minneápolis/Londres: University of Minnesota Press.

Sánchez-Escalonilla, A. (2014). Estrategias de guión cinematográfico. El proceso de creación de una historia. Barcelona: Ariel.

Seger, L. (2011). Cómo convertir un buen guión en un guión excelente. Madrid: Rialp.

Tobías, R.B. (1999). El guión y la trama. Fundamentos de la escritura dramática audiovisual. Madrid: Ediciones Internacionales Universitarias S.A.

Vogler, C. (2002). El viaje del escritor. Las estructuras míticas para escritores, guionistas, dramaturgos y novelistas. Barcelona: Robinbook.

WOLF, M.J.P. y Perron, B. (2005). Introducción a la teoría del videojuego. Formats: revista de comunicació audiovisual, (4). Recuperado de: http://www.raco.cat/index.php/ Formats/article/view/257329/344420

Zimmerman, E. (2004). Narrative, Interactivity, Play, and Games: Four naughty concepts in need of discipline. En Wardrip-Fruin, N. y P. Harrigan (Eds.), First Person. New Media as Story, Performance and Game (pp. 154-163). Cambridge: MIT Press. 


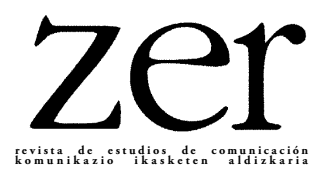

\title{
Pautas de redacción y análisis de contenido en noticias sobre suicidio en la prensa española e internacional: efecto Werther\&Papageno y seguimiento de las recomendaciones de la OMS
}

Espainiako eta nazioarteko prentsan suizidioari buruzko berrien edukia idazteko eta aztertzeko jarraibideak: WertherEPapageno efektua eta OMEren aholkuen jarraipena

Guidelines and analysis of the content of news about suicide in Spanish and international press: Papageno and Werther effect and level of compliance of WHO advice

\author{
Melani Lois-Barcia`, Icía Rodríguez-Arias, Miguel Túñez \\ Universidad de Santiago de Compostela
}

\begin{abstract}
RESUMEN: En España fallecen por suicidio el triple de personas que en accidente de tráfico, pero la muerte intencional sigue siendo un asunto que en las redacciones informativas se silencia por considerar que su visibilidad fomenta el aumento de conductas imitativas. La Organización Mundial de la Salud promueve desde 2000 una guideline para el abordaje informativo del suicidio en la que se proponen comportamientos diferentes: informar con responsabilidad y de modo que se colabore en dinámicas de prevención. Esta investigación revisa libros de estilo o códigos de conducta de FAPE, de los nueve colegios profesionales de España y de 23 organizaciones profesionales internacionales y analiza las noticias online durante seis meses en una muestra intencional de 11 periódicos de referencia (El País, El Mundo, La Vanguardia, La Voz de Galicia $y$ El Periódico, The Guardian, Le Monde, The New York Times, The Washington Post, Corrieri della Sera y Público) para identificar si existen pautas que orienten el abordaje informativo e intentar determinar si la política informativa apuesta por fomentar el efecto Werther (silencio) o el efecto Papageno (prevención).
\end{abstract}

PALABRAS CLAVE: Medios de comunicación, responsabilidad social, prensa, suicidio.

LABURPENA: Espainian, suizidioa dela eta, trafiko istripuetan hiltzen diren pertsonen hirukoitza hiltzen da. Hala ere, nahitako heriotza informazio erredakzioetan isila- 
razten den gaia da oraindik ere, horren ikusgaitasunak imitazio jokabideak sustatuko dituelakoan. Osasunaren Mundu Erakundeak, 2000. urtetik, guideline bat proposatzen $d u$ suizidioa informazioaren alorrean artatzeko; bertan, jarrera ezberdinak proposatzen dira: arduraz eta prebentzio dinamikak sustatzeko moduan informatzea. Ikerketa honetan, FAPEren estilo liburuak edo jokabide kodeak aztertzen dira, Espainiako bederatzi elkargo profesionalenak eta nazioarteko hogeita hiru elkarte profesionalenak. Horrez gain, sei hilabetean zehar, erreferentziazko 11 egunkariren online berriak ere aztertzen dira (El País, El Mundo, La Vanguardia, La Voz de Galicia eta El Periódico, The Guardian, Le Monde, The New York Times, The Washington Post, Corrieri della Sera eta Público), informazioa artatzera bideratutako jarraibideak dauden ikusteko eta horiek identifikatzeko, eta informazio politikak Werther efektuaren (isiltasuna) edo $\mathrm{Pa}-$ pageno efektuaren (prebentzioa) alde egiten duen zehazten saiatzeko.

HITZ-GAKOAK: Komunikabideak, erantzukizun soziala, prentsa, suizidioa.

\begin{abstract}
In Spain three people commit suicide for each traffic accident but intentional death is still silenced in newspapers for understanding that its visibility promotes imitation of this kind of behavior. The World Health Organization encourages since the year 2000 a guideline for suicide coverage in which different conducts are included; to inform responsibly and aiming prevention dynamics. This investigation looks through style guides and codes of ethics from the FAPE, Spanish Journalism associations and 23 international professional organizations. It analyzes online news from a six-month period in several media (El Pais, El Mundo, La Vanguardia, La Voz de Galicia y El Periódico, The Guardian, Le Monde, The New York Times, The Washington Post, Corrieri della Sera y Público) to identify if there is any guidance that orders the informative coverage. This study has also the aim to find out if these neewspapers tend to follow Werther (silence) or Papageno (prevention) effect.
\end{abstract}

KEYWORDS: Media, social responsability, press, suicide.

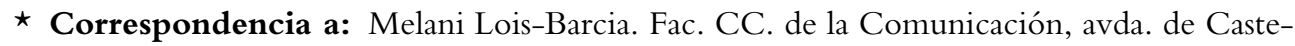
lao, s/n. Campus norte (15782 Santiago de Compostela).melani.lois@rai.usc.es http://orcid.org/0000-0001-5785-8620

Cómo citar: Lois-Barcia, Melani; Rodríguez-Arias, Icía; Túñez, Miguel. 2018. Pautas de redacción y análisis de contenido en noticias sobre suicidio en la prensa española e internacional: efecto Werther\&Papageno y seguimiento de las recomendaciones de la OMS. Zer. 23(45). 139-159.

https://doi.org/10.1387/zer.20244

Recibido: 16 setiembre 2018; aceptado: 18 octubre 2018

1137-1102 y 1989-631X / (C) 2018 UPV/EHU

(c) (1) Esta obra está bajo una licencia Creative Commons Atribución 4.0 Internacional 


\section{Werther o Pagageno, silencio o prevención como actitud informativa}

En el mundo se suicidan 800.000 personas cada año y por cada caso se producen varias tentativas. Igual que en las noticias sobre violencia de género y accidentes de tráfico, la manera que tenemos de contar las cosas puede cambiar la realidad. En esta cuestión es vital. La manera en la que nos referimos a una persona que cometió el acto suicida puede ser clave para evitar futuras pérdidas. En palabras del presidente de la Sociedad Española de Suicidiología, Andoni Anseán, en una entrevista de la agencia EFE: «en España y en otros países del entorno, los hombres jóvenes se mueren por suicidio, pero ese dato no sale en los medios de comunicación y es sorprendente: nadie quiere ver el elefante que tenemos en la habitación».

Informar sobre suicidio es una compleja tarea que en las redacciones se aborda mayoritariamente desde la creencia de que es un tema a excluir del temario porque la notoriedad del acto actúa de estímulo para desencadenar situaciones similares en otros individuos. En España, los últimos datos oficiales indican que el número de suicidios (ausentes de temario) triplican al número de muertes en accidentes de tráfico (presentes cada día en los medios). Sobre el suicidio hay, "una regla no escrita, a modo de autocensura, que dicta que no se debe informar de ellos, salvo en casos excepcionales, para evitar un efecto imitación entre los miembros vulnerables del público o la audiencia» (Olmo y García, 2015: 71).

Los estudios de expertos en Comunicación sobre la presencia de noticias en los medios de masas o sobre el modo de elaborar el contenido informativo son escasos. Los análisis acostumbran a realizarse desde las áreas de salud, principalmente psiquiatría y psicología, pero no tanto desde la perspectiva de expertos en newsmaking o en agenda setting que puedan analizar en profundidad los mecanismos que se activan o se detienen para determinar la selección de noticias sobre suicidio, el modo de presentarlas o descartarlas en la construcción del temario, su ubicación en secciones de salud o de sucesos, la selección de datos para el relato noticioso y el modo de jerarquizarlos y de abordar la narración final del hecho. Los enfoques de los trabajos científicos acostumbran a orientarse a los efectos sobre las audiencias y a valorar el impacto de los efectos Werther y Papageno en función de la intencionalidad de la información y de sus posibles efectos sobre la audiencia.

Sobre el suicidio como acontecimiento informativo los medios han adoptado un rol protector y han optado por silenciar aliándose con lo que el sociólogo David Philips denominó en 1974 como el efecto Werther, en alusión a lo acontecido a finales del siglo XVII cuando en países como Italia o Dinamarca se prohibió la venta de Las penas del joven Werther, de Johann Wolfgang von Goethe, porque tras su publicación en 1774 se detectaron casos de jóvenes que imitaban al protagonista suicida. La relación entre la notoriedad del sujeto y el impacto imitativo en la población, es una 
línea que sustentan, entre otros, los análisis de Philips, Lesyna e Paight (1992), Wasserman (1984) y Müller (2011) aunque también se cuestiona si el impacto es por la información sobre el hecho en sí o sobre el modo de narrar el acontecimiento, en ocasiones con sesgos literarios y erróneas asociaciones que conviertan la noticia en un texto sensacionalista o adornada con tintes románticos.

Derivar el suicidio a la realidad silenciada por los medios puede provocar, también, efectos que inciden negativamente sobre la población. La antítesis del efecto Werther está en el efecto Papageno según el cual la cobertura responsable de una noticia puede tener un efecto preventivo sobre la conducta suicida. Los defensores del efecto Papageno proponen que se informe de casos en los que se logró superar episodios de crisis suicida porque de ese modo el efecto imitativo podría incidir beneficiosamente sobre la población. «El impacto de la información sobre el suicidio no puede limitarse a los efectos nocivos, sino que la cobertura del abordaje positivo en circunstancias adversas, como se explica en los artículos de prensa sobre la ideación suicida, puede tener efectos protectores» (Niederkrotenthaler, 2012, en Herrera, 2015).

En general, en la literatura científica se apuesta por un equilibrio de ambos efectos. Olmo y García sostienen que "para eso se requiere informar responsablemente, sin sensacionalismos, pero sin eufemismos y tratándolo como un tema de salud pública» (2015: 88) y defienden que sean las propias organizaciones profesionales de periodistas las que, con asesoramiento de expertos en salud, generen sus códigos de actuación. Garrido-Fabian et al., por su parte, aseguran que en las investigaciones sobre ambos efectos concluyen que el impacto mediático de los suicidios es un continuo entre ambos efectos (2012: 812) y demandan «más investigación para evaluar la calidad del tratamiento de los medios de comunicación de sobre suicidios (2018: 821).

Entre las escasas propuestas localizadas en trabajos del área de Comunicación destacan el análisis del efecto Werther y del modo de informar de influencia de suicidios de personajes conocidos y su impacto en los receptores (Müller, 2011) o del efecto Papageno en la prensa española (Herrera, Ures y Martínez, 2015). La revisión de revistas científicas del área revela, también, las investigaciones de Olmo y García con mirada al pero de la información televisiva (2015) o su análisis sobre la relevancia pública y la responsabilidad social del tema (2014), y de Garrido-Fabián, Serrano-López y Catalán-Matamoros (2018), que estudian el uso por los periodistas de las recomendaciones de la OMS a través del análisis del diario ABC entre 1995 y 2005, periodo en el que detecta una tendencia "a reducir el número de noticias de suicidios específicos que incluyen descripciones del método empleado y la publicación de notas de suicidio, que presentan el suicidio como inexplicable o causado por un sólo factor y que lo describen como método para enfrentar problemas en mayor medida» (2018: 821).

Otros estudios científicos desde Comunicación abordan el tratamiento periodístico en la prensa canaria a finales de la primera década de este siglo (Carrascosa, 
2015), la información sobre suicidio en Chile (Urzúa, 2003) o la caracterización de noticias sobre suicidio en Colombia (Muñoz, 2014 y Rátiva, Ruíz y Medina-Pérez, 2013) o sobre el abordaje de medios colombianos y de manuales de estilo de periódicos de Colombia y España (Rubiano, Quintero y Bonilla, 2007). A la lista se suman referencias de trabajos en el entorno europeo, como la revisión de diarios Suecos (Catalán-Matamoros, Axelsson y Strid, 2007) y británicos (Goulden et al, 2011, Thornicroft et al, 2013) o las referenciales aportaciones de Philips (1982 y 1992), Norris (2001), Stack (2003), Niederkrotenthaler et al (2010) o Sisask y Värnik (2012), Ladwig el al (2012) o Scherr y Steinleitner, (2015).

Olmo y García $(2015,77-78)$ aportan un detallado recorrido por iniciativas en torno a un buen abordaje informativo del suicidio en el que incluyen la revisión crítica del trabajo realizado sobre el papel de los medios en la prevención elaborada por Sisask y Värnik (2012), los informes y normas para hablar sobre suicidios promovidos por la ONG británica Media Wise Trust, integrada por periodistas preocupados en fomentar prácticas honestas y éticas, y el trabajo de Pirkis y Blood (2010) en favor de que los medios contribuyan a la prevención. También refieren las recomendaciones del gobierno Australiano y su política intervencionista en la orientación de los contenidos mediáticos, la guía The reporting of Mental Health and Suicide by the Media publicada en 2006 por la National Union of Journalists of Scotland, a la propia Media Wise Trust y a la ONG Samaritans que se cita como referente para ampliar información sobre tratamiento correcto en el libro de estilo de la BBC, que dedica uno los capítulos de sus guidelines a cómo tratar «suicidio, intento de suicidio, autolesión y desórdenes de la conducta alimentaria» (Olmo y García, 2015, 85-86).

\subsection{LAS RECOMENDACIONES DE LA OMS}

El punto de equidistancia entre ambos efectos e intencionalidades informativas podría situarse en las recomendaciones de la Organización Mundial de la Salud que en un documento instructor para profesionales de los medios de comunicación resalta que se debe «informar del suicidio de manera adecuada, exacta y potencialmente útil a través de medios progresistas e inteligentes puede prevenir una trágica pérdida de vidas» (OMS, 2000).

Según la OMS, suicidio es un acto deliberadamente iniciado y llevado a cabo por un individuo con el conocimiento o la expectativa de que su resultado va a ser la muerte que se sitúa entre las diez primeras causas de muerte en el mundo (en torno a un millón de muertes al año). La magnitud del problema crece ya que se estima que hay un fenómeno iceberg: se estima que por cada suicidio consumado existen al menos 20 intentos pero se dispone a nivel mundial registros oficiales de comportamientos de riesgo suicida y la mayoría de intentos no se informan ni se registran. 
Las cifras sobre causas de la muerte que ofrece el Instituto Nacional de Estadísticas (INE) en 2108 registran 3.569 suicidios en España. Por género, la tasa de hombres (2.662) triplica la de mujeres (907). Los datos recogen oficialmente las defunciones de 2016 (se publican siempre dos años más tarde) y sitúan el suicido por delante de fallecimientos por paro cardíaco (3.460) y en accidentes de tráfico (1.890). Los casos se reparten entre 1.653 episodios por ahorcamiento, estrangulamiento o sofocación autoinflingida y 904 por salto intencionado desde un lugar elevado. Por comunidades, en términos absolutos el mayor número se concentra en Andalucía seguida de Cataluña, Galicia y Comunidad Valenciana, aunque al ponderar la incidencia en función del número de habitantes la lista se invierte y Galicia lidera con diferencia $(124,31$ casos por millón de habitantes). La falta de visibilidad mediática del suicidio hace que también resulte sorprendente analizar la pirámide de edad: el pico de incidencia está en la población de 30 a 39 años y, en general, a medida que la edad aumenta el número de suicidios desciende, aunque su incidencia es trasversal a toda la pirámide de edad.

Las propuestas de la Organización Mundial de la Salud son punto de partida para este trabajo sintetizando en su ficha de análisis las recomendaciones de la OMS para la correcta orientación de informaciones sobre actos suicidios incorporada al programa SUPRE (SUicide PREvention) como uno de los instrumentos dirigidos a colectivos profesionales que puedan ser «particularmente relevantes» en la prevención del suicidio, entre ellos los «comunicadores».

El documento de la OMS (2000) (http://www.who.int/mental_health/ publications/suicide_prevention/es/index) remite a las web de la Asociación Internacional para la Prevención del Suicidio, la Asociación Americana de Suicidología, la Red Australiana de Intervención Temprana para Salud Mental en Personas Jóvenes y la Academia Internacional de Investigación del Suicidio para ver las guías profesionales que han elaborado, pero añade su propia guideline en la que se deja libertad narrativa al periodista y se recomienda que en informaciones generales sobre el tema se interpreten las estadísticas cuidadosamente, se usen fuentes auténticas y confiables, se manejen con cuidado comentarios espontáneos, se eviten las magnificación de pequeñas cifras con expresiones superlativas y se aluda identificar el comportamiento suicida "como una respuesta entendible a los cambios o la degradación social o cultural» $(2000,9)$.

En las noticias sobre un suicidio concreto, se pide evitar: una cobertura sensacionalista, sobre todo si involucra a un actor social relevante; las fotografias de la víctima o de la escena del suicidio; y «las descripciones detalladas del método usado y cómo lo obtuvo la víctima» (2000: 9). También incide en que no se presente el suicidio como «algo inexplicable o simplista» porque «nunca es el resultado de un solo factor o hecho» sino que está causado por «una compleja interacción de muchos factores tales como enfermedad mental y fisica, abuso de sustancias, conflictos familiares e interpersonales y acontecimientos estresantes» (OMS, 2000: 9-10). 
El relato informativo, según la propuesta de la OMS, debe alejarse de describir al suicidio como un método de enfrentarse a problemas personales/sociales, debe orientarse a lamentar la muerte más que a presentar a la víctima como mártir o con términos de adulación, y a tener en cuenta el impacto sobre las familias y otros sobrevivientes en términos del estigma y el sufrimiento psicológico. Además, se anima a "describir las consecuencias físicas de intentos de suicidio (daño cerebral, parálisis, etc.)» porque "puede actuar como elemento de disuasión» $(2000,10)$.

La guía anima a los medios de comunicación a comportarse como actores proactivos en la prevención del suicidio «contextualizando las informaciones con listados de servicios de salud mental y líneas telefónicas de ayuda disponibles con sus números y direcciones actualizados, publicitar las señales de advertencia del comportamiento suicida, transmitir mensajes sobre la frecuente asociación entre la depresión y el comportamiento suicida, ofrecer un mensaje de solidaridad a los sobrevivientes» (2000: 10).

A modo de resumen sintetiza sus recomendaciones en pautas de comportamiento con lo que se debe hacer: trabajar estrechamente con autoridades de la salud en la presentación de los hechos; referirse al suicidio como un hecho logrado, no uno exitoso; presentar sólo datos relevantes en las páginas interiores; resaltar las alternativas al suicidio; proporcionar información sobre líneas de ayuda y recursos comunitarios; publicitar indicadores de riesgo y señales de advertencia (OMS, 2000: 11) y lo que se debe evitar: No publicar fotografias o notas suicidas; no informar detalles específicos del método usado; no dar razones simplistas; no glorificar ni magnificar el suicidio, no usar estereotipos religiosos o culturales; no aportar culpas (OMS, 2000: 11).

\section{Metodología}

Para analizar el abordaje informativo del suicidio se diseñó una investigación exploratoria con metodología triangular en las que, además de revisar pormenorizadamente el estado de la cuestión, se orientó a conocer las recomendaciones, pautas o normas de los principales periódicos y de las organizaciones profesionales más representativas y se realizó un análisis de contenido en informaciones publicadas para determinar si el enfoque de la narración en informaciones sobre suicidio se ajusta a las recomendaciones de la Organización Mundial de la Salud.

El principal objetivo es conocer si en las informaciones sobre suicidio se asumen las recomendaciones de la OMS y, por extensión, si se alinean en el efecto Werther (presencia escasa y centrada en personajes notarios) o en el efecto Papageno (incorporando referencias adicionales orientadas a prevención y apoyo). Además, se formularon de partida los siguientes objetivos/preguntas de investigación: ¿los me- 
dios incluyen el tratamiento del suicidio en sus libros de estilo?, ¿las organizaciones profesionales incluyen el suicidio en sus normas/recomendaciones?, ¿hay diferencias entre los medios nacionales y los internacionales?, ¿hay diferencias entre las organizaciones españolas y las de otros países?

Para identificar la existencia de normas o recomendaciones para elaborar informaciones sobre un suicidio se, en España se trabajó con la página web de la FAPE y las de los nueve Colegios Profesionales de Periodistas registrados en España pertenecientes a Andalucía, Asturias, Castilla y León, Cataluña, Euskadi, Galicia, La Rioja, Murcia y Navarra.

En el ámbito internacional se seleccionaron como sujetos de estudio 23 organizaciones: Centre for Investigative Journalism, Deutscher Journalisten-Verband, Fourth Estate (association), IFEX, Inter American Press Association, International Association of Press Clubs, International Center for Journalists, International Council for Press and Broadcasting, International Federation of Agricultural Journalists, International Francophone Press Union, International Journalism Festival, International Media Support, International Press Center (Brussels), International Press Institute, International Women's Media Foundation, Internationales Institut für Journalismus, Media Legal Defence Initiative, Mideast Dig, Technical Image Press Association, World Press Institute, Youth Journalism International, Internews y Media Development Investment Fund.

No se encontraron investigaciones anteriores en el área de Comunicación con un abordaje múltiple y comparativo de códigos de medios y entidades profesionales, y de estudio global (nacional e internacional) del seguimiento de las recomendaciones de la OMS en las informaciones sobre suicidio. Por eso, para el análisis de medios se estableció una muestra intencional basada en los cinco diarios nacionales generalistas mejor ubicados en términos de audiencia en el EGM (febrero-noviembre, 2017) y un corpus internacional compuesto por seis medios de referencia de Europa y Estados Unidos que sirve de elemento de contraste.

La muestra de diarios nacionales quedó confirmada por El País, El Mundo, La Vanguardia, La Voz de Galicia y El Periódico. La muestra de periódicos internacionales la integran The Guardian (Uk), Le Monde (Fr), The New York Times (EEUU), The Washington Post (EEUU), Il Corriere della Sera (It) y Público (Pt). Se analizó la versión online de las 11 cabeceras mediante búsquedas en Google para evitar distorsiones de los buscadores de cada medio. El periodo seleccionado fue de abril a septiembre, los seis meses con mayor número de suicidios según el INE. Se afinó la búsqueda para que los resultados se limitasen a informaciones del diario buscado colocando en el buscador insite:webdelmedio suicidio (por ejemplo, insite:elpais.com suicidio).

Los resultados de cada medio se filtraron siguiendo los siguientes requisitos: tratar el suicidio de una persona como hecho principal, siendo este lo más importante 
dentro de la pieza, o, al menos, de la misma importancia que otros acontecimientos descritos; no se recogen los ataques suicidas ni los intentos de suicidio; solo se incluirán géneros informativos; no se seleccionan informaciones sobre hechos supuestos en las que no se conozca realmente que es un caso de suicidio y quedan fuera de la selección piezas periodísticas limitadas a resúmenes estadísticos. Tras el filtrado, los 2.127 enlaces iniciales quedaron reducidos a 258 eliminando también entradas duplicadas y obteniendo la muestra de análisis de noticias final.

Para determinar el grado de seguimiento de las recomendaciones de la OMS se determinó una ficha de análisis en la que se anota fecha de análisis de la noticia, medio y se verifica si:

- Proporciona información sobre líneas de ayuda y recursos comunitarios. Se requiere que en la noticia aparezca algún dato de contacto de entidades que puedan servir como un primer referente a alguien en riesgo de suicidio, o aportar información a familiares, amigos...

- Proporciona indicadores de riesgo y señales de advertencia. Se considera que siguen esta recomendación los textos que expliquen algún comportamiento que pueda ayudar a detectar cuando alguien necesita ayuda. Es decir, aspectos que puedan interpretarse como indicadores para identificar esas llamadas de auxilio.

- Publica fotografías o notas suicidas. Imágenes de la persona en los momentos previos, durante o después del suicidio. En el caso de las notas suicidas, se contabiliza tanto si se ofrece escaneada, fotografiada o reproducida en el texto.

- Aporta detalles específicos del método empleado. Se considera que los aporta si va más allá de identificar el modo del fallecimiento y entra en relato del mismo.

- Aporta razones simplistas. Si en el texto hay conjeturas del autor sobre los motivos sin profundizar o si hay frases que pretenden justificar la acción.

- Aporta culpas. Si señala a personas físicas o jurídicas como la causa de la muerte porque se aleja de considerar el suicidio como una acción emprendida por una persona ante la situación en la que vive, generalmente experimentando incapacidad para gestionarla.

- Resalta alternativas al suicidio o aporta pautas que pudieran llevar a alguien con tendencia suicida a buscar apoyo para paliar su sufrimiento y superar la situación adversa.

Las noticias analizadas corresponden a los meses comprendidos entre el 1 de abril de 2017 hasta el 30 de septiembre de 2017. La búsqueda, selección y análisis se realizaron de febrero a abril de 2018. La interpretación y valoración de los resultados se llevó a cabo en mayo. 


\section{Resultados}

Para aproximarnos a conocer qué medios tienen una preocupación real por abordar el suicidio de una forma correcta, cuáles sólo se limitan a recoger éticamente el tema y cuáles lo omiten tanto a nivel ético-teórico como a nivel práctico estudiamos en primer lugar las referencias al abordaje informativo del suicidio en los documentos deontológicos o de estilo de los medios nacionales e internacionales escogidos y en las organizaciones profesionales de referencia de nuestro país y en el ámbito internacional.

\subsection{AnÁlisis De Códigos deONTOlógicos y libros De ESTILO}

TABLA 1

Análisis de códigos deontológicos/libros de estilo de los medios nacionales

\begin{tabular}{|l|l|l|l|}
\hline \multicolumn{1}{|c|}{ Medio } & \multicolumn{1}{|c|}{ URL } & \multicolumn{1}{c|}{$\begin{array}{c}\text { Incluye } \\
\text { recomendaciones para } \\
\text { informar sobre suicidio }\end{array}$} & $\begin{array}{c}\text { Acorde a las pautas } \\
\text { de la OMS }\end{array}$ \\
\hline El Mundo & www.elmundo.es & Sí. & Sí. \\
\hline La Vanguardia & www.lavanguardia.com & No. \\
\hline La Voz de Galicia & www.lavozdegalicia.es & No. & No. \\
\hline El Periódico & www.elperiodico.com & No. \\
\hline El País & www.elpais.com & Sí. & No. \\
\hline
\end{tabular}

Fuente y elaboración propias.

De los cinco periódicos nacionales con mayor número de lectores según el EGM (Estudio General de Medios), sólo El Mundo y El País proporcionan contenido orientativo sobre el suicidio en sus códigos éticos. El Mundo resalta que se trata de una cuestión delicada e invita al periodista a reflexionar sobre dos cuestiones: el efecto Werther y la confirmación de que se trata de un suicidio, para evitar por una parte el efecto de imitación y por otra la difusión de bulos. Incide en indicar si existen hipótesis que apuntan al suicidio, pero no confirmarlo si las autoridades y expertos aún no lo hicieron. Añade, además de un ejemplo para mostrar que se puede llegar a transgredir algún derecho personal si no se hace un buen tratamiento del suicidio, una parte jurídica que va más allá de la autorregulación periodística.

El País muestra interés, pero no desempeña un papel activo en la prevención ya que únicamente señala que debe ser tratado con cautela y que sólo deben 
cubrirse suicidios de personajes relevantes o si supone un hecho social de interés general. En su Libro de Estilo se refiere de modo conciso al suicidio en la sección de Política Editorial de su Título I. se aboga por la prudencia porque «la psicología ha comprobado que estas noticias incitan a quitarse la vida a personas que ya eran propensas al suicidio y que sienten en ese momento un estímulo de imitación».

TABLA 2

Análisis de códigos deontológicos/libros de estilo de los medios internacionales

\begin{tabular}{|l|l|l|l|}
\hline \multicolumn{1}{|c|}{ Medio } & \multicolumn{1}{|c|}{ URL } & \multicolumn{1}{c|}{$\begin{array}{c}\text { Incluye } \\
\text { recomendaciones para } \\
\text { informar sobre suicidio }\end{array}$} & $\begin{array}{c}\text { Acorde a las pautas } \\
\text { de las OMS }\end{array}$ \\
\hline The Guardian & theguardian.com & Sí. & Sí. \\
\hline The New York Times & nytimes.com & No. \\
\hline The Washington Post & washingtonpost.com & No. & No. \\
\hline Público (Pt) & www.publico.pt & No. \\
\hline Corriere della Sera & www.corriere.it & No. & No. \\
\hline Le Monde & www.lemonde.fr & No. No. \\
\hline
\end{tabular}

Fuente y elaboración propias.

En esta muestra integrada por medios de referencia a nivel internacional se percibe la carencia de interés por parte de los profesionales de la comunicación a la hora de abordar el suicidio. Sólo el periódico The Guardian, incluye una serie de recomendaciones bastante completas además de estar en sincronía con las de la OMS. Comienza invitando a tener cuidado con la cobertura de los suicidios, pero va más allá al especificar que no se debe profundizar en el método de suicidio empleado. Hace hincapié, además, en tener cuidado con los sentimientos de los familiares y en tratar de escribir mostrando empatía por los mismos. Pero lo más útil de lo que recoge para la prevención del suicidio, es que recomienda adjuntar el número de teléfono de una línea de ayuda tal y como defiende la OMS.

\subsection{Análisis de Colegios Profesionales, FAPE y organizaciones INTERNACIONALES}

La Federación de Asociaciones de Periodistas de España (FAPE), entidad de referencia del asociacionismo profesional a nivel nacional no posee recomendaciones o pautas específicas para un correcto tratamiento del suicidio en su código deontoló- 
gico, pero sí que contiene fragmentos que podrían ser aplicados a este tema. En su artículo 4, por ejemplo, se potencia el respeto al derecho de las personas a su propia intimidad e imagen justificando las intromisiones o indagaciones sobre la vida privada de una persona sin su previo consentimiento sólo en caso de interés público. Señala también que «en el tratamiento informativo de los asuntos en que medien elementos de dolor o aflicción en las personas afectadas, el periodista evitará la intromisión gratuita y las especulaciones innecesarias sobre sus sentimientos y circunstancias».

En la revisión de la documentación de los nueve Colegios Profesionales de Periodistas creados en España disponible online solo en tres (Andalucía, Cataluña y Galicia) se encuentran muestras de interés en orientar a los comunicadores en la temática del suicidio.

El Colexio Profesional de Xornalistas de Galicia trabajó con la Xunta de Galicia en la elaboración del Plan de Prevención del Suicidio integrado por una guía de estilo para el tratamiento informativo de esta cuestión, talleres para periodistas e iniciativas para elaborar protocolos e instrumentos de coordinación de los medios con otros sistemas, como el sanitario o el social. La guía desarrollada por esta entidad es bastante práctica pues ofrece una breve y concisa lista de pautas para tratar el suicidio en la línea de las recomendaciones de la OMS que desde el principio con una actitud proactiva: "habla sobre las muertes por suicidio, pero también sobre los factores de riesgo y los medios de prevención».

El Col-legi de Periodistes de Catalunya incluye directamente en su código ético un apartado específico para el suicidio en el que prioriza el respeto y la dignidad de las personas por encima de cualquier información y defiende que «los casos de suicidio sólo se difundirán cuando tengan relevancia personal o sean de manifiesto interés público, teniendo en cuenta, además, el riesgo de un efecto mimético».

El Colegio de Periodistas de Andalucía celebró en colaboración con la Junta de Andalucía en el año 2015 unas Jornadas de formación sobre comunicación y salud que contaron con un apartado específico para el suicidio y del que se extrajeron una serie de recomendaciones que actualmente ofrecen en su página web. Además, el Colegio andaluz ha actuado en varios casos de noticias en los que consideró que no se había hecho un buen tratamiento informativo con respecto a este tema. 
TABLA 3

Análisis de los Colegios Profesionales de Periodistas de España

\begin{tabular}{|l|l|}
\hline \multicolumn{1}{|c|}{ Organización } & \multicolumn{1}{|c|}{ Publica pautas para el tratamiento del suicidio } \\
\hline FAPE & $\begin{array}{l}\text { No, pero sí sobre «informaciones en las que me- } \\
\text { dien elementos de dolor» }\end{array}$ \\
\hline Colegio Profesional de Periodistas de Asturias & No. \\
\hline Colegio Profesional de Periodistas de la Rioja & No. \\
\hline $\begin{array}{l}\text { Colegio Profesional de Periodistas de Castilla y } \\
\text { León }\end{array}$ & No. \\
\hline Colegio de Periodistas Región de Murcia & No. \\
\hline Colexio Profesional de Xornalistas de Galicia & Ś, ofrece una guía para los periodistas. \\
\hline Colegio Profesional de Periodistas de Andalucía & Ś, incluye un apartado en su código ético. \\
\hline Colegio Vasco de Periodistas & No. \\
\hline Colegio de Periodistas de Navarra & No. \\
\hline Col·legi de Periodistes de Catalunya & Sí, ofrece una guía para los periodistas. \\
\hline
\end{tabular}

Fuente y elaboración propias.

Posteriormente se continuó con el análisis de las asociaciones internacionales. En este caso, la cuestión estaba en sí ofrecían algún tipo de información a los periodistas (pautas, noticias que hablasen sobre el tema...). De las 23 asociaciones en ninguna se ofrecía una guía como tal, aunque en el 60,9\% de ellas se encontró algún tipo de noticia que hablase sobre el suicidio o su tratamiento, sin pronunciarse ni dar consejos. En las restantes $(39,1 \%)$ entidades no contenían se detectó ninguna referencia a cómo informar sobre el suicidio.

\subsection{AnÁlisis de nOticias}

Es importante que los medios y asociaciones profesionales promuevan pautas para informar sobre suicidio, pero aún lo es más que las apliquen o que tomen como referencia autoridades en materia de salud. La guideline de la OMS se usa como referencia de análisis sobre un total de 258 noticias de los once medios de referencia que integran la muestra. El primer resultado se desprende del proceso metodológico: sólo uno de cada diez textos sobre suicidio se refería realmente a un acto suicida como eje vertebrador principal de la narración informativa. 
Los resultados del análisis son claros. En ninguno de los textos informativos españoles analizados se informa sobre líneas de ayuda, indicadores de riesgo o alternativas al suicidio. El dato más negativo es que en casi una de cada tres informaciones aún se siguen dando detalles que describen el modo en que se realizó el acto suicida. No aparece ninguna recomendación con 100\% de seguimiento en todos los medios aunque son muy elevados los casos en los que se evitan razones simplistas, identificar culpas y evitar fotos del suicida o del escenario del suicidio (tabla 4).

TABLA 4

Porcentaje de noticias de medios nacionales que cumplen cada recomendación

\begin{tabular}{|l|c|}
\hline \multicolumn{1}{|c|}{ Pauta de la OMS } & $\begin{array}{c}\text { Noticias que cumplen } \\
\text { esta recomendación }\end{array}$ \\
\hline Proporcionar información sobre líneas de ayuda y recursos comunitarios & $0,0 \%$ \\
\hline Proporcionar indicadores de riesgo y señales de advertencia & $0,0 \%$ \\
\hline No publicar fotografias o notas suicidas & $96,3 \%$ \\
\hline No aportar detalles específicos del método empleado. & $66,7 \%$ \\
\hline No dar razones simplistas. & $94,4 \%$ \\
\hline No aportar culpas & $94,4 \%$ \\
\hline No resaltar las alternativas al suicidio & $0,0 \%$ \\
\hline Nota media & $50,5 \%$ \\
\hline
\end{tabular}

Fuente y elaboración propias.

Desglosando los resultados se ven comportamientos muy similares. Sobresale el indicador de La Voz de Galicia y El Periódico sobre la no publicación de fotos o notas de suicidas, y de El País y El Periódico en no incorporar al relato la atribución de culpas. Algo que podría explicar la variación de los datos, especialmente en la pauta sobre la no publicación de notas suicidas y fotografias, es que ignoramos el dato de en cuántos de estos casos se disponía de esta información para poder valorar si fue una decisión de exclusión o simplemente que no se tenía el material gráfico. En segundo lugar, los porcentajes más altos en las pautas sobre no aportar culpas, razones simplistas o detalles específicos, también se podrían deber a que en muchos de los casos analizados no se da una cobertura extensa del tema, por lo que tampoco hay un gran margen para cometer estos errores. 
TABla 5

Porcentaje de noticias de medios nacionales que cumplen cada recomendación según el medio

\begin{tabular}{|l|c|c|c|c|c|}
\hline \multicolumn{1}{|c|}{ Pedios nacionales } \\
\hline \multicolumn{1}{|c|}{ Pauta de la OMS } & El País & El Mundo & Vanguardia & La Voz & Periódico \\
\hline $\begin{array}{l}\text { Informa sobre líneas de ayuda y recur- } \\
\text { sos comunitarios }\end{array}$ & $0,0 \%$ & $0,0 \%$ & $0,0 \%$ & $0,0 \%$ & $0,0 \%$ \\
\hline $\begin{array}{l}\text { Incluye indicadores de riesgo y señales } \\
\text { de advertencia }\end{array}$ & $0,0 \%$ & $0,0 \%$ & $0,0 \%$ & $0,0 \%$ & $0,0 \%$ \\
\hline $\begin{array}{l}\text { Evita fotografias o notas suicidas } \\
\text { Evita detalles específicos del método } \\
\text { empleado. }\end{array}$ & $96,0 \%$ & $96,6 \%$ & $92,9 \%$ & $100,0 \%$ & $100,0 \%$ \\
\hline Evita dar razones simplistas. & $96,0 \%$ & $93,1 \%$ & $92,9 \%$ & $92,3 \%$ & $100,0 \%$ \\
\hline Evita aportar culpas & $100,0 \%$ & $93,1 \%$ & $92,9 \%$ & $76,9 \%$ & $100,0 \%$ \\
\hline No resalta las alternativas al suicidio & $0,0 \%$ & $0,0 \%$ & $0,0 \%$ & $0,0 \%$ & $0,0 \%$ \\
\hline Porcentaje medio & $51,4 \%$ & $50,2 \%$ & $49,4 \%$ & $47,3 \%$ & $53,8 \%$ \\
\hline
\end{tabular}

Fuente y elaboración propias.

La pauta de «no aportar detalles específicos del método empleado» es una de las más vulneradas y esto se debe a la gran carga sensacionalista que se le atribuye a esta temática en los periódicos españoles. Nos encontramos con casos de suicidio como el del banquero Miguel Blesa, en el que todos los medios realizaron una cobertura detallada hasta el punto de describir todos y cada uno de los pasos que dio el presidente de Caja Madrid para llevar a cabo su suicidio con un rifle de caza.

En el gráfico 1 observamos la nota media de cada uno de los medios, siendo 0 un no cumplimiento de ninguna de las recomendaciones en ninguna de las noticias y el 10 un cumplimiento de cada una de las pautas en todos los casos. Podemos ver como en todos los casos se ronda el suficiente, pero destacando que como vimos en la tabla 3 hay un reparto muy heterogéneo del seguimiento de las reglas.

Al aplicar la ficha de análisis con las recomendaciones de la OMS a las noticias publicadas por los medios internacionales de referencia que integran la muestra intencional se observa una situación dispar. The Guardian informa sobre ayudas y recursos comunitarios de apoyo en nueve de cada diez informaciones $(88,2 \%)$ pero el resto ni lo menciona. También The Guardian (35,3\%) junto a The New York Times y The Washington Post son los únicos que incorporan al relato indicadores de riesgo o señales de advertencia. Solo en Corrieri della Sera y Le Monde se respeta siempre la pauta de no publicar fotos o notas suicidas. Los porcentajes de la situación detectada en cada uno de los 7 medios se detallan en la tabla 5 . 
10,00

Nota media

$$
8,00
$$

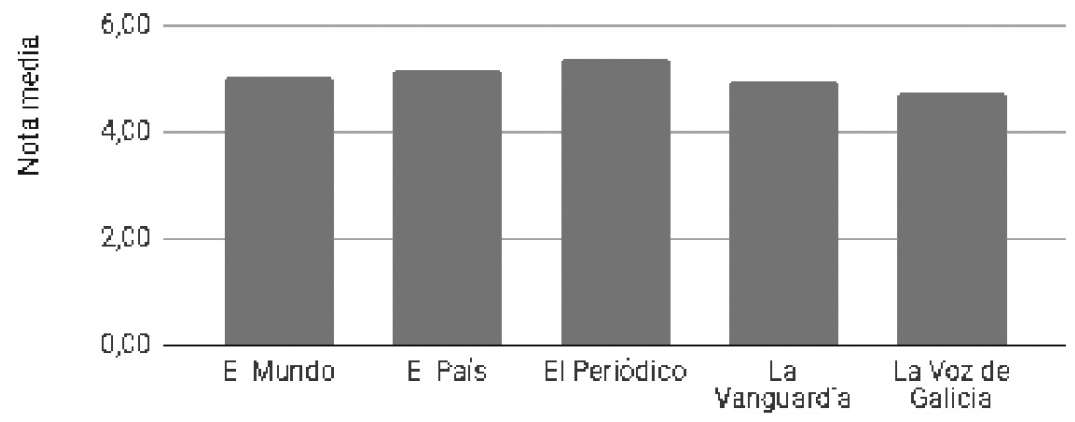

Medos

Fuente y elaboración propias.

\section{GrÁFICO 1}

\section{Notas medias de los medios nacionales}

Para las pautas en las que se consiguen los mayores porcentajes de seguimiento hacemos una observación semejante a la de los medios nacionales: en muchos casos no se dan datos del método empleado porque las informaciones son muy breves o se centran en declaraciones de la policía. Además, en estos apartados encontramos porcentajes muy bajos en relación a los resultados españoles. Es llamativo que el New York Times especifique cómo se llevó a cabo el acto en casi tres de cada cuatro de las piezas analizadas. 
TABLA 6

Porcentaje de noticias de medios internacionales que cumplen cada recomendación según el medio

\begin{tabular}{|c|c|c|c|c|c|c|c|}
\hline \multicolumn{8}{|c|}{ Medios internacionales } \\
\hline Pauta de la OMS & $\begin{array}{c}\text { Corrieri } \\
\text { della Sera }\end{array}$ & El País & Le Monde & $\begin{array}{c}\text { Público } \\
\text { (Portugal) }\end{array}$ & $\begin{array}{l}\text { The } \\
\text { Guardian }\end{array}$ & $\begin{array}{l}\text { The New } \\
\text { York Times }\end{array}$ & $\begin{array}{l}\text { The } \\
\text { Washington } \\
\text { Post }\end{array}$ \\
\hline $\begin{array}{l}\text { Informa sobre líneas } \\
\text { de ayuda y recursos } \\
\text { comunitarios }\end{array}$ & $0,0 \%$ & $0,0 \%$ & $0,0 \%$ & $0,0 \%$ & $88,2 \%$ & $0,0 \%$ & $0,0 \%$ \\
\hline $\begin{array}{l}\text { Incluye indicadores } \\
\text { de riesgo y señales } \\
\text { de advertencia }\end{array}$ & $0,0 \%$ & $0,0 \%$ & $0,0 \%$ & $0,0 \%$ & $35,3 \%$ & $11,1 \%$ & $5,6 \%$ \\
\hline $\begin{array}{l}\text { Evita fotografias o } \\
\text { notas suicidas }\end{array}$ & $100,0 \%$ & $96,0 \%$ & $100,0 \%$ & $88,9 \%$ & $90,2 \%$ & $72,2 \%$ & $86,1 \%$ \\
\hline $\begin{array}{l}\text { Evita detalles es- } \\
\text { pecíficos del mé- } \\
\text { todo empleado. }\end{array}$ & $55,6 \%$ & $64,0 \%$ & $62,5 \%$ & $66,7 \%$ & $74,5 \%$ & $27,8 \%$ & $38,9 \%$ \\
\hline $\begin{array}{l}\text { Evita dar razones } \\
\text { simplistas. }\end{array}$ & $88,9 \%$ & $96,0 \%$ & $87,5 \%$ & $100,0 \%$ & $94,1 \%$ & $72,2 \%$ & $77,8 \%$ \\
\hline Evita aportar culpas & $96,3 \%$ & $96,0 \%$ & $100,0 \%$ & $100,0 \%$ & $64,7 \%$ & $33,3 \%$ & $55,6 \%$ \\
\hline $\begin{array}{l}\text { No resalta las alter- } \\
\text { nativas al suicidio }\end{array}$ & $0,0 \%$ & $0,0 \%$ & $0,0 \%$ & $0,0 \%$ & $0,0 \%$ & $0,0 \%$ & $0,0 \%$ \\
\hline Porcentaje medio & $48,7 \%$ & $50,7 \%$ & $50,0 \%$ & $50,8 \%$ & $63,9 \%$ & $31,7 \%$ & $37,7 \%$ \\
\hline
\end{tabular}

Fuente y elaboración propias.

\section{Conclusiones}

El suicidio es omitido o tratado de forma negligente en gran medida, un hecho que no contribuye a solucionar el problema que supone el alto índice de muertes por esta causa en España y en el resto del mundo. En muchos casos se escoge silenciar este suceso aludiendo al efecto llamada, o efecto Werther. Sin embargo, la OMS nunca recomienda esta práctica, porque de igual manera que en los casos de violencia de género, los suicidios necesitan una atención especial. Además, las conductas más preocupantes son aquellas en las que se llega a culpar a la propia persona de la enfermedad mental o se achacan razones simplistas a su muerte. Cabe destacar que relacionado en el incorrecto tratamiento de este tipo de informaciones está el estigma que rodea tanto la cuestión como a la salud mental en general. 
Por otra parte, los resultados globales del análisis muestran que gran parte de los medios alcanzan un 50\% de seguimiento de las recomendaciones de la OMS. Pero al observar los resultados nos damos cuenta de su heterogeneidad. No hay patrones diferenciales en función del territorio y los comportamientos son dispares tanto en medios españoles, como en los europeos o los americanos.

La muestra integrada por diarios generalistas españoles con mayor audiencia no permite hablar de una atención preferencial al abordaje informativo del suicidio en los libros de estilo o en los códigos deontológicos. De los cinco analizados, solo se encontraron referencias concretas en dos y solo uno de ellos en línea con las recomendaciones de la OMS. En el caso de los medios internacionales solo en uno, The Guardian, se encontraron indicaciones específicas sobre el tema.

Tampoco se observa una gran preocupación en las organizaciones profesionales, a pesar de que se trata de una causa de muerte por encima de otras causas que habitualmente merecen cobertura informativa. No se localizaron recomendaciones específicas en el portal web de la Federación de Asociaciones de la Prensa, ni en seis de los nueve Colegios de Periodistas, ni en las 23 organizaciones profesionales internacionales analizadas.

La autorregulación profesional, en colaboración con expertos del campo de salud es todavía una tarea pendiente en la profesión periodística en España. En Galicia y Andalucía la tarea se hizo en común con las autoridades gubernamentales de Sanidad como primer acercamiento a contar con guías de abordaje integral del suicidio y en Cataluña se incluye en las pautas éticas, pero sin recomendaciones concretas.

El análisis de contenido de las informaciones sobre suicidio en los diarios nacionales e internacionales aún no permite hablar de rutinas asociadas a una cobertura de este tipo de acontecimientos que se aproxime a las recomendaciones de la OMS. El seguimiento de las pautas no comprende solo el informar sobre el hecho como se haría con sucesos similares, sino que también incluye la visibilización de acciones de apoyo y la participación de los medios como agentes divulgadores de textos que redunden en favor de aportar dinámicas o pautas comportamentales que ayuden a la prevención del suicidio de modo proactivo.

Los datos, como se evidencia, responden a las preguntas de investigación al identificar medios y organizaciones que incluyan el tratamiento del suicidio en sus libros de estilo, al señalar las diferencias entre los medios nacionales y los internacionales en su comportamiento ante actos suicidas y al ratificar como en ocasiones aún se recurre a aspectos morbosos al detallar el proceso del suicidio, publicar fotografias o notas e incluso hacer derivaciones de culpabilidad. No es posible sin embargo una diferenciación inequívoca de tendencia de las actitudes mediáticas a alinearse con el efecto Werther o con el efecto Papageno, aunque los indicadores manejados apuntan a 
un predominio de las políticas informativas de silencio deliberado (Werther) por la falta de visibilidad al comparar el número de suicidios con el número de noticias, por referencias claras a evitar estas informaciones para no suscitar comportamientos de imitación y en la notoria ausencia de contenidos que se alineen con actitudes favorables a promover la prevención a través de la incorporación al relato de datos significativos como entidades de apoyo o síntomas de identificación de posibles conductas de riesgo.

\section{Referencias bibliográficas}

Carrascosa, Lara (2015). El tratamiento sensacionalista y amarillista del suicidio por razones económicas en la prensa estatal y canaria a inicios de la crisis actual (agosto 2007-enero 2009). Revista internacional de Historia de la Comunicación, 5, 52-75. ISSN-e 2255-5129. Recuperado de https://dialnet.unirioja.es/ejemplar/424520.

Catalán-Matamoros, D., Axelsson R. y Strid, J. (2007). How do newspapers deal with health in Sweden? A descriptive study. Patient Education and Counseling, 67, 78-83.

Cohen, B.C. (1963). The press and foreign policy. Princeton, NJ: Princeton University Press.

Colegio Profesional de Periodistas de Andalucía (2018). El Colegio profesional de Periodistas expresa su preocupación sobre casos de suicidios en Cádiz. Recuperado de https:// periodistasandalucia.es/2018/01/12/colegio-periodistas-expresa-preocupacion-laspublicaciones-casos-suicidios-cadiz/

Colegio Profesional de Periodistas de Cataluña (2016). Código deontológico. Recuperado de https://fcic.periodistes.cat/es/codi-deontologic/

Colexio Profesional de Xornalistas de Galicia (2017). Recomendacións profesionais sobre información e sufrimento humano. Recuperado de http://www.xornalistas.org/novaseventos/novas/o-cpxg-e-o-copg-presentan-as-recomendacions-profesionais-sobreinformacion-e-sufrimento-humano-/

El Periódico (1993). Estatuto de redacción de El Periódico de Catalunya.

Dumon, E., y Portzky, G. (2014). Directrices de actuación para la Prevención, Intervención y Postvención del suicidio en el entorno escolar. Europa Belgica. Recuperado de http://blogs.grupojoly.com/con-la-venia/files/2015/06/HerramientaMedios Comunicacion.pdf

Garrido-Fabián, F, Eleazar Serrano-López A. y Catalán-Matamoros, D. (2018). El uso por los periodistas de las recomendaciones de la OMS para la prevención del suicidio. El caso del periódico Abc. Revista Latina de Comunicación Social. Recuperado de http:// www.revistalatinacs.org/073paper/1283/42es.html DOI: 10.4185/RLCS-2018-1283

Goulden, R., Corker E., Evans-Lacko, S., Rose, D., Thornicroft, G. y Henderson, C. (2011) Newspaper coverage of mental illness in the UK, 1992-2008. BMC Public Health, 11, 796. 
Herrera Ramírez, R., Ures Villar, M.B., y Martínez Jambrina, J.J. (2015). El tratamiento del suicidio en la prensa española: ¿efecto werther o efecto papageno?. Revista de la Asociación Española de Neuropsiquiatría, 35(125), 123-134. Recuperado de http://dx.doi. org/10.4321/S0211-57352015000100009

Instituto Nacional de Estadística (2016). Defunciones por suicidios en 2016. Cifras INE. Recuperado de http://www.ine.es/jaxiT3/Tabla.htm?t=7947

Instituto Nacional de Estadística (2016). Causas múltiples de defunción en 2016. Cifras INE. Recuperado de http://www.ine.es/jaxiT3/Tabla.htm?t=7947

Ladwig, K.H., Kunrath, S., Lukaschek, K., \& Baumert, J. (2012). The railway suicide death of a famous German football player: impact on the subsequent frequency of railway suicide acts in Germany. Journal of affective disorders, 136(1-2), 194-198.

Littmann, S.K. (1985). Suicide epidemics and newspaper reporting. Suicide and Life-Threatening Behavior, 15(1), 43-50.

Llobet, L. (2006). ¿La función social del periodismo o periodismo social? Unirevista, 1-11.

López, A.O., y Fernández, D.G. (2015). Suicidio y libertad de información: entre la relevancia pública y la responsabilidad. Revista de Comunicación de la SEECI, 38, 70-114.

Los medios de comunicación tienen que gritar que el suicidio no es una vergüenza, no tiene ninguna connotación moral negativa. (2016). Recuperado de http://fape.es/losmedios-de-comunicacion-tienen-que-gritar-que-el-suicidio-no-es-una-verguenza-notiene-ninguna-connotacion-moral-negativa/

McCombs, M.E., y Shaw, D.L. (1972). The agenda-setting function of mass media. Public opinion quarterly, 36(2), 176-187.

Morán, A. (2015). 800.000: el suicidio, el mal invisible [Documental]. España: 93 Metros.

Müller, F. (2011). El «Efecto Werther»: gestión de la información del suicidio por la prensa española en el caso de Antonio Flores y su repercusión en los receptores. Cuadernos de Gestión de Información, 1, 65-71. Recuperado de http://revistas.um.es/gesinfo/article/ view/207541

Muñoz Chávez, L.F. (2014) Caracterización de noticias sobre suicidio en medios impresos en Colombia Tesis presentada para optar al título de: Especialista en Psiquiatría Universidad Nacional de Colombia Facultad de Medicina, Departamento de Psiquiatría Bogotá. Recuperado de bdigital.unal.edu.co/45820/1/05599223.2014.pdf

Niederkrotenthaler, T., Voracek, M., Herberth, A., Till, B., Strauss, M., Etzersdorfer, E., y Sonneck, G. (2010). Role of media reports in completed and prevented suicide: Werther v. Papageno effects. The British Journal of Psychiatry, 197(3), 234-243.

Norris, B., Jempson, M., Bygrave, L., Thorsen, E. (2001). Reporting suicide worldwide. Media responsabilities. Recuperado de http://www.mediawise.org.uk

Olmo López, A. y García Fernández, D. (2015). Suicidio y libertad de información: entre la relevancia pública y la responsabilidad. Revista de Comunicación de la SEECI (Sociedad Española de Estudios de la Comunicación Iberoamericana), 38. Doi:http://dx.doi. org/10.15198/seeci.2015.38.70-114 
OMS/Organización Mundial de la Salud (2000). Prevención del suicidio. Un instrumento para profesionales de los medios de comunicación. Recuperado de http://www.who. int/mental_health/publications/suicide_prevention/es/index. htm

País, E. (1991). Manual de estilo. Madrid: Prisa.

Phillips, D.P., Lesyna, K., \& Paight, D.J. (1992). Suicide and the media. Assessment and prediction of suicide. New York, NY, US: Guilford Press, 499-519.

Phillips, D.P. (1985). The Werther Effect. The Sciences, 25, 33-39.

Philips, D.P. (1982). The impact of fictional television stories on US adult fatalities: new evidence on the effect of the mass media on violence. American journal of sociolog $\gamma, 87$, 1340-1359.

Rativa, J.S., Ruiz, V.A. y Medina-Pérez O.A. (2013). Análisis de las noticias sobre suicidio publicadas en un diario local de Quindío, Colombia, entre 2004 y 2011. Rev. Cubana Hig. Epidemiol, 51, 184-191.

Rubiano, H., Quintero, T. y Bonilla, C. I. (2007). El suicidio: más que una noticia, un tema de responsabilidad social. Palabra clave, 10, 2.

Sánchez Girón, J. (2016). El tratamiento del suicidio en la prensa digital española según las recomendaciones de la Organización Mundial de la Salud (OMS). Valladolid: Universidad de Valladolid.

Scherr, S. y Steinleitner, A. (2015). Zwischen dem Werther- und Papageno-Effekt. Nervenarzt, 86, 557-565.

de la Serna, V. (Ed.). (1996). El Mundo, libro de estilo. Madrid: Temas de hoy.

Sisask, M. \& Värnik, A. (2012). Media Roles in Suicide Prevention: A Systematic Review. Int. J. Environ. Res. Public Health, 9 , 123-138. Doi: http://dx.doi.org/10.3390/ ijerph9010123

Steven, S. (2003). Media coverage as a risk factor in suicide. Journal Epidemiology Community Health, 57(4), 238-240.

Thornicroft, A., Goulden, R., Shefer, G., Rhydderch, D., Rose, D., Williams, P., Henderson, C. et al. (2013). Newspaper coverage of mental illness in England 2008-2011. The British journal of psychiatry, 202(55), 64-69.

Urzúa Aracena, Mario (2003). Suicidio, intimidad e información. Documentación de las Ciencias de la información. Chile: Facultad de Comunicación Universidad Católica de Concepción, 26, 351-358.

Voz de Galicia, L. (1992). Manual de estilo. A Coruña: Biblioteca Gallega.

Wasserman, I. (1984). Imitation and suicide: A re-examination of the Werther effect. American Sociological Review, 49, 427-436. 



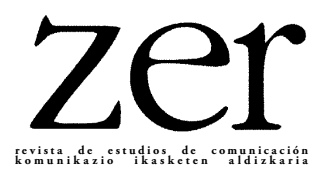

\title{
¿Quiénes hablan en las noticias? Desequilibrio de género en las fuentes informativas de la prensa de proximidad
}

\author{
Who speaks on the news? \\ Gender imbalance in local press sources
}

Cristina Prieto Sánchez ${ }^{\star}$

\begin{abstract}
RESUMEN: El objetivo de este artículo es determinar si mujeres y hombres participan de manera equilibrada en los contenidos que los medios ofrecen a la audiencia. El análisis de los datos constata que ni las voces recogidas en las noticias ni sus posiciones dentro de las mismas alcanzan la paridad. Las mujeres ocupan lugares poco relevantes y desaparecen de los informativos locales en el tránsito de las convocatorias a las noticias elaboradas. Este artículo presenta los resultados de un estudio de caso realizado sobre los medios de Granada para el que se han evaluado 1.586 informaciones y 184 convocatorias de agenda.
\end{abstract}

PALABRAS CLAVE: Medios de comunicación, comunicación local, género, fuentes informativas.

LABURPENA: Artikulu honen xedea da hedabideek ikusleei eskaintzen dizkieten edukietan emakumeen eta gizonen parte-hartzea orekatua den ala ez zehaztea. Datuak aztertu ondoren, ondoriozta daiteke albisteetan jasotako ahotsek ez eta ahots horien posizioak ere ez dutela parekidetasuna erdiesten. Emakumeek garrantzia txikiko posizioak izaten dituzte, eta tokiko albistegietatik desagertzen dira albiste xehatuagoak ematen direnean. Artikulu honetan, Granadako hedabideei buruzko kasu-ikerketa baten emaitzak jasotzen dira; bertan, 1.586 informazio eta 184 agenda-deialdi aztertu dira.

HITZ-GAKOAK: Hedabideak, tokiko komunikazioa, generoa, informazio-iturriak. 


\begin{abstract}
The objective of this article is to determine if women and men participate in a balanced way in the contents offered by the media to the audience. The analysis of the data shows that neither the voices collected in the news nor their positions within them reach parity. Women are generally relegated to scarcely relevant places and, in local news, they often disappear altogether in the course towards the final piece of news. This article presents the results of a case study conducted on the media of Granada for which 1,586 news reports and 187 agenda press calls were evaluated.
\end{abstract}

KEYWORDS: Mass media, local communication, gender, information sources.

* Correspondencia a: Cristina Prieto Sánchez. C/Ancha de Gracia, 5-6 A (18002 Granada).cpcristinaprieto@gmail.com

http://orcid.org/0000-0002-9151-081X

Cómo citar: Prieto Sánchez, Cristina. 2018. ¿Quiénes hablan en las noticias? Desequilibrio de género en las fuentes informativas de la prensa de proximidad. Zer. 23(45). 161-184. https://doi.org/10.1387/zer.

Recibido: 00 octubre 2018; aceptado: 00 octubre 2018

1137-1102 y 1989-631X / (C) 2018 UPV/EHU 


\section{Introducción}

El pasado 8 de marzo marcó un punto de inflexión en las reclamaciones de las mujeres, sin embargo, continúan relegadas en las informaciones que periódicos, emisoras de radio y televisiones lanzan a diario a su audiencia, tanto a nivel nacional como local. En ocasiones, se habla de lo que hacen, lo que dicen, lo que piensan pero ¿quiénes hablan?

El origen de este estudio surge como respuesta a las inquietudes de un grupo de periodistas e investigadoras granadinas ${ }^{1}$ interesadas por conocer la realidad de los datos sobre el desequilibrio de género en las noticias de la provincia en cuanto al número de declaraciones femeninas y masculinas en las informaciones. Como parte de la audiencia, intuíamos que los porcentajes no representan la realidad social que nos rodea y, como profesionales de los medios, queríamos averiguar dónde se producen esos desequilibrios y si la visión androcéntrica de las noticias alcanzaba también a aquellas fuentes informativas en cuya cúspide se sitúan mujeres. Constituye pues, una buena colaboración entre la profesión y la academia para explorar, desde distintos ángulos, la realidad de la información de proximidad, sus prácticas, la agenda con la que se construye el mosaico informativo diario y la realidad de sus protagonistas.

Las trece periodistas que hemos participado en la elaboración de este estudio hemos accedido a las informaciones analizadas sin privilegios, como parte de la audiencia (excepto para las noticias de agencia que sólo llegan a los abonados pero con cuyo servicio hemos podido contar a través de compañeras que trabajan en gabinetes de comunicación y tienen acceso a estos contenidos) por lo que podemos tildar esta investigación de una auditoría ciudadana de la información en Granada. Para ello hemos contado con la experiencia de dos de las componentes del equipo (entre las que se encuentra la autora de este artículo) que participaron en 2015 en el Monitoreo Global de Medios (GMMP) cuya metodología de estudio hemos tomado como base aunque con algunas modificaciones para adaptarla a nuestro objeto de estudio.

\section{Una aproximación teórica a los estudios de género y medios de comunicación}

Con la consolidación de la democracia en España, el marco legal que proporcionó en 1978 la Constitución Española y la Ley de Igualdad de 2007 aprobada por el go-

\footnotetext{
${ }^{1}$ Las profesionales que han participado en el trabajo de campo de este estudio son: María José Anguita Escolano, Manuela Cobo Maeso, Lola Fernández Palenzuela, Ana Fuentes Prior, Mónica García García, Noelia Jiménez García, Ángela Jiménez Maldonado, Marisa Molina Carbonell, Silvia Muñoz Pérez, Lola Prieto Moraleda, Luz Sánchez Gámez, Esther Sanz Urcia y la autora de este artículo.
} 
bierno de José Luis Rodríguez Zapatero, parecía que las mujeres disfrutaban ya de un marco legal suficientemente desarrollado para fijar su posición por derecho en todos los ámbitos de nuestra sociedad. Sin embargo, la realidad nos devuelve cada día la otra cara de la moneda y nos demuestra que lo expuesto con claridad en estos textos legales no es así en la práctica y que aún queda un largo camino por recorrer para la consecución de una sociedad igualitaria. En este proceso, los medios de comunicación tienen un papel fundamental en cuanto que son transmisores de los valores sociales «que acaban conformando el ideario de nuestro modelo social y de nuestras actitudes» (Beltrán, 2014: 720).

Para entender mejor nuestro entorno, los estudios de género constituyen una de las mejores aportaciones (Papí, 2003), especialmente para el tema que nos ocupa, en tanto que orientados a la investigación del papel de las mujeres en los medios de comunicación y la publicidad, bien como parte de la estructura organizativa de las empresas periodísticas o como protagonistas de las informaciones presentadas a la opinión pública por periódicos, emisoras de radio, formatos digitales, revistas, televisiones o agendas de noticias. En la década de los 70, Courtney y Lockeretz (1971) abordaron los roles con los que las mujeres trabajadoras estaban representadas en la publicidad, aspecto que también trataron Culley y Bennett (1976) quienes centraron su investigación en los anuncios.

En la década de los 80, Tan (1982) y Zemach y Cohen (1986) introdujeron la idea de que los estereotipos están relacionados con el consumo televisivo y Litcher y Rothman (1986) se centraron en la proporción de mujeres como presentadoras de televisión. Tuchman (1983) determinó el papel de las profesionales de la comunicación dentro de la estructura productiva de los medios, Karpf (1980) colocó en su punto de mira a los formatos radiofónicos y Gallagher apuntaba que la desigualdad de oportunidades entre mujeres y hombres en el campo de la comunicación en aquellos momentos, estaba en el dominio de los varones por lo que «el personal femenino de los medios de comunicación social ocupa una posición claramente desventajosa en comparación con la de sus colegas masculinos» (Gallagher, 1983: 40).

El final de pasado siglo también dejó investigaciones relevantes sobre el género y los medios de comunicación como el de Pearson, Turner y Todd-Mancillas (1993) «Comunicación y género» y el de Trancart (1999) Les femmesabsentes de l'information. Quand les chiffresparlent.

En España, Franquet (1982a), Fagoaga y Secanella (1984), Comas (1988) y Gallego et al. (1998) realizaron importantes aportaciones a la materia y señalaron el desequilibrio entre las mujeres pertenecientes a las cúpulas directivas de los medios y sus compañeros varones. Los diversos estudios realizados a principios del presente siglo han puesto de manifiesto tanto la invisibilidad de la mujer en los medios como 
la influencia de estereotipos masculinos en los contenidos (García de Cortázar, M. y García de León M.A., 2000; Canel, M.J., 2000; Humanes, M.L., 2003; Soriano, J., Cantón, M.J. y Díez, M., 2005 y Blanco Castilla, E., 2005, entre otros).

En los últimos años, las líneas de investigación sobre el género y los medios de comunicación se han ampliado y han puesto el foco en la relación existente entre la ausencia de mujeres en puestos de responsabilidad dentro de las estructuras orgánicas de los medios de comunicación y los contenidos informativos que continúan relegando los temas de género y las noticias con fuentes femeninas a lugares poco destacados dentro de cada uno de los formatos. Es destacable, en este aspecto, el trabajo realizado por la Alianza Global sobre Medios y Género (GAMAG) integrada en la red Red UniTWIN de la Unesco que tiene como objetivos incrementar la participación y acceso de las mujeres a la toma de decisiones en los medios y promover una representación equilibrada y no estereotipada en las noticias.

El estudio Global Report on the Status of Women in the News Media de la International Women's Media Foundation (IWMF) realizado en 2011 dejaba al descubierto la desigual relación de género en las redacciones ya que de las 170.000 personas empleadas en periodismo, los varones representaban casi dos tercios del total $(64,9 \%)$ frente al tercio de las mujeres $(35,1 \%)$. La investigación no dejaba datos alentadores para España donde la representación de mujeres en los cargos de alto nivel de dirección representaba sólo el 17,6\% y esta baja presencia indica su falta de poder en los medios de comunicación.

\section{La mirada androcéntrica de las noticias}

Los medios de comunicación juegan un papel esencial como transmisores de valores y como agentes de cambio social porque son un poderoso instrumento para modelar la opinión pública, «no sólo actúan como notarios de la realidad, sino que la construyen y la interpretan» (Moreno, 2001: 158). Pueden erigirse como motor de cambio o como rémora y esta dualidad es lo que les convierte en un foro público tan importante porque, de una parte «reproducen las bases cognitivas de la sociedad y en parte son poderosos instrumentos para poder propiciar el cambio social» (Gallego, 2010: 6). Y en este punto, cabría preguntarse ¿quiénes dirigen esos medios de comunicación? La respuesta es obvia, los hombres en su gran mayoría. Ellos continúan dominando el espacio público, creando opinión y enfocando las noticias desde una perspectiva androcéntrica.

Un cúmulo de circunstancias, algunas debidas a las malas prácticas por parte de los profesionales de la información y la comunicación y otras de difícil solución porque atañen directamente a las empresas propietarias, han favorecido que los medios se resistan a dar cuenta de los cambios sociales y persistan en un enfoque androcén- 
trico «restringido a una parte de la población, varones adultos de pueblos y clases dominantes que actúan en los escenarios del poder, que margina a la mayoría de mujeres y hombres como si sus aportaciones fueran insignificantes para el buen funcionamiento de la democracia» (Moreno y Simelio, 2011).

Entre las malas prácticas nos encontramos con un exceso de fuentes institucionales que coloca el foco de atención en sus máximos responsables (hombres), el seguimiento constante de la agenda política que determina un amplio porcentaje de los contenidos informativos y aleja a los medios de la diversidad social y las rutinas que las mujeres periodistas han aceptado al integrarse en las redacciones (Franquet, 1982b; Altés y Gallego, 2004) establecidas desde una óptica exclusivamente masculina con el objetivo de "ser una de ellos» (Melin-Higgins y Dejerf Pierre, 1998) y no ver comprometida la posibilidad de ascender en la estructura organizativa del medio.

Las causas relacionadas con las empresas apuntan a la reducción de las redacciones hasta límites incompatibles con la calidad de los contenidos, la presión ejercida por los grandes grupos multimedia que han convertido la información en productos que pretenden venderse con criterios de marketing y a la precariedad laboral de los y las periodistas.

Aun así, todas estas circunstancias no eximen al conjunto de profesionales de los medios de comunicación de aplicar la perspectiva de género en los contenidos periodísticos para que comiencen a ser tipificados como un posible "valor noticia» (Gallego, 2003):

La dimensión de género - es decir: aquellos rasgos que afectan a las personas por razón de pertenecer a un género, y que creemos son significativos informativamente-, no está tipificada como un posible 'valor noticia', de tal manera que esta perspectiva permanece ignorada y oculta en la mayoría de las informaciones, y tan solo hace acto de presencia cuando es la propia fuente la que incorpora la significación de género.

Es necesario que a los puestos de dirección accedan periodistas y comunicadoras con perspectiva de género para imprimir a los contenidos una visión de la realidad más cercana a la sociedad paritaria y democrática a la que aspiramos. Serán ellas, desde los estamentos jerárquicos de las redacciones donde se deciden los temas de cobertura y la agenda diaria, las que podrán evitar que los contenidos con temas de género se queden en «los ámbitos periféricos de la escena pública» (Gallego, 2003) y cuenten con más posibilidades de ser tratados. Aún hoy, las redacciones «están copadas ya no por los varones sino por los valores androcéntricos; las condiciones laborales desalientan las reivindicaciones, y el conjunto de todo ello permite la defensa y la legitimación del dominio» (Vera Balanza, 2009: 70). 
Las cifras ponen de manifiesto que el número de mujeres en puestos directivos es muy bajo pese a que la profesión está, en términos globales, feminizada. En 2009, el porcentaje para ellas se situaba en el 14,7 frente al 85,3 de los hombres a nivel nacional y tomando como base de este estudio la Agenda de la Comunicación del año 2009 publicada por el Gobierno de España y las 103 cabeceras nacionales de prensa diaria (Caro, García-Gordillo y Bezunartea, 2010). Este estudio aventuraba la hipótesis de que a mayor número de mujeres directivas y mayor número de directoras se produce un aumento de lectoras femeninas y un cambio en los valores noticiables, tal y como proponían las investigaciones feministas en comunicación y, particularmente, Van Zoonen (1994).

Los datos más recientes persisten en la situación desfavorable de las mujeres en el sector de la comunicación. El Informe Anual de la Profesión Periodística en España 2017, editado por la Asociación de la Prensa de Madrid, constata que la precariedad laboral se ceba en las mujeres con un 64\% de paro, frente al 36\% de los varones.

\section{Las fuentes informativas como indicador de calidad}

En el ámbito profesional es sabido que un periodista vale lo que pesa su agenda y que las fuentes y su nivel de conocimiento o cercanía al tema tratado determinan el valor de la información. En estos momentos, los y las periodistas son, cada vez en mayor medida, procesadores de información porque están abandonando su tarea de «escrutinio crítico sobre las élites políticas y económicas de la sociedad» (Casero, 2012) con el objetivo de defender los intereses de los ciudadanos y alertar de los posibles abusos de los poderosos. Por eso, esta tarea del periodismo le configura como un Cuarto Poder y los periodistas se convierten en el perro guardián (watchdog) de la democracia. Sin embargo, muchos profesionales se están entregando, exclusivamente, a la gestión de los contenidos externos que reciben (Rodríguez, Enguix, Rojas y García-Gordillo, 2015).

La proliferación de gabinetes y agencias de comunicación en instituciones y empresas, con periodistas profesionales, inundan a diario las redacciones de notas de prensa redactadas y estructuradas perfectamente a las que, en muchas ocasiones, se acompañan de cortes de sonido, totales de vídeo o fotografias preparadas para ser publicadas. Como señala Schudson, estos «paraperiodistas» no dejan tiempo a los profesionales de los medios para hablar con sus contactos y cuidar sus fuentes por lo que seguir temas propios se ha convertido en un lujo (Schudson, 2003: 3) En las redacciones, las exiguas plantillas y el fast journalism espoleado por los medios digitales que actualizan constantemente las noticias, hacen el resto. El resultado son contenidos de baja calidad, carentes de profundidad, en los que las fuentes redactan la noticia, la protagonizan y dan su versión sin ningún otro elemento que ofrezca a la audiencia el necesario contraste para formarse una visión crítica del hecho referenciado. 
Esta situación es más preocupante en la prensa de proximidad. Los medios locales son los referentes de lo que acontece en el espacio geográfico más inmediato de la audiencia que se informa a través de ellos porque los receptores identifican los escenarios y porque las informaciones les afectan directamente. Si se delega en las fuentes la selección de temas que aparecen en los distintos soportes, el medio no está respondiendo al ritmo vital de la sociedad y los periodistas pasan a estar más atentos a las noticias de los políticos que a sus acciones de gobierno (García-Gordillo, Bezunartea, Rodríguez y Sánchez, 2014).

El creciente número de informaciones que presentan como protagonistas a instituciones, organizaciones políticas, empresas, datos, cosas o entes, están deshumanizando la información y alejando el foco de la ciudadanía plural. «Este retroceso en el enfoque de los protagonistas humanos afecta principalmente a las mujeres y a los colectivos que forman parte de la sociedad civil. Contrariamente, la atención hacia los varones identificados ha permanecido estable» (Moreno, Simelio, Rovetto y Buitrago, 2007).

Precisamente, el tratamiento informativo de las mujeres en los medios es el objetivo principal del Proyecto Monitoreo Global de Medios (GMMP en sus siglas en inglés), la investigación mundial más amplia y de mayor trayectoria que aborda el tema de género en los medios de comunicación. Se inició en 1995, como resultado de los acuerdos alcanzados en la Conferencia Internacional de Beijing, cuando voluntarios y voluntarias en 71 países de todo el mundo (en 2015 han participado 114) monitorearon la presencia de las mujeres en los espacios informativos de radio, televisión y prensa escrita nacionales. La investigación reveló que sólo 17\% de los sujetos de las noticias - esto es, las personas entrevistadas o sobre quienes tratan las noticas- fueron mujeres.

Cada cinco años se realiza un nuevo estudio y, aunque las cifras de representación de las mujeres han evolucionado hacia porcentajes más positivos, la progresión es muy lenta y en los últimos cinco años se ha estancado, contradiciendo las propias dinámicas sociales que acontecen respecto a la presencia y la participación de las mujeres en el mundo. Del 17\% del primer estudio en 1995 al 24\% en el último de 2015 - la misma cifra que se alcanzó en 2010 - puede decirse que la representación del $50 \%$ de la población mundial no ha estado acompasada con los cambios sociales que se han producido en estos últimos 20 años. Margaret Gallagher alerta sobre la situación en el prólogo del informe de 2015:

La realidad es que el tema de los medios languidece al margen de la mayor parte de las agendas políticas que promueven la igualdad de género. A 20 años de Beijing, las transformaciones tecnológicas han contribuido a que los medios y la comunicación se atrincheren todavía más en relaciones de poder de género y en su negociación. 
En España, los datos son algo más alentadores pero se sitúan lejos de la paridad y de la realidad. Las mujeres comprenden sólo el $28 \%$ del total de sujetos y fuentes en las noticias de prensa y los informativos de radio y televisión y el 33\% en los diarios digitales y Twitter. Este porcentaje es ligeramente superior al de la media europea que es de $26 \%$ y $25 \%$, respectivamente. También significa un pequeño avance respecto a los datos del estudio de 2010, donde las mujeres en las noticias de prensa, radio y televisión eran el 23\% del total.

El trabajo del Monitoreo Global de Medios se realiza sobre las noticias difundidas durante una única jornada (en el caso de 2015 se eligió como fecha el 25 de marzo) y en distintos soportes (diarios impresos, radios, televisiones, diarios digitales y Twitter). La evaluación se realiza sobre medios y espacios informativos de ámbito nacional por lo que quedan al margen los medios de ámbito regional y local. Entendemos que es en este marco donde se puede observar, por comparación y contraste, si los medios son receptivos a los cambios producidos.

\section{Objetivo e hipótesis}

El objetivo principal de este estudio de caso es determinar las fuentes utilizadas por los medios de comunicación de Granada y analizar la relevancia otorgada a las mismas para conocer si el género condiciona la posición que ocupan dentro de cada de una de las informaciones difundidas. Sustentada en nuestra percepción como consumidoras de medios de comunicación y profesionales de los mismos, nuestra hipótesis de partida apunta que las voces femeninas como fuentes informativas tienen menor peso en la información local que las voces masculinas. Al mismo tiempo, el análisis de las noticias permitía además conocer si los medios de comunicación recogían en sus informaciones identidades de género distintas a la fórmula binaria femenino/masculino acercándose de esta manera a la realidad social actual.

Diseñada esta línea de trabajo, nos planteamos las siguientes preguntas de investigación: ¿qué temas informativos cuentan con fuentes femeninas?, si la práctica profesional otorga más valor noticiable a los máximos representantes de las instituciones ¿aparecerán con más frecuencia las declaraciones femeninas en instituciones u organismos que cuentan con mujeres en la cúspide de su organigrama?, ¿marca la agenda informativa distribuida por las agencias de noticias la posición de las declaraciones femeninas y masculinas en las informaciones que difunden los medios? ¿Se da voz a otras identidades de género presentes en la sociedad? 


\section{Metodología}

La metodología mixta y descriptiva diseñada para abordar estas cuestiones y encontrar respuesta a nuestras preguntas nos llevó, en primer lugar, a seleccionar los medios de comunicación que iban a ser objeto de nuestro estudio y el período de tiempo destinado al seguimiento de sus contenidos. Realizar coberturas diarias de la agenda informativa local, contar con una plantilla estable de profesionales de la información y estar presentes de forma continuada en el panorama informativo provincial fue el criterio acordado. Estas condiciones las cumplían cinco emisoras de radio - Radio Nacional de España, Onda Cero, Cadena Cope, Canal Sur Radio y Cadena Ser-, dos televisiones - Canal Sur TV y TG7-, tres diarios digitales - Ahora Granada, Granada Digital y El Independiente de Granada-, dos diarios impresos — Ideal y Granada Hoy - y dos agencias de noticias — Europa Press y Agencia EFE-.

El estudio se llevó a cabo durante dos semanas completas, de lunes a domingo; la primera del 21 al 27 de mayo y la segunda del 4 al 10 de junio. Se descartó la semana del 28 de mayo al 3 de junio por la celebración de la Feria del Corpus en Granada y la alteración que en estas fechas registra la información local en su conjunto. Para tener una visión amplia de los contenidos informativos ofrecidos a la audiencia por los doce medios seleccionados y las dos agencias de noticias se analizaron, en los formatos audiovisuales, los programas informativos completos destinados a las noticias locales en franjas de mañana y mediodía para las radios y de mediodía y noche para las televisiones locales.

El análisis de las noticias en los medios digitales se realizó sobre todas las informaciones locales subidas a la web durante una jornada completa y en los periódicos en papel se evaluaron todas las noticias locales en cada una de las secciones del número seleccionado.

Los contenidos distribuidos por las agencias de noticias se sometieron a un doble análisis. Por un parte los despachos correspondientes a la cobertura de noticias locales enviadas a los abonados y, por otra, las convocatorias de agenda donde se recogen todas las citas informativas de la jornada. En todos los casos, las evaluaciones se realizaron, en cada medio, en días alternos.

Quedaron al margen de nuestro análisis las informaciones de servicio (tráfico, predicciones meteorológicas, anuncios por palabras...), los artículos de opinión, los editoriales, las columnas, los espacios de humor gráfico, los suplementos, los publirreportajes, las noticias patrocinadas dentro de los espacios informativos y los sumarios o 'llamadas' en las portadas de los diarios en papel porque su brevedad no podía aportar datos a nuestra investigación. 
Para conocer la procedencia de las fuentes informativas se diseñó una plantilla de trabajo para cada tipo de soporte (televisiones, radios, diarios digitales, diarios en papel, noticias de agencia y convocatorias de agencia) en la que se incluyeron los 17 sectores generadores de noticias en Granada (16 específicos más uno con la categoría de "otros» para aquellos contenidos de dificil inclusión en las anteriores). Además, se destinó un espacio para señalar el número de declaraciones textuales identificadas de cada noticia, el género ${ }^{2}$ de cada una y el lugar que ocupa dentro de la información.

En total, se han analizado 1.586 informaciones y 184 convocatorias de agenda con la siguiente distribución por formato:

\section{TABLA 1}

Medios y noticias analizadas

\begin{tabular}{|l|c|}
\hline \multicolumn{1}{|c|}{ Tipo de medio } & $\begin{array}{c}\text { Número de informaciones } \\
\text { analizadas }\end{array}$ \\
\hline Radios & 245 \\
\hline Diarios digitales & 388 \\
\hline Prensa diaria en papel & 610 \\
\hline Televisiones & 95 \\
\hline Noticias de agencias & 248 \\
\hline Convocatorias de agencias & 184 \\
\hline
\end{tabular}

Fuente: Elaboración propia.

\section{Resultados}

\subsection{Declaraciones de MUJERES y hOMbreS EN LAS NOTICIAS}

El análisis pormenorizado de las informaciones evaluadas confirma que las voces femeninas se escuchan o se leen en los medios de comunicación de Granada la mitad que las voces masculinas. De las 1.586 noticias evaluadas, el 41,60 contienen declaraciones realizadas por hombres (861 citas textuales) mientras que el 22,70 corres-

\footnotetext{
${ }^{2}$ La casilla destinada al género de cada noticia contempló la posibilidad de encontrar informaciones fuera del planteamiento binario hombre/mujer pero en los días analizados no se registró ninguna información de estas características por lo que en nuestras tablas no queda reflejado.
} 
ponden a mujeres (470 citas textuales) y el 35,70 tienen como fuentes informativas instituciones, organismos, empresas o entes, es decir, un origen no humano. Para la consideración de "declaración» sólo se han tenido en cuenta las frases textuales entrecomilladas y perfectamente identificadas con nombres, apellidos y cargo o responsabilidad que ostenta la persona que la realiza (para los medios escritos), los cortes de voz (para las radios) o los totales (para las televisiones).

El reconocimiento de las fuentes en la prensa de proximidad es esencial para contextualizar la noticia porque el espacio geográfico reducido en el que se sitúan otorgan cercanía y reconocimiento del trabajo realizado a la vez que ofrecen a los receptores la identificación de los escenarios (Rodríguez et al., 2015) y sus protagonistas. Por otro lado y en el caso de las mujeres, refuerzan su acción individual y reafirman su actividad pública, alejándolas del tratamiento como género o colectivo (Gallego, 2010). En este contexto, consideramos esencial para nuestra investigación delimitar a su sentido más restringido el concepto «declaración» ya que es habitual que en los textos periodísticos se incluyan referencias a lo que una persona dice pero sin incluir textualmente sus palabras ni la identificación completa de quien las pronuncia.

En el caso de las mujeres esta práctica supone una especie de «tutela informativa» (si se nos permite la expresión) porque aparece en los medios con declaraciones pasadas por el tamiz de quien realiza la información (periodista de la redacción del medio o responsable del gabinete de prensa que elabora la nota para distribuirla). La ausencia de las palabras textuales oculta el lenguaje utilizado por quien protagoniza la información y con ello puede diluir la idoneidad para la responsabilidad que ostenta invisibilizando y neutralizando el nivel intelectual y técnico, la capacitación o competencia de las protagonistas.

Aunque en el planteamiento metodológico diseñado para la realización de este estudio, como paso previo al trabajo de campo desarrollado con la evaluación de las noticias, ya se había tomado en consideración la posibilidad de encontrarnos con fuentes no sexuadas, el análisis de los datos nos ha dejado cifras no esperadas. El 35,70 de las informaciones presentan como fuente a instituciones, empresas, clubes de fútbol, sindicatos, tribunales... que «hacen», «dicen», "explican» o «aprueban» sin que aparezcan sus responsables. Esta práctica, cada vez más habitual en las redacciones, además de constituir una perversión del lenguaje (un ayuntamiento no dice, lo harán sus responsables) indica hasta qué punto la información se ha deshumanizado ${ }^{3}$ y cómo, en el reparto de papeles, ha entregado los de protagonistas a los varones y a las instituciones dejando de lado a las mujeres y a la ciudadanía plural (Moreno y Si-

3 Para ampliar este concepto véase la investigación $\mathrm{I}+\mathrm{D}+\mathrm{I}$ sobre «La representación de las relaciones entre mujeres $y$ hombres $y$ del recambio generacional en la prensa, de 1974 a 2004», financiada por el Instituto de la Mujer y liderada por Amparo Moreno Sardà. 
melio, 2011).La suma de las fuentes informativas de hombres y no humanas representa un 77,3 de la información local de Granada.

El reparto de las declaraciones masculinas y femeninas en las noticias locales ofrece datos relevantes. Del total de noticias con opiniones de hombres y mujeres recogidas de manera textual -1.190 en los diecisiete sectores generadores de noticias en los que se ha distribuido este estudio- las voces de ellos se encuentran en 757 noticias (un 63,61) mientras que las de ellas aparecen en 433 (un 36,38).

TABLA 2

Sectores informativos y porcentaje de noticias con declaraciones de hombres y mujeres

\begin{tabular}{|l|c|c|}
\hline \multicolumn{1}{|c|}{ Origen de las fuentes } & $\begin{array}{c}\text { Porcentaje de noticias } \\
\text { con declaraciones } \\
\text { masculinas }\end{array}$ & $\begin{array}{c}\text { Porcentaje de noticias } \\
\text { con declaraciones } \\
\text { femeninas }\end{array}$ \\
\hline Gobierno central & 3,03 & 0,50 \\
\hline Junta de Andalucía & 7,73 & 6,64 \\
\hline Diputación Provincial de Granada & 4,70 & 2,69 \\
\hline Ayuntamiento de Granada & 13,87 & 9,08 \\
\hline Universidad de Granada & 1,51 & 0,59 \\
\hline Partidos Políticos & 7,48 & 6,05 \\
\hline Organizaciones sindicales & 2,10 & 1,76 \\
\hline Tribunales & 2,77 & 0,92 \\
\hline Colectivos ciudadanos y ongs & 3,95 & 2,60 \\
\hline Bancos, cajas y entidades financieras & 0,42 & 0,00 \\
\hline Organizaciones empresariales & 1,76 & 0,76 \\
\hline Policía y Guardia Civil & 1,18 & 0,42 \\
\hline Colegios profesionales & 0,59 & 0,25 \\
\hline Clubes deportivos & 4,12 & 0,25 \\
\hline Artistas, escritores y profesionales liberales & 3,11 & 1,01 \\
\hline Fundaciones y asociaciones culturales & 0,92 & 0,92 \\
\hline Otros & 4,37 & 1,94 \\
\hline
\end{tabular}

Fuente: Elaboración propia.

La distribución por sectores generadores de noticias en los que se concentran las declaraciones confirma que los medios de comunicación de la prensa local de 
Granada se inclinan, mayormente, por dar voz a los varones. En temas como los relacionados con el Gobierno Central, los clubes deportivos o los contenidos culturales, las diferencias se triplican. Especialmente significativas resultan las cifras en las instituciones donde los hombres designados por los partidos políticos continúan copando los puestos de decisión y representación ante los medios de comunicación actuando como portavoces.

Especialmente llamativos son los porcentajes en la Junta de Andalucía y la Universidad de Granada que tienen como máximos responsables en Granada a dos mujeres, la Delegada del Gobierno andaluz y la Rectora, un posicionamiento institucional que no se traslada al tratamiento informativo de las noticias relacionadas con ambos sectores.

\subsection{Posiciones de las DeClaraciones}

En este estudio se han valorado también las posiciones que ocupan dentro de las noticias las declaraciones que realizan las distintas personas cualificadas ante los medios de comunicación, bien como portavoces o responsables de sus organizaciones o las administraciones a las que pertenecen, o bien como personas expertas sobre los temas tratados. Para valorar estas posiciones se han empleado criterios periodísticos. Es decir, las declaraciones que aparecen en primer término son las consideradas más importantes y las que aparecen con posterioridad se entienden como complementarias y, por ello, menos relevantes.

\section{TABLA 3}

Posición de las declaraciones de hombres y mujeres en los medios de comunicación de Granada. Porcentajes globales

\begin{tabular}{|c|c|c|c|c|c|}
\hline \multicolumn{2}{|c|}{ Declaraciones de hombres } & \multicolumn{3}{c|}{ Declaraciones de mujeres } \\
\hline $\begin{array}{c}1 .^{\mathrm{a}} \text { Fuente o } \\
\text { fuente única }\end{array}$ & $2 .^{\mathrm{a}}$ Fuente & $3 .^{\mathrm{a}}$ Fuente & $\begin{array}{c}1 .^{\mathrm{a}} \text { Fuente o } \\
\text { fuente única }\end{array}$ & 2. $^{\mathrm{a}}$ Fuente & $3 .^{\mathrm{a}}$ Fuente \\
\hline 41,75 & 13,82 & 7,86 & 22,91 & 8,61 & 5,01 \\
\hline
\end{tabular}

Fuente: Elaboración propia.

Atendiendo a este criterio en los distintos medios de comunicación de Granada y en datos globales, las mujeres aparecen como primera fuente en el 22,91 de las informaciones con declaraciones mientras que los hombres consiguen esta posición en el 41,75. Esta situación se repite en las declaraciones que aparecen en segundo lugar ya que las mujeres consiguen esta segunda posición en el 8,61 de las informaciones y los hombres en el 13,82. Para el tercer puesto o sucesivos, el esquema continúa con 
la misma tónica. Los hombres obtienen un 7,86 de apariciones como tercera fuente o sucesivas y las mujeres un 5,01.

\section{TABLA 4}

Posición de las declaraciones de hombres y mujeres en los medios de comunicación de Granada. Porcentajes por formato

\begin{tabular}{|c|c|c|c|c|c|c|}
\hline \multirow[b]{2}{*}{ Medios } & \multicolumn{3}{|c|}{ Número de declaraciones de hombres } & \multicolumn{3}{|c|}{ Número de declaraciones de mujeres } \\
\hline & $\begin{array}{l}\text { 1. }{ }^{\circ} \text { Fuente o } \\
\text { fuente única }\end{array}$ & 2. ${ }^{\circ}$ Fuente & $\begin{array}{c}\text { 3. }{ }^{\circ} \text { Fuente o } \\
\text { sucesivas }\end{array}$ & $\begin{array}{l}\text { 1. }{ }^{\circ} \text { Fuente o } \\
\text { fuente única }\end{array}$ & $2 .^{\circ}$ Fuente & $\begin{array}{c}3 .^{\circ} \text { Fuente o } \\
\text { sucesivas }\end{array}$ \\
\hline Radios & 48,61 & 12,50 & 4,61 & 26,00 & 6,48 & 1,80 \\
\hline Televisiones & 27,32 & 17,53 & 13,40 & 17,01 & 11,34 & 13,40 \\
\hline Prensa en papel & 47,62 & 13,29 & 8,03 & 21,30 & 7,01 & 2,75 \\
\hline Prensa digital & 43,83 & 14,19 & 9,25 & 20,99 & 8,65 & 3,09 \\
\hline Agencias & 41,41 & 11,62 & 4,04 & 29,29 & 9,60 & 4,04 \\
\hline
\end{tabular}

Fuente: Elaboración propia.

Una lectura pormenorizada de estos datos nos lleva a constatar que esta diferencia en el número de declaraciones femeninas y masculinas como primera fuente en los periódicos en papel es aún mayor. En este caso, las mujeres constituyen primera fuente informativa en un 21,30 de las informaciones publicadas mientras que los hombres aparecen en un 47,61, lo que arroja un resultado positivo para ellos de más de 26 puntos porcentuales. Esta gran diferencia se repite en los casos en los que sus opiniones son requeridas como segunda fuente ya que ellas recaban el 7,01\% y ellos 13,28\%, casi el doble. Las cifras para la tercera y sucesivas apariciones son de $8,02 \%$ para ellos y un 2,75\% para ellas, es decir, los varones aparecen tres veces más que las mujeres en esta posición.

La prensa digital, aunque renovada en el soporte y en los mensajes, presenta unos resultados muy similares a los diarios en papel. Un total de 22 puntos porcentuales de diferencia separan a hombres y mujeres como personas que plasman sus opiniones en las noticias ya que la cifra para ellos se sitúa en el 43,83 mientras que ellas se quedan en un 20,99. Este desequilibrio se mantiene para la segunda posición de las declaraciones y alcanza el triple en la tercera o sucesivas. Situaciones similares presentan los formatos radiofónicos y las agencias de noticias en sus despachos con informaciones elaboradas aunque en estas últimas las segundas reducen las diferencias y alcanzan el equilibrio en la tercera o sucesiva fuente.

Las menores diferencias se encuentran en las televisiones aunque para la primera fuente se sigue prefiriendo al varón que aparece como voz principal en el 27,32 de 
las informaciones frente al 17,01 de las mujeres, algo más de 10 puntos porcentuales. $\mathrm{Al}$ igual que las agencias, el desequilibrio se reduce para la segunda fuente y se iguala en la tercera.

\subsection{NÚMERO DE FUENTES EN LAS NOTICIAS}

Del total de las 1.586 noticias analizadas, 1.212 se presentan a la audiencia con una única fuente informativa lo que representa el 76,42 de las informaciones. Con dos fuentes se han encontrado 240 que se corresponde con el 15,13, con tres fuentes 81 que representan el 5,11 y con cuatro o más fuentes un total de 53 , lo que representa el 3,34 del total. Los datos reflejan que, en líneas generales, el tratamiento de la prensa de proximidad en Granada ofrece a su audiencia una información carente de profundidad con la que no se logra «completar la historia» (Rodríguez et al., 2015) ya que las fuentes son recursos imprescindibles para construir el relato.

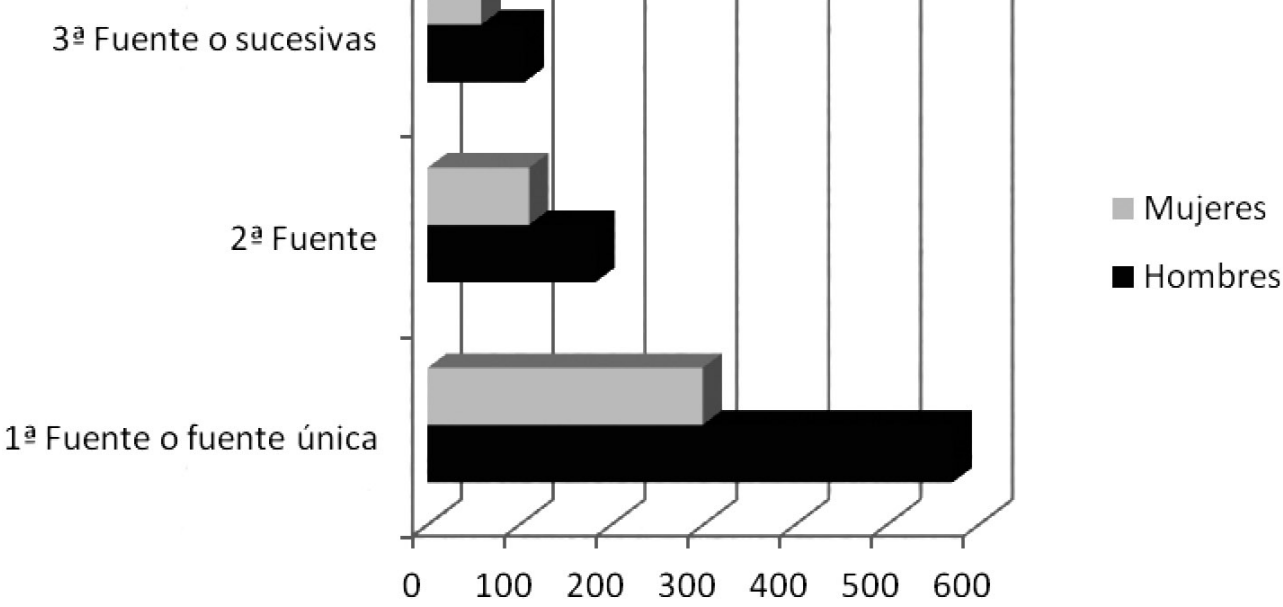

Fuente: Elaboración propia.

GrÁFICO 1

Noticias con declaraciones de hombres y mujeres y posición que ocupan

La lectura atenta de los datos atendiendo al número de voces femeninas y masculinas con declaraciones identificadas en las noticias y el orden que éstas ocupan dentro de las informaciones, confirma que la paridad está aún lejos de alcanzarse. De las 861 citas textuales de varones, 572 aparecen como primera fuente o fuente única, 
183 se localizan como segunda fuente y 106 como tercera o sucesivas. En el caso de las 470 declaraciones identificadas para las mujeres, 300 se realizan como primera o única fuente informativa, 111 como segunda y 59 aparecen en tercer lugar o sucesivos. Como indica la profesora Juana Gallego (2010), «el grupo de hombres y mujeres [de los medios de comunicación] conforman una privilegiada atalaya desde la que contemplan e interpretan el mundo» pero la sociedad ha evolucionado y los discursos deberían adecuarse a los tiempos que vivimos.

\subsection{Análisis de las CONVOCATORias de AGENCIA}

Como indicamos en la metodología de este estudio, además de analizar las informaciones elaboradas por los medios de comunicación y las agencias de noticias con delegación estable en Granada, se evaluaron además las 184 convocatorias de actos informativos distribuidos por estas últimas para observar si el desequilibrio de género tenía su origen en las fuentes informativas señaladas por instituciones, colectivos, partidos políticos, organizaciones empresariales, agentes culturales o sindicatos, entre otros, en el momento de elegir quiénes de sus representantes comparecen ante los medios de comunicación para informar de sus actuaciones a nivel local.

Aunque las convocatorias de las citas informativas no pueden considerarse noticias en sí mismas, configuran el paso intermedio para la elaboración de las informaciones que los medios ofrecerán con posterioridad a la audiencia. La propia disposición de los intervinientes en el anuncio del acto informativo también nos aporta información sobre el peso que cada cual tiene dentro de sus organizaciones. Los gabinetes de prensa, que envían sus convocatorias a las agencias para que éstas conformen la agenda diaria que distribuye a sus abonados, indican el nombre y apellidos de los comparecientes y el lugar que ocupan dentro del orden jerárquico de su organización o empresa, además del asunto sobre el que hablarán ante los medios de comunicación. Por otra parte, en los actos informativos en los que se anuncia la participación de varios intervinientes, el orden en el que aparecen también nos ofrece datos relevantes porque esta secuencia suele ser reproducida por los medios de comunicación en el momento de elaborar sus informaciones. 
TABla 5

Origen de las fuentes en las convocatorias de las agencias de noticias

\begin{tabular}{|l|c|c|}
\hline \multicolumn{1}{|c|}{ Origen de las fuentes informativas } & $\begin{array}{c}\text { Número de } \\
\text { convocatorias }\end{array}$ & $\begin{array}{c}\text { Porcentaje } \\
\text { sobre el total }\end{array}$ \\
\hline Gobierno central & 2 & 1,09 \\
\hline Junta de Andalucía & 41 & 22,28 \\
\hline Diputación Provincial de Granada & 15 & 8,15 \\
\hline Ayuntamiento de Granada & 46 & 25,00 \\
\hline Universidad de Granada & 12 & 6,53 \\
\hline Partidos Políticos & 16 & 8,70 \\
\hline Organizaciones sindicales & 8 & 4,35 \\
\hline Tribunales & 2 & 1,09 \\
\hline Colectivos ciudadanos y ongs & 5 & 2,72 \\
\hline Bancos, cajas y entidades financieras & 1 & 0,54 \\
\hline Organizaciones empresariales & 5 & 2,72 \\
\hline Policía y Guardia Civil & 1 & 0,54 \\
\hline Colegios profesionales & 1 & 0,54 \\
\hline Clubes deportivos & 16 & 0,00 \\
\hline Artistas, escritores y profesionales liberales & 10 & 5,44 \\
\hline Fundaciones y asociaciones culturales & 18 & 0,54 \\
\hline Otros & & 9,77 \\
\hline
\end{tabular}

Fuente: Elaboración propia.

Las instituciones y los partidos políticos dominan la agenda informativa de la información local en Granada. Las convocatorias de la Junta de Andalucía, la Diputación Provincial y el Ayuntamiento representan casi dos tercios de las citas informativas, un 64,13 . En el extremo opuesto se sitúan las organizaciones de la sociedad civil y los temas relacionados con la cultura (fundaciones, colectivos ciudadanos y ONGs, colegios profesionales y sindicatos) que, sumados, alcanzan sólo el 13,59 de las convocatorias. 


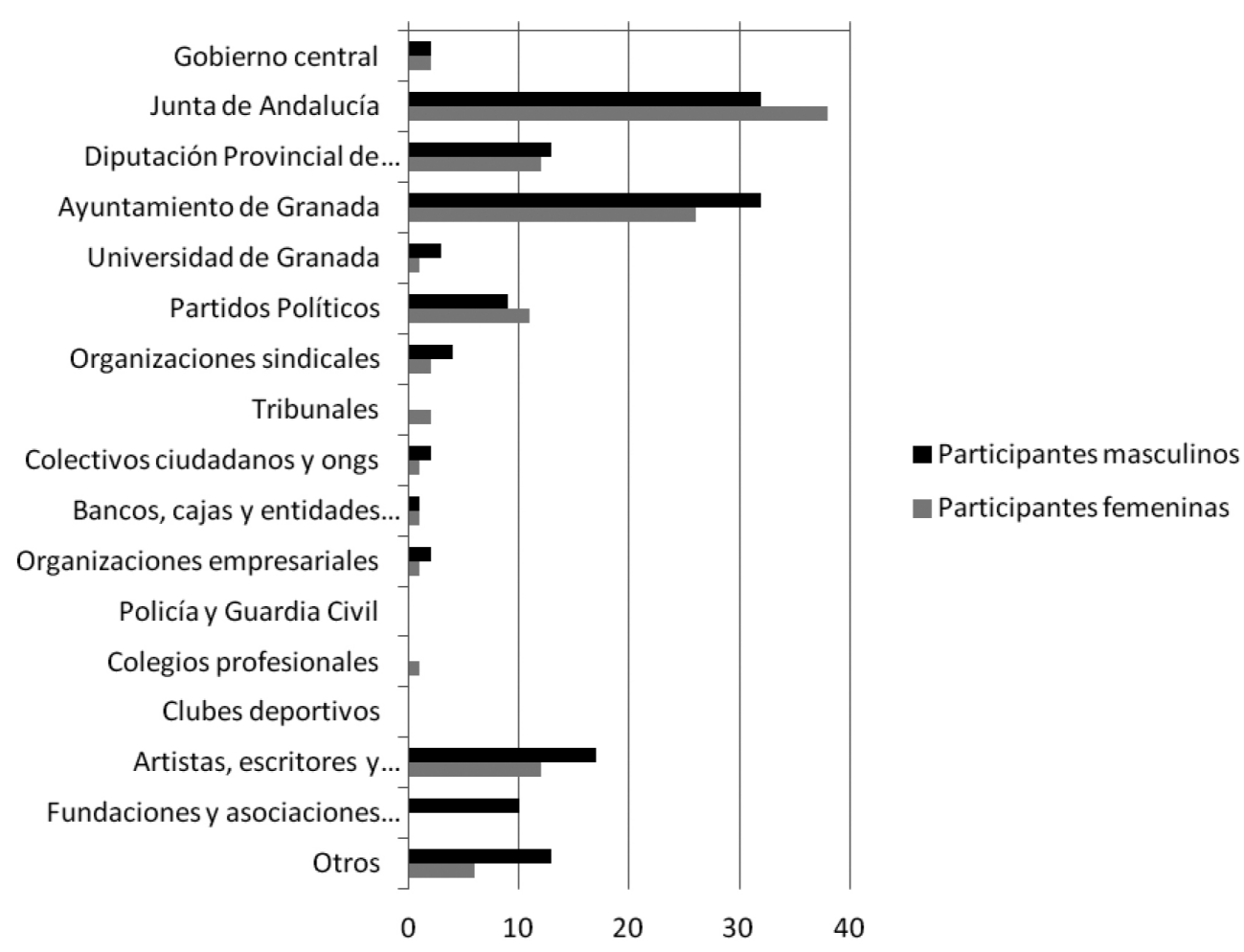

Fuente: Elaboración propia.

\section{GRÁFICO 2}

Intervinientes en las convocatorias de prensa de las agencias de noticias. Distribución por género

Los desequilibrios de género en las convocatorias no aparecen tan acusados, incluso en algunos sectores generadores de noticias en los que se ha dividido la información local de Granada para la elaboración de este estudio, las mujeres aparecen con más frecuencia en las convocatorias que los hombres. Es el caso de las citas informativas anunciadas por la Junta de Andalucía, los partidos políticos, los tribunales o los colegios profesionales. En los encuentros informativos de los medios de comunicación convocados por la Diputación de Granada, prácticamente se alcanza el equilibrio, una equidad conseguida también en los temas relacionados con los bancos, cajas y entidades financieras y en las convocatorias realizadas por representantes del Gobierno Central en la provincia granadina. 
TABLA 6

Orden de las intervenciones en las convocatorias de prensa de las agencias

\begin{tabular}{|l|c|c|c|c|}
\hline \multirow{2}{*}{} & \multicolumn{4}{|c|}{ Número de participantes en las convocatorias } \\
\cline { 2 - 5 } & Interviniente 1 & Interviniente 2 & Interviniente 3 & Interviniente 4 \\
\hline Hombres & $28,91 \%$ & $17,18 \%$ & $7,42 \%$ & $3,91 \%$ \\
\hline Mujeres & $29,30 \%$ & $9,76 \%$ & $3,13 \%$ & $0,39 \%$ \\
\hline
\end{tabular}

Fuente: Elaboración propia.

Contrariamente a lo que ocurre en las informaciones elaboradas, las convocatorias de prensa consiguen el equilibrio de género en el primer lugar de las intervenciones, incluso con un leve repunte de las mujeres. El resto de posiciones dentro de las citas informativas anunciadas no consigue la paridad pero no presenta las diferencias tan abrumadoras que se registran en las informaciones que se ofrecen a la audiencia. Estos datos corroboran un desajuste entre el planteamiento diseñado por las fuentes informativas (instituciones, partidos políticos, organizaciones empresariales...) en el momento de decidir quiénes presentan sus hechos noticiosos a los medios de comunicación de acuerdo con el organigrama de responsabilidades de cada una de ellas y el resultado final de esas informaciones una vez elaboradas por los profesionales del periodismo. El tránsito entre la convocatoria y la noticia abandona las declaraciones de las mujeres como sujetos activos e identificados de las informaciones.

\section{Conclusiones}

Como se ha podido constatar con el análisis de los datos, el desequilibrio de género es una constante en los medios de comunicación de Granada. La prensa de proximidad reproduce los esquemas de la prensa de ámbito nacional y concede mayor protagonismo a las voces masculinas que aparecen identificadas con nombres, apellidos y cargo casi en el doble de ocasiones que las voces femeninas. Esta situación se repite en todos los soportes analizados (emisoras de radio, televisiones, diarios en papel, prensa digital y agencias de noticias en sus teletipos con información elaborada) por lo que nuestra hipótesis de partida queda reforzada.

Sobre la posición de las declaraciones textuales de hombres y mujeres en los medios de comunicación granadinos, el análisis de las 1586 noticias evaluadas confirma que las opiniones y valoraciones realizadas por mujeres quedan relegadas a posiciones con menos relevancia informativa $y$, aun en estas posiciones secundarias, la presencia de las citas textuales de los varones se localizan en un mayor porcentaje que las de las mujeres. Especialmente significativas son las diferencias registradas 
en los diarios en papel que alcanzan los 26 puntos porcentuales; la prensa digital ha adoptado los mismos esquemas que la prensa tradicional y presenta un desequilibrio a favor de los varones en 23 puntos. El formato que más se acerca a la paridad es la televisión a pesar de los 10 puntos favorables a ellos.

El análisis de los temas abordados en las noticias nos confirma que el peso de la información institucional es muy elevado en los medios de proximidad y copa más de la mitad de la agenda informativa. La presencia de mujeres en estos organismos facilita su inclusión en las noticias pero los hombres continúan dominando este espacio público a través de la información publicada y la presencia de declaraciones identificadas en los medios de comunicación obtiene porcentajes más elevados. Incluso en aquellas instituciones granadinas en cuya cúspide se sitúan mujeres - la Delegación del Gobierno de la Junta de Andalucía y la Universidad de Granada- el número de voces masculinas supera al de voces femeninas.

Los resultados obtenidos a partir de las convocatorias de agencia obligan a una reflexión profunda de los medios de comunicación y sus prácticas en el momento de diseñar la agenda diaria. El equilibrio de hombres y mujeres como primera fuente informativa en las convocatorias no se traduce posteriormente en las noticias elaboradas para su difusión por los medios. El tránsito de la convocatoria a la información redactada relega a las mujeres o las oculta.

Es destacable también la ausencia de voces con identidades de género diferentes al eje binario masculino/femenino lo que pone de manifiesto el alejamiento de los medios de comunicación de la realidad social en la que se asientan. Los colectivos de personas gays, lesbianas, bisexuales, transexuales e intersexuales se encuentran completamente silenciados y sin espacio en los medios lo que refuerza el diseño profundamente masculinizado de la agenda.

En resumen, la perspectiva de género en los medios de comunicación se presume urgente en un momento en el que la sociedad está registrando cambios significativos. El pasado 8 de marzo, las profesionales de los medios de comunicación nos sumamos con fuerza a las reivindicaciones feministas con el movimiento Las Periodistas Paramos (LPP), una iniciativa que se mantiene activa y con el que estamos decididas a desligarnos de la cultura machista de las redacciones. Los resultados de esta acción reivindicativa deberán tener su reflejo en el tratamiento de las informaciones por lo que sería aconsejable realizar una nueva revisión de la prensa de proximidad en un futuro cercano para comprobar su incidencia. 


\section{Referencias bibliográficas}

Altés, E. y Gallego, J. (2004). Estereotipos y roles de género en los medios de comunicación. En LÓPEZ DÍAZ, Pilar (ed.), Manual de información en género (pp. 37-69). Madrid: Instituto Oficial de Radio y Televisión.

Beltrán Vidal, J.M. (2014). Género, Constitución y medios de comunicación. En VV.AA., Igualdad y democracia: el género como categoría de análisis jurídico. Estudios en homenaje a la profesora Julia Sevilla Merino (pp.718-730). Valencia: Corts Valencianes.

Blanco Castilla, E. (2005). Mujer y poder en los medios: Dificultades para una incorporación plena. En Informe anual de la profesión periodística 2005. Madrid: Asociación de la prensa.

Canel, M.J. (2000). Periodistas al Descubierto. Madrid: Centro de Investigaciones Sociológicas.

Caro González, F.J., García-Gordillo, M. y Bezunartea Valencia, O. (2010). Las mujeres como sujeto de la información: techo de cristal y audiencias en las empresas periodísticas. En Vázquez Bermúdez, I. (coord.), Investigaciones multidisciplinares en género: II Congreso Universitario Nacional Investigación y Género (pp. 187-197). Sevilla, 17 y 18 de junio.

Casero, A. (2012). El periodismo político en España: algunas características definitorias. Periodismo político en España: concepciones, tensiones y elecciones (pp. 19-46). La Laguna: Sociedad Latina de Comunicación Social. Recuperado de http://hdl.handle. net/10234/80553

Courteney, A. y Lockeretz, S. (1971). A woman's place: an analysi of the roles portayed by women in magazine advertisements. Journal of Marketing Research, 8. (1) 92-95.

Culley, J.D. y Bennett, R. (1976). Selling women, selling Blacks. Journal of Communication, 26, 160-174.

Faoaga, C. y Secanella, P.M. (1984). Umbral de presencia de las mujeres en la prensa española. Madrid: Instituto de la Mujer.

Franquet, R. (1982a). Por un discurso no androcéntrico de los medios de comunicación. En VV.AA. El sexismo en la ciencia. Barcelona: Universidad Autónoma de Barcelona.

Franquet, R. (1982b). La mujer y su relación con los medios. Chasqui: Revista Latinoamericana de Comunicación (4 julio-septiembre) 36-43 Recuperado de http://revistachasqui. org/index.php/chasqui/article/view/1697/1717

Gallagher, M. (1983). Unequal opportunities. The case of women and Media. París: Unesco.

Gallego, J. (2002). La prensa por dentro. Producción informativa y transmisión de estereotipos de género. Barcelona: Libros de la Frontera.

Gallego J. (2003). Producción informativa y transmisión de estereotipos de género en la prensa diaria. Comunicación y sociedad, XVI (2), 49-66. Recuperado de http://hdl. handle.net/10171/8055

Gallego, J. (2010). De reinas a ciudadanas. Género, comunicación y cambio social. II Jornadas Mujer y Medios de Comunicación (pp. 5-28). Universidad de País Vasco. 
García de Cortázar, M. y García de León, M.A. (coords.) (2000). Profesionales del Periodismo. Hombres y Mujeres en los Medios de Comunicación. Colección monografias, n. ${ }^{\circ} 181$. Madrid: Centro de Investigaciones Sociológicas.

García Gordillo, M.; Bezunartea Valencia, O.; Rodríguez Rey, A. y Sánchez González, M.T. (2014). La calidad en los medios y el uso de fuentes periodísticas. Una evolución del VAP (pp. 1.541-1.555). IV Congreso Internacional de la Asociación Española de Investigación en Comunicación.

Global Alliance on Media and Gender. Recuperado de http://gamag.net/

International Women's Media Foundation (IWMF) (2011) Global Report on the Status of Women in the News Media. Washington: Unesco. Recuperado de https://www.iwmf. org/wp-content/uploads/2018/06/IWMF-Global-Report.pdf

Humanes, M.L. (2003). Evolución de Roles y Actitudes. Cultura y Modelos Profesionales del Periodismo. Telos, (54 enero-marzo). Recuperado de https://telos.fundacion telefonica.com/archivo/numero054/cultura-y-modelos-profesionales-del-periodismo/

Asociación de la Prensa de Madrid. Informe anual de la profesión periodística en España 2017. Recuperado de https://www.apmadrid.es/publicaciones/informe-anual-de-laprofesion/

Karpf, A. (1980). Women and radio. Women's Studies Internationnal Quarterly, 3 (1) 41-54.

Lichter, R., Lichter, L.S. y Rothman, S. (1986). From Lucy to Lacey: TV's Dream Girls. Public Opinion, (9) 16-19.

Melin-Higgins, M. y Djerf Pierre, M. (1998). Networking in newsroom. Journalist and Gender Cultures. Paper of AIERI. Glasgow.

Moreno Sardá, A. (2001). Reflejos de los temas de género en los medios de comunicación: un asunto controvertido. En Caporale Bizzini, S.; Fuentes Soriano, O.; Mañas Viejo, C.; Montesinos Sánchez, M.N. y Ruiz Cantero, M.T. (eds.). La difusión del conocimiento en los estudios de las mujeres. Dinámicas y estrategias de poder y ciudadanía. Actas del II Congreso Internacional de AUDEM (pp. 151-166). Universidad de Alicante 7, 8 y 9 de mayo de 2001. Centro de Estudios sobre la Mujer.

Moreno Sardà, A. y Simelio Sola, N. (2011). El periodismo margina a mujeres y hombres como protagonistas de la democracia. Resultados preliminares de la evaluación de la presencia que las personas reciben en los titulares de El País, 2005 y 2010. Actas del III Congreso Latina de Comunicación Social, diciembre 2011. Universidad de La Laguna.

Moreno Sardà, A.; Simelio Solà, N.; Rovetto Gonem, F. y Buitrago Londoño, A. (2007). Periodismo y ciudadanía plural: problemas, rutinas y retos. Estudios sobre el Mensaje Periodístico, 13 157-168. Recuperado de https://revistas.ucm.es/index.php/ESMP/issue/ view/ESMP070711/showToc

Papí Gálvez, N. (2003). Un nuevo paradigma para el análisis de las redes sociales: el enfoque de género. Feminismo/s, 1, 135-148 Recuperado de: https://rua.ua.es/dspace/ bitstream/10045/2866/1/Feminismos_1_10.pdf

Pearson, J.C.; Turner, L.H. y Todd-Mancillas, W. (1993). Comunicación y género. Barcelona: Paidós. 
Report of the Fourth World Conference on Women. Beijing, 4-15 september 1995. Recuperado de http://www.un.org/womenwatch/daw/beijing/pdf/Beijing\%20full\%20 report $\% 20 \mathrm{E} . \mathrm{pdf}$

Rodríguez Rey, A.; Enguix González, A.; Rojas Torrijos, J.L. y García Gordillo, M. (2015). La calidad de los medios y el uso de fuentes periodísticas en la prensa local de referencia en España. Estudios sobre el Mensaje Periodístico, 21, (número especial noviembre) 85-100. doi: 10.5209/rev_ESMP.2015.v21.50659

Schudson, M. (2003). The Sociology of News. New York: Norton.

Soriano, J.; Cantón, M.J. y Díez, M. (2005). La pseudofeminización de la profesión periodística en España. Zer Revista de Estudios de Comunicación 10 (19) 35-52. Recuperado de http://www.ehu.eus/ojs/index.php/Zer/article/view/3838/3420

Tan, A. (1982). Television use and social stereotypes. Journalism Quaterly, 59, 119-122.

The Global Media Monitoring Project (GMMP) http://whomakesthenews.org/gmmp-2015

Trancart, M. (1999). Les femmes absences de l'information. Quand les chiffres parlent. En Rapport sur les recherches dans l'Unión Européenne, Emploi \& Affaires Sociales. Bruselas: Comisión Europea.

Tuchman, G. (1993). Realism and romance: The study of media effects. Journal of Communication, 43 (4) 36-41.

Unesco UnitWin Network On Gender, Media and ICTs. Recuperado de http://www. unitwin.net/

Vera Balanza, T. (2009). El perfil de las periodistas en Andalucía: formación y expectativas laborales. Un balance, 1989-2009. En Núñez Domínguez, T. y Loscertales Abril, F. (coords.) Las mujeres y los medios de comunicación. Una mirada de veinte años (1989-2009) (pp. 57-73) Sevilla: Instituto Andaluz de la Mujer.

Zemach, T. y Cohen, A.A. (1986). Perception of gender and quality. Journal of Broadcasting and Electronic Media, 30, 427-444.

Zoonen, L. van (1994). Feminist Media Studies. London:Sage. 


\title{
Repensar Gran Hermano 20 años después: la casa como simulacro ${ }^{1}$
}

\author{
Rethinking Big Brother Twenty Years Later: \\ The House as Simulacrum
}

\author{
Carolina Sanabria Sing $\star$
}

\begin{abstract}
RESUMEN: A finales del siglo XX surge un programa televisivo mundialmente revolucionario dentro de los concursos de entretenimiento y mantenido hasta hoy: "Gran hermano». La transparencia que pregona como ideal es consonante con el que caracteriza a la sociedad actual. En este caso, la hiperrealidad que funda el espacio se aprecia en la construcción de réplicas que intentan proponerse como simulacros. Pero el carácter de simulación queda expuesto en su contenido — sus habitantes- y en su continente: los artificios que la rodean, así como en su infraestructura, con el recinto conocido como confesionario que funciona como proveedor de verdad.
\end{abstract}

PALABRAS clave: televisión; representación; transparencia; realidad; sexo.

LABURPENA: XX. mende bukaeran, mundu osoko entretenimendu-lehiaketen alorrean iraultzailea izan zen telebista-programa bat agertu zen, eta gaur egunera arte iraun du: "Gran hermano". Saioak aldarrikatzen zuen gardentasuna bat dator egungo gizartea ezaugarritzen duenarekin. Kasu honetan, espazioaren oinarria den hiper-errealitatea hauteman egin daiteke simulakro gisa proposatu nahi diren errepliken eraikuntzan. Hala ere, simulazioaren izaera azaleratu egiten da edukian (biztanleak) eta edukitzailean: inguratzen duten artifizioak nahiz azpiegitura bera, aitorleku gisa ezagutzen den gunearen bidez, zeina egia-hornitzaile den.

HITZ-GAKOAK: telebista, errepresentazioa, gardentasuna, errealitatea, sexua.

${ }^{1}$ Este artículo surgió de un proyecto de investigación en el Instituto de Investigaciones en Arte de la Universidad de Costa Rica. 


\begin{abstract}
At the end of the 20th century, a revolutionary television program emerged world-wide within the entertainment competitions and maintained until today: «Big brother». The transparency as an ideal alignes with that which characterizes today's society. In this case, the hyperreality that founds the space is seen in the construction of replicas that try to pose as simulacra. But the character of simulation is exposed in its content - its inhabitants - and in its continent: the artifices that surround it, as well as in its infrastructure, with the enclosure known as a confessional that functions as a truth provider.
\end{abstract}

KEYWORDS: television; representation; transparency; reality; sex.

* Correspondencia a: Carolina Sanabria Sing. Universidad de Costa Rica, Vicerrectoría de investigación (11501-2060 Costa Rica). csanabriacr@yahoo.com http://orcid.org/0000-0003-0066-5179

Cómo citar: Sanabria Sing, Carolina. 2018. Repensar Gran Hermano 20 años después: la casa como simulacro. Zer. 23(45). 185-202. https://doi.org/10.1387/zer.

Recibido: 00 octubre 2018; aceptado: 00 octubre 2018

1137-1102 y 1989-631X / C 2018 UPV/EHU

(c) (i) Esta obra está bajo una licencia Creative Commons Atribución 4.0 Internacional 


\section{Introducción}

Unos pocos meses antes de que culminara el siglo $\mathrm{xx}$ tuvo lugar el estreno de un programa holandés que habría de modificar radicalmente la forma de hacer y pensar la televisión: «Gran hermano». España no tardó en adquirir la fórmula, aunque el impacto inicial daría paso a un panorama mediático en la actualidad donde el espacio en cuestión prácticamente alcanza la XX temporada ininterrumpida en emisión, siendo el programa en el país con mayor número de ediciones producidas y emitidas.

Dada la persistencia en la parrilla televisiva a lo largo de casi dos décadas de posteridad, la discusión se propone esta vez desde la infraestructura mediática como simulacro, con las hondas implicaciones que de ahí se derivan: la transparencia y la idea de realidad, en consonancia con el reclamo político y económico hacia el que se dirige la sociedad actual. Así pues, el presente artículo pretende estudiar, a partir de una metodología consistente en una revisión bibliográfica de las publicaciones académicas relacionadas, las particularidades que componen el mencionado espacio televisivo en un estudio de corte semiológico e interdisciplinario. Este enfoque establece una relación a partir de categorías culturales como las nociones de casa e intimidad que se problematizan en relación con conceptos operativos como el de simulacro y realidad de Baudrillard en relación con el panorama mediático, el de la transparencia repensado por Byung-Chul Han indirectamente derivado del panóptico, cuyo referente foucaultiano está ligado asimismo con la confesión entendida como productor discursivo de verdad. La pretensión se centra en una reflexión desde otros ángulos de las representaciones sociales y sus corolarios a la luz de este tipo de espacios que se prolongan en los medios.

\section{Antecedentes}

En la historia de la televisión figuran dos géneros básicos —informativos y entretenimiento- que se conjuntan en lo que viene a ser un híbrido al que se conoce como infotainment (Prado et al., 1999). Hubo varios acontecimientos mediáticos que funcionaron también como antecedentes directos de "Gran hermano», pero televisivamente los más relevantes fueron dos. El primero fue "An American Family», una serie producida por Craig Gilbert, filmada en California durante siete meses rodada ininterrumpidamente sin guion ni escenografia que no fuera la del hogar de la familia Loud. Estrenado en 1973, constituyó una crónica de la cotidianidad seguida por 20 millones de espectadores (Baudrillard, 2012: 58-59). Al día de hoy el formato se ha renovado y revigorizado en abundantes y exultantes programas de TV realidad de clanes familiares como «Keeping Up with the Kardashians» (2007-).

El otro referente destacado es un par de décadas posterior, "The Real World», un espacio de entretenimiento creado por Mary-Ellis Bunim y Jonathan Murray 
para la cadena MTV que se emitió de 1992 a 2013. A diferencia de una familia en el sentido estricto como en el caso del precedente directo de Gilbert, los participantes eran un grupo de 7 u 8 jóvenes entre los 18 y 25 años (el target de la población representativa de la audiencia del canal). La dinámica se centraba en la discusión de temas como la sexualidad, la religión, la muerte, pero con los años la producción acentuó aún más la ostentación de la banalidad y la inmadurez.

En ese programa de la cadena MTV, la vivienda empezó siendo un apartamento itinerante en distintas ciudades al que previamente se le habían incorporado cámaras, luces y audífonos. El emplazamiento funcionaba como ambientación narrativa en tanto escenario de acciones que la ficción televisiva ha venido explotando desde las sit-coms de los años 60. Pero el que se trate de un piso compartido tiene implicaciones en que se le perciba como dinámico y cambiante (Robertson Wojcik, 2010: 22), sobre todo tratándose de sujetos mayormente jóvenes que comparten un espacio común. ${ }^{2}$

Lo que sobresale de estos dos programas fundacionales es que en ellos se recalca el carácter (real y americano) de su referente (el mundo y la familia), como constructos ideales que en su intento de representación documental producía el efecto de simulación que conduce a la hiperrealidad. Sin embargo, ni "An American Family" ni "The Real World» fueron pensados como concursos de convivencia de la manera en como lo elaboró el reality show "Gran hermano» en un panorama renovador en los concursos de la producción televisiva.

Finalmente, la concepción de "Gran hermano» fue producida por el neerlandés John de Mol, propietario de la productora holandesa Endemol Entertainment. En 1997 desarrolló su idea con su propia compañía de producción y en 1999 se produjo su estreno mundial, llegando a emitirse en alrededor de 70 países. Un año después de su estreno se llevó a cabo en España, adquirido por Telefónica y emitido hasta la fecha por la cadena generalista Tele5. El programa en cuestión se desarrolla en un emplazamiento que integra una serie de nociones culturales como intimidad, domesticidad, confort. Estas nociones se relacionan alrededor del concepto de casa, que, como había planteado el historiador Philippe Ariès, es propia de la modernidad y se asienta en la fuerza que deviene de ahí: la individualidad (1962: 392), que se encarga de encumbrar el concurso.

2 Su más cercano referente en la ficción serial se encuentra en la exitosísima serie Friends (NBC, 1994-2004) que gira sobre las peripecias de un grupo de adultos jóvenes que conviven en un apartamento urbano. 


\section{Las casas de Gran Hermano}

Uno de los rasgos que particularizan el programa está en el acondicionamiento del lugar que semeja una casa. Pero no es una casa al uso: no está pensada como un lugar para vivir, sino un espacio construido ad hoc (antes que de un piso de un bloque ya existente, como en el itinerante "The Real World») y por tanto más impersonal que una casa. En España, los emplazamientos del programa han estado situados en dos puntos: las instalaciones centrales de la empresa en Madrid y las de las afueras de Guadalix de la Sierra a partir de la segunda edición, ${ }^{3}$ donde se ha habilitado ese espacio del concurso de convivencia para recibir a los concursantes a los que se les ha dado en llamar habitantes de la casa. En un primer momento, el lugar estaba rodeado de 60 micrófonos y 29 cámaras camufladas con espejos (Lacalle, 2001: 142), las cuales se aumentaron a casi el doble en la séptima edición: 59.

En realidad, la casa donde aquellos sujetos permanecen durante el lapso del concurso está adosada a otra "casa»: un amplio estudio televisivo que consta de una pequeña recepción del control de visitas, una sala que da acceso a realización, sonido y a la casa misma. Para esa primera edición, el número de trabajadores era cuantitativamente mayor que los concursantes: alrededor de 130 (Lacalle, 2001: 142). En el cuarto de realización se encuentra la sección de redacción, el control de cámaras que se ocupa de nivelar el color de la imagen, un primer operario que maneja todas las cámaras que hay en las paredes dentro de la casa, luego dos realizadores que se encargan de dos programas de los cuatro en total que llevan a cabo y un segundo operario que manipula las cámaras de las paredes. La sala de realización está en comunicación con la de sonido que a la que corresponde subir o bajar el volumen según las tramas que se les indican desde redacción.

Aparte de este estudio, hay otra sección donde las cámaras están robotizadas y se manipulan a distancia desde la sala de control, en una especie de túnel que se extiende por toda la vivienda que se le conoce como cruz de cámaras (Lacalle, 2001: 142). Se trata de una zona de pasillo más oscura y silenciosa o una sucesión de corredores de los que, según el periodista Israel Álvarez, sería difícil salir sin un guía (14/02/2012). Así pues, la espectacular casa televisiva no resulta otra cosa que una estructura laberíntica, ya que a lo largo de los corredores se abren más de 100 ventanas y para llegar a ellas se mueven las cámaras montadas sobre trípodes con ruedas.

Por lo demás, esta construcción siempre consta de las estancias básicas que componen una casa, como se viene produciendo desde la primera edición (2000):

\footnotetext{
3 Solo la primera edición se realizó en la localidad madrileña Soto del Real, pero aunque la cadena no ofreció explicaciones se presume que el cambio estuvo dado en función de la seguridad y el aislamiento.
} 
dormitorios divididos (en algunas ediciones unificados) de acuerdo con el género, ${ }^{4}$ cuartos de baño, cocina, comedor y ambientes de esparcimiento, entre ellos el patio con piscina. En alguna ocasión, como en la edición 11 (2009-2019), hubo dos viviendas — una idea tomada de la versión precedente, la 10-, pero una era la casa verdadera y la otra era la casa espía, hecha de materiales reciclados y más pequeña, con el pasto del jardín también artificial. La casa espía acogía a los postulantes los cuales se dedicaban a mirar a los concursantes nominados para prever cuál sería eliminado, con lo que se constituyen como nuevas réplicas del espectador ideal. Era la exacerbación de la simulación, la realidad de la realidad replicada, de la estructura al estilo de una dinámica de mise en abyme, cuyos prototipos generan otros casi idénticos.

De la evolución anterior del espacio varias derivaciones que surgen son constantes en el concurso. Por un lado el emplazamiento articula dos magnitudes discordantes, conservando las condiciones precarias típicas de una sociedad primitiva (el sedentarismo que se exacerba al inmovilismo, la segregación de los concursantes en grupos para competiciones tribales, la limitación alimenticia así como del agua caliente para la ducha) en el combate estratégico por la supervivencia — todos ligados a la permanencia en la casa-.

La casa de "Gran Hermano» viene a ser propia de una civilización globalizada (de una casa equipada con el sibaritismo de los placeres lúbricos: la piscina, el jacuzzi, el baño sauna, la suite). Sin embargo, no todo es tan idílico y tan ordinario: además de las entradas y salidas, la normativa prohíbe el acceso a cualquier medio y dispositivos impresos, electrónicos y digitales que, por el contrario, son habituales en la cotidianidad actual - lo que contribuye a sellar la paradoja de una sociedad del siglo XXI en relación con la forma de vida primaria más propia de la vida rural del siglo XIX - ${ }^{5}$. Pero tal vez la mayor paradoja es que todo está pensado para que no haya necesidad de salir —en una dirección parecida a la mítica mansión Playboy de Hugh Hefner (Colomina en CCCB, 2016: 105) porque todo su mundo está ahí contenido-.

${ }^{4}$ Como en una vuelta a la Edad Media donde los dormitorios eran colectivos, como sostenía Rybczynski; «en el siglo XVI era raro que alguien tuviera una habitación sólo para él» (2009: 30), porque el hecho de que las más jugosas aproximaciones entre los inquilinos se producen en este entorno no deja de ser un potencial espectacular. En efecto, de lo que se trata es de potenciar el morbo y los discursos en programas paralelos del mismo canal en torno a los actos, actitudes y confesiones íntimas de los sujetos en cuestión en un momento de suma intimidad.

${ }^{5}$ Desde ese punto de vista, podría resultar más consonante con el espíritu de otra de las variaciones del exitoso realit showy, "The Farm» (de la productora sueca Strix en asociación con Endemol). En España se desarrolló por la competencia como "La Granja» (2004, 2005, Antena 3) o "Acorralados» (2011, Antena 3), adecuado a un entorno de la sociedad rural del siglo xIX, donde además los concursantes carecían de otros servicios como agua caliente o luz eléctrica. 
La vivienda en "Gran hermano» adquiere no solo el carácter de protección sino de apropiación: aparte de los implementos domésticos de rigor, los concursantes suelen llevar objetos personales como fotografias o recuerdos de cualquier índole de su casa anterior que tienen ante todo una función simbólica que Desmond Morris categorizaba como los territorios en potencia (1995). En esa línea, Galmés Cerezo apunta la función de los objetos con los que el sujeto se adueña del espacio, colonizándolo: «Uno de los poderes que atesoramos en nuestras casas es de acumular objetos para darles un significado que nos permita escapar del paso inexorable del tiempo objetivo y sumergirnos, así, en el de la intimidad» (2014: 74). Por tal razón a los concursantes se les permite llevar alguna pequeña pieza personal que en el nuevo contexto de la casa sustitutoria cumple el cometido de una forma de apropiación espacial en el ejercicio de intimidad. Pero esa intimidad en un reality no tiene otra forma que representarse sino a partir de su simulación (Ordóñez Díaz, 2005: 54) porque aquella no suele —o mejor, solía entonces- ser objeto de espectáculo.

Por eso, a diferencia del plató televisivo de las series típicas estadounidenses, que simula ser un lugar habitable porque forma parte de la escena dramática, ficticia, la casa de Guadalix está pensada como real en primera instancia para ser habitada por un lapso puntual de algunos pocos meses. Pero más que habitada, su función prioritaria está destinada a la visión, como pondera el eslogan de «Gran hermano, tienes mucho que ver»: la idea que la sustenta es la transparencia física y metafórica. «Esta primacía del ver sobre el saber es fundamental porque le da a la realidad representada un modo de existencia propio y establece con el espectador una relación de adhesión in-mediata (sin mediación)", dice Imbert (1999: 2). No es la comodidad ni el sentido práctico en la vida de sus habitantes, ni su confort y bienestar lo que importa, sino la visualidad de los espectadores abocada al mito de la transparencia total. Esta exacerbación por la visibilidad, cada vez más creciente, implica «un intento permanente de simplificación, de reducir las cosas a sus rasgos más atrayentes» (Martín Prada 2018: 17). Pocas veces acaso se piensa tan descomedidamente una casa — aparte de las de excentricidades de diseño como las de Le Corbusier-, que en principio responde a un sentido práctico o estético, no para sus moradores, sino para sus espectadores.

\section{La casa transparente y la producción del secreto}

Si el mundo del siglo XVIII es el del teatro del mundo, en el que el espacio público se parece a un escenario teatral, como dice el filósofo coreano Byung-Chul Han sobre la sociedad occidental, en la modernidad se renuncia cada vez más a esa distancia teatral a favor de lo digital, de la intimidad, animado en última instancia por el ideal de transparencia (2016: 67), que ofrecido a los televidentes como panóptico bajo el presupuesto de que todo es visible, controlable y comprobable. 
Este ideal elabora un producto que en su voluntad realista deriva en un hecho hiperreal. La transparencia se articula con una variable que introduce la creación de John de Mol a partir del eje literario en un espectáculo televisivo: la transformación del público en la temible figura homónima de la novela de George Orwell, en el que la audiencia asume la fiscalización de los moradores de la casa, con lo que cada espectador se vuelve un potencial delator, multiplicado en millones de ojos. La pretendida transparencia — que, como ha dicho Han, no supone una equivalencia a la verdad (2016: 79) — postula la consiguiente pérdida de referentes de la que hablaba Baudrillard, donde lo real queda sustituido por las simulaciones:

No se trata en semejante experiencia ni de secreto ni de perversión, sino de una especie de escalofrío de lo real, o de una estética de lo hiperreal, escalofrío de vertiginosa y truculenta exactitud, de distanciación y de aumento a la vez, de distorsión de escalas, de una transparencia excesiva (2012: 59).

Los órdenes de simulacros grafican la circulación de signos en tres etapas (falsificaciones, reproducciones y simulaciones), donde dominan y al final terminan reemplazando lo real. Como afirma Imbert, «[d]e la reproducción hemos pasado a la simulación de realidad, y de la mostración realista del mundo, al cómo la televisión es capaz de crear mundos mostrándonos además este proceso de invención de la realidad» (2003: 247). En virtud de la conciencia de exposición, la representación pasa a ser sustituida por la simulación, de lo contrario sus participantes no serían más que actores que recobran sus identidades al final de la representación: «[a]sí es como el reality escapa a la paradoja de la representación, sólo para caer en lo que podríamos denominar la paradoja de la simulación», porque «intenta trascender ese juego: ya no más representaciones de la vida diaria que la suplantan y ocultan; mejor mostrarla en su despliegue. Sin embargo, nadie vive su vida diaria con el propósito de mostrarla» (Ordóñez Díaz, 2005: 53). Esta última precisión ha de matizarse: no se supone que las representaciones de la vida cotidiana se pensaran entonces para ser mostradas, al menos para alrededor de la primera década en que empezó el concurso. No obstante, con la emergencia de las redes sociales - empezando por Twitter que se lanzó en 2006, luego Facebook entre 2007 y 2008 e Instagram en 2010 - , el panorama mediático dio un cambio sustancial de $360^{\circ}$. En efecto, casi dos décadas después, tal escenario vendría a estar caracterizado "por una atención microscópica a los acontecimientos más banales y cotidianos» (Martín Prada 2018: 26). ${ }^{6}$ Es así como la confusión se materializa en la incapacidad de distinguir si las casas por dentro públicas - y por consiguiente, espectaculares - se parecen a las reales o viceversa.

${ }^{6}$ Que se ofrecen con desmesura en espacios públicos que no solo contempla a la televisión. En efecto, la expectación se complementa con un seguimiento en la red que permite, como dice Perales Bazo, un mayor control de los concursantes y acontecimientos (2011: 129). 
La construcción de la hiperrealidad y el borramiento de toda intención de puesta en escena (Perales Pazos, 2011: 129) interactúan con la transparencia. Esta suprime, como había dejado claro Han, toda traza de negatividad en la sociedad, formalizando una coacción que «nivela al hombre mismo hasta convertirlo en un elemento funcional de un sistema» (2016: 14). Por tanto, en una sociedad donde se encumbra la transparencia como deseable, la extrapolación a la casa resulta a todas luces inconsonante con la idea de intimidad, de privacidad - pues una negatividad del vacío produciría una sociedad sin dicha (Han, 2016: 17)—. El mismo Georg Simmel había planteado como desiderata, hacia finales del siglo XIX e inicios del xx, lo que llamaba "el derecho a guardar el secreto» (1986: 378), mientras que "Gran hermano» parte del supuesto ubicado a las antípodas. Paradójicamente la llamada casa está construida para favorecer el secreto entre los concursantes, lo que explica sus amplias dimensiones y variados espacios por donde hay posibilidad física de sobra para formar pequeños grupos espontáneos de concursantes, pero ese secreto fabricado pretende ser develado ahí mismo.

De hecho el secreto, que es lo contrario a la transparencia, no dura mucho, por no decir que se replica casi al instante, mediáticamente (Lacalle, 2001: 167), de modo que resulta impensable que no se propague al menos como especulación. Lo que el lugar en cuestión consigue es generar producción discursiva en todas las direcciones posibles, la cual será reproducida y glosada en los programas paralelos, resúmenes diarios, debates dominicales y la gala semanal donde tiene lugar la expulsión del miembro más votado por el público con base en la directriz de los mencionados espacios germinales. Esa autorreferencialidad a nivel interno funciona como una muestra de lo que a mayor escala resulta el funcionamiento de la televisión, que cumple la máxima de la característica principal de la llamada Neotelevisión según Umberto Eco: que cada vez habla menos (como hacía o fingía hacer la Paleotelevisión) del mundo exterior (1999: 151). La casa, con la referencia a sí misma y no a otra realidad es la metáfora de la sociedad actual que mira al aparato en una dinámica moebiana.

Los sujetos son por lo general desconocidos entre sí, como los concursantes del programa original estadounidense, pero en la franquicia europea de Endemol el promedio del número duplica el equivalente de la MTV. El hecho de que su composición esté dictaminada por un orden ajeno e invisible dificulta el concepto tradicional de casa, cuya ontología radica no solo en fungir como espacio de protección y albergue, según se dijo, sino de espacio de desocialización, de acceso de soledades (Bachelard, 2000: 31) individuales. En cambio, en la casa de "Gran hermano» resulta imposible la permanencia fisica en aislamiento, sin la compañía de los otros sujetos —a no ser que se esté provisionalmente retirado (en el confesionario)-, pero en esa circunstancia tampoco puede hablarse de apartamiento total. De hecho, el carácter espectacular del programa está ligado al grupo, porque el individuo por sí mismo carece de este valor. Previo a ello, ha habido una selección puntillosa que elige un 
conjunto de personalidades contrastantes para dar garantía del choque en los términos dispuestos por la organización, como que siempre y cuando sea verbal y evite confrontaciones de tipo político o religioso. Lo que se privilegia es la discursividad, por encima de todo, con preferencia si tiene lugar en torno al sexo.

Más que sus muros y su acondicionamiento, lo que hace verdaderamente real la casa es su contenido. «El cuerpo, el cuerpo del otro, y ulteriormente el cuerpo de las cosas, del mundo, se constituye en la materia nuclear de todo espectáculo», dicen González Requena y Martín Arias (1994: 9) a propósito del discurso televisivo. El cambio inaugurado por el programa termina por encumbrar a sujetos carentes de atractivo por sus acciones o su linaje de acuerdo con la caracterización de la prensa del corazón, apoteosis del reino de los cualquiera. La elección funciona como un cuidadoso proceso de selección en consonancia con los sujetos que pueblan los programas televisivos desde finales del siglo pasado hasta hoy que son considerados irrelevantes por sí mismos - lo que John Langer llamaba sujetos no destacables (2000: 72-74) - que en el caso de la familia Loud, lo que para Baudrillard la convertía en hiperreal era la selección de un clan idílico - típico californiano de un estatus profesional y social por encima de la media con 3 espacios para garaje, 5 hijos blancos(2012: 59). Pero en "Gran hermano» esa selección opera sobre sujetos postulantes, es decir, no sobre criterios sociológicos, sino sobre subjetividades narcisistas que consienten — más aún, que anhelan — la exhibición continuada, con lo que el programa de de Mol podría ubicarse como la contraparte, en su dinámica de la visión de los espacios, de "Candid Camera». Pero en «Gran hermano», lo doméstico, presentado como apegado a la realidad, adquiere, a través de la mediación televisiva, carácter espectacular y, parafraseando a Imbert, especular.

Claro que esa muestra de un grupo ideal (familiar o fabricado) siempre se resquebraja, como llegó a constatarse con el hecho de que durante la producción del programa la familia atravesara una crisis que acelerara su ruptura: los padres se divorciaron al terminar el documental y el hijo mayor declaró públicamente su condición gay, ambas fisuras irreparables al concepto convencional de familia. Paradójicamente un impacto de ese tipo venía a ser deseable para el concurso, por lo que de una manera ciertamente equivalente viene a operar la selección de concursantes, que para la primera edición del concurso, la periodista que fungía como conductora del programa, Mercedes Milà, definió como "perfectos representantes de la clase media española» en el día del estreno de la primera temporada. Como no podía ser de otro modo, la muestra resultó tan hiperreal como los Loud, derivado en el hecho (convenientemente noticioso) de que para esa edición inaugural dos participantes femeninas fueron señaladas por haber ejercido la prostitución y por tal razón debieron abandonar el programa. Es probable que en ese momento el equipo de producción descubriera la importancia del casting, que tarde o temprano se develaría como fórmula esencial en el pretendido experimento sociológico según la propia Milà. Por eso, tal vez a partir de la segunda edición, la elección es más cerebral y estratégica- 
mente calculadora en función de la espectacularización (Sanabria, 2011: 223), a saber, con personalidades, condiciones y sexualidades que rozan la excentricidad aunque sin caer en la ilicitud y que se prestan, se exhiben para ser comentadas. Como se dijo, "Gran hermano» es ante todo, incluso antes que el sexo y la intimidad, un concurso de la palabra, del discurso.

\subsection{LA vOZ ACUSMÁtica}

Como lugar de producción discursiva funciona una dinámica de voces en la estructura del programa, aunque esta aparente polifonía más que nunca sigue siendo monoglósica y por descontado tecnocrática, como caracteriza a las sociedades mediáticas del orbe (Zeledón Cambronero, 1994). Primero que todo, el programa se funda en la circulación de discursos a lo interno del espacio. Sin embargo, no se puede pasar por alto la existencia de esa palabra articulada de una fuente no procedente de ninguno de los moradores que resuena en todos los espacios. Es una voz acusmática, según el término acuñado por Pierre Schaeffer en referencia a aquella que se oye el sonido sin ver su causa, es decir, exacerbando la escucha casual privada de la vista (en Chion, 1993: 30) y especialmente es un recurso explotado en el cine de terror. De igual modo, en el programa no interesa identificar la fuente por ninguno de los medios, visual o auditivo. Vendría a ser una variante de la novela de Eric Blair, que identifica al insondable personaje del Gran hermano con la voz y la imagen proyectadas, pero en el programa televisivo la concordancia es más sutil o menos refleja porque como se dijo, la función de la vigilancia se delega en la audiencia, es decir, se desdobla.

Siendo de esperar porque no se trata del género de ficción de terror, en «Gran hermano» el carácter conminatorio de una voz que no se corporaliza llega a ser naturalizada como parte de la cotidianidad de la casa. La extrañeza se matiza por la habituación a su presencia que otorga la repetición constante que la hace parte de la cotidianidad. ${ }^{7}$ Lo anterior no significa que esa voz no deja de entrañar autoridad, extrañeza que ha sido normalizada. En efecto, los concursantes obedecen sin chistar, con sometimiento evidente, prueba de lo cual es que cuando son compelidos, entornan automáticamente la mirada hacia lo alto - preeminencia que se traslada al acto lingüístico, pues se le refiere como súper_, en una dinámica propia de regímenes totalitarios como el estalinista que subyacen a la novela de Orwell. En ese sentido, la representación se presenta como un juego inocente, la simulación es voluntariamente asumida, la amenaza de eliminación los concierne por igual y cualquiera

\footnotetext{
7 Como recurso, la voz sin fuente perceptible ha sido especialmente utilizado en filmes narrativos de intriga o terror con la introducción de personajes asociados a situaciones anómalas que amenazan con alterar el orden hasta que finalmente con su aparición se produce la llamada desacustomatización de la voz donde se alcanza a visualizar la fuente temible de emisión.
} 
puede ser el próximo eliminado que lo regresará a la masa indiferenciada, a partir de lo cual Ordóñez Díaz plantea una analogía de contraste, a saber, mientras que en la dictadura totalitaria es preciso simular para sobrevivir, en el reality es preciso sobrevivir para simular (2005: 56).

La condición superior de la mencionada voz se antoja de especial evocación de la voz acusmática del Dr. Mabuse (Das testament des Dr Mabuse, 1933) de Fritz Lang en la que ese recurso expresivo y humano llega a ser empleado como instrumento mecanizado despersonalizado. Y por haberse independizado del campo diegético, es decir, por estar fuera - o por encima - de las relaciones cotidianas propias de la casa, la voz del súper se encuentra como la de Mabuse, en una posición distanciada y por tanto de privilegio (Morris, 1995): es omnisciente, omnipotente y omnipresente.

La diferencia con respecto a la mirada es que como voz se remite a una fuente personal con nombre y apellidos, pero no necesariamente le corresponde una o varias fisonomías, como la de Roberto Ontiveros, Pepa Álvaro y Floren Abad. Evidentemente ninguna de las voces de los súper están lejos de exudar el dejo siniestro y taxativo de la voz metálica en el discurso repetitivo tras la grabadora de la cortina de quien se hace pasar por el diabólico Mabuse. En todo caso no importa, prueba de lo cual es que no suelen ser sujetos que figuren con la misma intensidad que los presentadores o concursantes. Es una instancia que remite a lo que formulaba Flaubert en una carta de 1875 , esto es, a ese dios invisible y omnipotente que habría de ser escuchado por todos pero visto por nadie (en Fanés, 1985: 29).

\subsection{LA HABITACIÓN ÍNTIMA}

La visualidad total que despliega la casa a través de su arquitectura y artilugios no es íntegra si no se considera la dimensión íntima de los sujetos que alberga, evidenciada no solo a través de las relaciones entre los mismos concursantes. Como en la novela, también se busca extraer esa verdad a través de otros medios, como el llamado confesionario, donde ante la mencionada voz de autoridad los concursantes son convocados a mostrar su interior. Consiste en una forma, según Foucault, de autentificar el discurso verdadero que es capaz de formular sobre sí mismo o que se obliga a formular (1989: 74). Con este recinto, la configuración del espacio acentúa la idea de la individualidad elevada a absoluto según se llegó a gestar en la mentalidad moderna.

Lo mismo que la sala de expulsión pero de mayor importancia porque los concursantes acuden más cantidad de veces, el confesionario es un espacio diseñado ad hoc: Lacalle sostiene que se trata de la dependencia más importante de la casa:

una pequeña habitación insonorizada, compuesta únicamente por una cámara y un sillón, donde los concursantes dialogaban con los invisibles psicólogos 
del programa (cuya asistencia requerían a título voluntario e individual), con su redactor de seguimiento o con el director de «Gran hermano» (2001: 148).

La sala conserva un estilo austero y viene manteniéndose con un cuadro, un sofá unipersonal con uno o varios cojines carmín con forma de corazón, ubicado frontalmente a la cámara, que queda fuera de marco. Este último elemento no es azaroso: la conversación suele girar en torno a sus afecciones y a la sexualidad en relación sobre todo con los demás participantes, lo que por cierto hace de la casa un espacio esencialmente endógeno. Una vez ahí convocado, el concursante sabe que tiene que tomar asiento y dar réplica a las preguntas que el súper o las psicólogas le formulen, casi siempre bajo condiciones de instigación.

Esta habitación es lo que distingue a la casa del programa de las casas habituales y la aproxima más a un diseño conventual, si cabe. Se trata de un austero recinto donde tiene lugar la mayor producción discursiva que sirve para nutrir al programa mismo y a los espacios paralelos. Históricamente puede tener su referencia en el aposento más recóndito e íntimo que los griegos llamaban thalamos. De nombre extraído del lenguaje luterano, el llamado confesionario viene a funcionar como una reproducción pagana del habitáculo de los templos, donde el sujeto no puede ver directamente a su confesor sino intuir su presencia y escuchar una voz - la del súper, los psicólogos o el redactor personal - y, de esta manera, orienta la actitud de los concursantes en momentos determinados (Menéndez Menéndez 2002: 237). Esta vez la rejilla se ve sustituida por la tecnología, porque la diferencia es que el discurso se mantiene fuera del acceso de los otros concursantes, donde lo ahí comentado acostumbra tener que ver con la situación emocional actual del concursante. Lo que ocurre es que el mismo término resulta descaradamente anfibológico, ya que la conversación, que trata siempre sobre la intimidad del confesado, se da a conocer a todo el público televidente que en ocasiones excede a otros medios, con la única y provisional excepción de los demás compañeros que en ese momento fungen como contrincantes y que sin duda provocará diferencias. El concepto, más que la habitación misma, es fundamental en programas televisivos contemporáneos en general que implican la participación de concursantes. ${ }^{8}$

De esta manera, se lleva a la espectacularidad y a la cotidianidad los procedimientos para satisfacer ese deseo por el sexo a través de la confesión, que durante

\footnotetext{
${ }^{8}$ Fuera de «Gran hermano», en otros reality shows, la habitación física en la que se recluyen los participantes se descorporiza y de estar diegéticamente encuadrada — siempre desde su inmaterialidad - en la habitación o confesionario, la voz pasa a offscreen. En el resultado final de la edición, desaparece como tal pero mantiene el control de la discursividad del sujeto. En efecto, la edición de estos programas no puede dejar de prescindir de este pilar, y lo hace con la incorporación de la figura del sujeto en cuestión desde un plano medio con comentarios en ese momento sobre el flujo narrativo que se está presentando.
} 
mucho tiempo hasta el siglo XVI, como dice Foucault, había permanecido encastrada en la práctica de la penitencia $(1989: 79,85)$. Por un lado, lo expresado en el confesionario suele hacerse equivaler con el discurso verdadero y por eso su edición suele ocupar un lugar medular y hasta determinante en la emisión de los programas, sean galas, resúmenes diarios o debates. Por otro lado, la dinámica actualiza la sociedad de la revelación del siglo XVIII en las Confesiones de Jean-Jacques Rousseau que asocia la transparencia a la verdad de corazón pero no como imperativo moral, sino que aspira a la atención y al provecho máximos (Han, 2016:85-86). La verdad de "Gran hermano» es una asociada a lo económico, a la lógica de la utilidad.

El programa promete una fruición intrínseca en torno al tema del sexo en los dos sentidos que propone Foucault, a saber, como interrogatorio — propiamente en esa habitación - y problematización (1989: 89) —en el resto, incluidos los programas paralelos-, donde el espectador se alinea con el súper (de nuevo, con el Gran hermano) en la petición de la verdad de su secreto, tanto del concursante como en última instancia de la audiencia. En esta producción de verdad sobre los resquicios más íntimos, se tiene, como sostiene el filósofo francés, la creación colateral de placeres intrínsecos:

placer en la verdad del placer, placer en saberla, en exponerla, en descubrirla, en fascinarse al verla, al decirla, al cautivar y capturar a los otros con ella, al confiarla secretamente, al desenmascararla con astucia; placer específico en el discurso verdadero sobre el placer (1989: 89).

El confesionario entronca además con esos pequeños santuarios engañosos en el corazón de la vivienda y al mismo tiempo diferenciados, como los studioli renacentistas referidos por Baudrillard (2012: 32-34) que consistían en gabinetes que funcionaban básicamente como lugares íntimos de estudio a partir del siglo XVIII y los libros ahí contenidos no eran sino patrimonio doméstico, todo lo cual representaba una de las formas más puras de intimidad (Echeverría, 1999: 42). Y en medio de las espaciosas habitaciones rodeadas de placeres meramente lúbricos que contiene la casa se encuentra este pequeño y austero recinto diferenciado (que comparte con el moderno confesionario de la casa de «Gran hermano» el hecho de espacio limitado y desprovisto de ventanas, como corresponde a los rincones privados, de recogimiento). Es ahí donde tiene lugar la producción del secreto que no tardará en salir a luz. Es probable que la fórmula repetida e ininterrumpida del programa a lo largo de dos décadas encuentre su respuesta a la incógnita de su existencia y mantenimiento en la producción de verdad que le proporciona al espectador una sensación de dominio y conocimiento por encima de las pequeñas criaturas.

«Gran Hermano» formaliza, normaliza y actualiza un nuevo tipo de confesión mediática que se ha generalizado en la televisión, donde el presentador hace las veces de inquisidor moderno, que lleva a sus audiencias a victimizar o encumbrar al 
individuo (concursante) en cuestión. En la Edad Media la confesión funcionó acompañada de tortura para arrancar la verdad, y con el paso del tiempo ha llegado a ser espontánea o impuesta por algún imperativo, por lo general asociada con lo religioso pero de derivaciones sutiles en otras áreas: «La más desarmada ternura, así como el más sangriento de los poderes, necesitan de la confesión. El hombre, en Occidente, ha llegado a ser un animal de confesión» (Foucault, 1989: 75).

\section{Cierre}

Aunque se proponga lo contrario, la casa dista de ser una vivienda común y corriente. En primer lugar, por la naturaleza hiperreal de los sujetos que la habitan. Por lo general suelen ser adultos jóvenes que no se reúnen en ese espacio por otra razón más que por la obligatoriedad de las normas del concurso durante el lapso estipulado que le merecerá al ganador un premio importante. Además, la dinámica del concurso les obliga a permanecer ahí, sin salir para visitar a sus familiares o amigos ni para trabajar - en un contrato que les asigna una mensualidad por el tiempo ahí destinadoporque el concepto de trabajo — así como el de estudio- está excluido. Ello forma parte del mismo simulacro, que asimismo oculta la ausencia de trabajo, en una línea semejante a la propuesta por Baudrillard en su concepción del funcionamiento de las sociedades modernas (2012: 57 ). Todo el tiempo se dedica al ocio que deriva en aburrimiento - de quien habita y de quien mira-, porque ya se sabe que la cotidianidad riñe con la espectacularidad y el reality show no es más que un oxímoron.

En segundo lugar, porque la zona está rodeada de micrófonos y cámaras, tanto fijas como móviles, en todos los recintos, lo que ofrece la promesa de transparencia, aparte de la infraestructura paralela. En realidad esa mentada transparencia resulta una ilusión, porque como había dicho André Bazin, la imagen visual —a la que se sumaría el registro acústico también - ofrece pruebas, pero estas no constituyen la prueba (1990: 44). El nexo indicativo especialmente propio del género documental al que "Gran hermano» se acerca, si se quiere, no es infalible, depende de inferencias y hasta de eventuales manipulaciones: «el mismo film suele estar concebido como una conferencia ilustrada donde la presencia o la palabra del conferenciante-testigo completan y autentifican la imagen» (1990: 44), había sostenido el teórico francés a propósito del documental Scott of the Antartic (1911-1912) de Charles Frend. La imagen (visual, acústica) no es nunca su propia garantía ni ofrece comprobante seguro.

Y en tercer lugar y tal vez más importante, porque existe esa estancia - fundamental en el programa - que no suele haber en ninguna casa en la actualidad - que sí en cambio tienen las iglesias católicas y conventos - que, a partir de mecanismos que evidencian la limitación de la visibilidad total como la extracción del discurso por la confesión, en una suerte de introspección dirigida - propiciada e insistidaabocada a lo no visible. 
El elemento medular que pone en cuestión la condición real de la casa - hiperreal, más real que cualquier otra, donde cobra «alucinante parecido de lo real consigo mismo» (Baudrillard, 2012: 53) — es la mediación, como corresponde a las prácticas contemporáneas de interacción donde medie una pantalla. La particularidad de esta casa es que se ha construido no tanto para vivir como para ser vista - a través, eso sí, de la televisión, es decir, de la pantalla al igual que su referente literario-. De ahí que el programa resulte enteramente consonante con una sociedad obsesionada con la transparencia y lo que supone - la eliminación de cualquier traza de negatividad-, aunque en los inquilinos temporales procuren exaltarse las conductas que están a las antípodas y se hayan dado casos de expulsión.

De todas formas, la casa y el concepto de intimidad — propio de la modernidad- conducen a la supresión simple de la humanidad y al paroxismo de la subjetividad: concebida plenamente como independiente, compuesta por mitos e ilusiones del individuo que potencian los mass media. No en vano el ganador es quien se impone ante los demás y queda solo en la casa, la cual pierde el sentido de albergue y protección inicial para ser espacio interminable de confrontaciones y acercamientos, propiciados a partir de la tensión de las circunstancias materiales. En ese momento, el espectáculo ha terminado.

Como simulación, la casa duplica el referente y al en este proceso de conversión en hiperreal paradójicamente conduce a un alejamiento de la realidad. Lo que pretende es convencer al espectador de que en condiciones tan atípicas, tan irregulares de convivencia, cualquiera puede hacer vida cotidiana rodeado de micrófonos y cámaras en esa infraestructura como si estuviera en su propio domicilio. Junto con la mediación, el distanciamiento de la casa con la realidad se evidencia en recursos logísticos de la construcción que se complementan entre sí, como la voz acusmática o el confesionario, que constituye la mayor diferencia con respecto al concepto consensuado de casa. Destaca ese pequeño recinto es ante todo un lugar de reproducción de placer y de discurso, porque se sigue partiendo de ese estadio anterior del signo que refiere a la teleología de la verdad y el secreto. Pero no se basta con eso: en tanto "Gran hermano» involucra o más bien parte de la visualidad, no deja de remitir al estadio de la simulación, como signo que ha perdido su referente, porque la vida que alberga y que se propone tan idílica nunca ha existido como tal ni llegará a existir, aunque así se pretenda. En eso consiste su auténtica naturaleza.

\section{Referencias bibliográficas}

Álvarez, I. (2012). La cruz de cámaras de Gran hermano: las arterias del reality, 20 minutos, Recuperado de http://www.20minutos.es/noticia/1307406/0/gran-hermano/cruzde-camaras/casa-secretos//\#xtor=AD-15\&xts $=467263$ 
Ariès, P. (1962). Centuries of Childhood. Nueva York: Knopf.

Bachelard, G. (2000). La poética del espacio. Argentina: Fondo de Cultura Económica.

Baudrillard, J. (2012). Cultura y simulacro. Barcelona: Kairós.

- (2014). El sistema de los objetos. México: Siglo XXI.

Bazin, A. (1990). ¿Qué es el cine?. Madrid: Rialp.

Centro de Cultura Contemporánea de Barcelona (CCCB) (2016). $1.000 \mathrm{~m}^{2}$ de deseo. Arquitectura y sexualidad. Barcelona: Centro de Cultura Contemporánea de Barcelona y Gabinete de prensa y comunicación de la Diputación de Barcelona.

Chion, M. (1993). La audiovisión: introducción a un análisis conjunto de la imagen y el sonido. Barcelona: Paidós.

Echeverría, J. (1999). Cosmopolitas domésticos. Barcelona: Anagrama.

Eco, U. (1999). La estrategia de la ilusión. Barcelona: Lumen.

Fanés, F. (1985). Història de l'ull: de Redon a Duchamp, Saber, (2), 24-33.

Foucault, M. (1989). Historia de la sexualidad. 1. La voluntad de saber. México: Siglo XXI.

Galmés Cerezo, A. (2014). Morar. Arte y experiencia de la condición doméstica. Madrid: Ediciones Asimétricas.

González Requena, J. y Martín Arias, L. (1994). El texto televisivo, Signos. Teoría y práctica de la educación, 12, 4-13.

Han, B-C. (2016). La sociedad de la transparencia. Barcelona: Herder, 2016.

Imbert, G. (1999). La hipervisibilidad televisiva: nuevos imaginarios/nuevos rituales comunicativos, Textos de las I Jornadas sobre televisión. Recuperado de https://www.um.es/tic/ LECTURAS\%20FCI-II/FCI-II\%20tema2textocomplementario2.pdf

- (2003). El zoo visual. De la televisión espectacular a la televisión especular. Barcelona: Gedisa.

Lacalle, C. (2001). El espectador televisivo. Los programas de entretenimiento. Barcelona: Gedisa.

Langer, J. (2000). La televisión sensacionalista. Barcelona: Paidós.

Martín Prada, J. (2018). El ver y las imágenes en el tiempo de internet. Madrid: Akal.

Menéndez Menéndez, I. (2002). La vida en directo o la falacia de Gran Hermano: la representación dramática en el post-reality televisivo. Signa Revista de la Asociación Española de Semiótica, 11, 229-238.

Morris, D. (1995). El animal humano (The Human Animal). Reino Unido: BBC.

Ordóñez Díaz, L. (2005). La realidad simulada. Una crítica del reality show. Análisis político, $54,49-62$.

Perales Bazo, F. (2011). La realidad mediatizada: el reality show. Comunicación, 9, 1, 120131.

Prado, E. et al. (1999). El fenómeno Infoshow: la realidad está ahí fuera, área 5inco, Revista de Comunicación Audiovisual y Publicitaria, (6), 197-210.

Sanabria, C. (2011). Contemplación de lo íntimo. Madrid: Biblioteca Nueva.

Simmel, G. (1986). Sociología 1. Estudio sobre las formas de socialización. Madrid: Alianza. 
Robertson Wojcik, P. (2010). The Apartment Plot. Durham \& London: Duke University Press.

Rybczynski, W. (2009). La casa. Historia de una idea. Donostia: Nerea.

Zeledón Cambronero, M. (1994). Semiótica y vida cotidiana. San José, Costa Rica: Alma máter. 


\section{Series de televisión y percepción de prejuicios acerca de la figura del inmigrante. Un estudio con universitarios}

Immigranteei buruzko telebista saioak eta aurreiritzien pertzepzioa. Ikerketa unibertsitateko ikasleekin

T.V. Series and perception of prejudices towards the figure of the immigrant. A study with university students

Martin Yael Santana Mejía`, Juan Ignacio Martínez de Morentin, Concepción Medrano Samaniego

$\mathrm{UPV} / \mathrm{EHU}$

RESUMEN: La presente investigación analiza prejuicios en personajes inmigrantes que perciben jóvenes universitarios en las series que ven. Este es un estudio preliminar que cuenta con una muestra de 70 alumnos en los grados de educación infantil y comunicación audiovisual. Para ello se ha utilizado el cuestionario de percepción de prejuicios de la diversidad cultural en series de tv creado "ad hoc» para este estudio. Se han hallado datos significativos sobre prejuicios percibidos en función a la titulación del alumnado, formato de la serie y el origen de producción. En vista de los datos encontrados podemos decir que los prejuicios percibidos varían según características de las series y del espectador.

PALABRAS CLAVE: Series de televisión; Prejuicios; Inmigrante; Formato; Producción.

LABURPENA: Ikerketa honek unibertsitateko gazteek ikusten dituzten telebista saioetan immigranteen inguruan antzematen dituzten aurreiritziak aztertzen ditu. Aurretiko ikerketa da, Haur Hezkuntza eta Ikus-entzunezko Komunikazioa graduetako 70 ikasleren laginak biltzen dituena. Horretarako, ikerketa honetarako ad hoc sortu den galdetegia erabili da, zehazki, hainbat telebista saiotako kultur aniztasunaren aurreiritzien pertzepzioari buruzko galdetegia. Oso datu esanguratsuak lortu dira antzemandako aurreiritziei buruz, ikasleen titulazioaren arabera, saioaren formatuaren arabera eta ekoizpenaren jatorriaren arabera. Horiek horrela, 
esan dezakegu antzemandako aurreiritziak aldatu egiten direla saioen eta ikus-entzuleen ezaugarrien arabera.

HITZ-GAKOAK: Telebista saioak; aurreiritziak; immigrantea; formatua; ekoizpena.

\begin{abstract}
The present investigation analyzes prejudices towards to immigrant characters that are perceived by university students in the TV series that they watch. This is a preliminary study, which has a sample of 70 students in the grades of early childhood education and audiovisual communication. For this purpose, was used the questionnaire on the perception of cultural diversity prejudices in TV series created "ad hoc». We have found significant data on perceived prejudices based on the students' qualifications, format of the series and the origin of production. Regarding the found data, we had determinate that the perceived prejudices vary according to the characteristics of the series and the viewer.
\end{abstract}

KEYWORDS: T.V. series; Prejudices; Immigrant; Format; Production.

^ Correspondencia a: Martin Yael Santana Mejía. UPV/EHU. Facultad de Psicología, avda. de Tolosa, 70 (20018 San Sebastián).martinyaelsantana@gmail.com http://orcid.org/0000-0003-0766-2747

Cómo citar: Santana Mejía, Martin Yael; Martínez de Morentin, Juan Ignacio; Medrano Samaniego, Concepción. 2018. Series de televisión y percepción de prejuicios acerca de la figura del inmigrante. Un estudio con universitarios. Zer. 23(45). 203-225. https://doi.org/10.1387/zer.20030

Recibido: 3 julio 2018; aceptado: 9 noviembre 2018

1137-1102 y 1989-631X / C 2018 UPV/EHU 


\section{Introducción}

Los medios de comunicación tienen un papel importante en la percepción que posee la juventud sobre la diversidad cultural. En este sentido, uno de los agentes de socialización, junto con la familia y los iguales, que es preciso tener en cuenta de acuerdo a las investigaciones previas, es el contenido televisivo, por ser uno de los más consumidos y al que cada vez se facilita más el acceso a través de diferentes plataformas (López Vidales, González Aldea y Medina de la Viña, 2011). Evidentemente como afirman Martín, Muntada, Gotzens, Cladellas y Descallar (2015) «La televisión es un arma poderosa que ha desplazado, en muchos casos, a la lectura y a otras actividades lúdicas» (p. 28).

De acuerdo al estado del arte, la televisión es capaz de modelar nuestras actitudes e influir en ellas y parece estar haciéndolo de manera constante (Medrano y Palacios 2008; Medrano, Martínez de Morentin y Pindado, 2014). Este medio de comunicación contribuye a la construcción de la imagen social y la percepción que pueda tener una persona sobre el mundo (Gerbner, 1996; Signorielli, Morgan, Gross y Gerbner, 1996). Esta percepción colectiva que se crea con lo que se transmite a través de la ficción televisiva entre otras variables puede forjar las actitudes de toda una generación (Montero, 2005).

En este contexto, de acuerdo a distintas investigaciones la juventud consume y exige más ficción en la programación televisiva (López Vidales, Medina de la Viña y González Aldea, 2013). Así mismo, existe evidencia empírica respecto a que, aproximadamente, la mitad de los jóvenes que perciben la inmigración en contenidos televisivos lo hace en series de televisión, y en éste y los demás medios el exogrupo es relacionado con temas contraproducentes para la sociedad (Prats, De Régil, Lobarte, Higueras y Santamaría 2005).

De acuerdo con Bermejo y Núñez (2008) y Moreno y Rodríguez (2016) las series de televisión son los contenidos que mayor consumo presentan, por ello es importante estudiar los prejuicios que perciben los jóvenes espectadores de los inmigrantes en dichos contenidos, dado que los mismos pueden estar influyendo en las actitudes o prejuicios acerca de la inmigración que los jóvenes puedan desarrollar a lo largo de su vida. Si bien es cierto que los medios tienen mucha influencia en el ámbito social, éstos no deciden por las personas, pero sí pueden manejar los temas a los que tienen acceso las personas en su diario vivir (Díaz, 2004). 


\section{Marco teórico}

\subsection{TeleVisión Y PERCEPCiÓN DE PREJUiCIOS EN LA INMIGRACIÓN}

El prejuicio es una concepción que puede ser negativa o positiva hacia una persona por pertenecer a un determinado grupo, basándose o no en alguna experiencia previa (Allport, Malfé y Verón, 1968; Igartua y Frutos, 2016). No obstante, en la actualidad, cuando nos referimos a prejuicios se señala una concepción negativa, y estas actitudes en los medios de comunicación están consideradas como una forma de racismo (Van Dijk, 2005).

Gran parte de la investigación disponible acerca de la figura del inmigrante en los medios está centrada en la prensa. De acuerdo con Gálvez (2009) en la prensa el tema de la inmigración se presenta de forma negativa. Esto es consecuencia de la forma sesgada en la que se presentan las diferentes etnias en las noticias (Igartua, 2013). Por otro lado, Giró y Jarque (2006) explica que la prensa escrita enfoca sus noticias para fomentar la integración de la inmigración, sin embargo la mayor parte de los editoriales plantean controlar la inmigración lo que le hace ver como un fenómeno «peligroso». En esta línea Galán (2006) llegó a la conclusión que este tratamiento de la prensa es muy rico en recursos dramáticos, y estos recursos son los que utilizan los guionistas para la creación de personajes de ficción televisiva; de forma que, el prejuicio que se percibe tanto en la ficción televisiva como en la prensa sigue una misma tendencia. Una revisión reciente de Eberl et. al (2018) sobre el tema indica que:

A pesar de que es más probable que la audiencia esté más expuesta a contenidos de entretenimiento, series o películas, que a noticias en los medios. Ignoramos el discurso social del entretenimiento sobre la inmigración y los grupos de inmigrantes, descuidamos una parte de la realidad de los medios, que una gran parte del público europeo usa exclusivamente (p. 128).

Hay que destacar el hecho de que Estados Unidos es uno de los países donde empiezan a tomarse en cuenta las minorías respecto a la ficción, ya sea en cine o televisión, debido a que fueron pioneros en cuanto a la producción de contenidos audiovisuales, lo que logra que las representaciones raciales en su ficción formen parte de la creación de su identidad social (Lacalle, 2008). En este contexto se han realizado investigaciones respecto al tema de gran relevancia, las cuales han arrojado resultados similares a través del tiempo, entre los que se destacan la infrarrepresentación de la inmigración en las series, los estereotipos negativos en los personajes inmigrantes, caracterizados por empleos bajos, roles de poca importancia, bajo nivel educativo, violencia y diferentes aspectos enmarcados como prejuicios (Harwood y Anderson 2002; Mastro y Greenberg, 2000; Mastro y Behm-Morawitz 2005; Monk-Turner, Heiserman, Johnson, Cotton y Jackson 2010). 
Ramos (2014) analizó el contenido de ficción televisiva en la franja prime time en el cual se halló una imagen del inmigrante sesgada y negativamente estereotipada, donde la mayoría desempeña roles de villanos y en general son personajes violentos El fenómeno también se ha estudiado en la última década desde el enfoque del framing y el análisis de discurso, que son técnicas diferentes a las utilizadas por los autores citados anteriormente. Aunque los resultados son similares encontrando una imagen del inmigrante negativa y estereotipada (Adams 2018; Arellano, 2017).

En efecto, la imagen que se transmite en los mass media acerca del exogrupo trae consigo diferentes prejuicios incluyendo colocarlos como villanos/antagonistas (Ramos, Igartua, Frutos, Barrios, Mohedano y Naval, 2014). Asimismo, esta imagen va acompañada de un discurso social que continuamente se ve reforzado de manera explícita en programas televisivos, series de televisión y películas (Benavides y Retis, 2005; Galán, 2009; Van Dijk, 2007). Lacalle (2008) en su estudio halló que dentro de algunas características generales de 30 series que estudió, los personajes inmigrantes están mejor representados en las series dramáticas que en las comedias. Asimismo también se les asocia con estatus de ilegalidad y tener ocupaciones de bajo nivel. El 80\% de personajes inmigrantes analizados están representados como víctimas en la trama, víctimas de personajes españoles a nivel de explotación y/o violencia.

También, algunos autores señalan que existen series de producción española que contienen prejuicios en personajes inmigrantes, donde, habitualmente, se les muestra como embaucadores, seductores y extrovertidos igualmente aparecen en roles sin importancia y siendo marginados ligados a tramas violentas (Galán, 2006; 2009; Igartua, Barrios y Ortega, 2012; Ruiz, Ferrer, Obradors, Pujadas, y Pérez, 2007). Además, cuando se trata de diversidad cultural en series de televisión o ficción televisiva los inmigrantes tienen cierta tendencia a ser antagonistas/villanos (Igartua, Marcos, Alvidrez y Piñeiro 2013). Cabe señalar que lo que perciben los espectadores en las series de ficción provoca cambios en las actitudes de estos, este componente de la influencia que ejercen los contenidos sobre los individuos es conocido como persuasión narrativa, el cual es bastante novedoso y no poseemos, a penas, investigaciones en este ámbito. (Igartua, 2007). En los cambios de actitud que describe la persuasión narrativa se indica la existencia de una amplia incidencia de la identificación con los personajes entre otros procesos mediadores (Cohen, 2001; Igartua, 2008; Igartua y Páez, 1998; Moyer-Gusé, 2008). Está demostrado que el público se identifica con mayor facilidad con un personaje de su nacionalidad o grupo social (Cohen, 2001; Ugalde, Medrano y Aierbe 2012). Estos cambios de actitud propiciados por la persuasión narrativa han sido evidenciados en estudios realizados en Estados Unidos, en función de cómo se representa la diversidad cultural en la ficción (Muñiz, Serrano, Aguilera y Rodríguez, 2013). 


\subsection{Formatos televisivos}

Las series de televisión poseen una taxonomía referida a su clasificación. Por lo tanto, la ficción televisiva como género abarca lo que es una miniserie, una serie y un telefilme. Dentro de las categorías, anteriormente, mencionadas hay que destacar los dramas y las comedias con sus respectivos formatos que funcionan como subcategorías (Soap opera, telenovela, drama, sitcom, dramedy, etc.) en los cuales se clasifican estos contenidos (Carrasco, 2010).

De acuerdo a los datos hallados en la investigación previa, los géneros y formatos televisivos tienen influencia en lo que el espectador pueda percibir respecto a la diversidad cultural (Hoekstra, Stos, Swendson y Hoekstra, 2012). Atendiendo a estas consideraciones existen estudios que establecen que en las series dramáticas tienen múltiples prejuicios hacia una determinada minoría, a pesar de que están buscan tener una visión más realista (Galán, 2006). En efecto, esta línea de crear ficción realista dentro del formato drama es una fórmula que le da a la ficción televisiva historias con situaciones y tramas creíbles y, al mismo tiempo, con valores y tendencias sociales de actualidad, de ahí que el público pueda entrar contacto con éstas y percibir diferentes prejuicios (Castro, 2002).

Cabe destacar que las series de comedia no provocan respuestas reflexivas sino más bien de disfrute, esto no genera mucha empatía hacia los personajes que formen parte de alguna trama. En cambio, la ficción que contiene drama puede provocar otro tipo de efecto en los espectadores que la prefieren ya que éstos buscan contemplar verosimilitud en lo que eligen para entretenerse con la necesidad de auto-reflexión (Oliver y Raney, 2011).

En esta línea y, teniendo en cuenta la revisión del estado del arte, esta investigación aborda como objeto de estudio la percepción de prejuicios hacia la inmigración en series de televisión en función del formato televisivo que prefieren los estudiantes universitarios, al igual que el origen de producción de la serie. Igartua y Frutos (2016) sugieren que en el futuro deben existir más investigaciones donde se aborde este tópico, y de esta forma contrastar si los formatos narrativos que ofrece el entretenimiento mediático estimulan en mayor o menor medida la reflexión en el espectador. Asimismo se toma en cuenta en la investigación de Lacalle (2008) que los inmigrantes están mejor representados en los dramas que en las comedias.

\subsection{INVESTIGACIONES CON UNIVERSITARIOS}

A pesar de que la investigación académica sobre la televisión es bastante extensa, las investigaciones con alumnado universitario son bastante escasas (Martínez-Serrano, 
2014), y cabe señalar que la mayoría de estas investigaciones con minorías están basadas en los medios de comunicación de corte noticioso (Ramos, 2014), y en su mayor parte están enfocadas en la percepción negativa que se transmite del exogrupo (Park, 2012).

Existen estudios actuales acerca de series de televisión y la diversidad cultural enfocados desde la educación-entretenimiento para propiciar cambios positivos en la percepción de prejuicios hacia el exogrupo. Así Müller (2009) halló datos que demuestran que el contacto de individuos de culturas diferentes puede fomentarse a través de las series de TV. En esta línea, Igartua y Ramos (2013) plantearon una intervención en estudiantes universitarios con largometrajes para favorecer las actitudes hacia los inmigrantes. En cuanto a consumo de ficción de estudiantes universitarios Martínez-Serrano (2014) halló que la mayor parte del tiempo que los estudiantes dedican a esta actividad, éstos consumen series locales en primer lugar y, en segundo lugar, series extranjeras. En el trabajo que se presenta se trata de analizar qué tipo de prejuicio perciben los sujetos dependiendo del origen de producción (local o extranjera) de la serie.

Igartua y Frutos (2016) en un trabajo con estudiantes universitarios afirman que «es más efectiva una estrategia basada en fomentar la empatía hacia los inmigrantes que mostrar, con un tono desenfadado o cómico, situaciones de contacto íntimo de carácter intergrupal» (p. 57). Por lo que la presente investigación, se propone analizar los formatos de las series y los prejuicios verificando qué prejuicios pueden ser percibidos si es comedia o drama.

En otros estudios de diferentes modalidades realizados también con alumnado universitario se ha establecido un incremento de la matriculación en las profesiones que aparecen en series de ficción, poniendo en evidencia la influencia que tiene la ficción en las actitudes e intereses de los jóvenes (Montero, 2006).

En definitiva, la investigación previa sobre la inmigración en la ficción que consumen los jóvenes tiene aportes significativos; asimismo, genera investigación para crear y concienciar a la juventud y lograr que tengan una mejor competencia mediática. Una competencia necesaria, en la actualidad, ya que vivimos en una sociedad multipantalla.

\section{Objetivos}

El principal objetivo de esta investigación es conocer los prejuicios hacia el inmigrante que percibe el alumnado universitario en las series de televisión que más le gustan. A partir de un objetivo general, y los objetivos específicos que son los siguientes: 
1. Conocer la percepción de algunas variables conceptualizadas como prejuicios en el personaje inmigrante que son: rol narrativo, violencia como agresor, violencia como víctima, hábitos nocivos y temas de conversación. En las series de tv favoritas elegidas por la muestra en función de:

1.1. El tipo de titulación del alumnado de primer año de: Educación infantil y Comunicación audiovisual.

1.2. El formato de la serie.

1.3. El origen de producción de la serie.

\section{Método}

Se trata de un estudio piloto con un diseño descriptivo, puesto que éste es el diseño que se ajusta a las necesidades de esta investigación. No se manipulan las variables.

\subsection{Muestras}

La muestra para este estudio es de conveniencia y se recolectaron datos de 70 (58 chicas y 12 chicos) estudiantes de la Universidad del País Vasco de dos carreras universitarias que son: Comunicación y Educación infantil, y con el fin de establecer comparaciones en estas dos áreas de las ciencias sociales. Ya que el alumnado de comunicación puede tener una perspectiva diferente sobre los personajes inmigrantes en las series que los alumnos de magisterio.

\subsection{INSTRUMENTOS}

El instrumento utilizado para este estudio es el Cuestionario de Percepción de prejuicios de la diversidad cultural en series de tv (PPDC-STV), creado, "ad hoc» para los fines de esta investigación. Los ítems de este cuestionario se han elaborado partiendo de los códigos del análisis de contenido utilizados por Igartua, Barrios y Ortega (2012) en su estudio "Analysis of the Image of Immigration in Prime Time Televisión Fiction» en el cual se encontraron indicadores de cómo se muestra la diversidad cultural en la series de tv en la actualidad. Se llevó a cabo un análisis de fiabilidad mediante el coeficiente de acuerdo observado (OA) y Pi de Scott para variables cualitativas. Con una media de 55 variables consideradas el $\mathrm{OA}=0,86$, y $\pi=0,75$ unos valores muy aceptables.

El cuestionario cuenta con 9 dimensiones las cuales pretenden medir lo que percibe la muestra acerca de los personajes inmigrantes en diferentes aspectos sociales 
que involucran prejuicios y con la frecuencia que el espectador los recibe dentro de la ficción televisiva. Estas dimensiones son:

—Dimensión rol Narrativo (Ítem 1).

-Dimensión educativa del personaje (Ítem 2).

—Dimensión laboral del personaje (Ítem 3).

-Dimensión económica del personaje (Ítem 4).

—Dimensión de aspectos de violencia del personaje (Ítem 5 y 6).

—Dimensión de hábitos nocivos del personaje (Ítem 7).

—Dimensión conversacional de personaje (Ítem 8).

—Dimensión de cualidad personal del personaje (Ítem 9).

Para este trabajo se han utilizado únicamente 4 dimensiones debido a su amplitud y son: rol narrativo, la violencia del personaje, hábitos nocivos y dimensión conversacional del personaje.

El análisis de fiabilidad fue realizado en las dimensiones que fueron tomadas en cuenta para su utilización y creación en el instrumento son: la dimensión de aspectos de violencia con un alpha de .758 , dimensión de hábitos nocivos con un alpha .822 de y dimensión conversacional del personaje con un alpha de .792. Se ha obviado la dimensión de cualidad personal del personaje para esta investigación ya que ésta arrojó una fiabilidad -.089 debido al planteamiento utilizado con el ítem y sus opciones de respuesta.

Los ítems de este cuestionario son de tipo Likert con opciones de respuestas múltiples según requiere el carácter del ítem. Fue elaborado y utilizado en versión digital con la finalidad de optimizar su cumplimentación y recogida así como el manejo de los datos.

\subsection{Procedimiento}

Se contactaron profesores del área de educación y comunicación en la Universidad del País Vasco para verificar la disponibilidad de sus alumnos en la participación de este estudio piloto. Previamente a la prueba se les explico que no era obligatoria. Una vez aprobada la solicitud por los profesores responsables se acordaron fechas y horarios de recogida.

Esta investigación fue aprobada por el comité de Ética de la UPV/EHU, para la recogida de datos con seres humanos, dentro de la línea de investigación «Valores, socialización y medios de comunicación». Se ha salvaguardado la identidad y la integridad psicológica de los participantes, y por confidencialidad, no constará en los cuestionarios la identidad de los sujetos. 
Una vez en el aula, se procedió a explicar oralmente la forma correcta de la cumplimentación del instrumento y se aplicaron los cuestionarios PPDC-STV, donde las y los sujetos suministrarán los datos sobre sus series de TV favorita y el personaje inmigrante que aparezca en esta. El tiempo de cumplimentación del instrumento es de 20-25 minutos.

\section{Resultados}

A continuación se muestran los resultados obtenidos según los objetivos trazados de este estudio.

Objetivo 1.1: Conocer la percepción de algunas variables conceptualizadas como prejuicios como son el rol narrativo, violencia como agresor, violencia como víctima, hábitos nocivos y temas de conversación en el personaje inmigrante. En función de la titulación en el alumnado de primer año de: Educación infantil y Comunicación audiovisual

La tabla 1 muestra las diferencias significativas entre ambos grupos respecto al rol de secundario no protagónico del personaje inmigrante. Los estudiantes de comunicación percibieron más al personaje inmigrante en el rol secundario no protagónico que los de educación infantil.

\section{TABLA 1}

Rol narrativo en función de la titulación del alumnado

\begin{tabular}{|l|l|c|c|c|c|c|}
\hline \multicolumn{1}{|c|}{ Variable } & \multicolumn{1}{|c|}{ Grados } & N & Media & DT & t & p \\
\hline \multirow{2}{*}{ Rol Protagonista } & Educ. infantil & 35 & 2.80 & 1.30 & \multirow{2}{*}{1.42} & \multirow{2}{*}{1.00} \\
& Comunicación & 35 & 2.80 & 1.10 & & \\
\hline \multirow{2}{*}{ Rol Antagonista } & Educ. infantil & 35 & 2.26 & 1.14 & \multirow{2}{*}{.458} & .514 \\
& Comunicación & 35 & 2.09 & 1.04 & & \\
\hline \multirow{2}{*}{ Rol Secundario protagónico } & Educ. infantil & 35 & 3.37 & 1.06 & \multirow{2}{*}{.173} & \multirow{2}{*}{.832} \\
& Comunicación & 35 & 3.31 & 1.18 & & \\
\hline \multirow{2}{*}{ Rol secundario no protagónico } & Educ. infantil & 35 & 2.09 & 1.09 & \multirow{2}{*}{.149} & \multirow{2}{*}{.016} \\
& Comunicación & 35 & 2.69 & 1.13 & & \\
\hline
\end{tabular}

En lo que respecta a las variables violencia como agresor y violencia como víctima percibida del personaje inmigrante por ambos grupos, tomando en cuenta su titulación, no se encontraron diferencias estadísticamente significativas entre ellos. 
En cuanto a la variable de hábitos nocivos se encontraron diferencias significativas de medias, en el hábito nocivo de fumador, esto puede se puede observar en la tabla 2. Lo que indica que el alumnado de comunicación ha percibido más al inmigrante como fumador que el alumnado de educación infantil.

TABLA 2

Hábitos nocivos en función de la titulación del alumnado

\begin{tabular}{|l|l|c|c|c|c|c|}
\hline \multicolumn{1}{|c|}{ Variable } & \multicolumn{1}{|c|}{ Grados } & $\mathrm{N}$ & Media & $\mathrm{DT}$ & $\mathrm{t}$ & $\mathrm{p}$ \\
\hline \multirow{2}{*}{ Fumador } & Educ. infantil & 35 & 1.11 & .471 & \multirow{2}{*}{20.6} & \multirow{2}{*}{.017} \\
& Comunicación & 35 & 1.63 & 1.14 & & \\
\hline \multirow{2}{*}{ Alcoholismo } & Educ. infantil & 35 & 1.54 & .980 & \multirow{2}{*}{.830} & .155 \\
& Comunicación & 35 & 1.91 & 1.17 & & \\
\hline \multirow{2}{*}{ Adicción a Fármacos } & Educ. infantil & 35 & 1.23 & .690 & \multirow{2}{*}{3.28} & -.200 \\
& Comunicación & 35 & 1.43 & 1.00 & & \\
\hline \multirow{2}{*}{ Adicción a sustancias ilegales } & Educ. infantil & 35 & 1.14 & .430 & \multirow{2}{*}{9.22} & -.286 \\
& Comunicación & 35 & 1.43 & 1.09 & & \\
\hline
\end{tabular}

Respecto a los temas de conversación recurrentes del personaje inmigrante que percibió la muestra, no se encontraron diferencias estadísticamente significativas entre el alumnado de las dos titulaciones diferentes.

Objetivo 1.2: Conocer la percepción de algunas variables conceptualizadas como prejuicios como son el rol narrativo, violencia como agresor, violencia como víctima, hábitos nocivos y temas de conversación en el personaje inmigrante de las series de tv favoritas, en función del formato de la serie.

Se realizaron pruebas $\mathrm{t}$ de student para evaluar si las medias tienen diferencias estadísticamente significativas respecto al formato de las series que prefiere la muestra.

En el caso de la variable de rol narrativo del personaje inmigrante, la prueba t muestra que se encontraron diferencias significativas en dos de los roles de esta variable como se observa en la tabla 3. Por lo que los roles de protagonista y de antagonista fueron más percibidos en los dramas que en las comedias. 
TABLA 3

Rol narrativo percibido en función del formato de la serie

\begin{tabular}{|c|c|c|c|c|c|c|}
\hline Variable & Formato & $\mathrm{N}$ & Media & DT & $\mathrm{t}$ & $\mathrm{p}$ \\
\hline Rol Protagonista & $\begin{array}{l}\text { Drama } \\
\text { Comedia }\end{array}$ & $\begin{array}{l}31 \\
39\end{array}$ & $\begin{array}{l}3.23 \\
2.46\end{array}$ & $\begin{array}{l}1.23 \\
1.07\end{array}$ & 2.77 & .007 \\
\hline Rol Antagonista & $\begin{array}{l}\text { Drama } \\
\text { Comedia }\end{array}$ & $\begin{array}{l}31 \\
39\end{array}$ & $\begin{array}{l}2.55 \\
1.87\end{array}$ & $\begin{array}{l}1.15 \\
.951\end{array}$ & 2.69 & .009 \\
\hline Rol Secundario protagónico & $\begin{array}{l}\text { Drama } \\
\text { Comedia }\end{array}$ & $\begin{array}{l}31 \\
39\end{array}$ & $\begin{array}{l}3.52 \\
3.21\end{array}$ & $\begin{array}{l}1.02 \\
1.17\end{array}$ & 1.16 & .249 \\
\hline Rol Secundario no protagónico & $\begin{array}{l}\text { Drama } \\
\text { Comedia }\end{array}$ & $\begin{array}{l}31 \\
39\end{array}$ & $\begin{array}{l}2.19 \\
2.49\end{array}$ & $\begin{array}{l}1.19 \\
1.12\end{array}$ & -1.05 & .294 \\
\hline
\end{tabular}

En el caso de la variable de violencia percibiendo al personaje inmigrante como agresor en función del formato de la serie (drama-comedia), se encontraron diferencias significativas en todas medias así como de los tipos de violencia exceptuado la violencia sexual; como se observa en la tabla 4. De acuerdo a los resultados obtenidos se puede decir que en el caso del formato drama la muestra percibió en el personaje inmigrante que éste utiliza más la violencia física, la intimidación, el daño a la propiedad y la violencia verbal.

TABLA 4

Violencia como agresor percibida en función del formato de la serie

\begin{tabular}{|c|c|c|c|c|c|c|}
\hline Variable & Formato & $\mathbf{N}$ & Media & DT & $\mathrm{t}$ & $\mathrm{p}$ \\
\hline Violencia física/agresor & $\begin{array}{l}\text { Drama } \\
\text { Comedia }\end{array}$ & $\begin{array}{l}31 \\
39\end{array}$ & $\begin{array}{l}2.84 \\
1.33\end{array}$ & $\begin{array}{l}1.18 \\
.701\end{array}$ & 6.61 & .000 \\
\hline Intimidación/agresor & $\begin{array}{l}\text { Drama } \\
\text { Comedia }\end{array}$ & $\begin{array}{l}31 \\
39\end{array}$ & $\begin{array}{l}3.13 \\
1.49\end{array}$ & $\begin{array}{l}1.28 \\
.854\end{array}$ & 6.40 & .000 \\
\hline Daño a la propiedad/agresor & $\begin{array}{l}\text { Drama } \\
\text { Comedia }\end{array}$ & $\begin{array}{l}31 \\
39\end{array}$ & $\begin{array}{l}2.29 \\
1.21\end{array}$ & $\begin{array}{l}1.10 \\
.570\end{array}$ & 5.32 & .000 \\
\hline Violencia verbal/agresor & $\begin{array}{l}\text { Drama } \\
\text { Comedia }\end{array}$ & $\begin{array}{l}31 \\
39\end{array}$ & $\begin{array}{l}2.90 \\
1.49\end{array}$ & $\begin{array}{l}1.27 \\
.914\end{array}$ & 5.41 & .000 \\
\hline Violencia sexual/agresor & $\begin{array}{l}\text { Drama } \\
\text { Comedia }\end{array}$ & $\begin{array}{l}31 \\
39\end{array}$ & $\begin{array}{l}1.55 \\
1.10\end{array}$ & $\begin{array}{l}1.20 \\
.502\end{array}$ & 2.09 & .061 \\
\hline
\end{tabular}

Se encontraron diferencias significativas en la variable violencia percibiendo al personaje inmigrante como víctima en el ítem de violencia fisica, dichas diferen- 
cias se pueden observar en la tabla 5. Es decir, en el formato drama se percibe más al personaje inmigrante como víctima de violencia física que como al resto de violencias como víctima.

TABLA 5

Violencia como víctima percibida en función del formato

\begin{tabular}{|l|l|c|c|c|c|c|}
\hline \multicolumn{1}{|c|}{ Variable } & \multicolumn{1}{|c|}{ Formato } & $\mathrm{N}$ & Media & $\mathrm{DT}$ & $\mathrm{t}$ & $\mathrm{p}$ \\
\hline \multirow{2}{*}{ Violencia fisica/víctima } & Drama & 31 & 2.52 & 1.02 & \multirow{2}{*}{2.67} & \multirow{2}{*}{.009} \\
& Comedia & 39 & 1.82 & 1.12 & & \\
\hline \multirow{2}{*}{ Intimidación/víctima } & Drama & 31 & 2.71 & .973 & \multirow{2}{*}{.648} & \multirow{2}{*}{.520} \\
\hline \multirow{2}{*}{ Daño a la propiedad/víctima } & Comedia & 39 & 2.51 & 1.55 & & \\
\hline \multirow{2}{*}{ Violencia verbal/víctima } & Drama & 31 & 1.87 & 1.08 & \multirow{2}{*}{.65} & \multirow{2}{*}{.103} \\
& Comedia & 39 & 1.49 & .854 & & \\
\hline \multirow{2}{*}{ Violencia sexual/víctima } & Drama & 31 & 2.74 & 1.12 & \multirow{2}{*}{.289} & .774 \\
& Comedia & 39 & 2.85 & 1.74 & & \\
\hline
\end{tabular}

Respecto a la variable de hábitos nocivos percibidos en el personaje inmigrante no se han encontrado diferencias significativas en las medias de ambos grupos (drama-comedia), esto puede observarse en la tabla 6.

TABLA 6

Percepción de hábitos nocivos en función del formato de la serie

\begin{tabular}{|l|l|c|c|c|c|c|}
\hline \multicolumn{1}{|c|}{ Variable } & \multicolumn{1}{|c|}{ Formato } & N & Media & DT & T & p \\
\hline \multirow{2}{*}{ Fumador } & Drama & 31 & 1.45 & 1.15 & \multirow{2}{*}{.659} & .512 \\
& Comedia & 39 & 1.31 & .655 & & \\
\hline \multirow{2}{*}{ Alcoholismo } & Drama & 31 & 1.81 & 1.19 & .531 & .597 \\
& Comedia & 39 & 1.67 & 1.00 & & \\
\hline \multirow{2}{*}{ Adicción a fármacos } & Drama & 31 & 1.42 & 1.05 & \multirow{2}{*}{.782} & .437 \\
& Comedia & 39 & 1.26 & .677 & & \\
\hline \multirow{2}{*}{ Adicción a sustancias ilegales } & Drama & 31 & 1.48 & 1.15 & \multirow{2}{*}{.179} & .077 \\
& Comedia & 39 & 1.13 & .409 & & \\
\hline
\end{tabular}

De acuerdo con la variable de temas conversación percibidos del personaje inmigrante se encontraron diferencias significativas en el tema de la violencia en el 
caso del formato drama, como se puede ver en la tabla 7 , lo que indica que los que prefieren el drama perciben que el personaje inmigrante habla más de este tema que los que prefieren en la comedia.

También se aprecia en este resultado que en el formato comedia se percibe que el personaje inmigrante utiliza más los temas de conversación recurrentes como el amor, medio ambiente y la inmigración.

TABLA 7

Temas de conversación recurrente en función del formato de la serie

\begin{tabular}{|c|c|c|c|c|c|c|}
\hline Variable & Formato & $\mathbf{N}$ & Media & DT & $\mathrm{t}$ & $\mathbf{P}$ \\
\hline Amor & $\begin{array}{l}\text { Drama } \\
\text { Comedia }\end{array}$ & $\begin{array}{l}31 \\
39\end{array}$ & $\begin{array}{l}2.90 \\
3.46\end{array}$ & $\begin{array}{l}1.24 \\
1.02\end{array}$ & -2.05 & .043 \\
\hline Violencia & $\begin{array}{l}\text { Drama } \\
\text { Comedia }\end{array}$ & $\begin{array}{l}31 \\
39\end{array}$ & $\begin{array}{l}3.23 \\
1.82\end{array}$ & $\begin{array}{l}1.05 \\
1.04\end{array}$ & 5.55 & .000 \\
\hline Medio ambiente & $\begin{array}{l}\text { Drama } \\
\text { Comedia }\end{array}$ & $\begin{array}{l}31 \\
39\end{array}$ & $\begin{array}{l}1.19 \\
1.69\end{array}$ & $\begin{array}{l}.477 \\
.922\end{array}$ & -2.73 & .008 \\
\hline Inmigración & $\begin{array}{l}\text { Drama } \\
\text { Comedia }\end{array}$ & $\begin{array}{l}31 \\
39\end{array}$ & $\begin{array}{l}2.26 \\
2.97\end{array}$ & $\begin{array}{l}1.41 \\
1.24\end{array}$ & -2.25 & .028 \\
\hline
\end{tabular}

Objetivo 1.3: Conocer la percepción de algunas variables conceptualizadas como prejuicios como son el rol narrativo, violencia como agresor, violencia como víctima, hábitos nocivos y temas de conversación en el personaje en el personaje inmigrante de las series de tv favoritas en función del origen de producción de la serie.

Según el origen de producción de las series se encontró que la mayor parte de la muestra $(55 \%)$ prefiere series de producción extranjera mientras que el resto $(45 \%)$ prefiere series de producción local.

Se realizaron pruebas $\mathrm{t}$ de student para verificar si las medias diferían respecto al origen de producción de las series preferidas por la muestra.

En el caso de la variable de rol narrativo del personaje inmigrante, en la prueba t se observan diferencias significativas en los roles de; protagonista y secundario protagónico. A diferencia de los roles antagonista, secundario no protagónico donde no hubo diferencias significativas en las medias como se puede ver en la tabla 8. Lo que indica que en las series de producción extranjera el personaje inmigrante fue percibido como protagonista y secundario protagónico. 


\section{TABLA 8}

Rol narrativo percibido en función del origen de producción de la serie

\begin{tabular}{|c|c|c|c|c|c|c|}
\hline Variable & Producción & $\mathrm{N}$ & Media & DT & $\mathrm{t}$ & $\mathrm{p}$ \\
\hline Rol Protagonista & $\begin{array}{l}\text { Local } \\
\text { Extranjera }\end{array}$ & $\begin{array}{l}32 \\
38\end{array}$ & $\begin{array}{l}2.44 \\
3.11\end{array}$ & $\begin{array}{l}1.29 \\
1.03\end{array}$ & -2.40 & .022 \\
\hline Rol Antagonista & $\begin{array}{l}\text { Local } \\
\text { Extranjera }\end{array}$ & $\begin{array}{l}32 \\
38\end{array}$ & $\begin{array}{l}2.34 \\
2.03\end{array}$ & $\begin{array}{l}1.23 \\
.944\end{array}$ & 1.12 & .239 \\
\hline Rol Secundario protagónico & $\begin{array}{l}\text { Local } \\
\text { Extranjera }\end{array}$ & $\begin{array}{l}32 \\
38\end{array}$ & $\begin{array}{l}3.00 \\
3.63\end{array}$ & $\begin{array}{l}1.01 \\
1.12\end{array}$ & -2.44 & .017 \\
\hline Rol Secundario no protagónico & $\begin{array}{l}\text { Local } \\
\text { Extranjera }\end{array}$ & $\begin{array}{l}32 \\
38\end{array}$ & $\begin{array}{l}2.47 \\
2.26\end{array}$ & $\begin{array}{l}1.16 \\
1.15\end{array}$ & .739 & .462 \\
\hline
\end{tabular}

En el caso de la variable de violencia, percibiendo al personaje inmigrante como agresor se hallaron diferencias significativas en el apartado de violencia fisica e intimidación como se puede ver en la tabla 9. Lo que indica que en las series extranjeras la muestra percibe que el personaje inmigrante hace más utilización de la violencia fisica y la intimidación.

TABLA 9

Percepción de violencia como agresor en función al origen de producción de la serie

\begin{tabular}{|c|c|c|c|c|c|c|}
\hline Variable & Producción & $\mathrm{N}$ & Media & DT & $\mathrm{t}$ & $\mathrm{p}$ \\
\hline Violencia física/agresor & $\begin{array}{l}\text { Local } \\
\text { Extranjera }\end{array}$ & $\begin{array}{l}32 \\
38\end{array}$ & $\begin{array}{l}1.53 \\
2.39\end{array}$ & $\begin{array}{l}.983 \\
1.24\end{array}$ & .045 & .002 \\
\hline Intimidación/agresor & $\begin{array}{l}\text { Local } \\
\text { Extranjera }\end{array}$ & $\begin{array}{l}32 \\
38\end{array}$ & $\begin{array}{l}1.81 \\
2.55\end{array}$ & $\begin{array}{l}1.23 \\
1.35\end{array}$ & .561 & .020 \\
\hline Daño a la propiedad/agresor & $\begin{array}{l}\text { Local } \\
\text { Extranjera }\end{array}$ & $\begin{array}{l}32 \\
38\end{array}$ & $\begin{array}{l}1.53 \\
1.82\end{array}$ & $\begin{array}{l}.803 \\
1.13\end{array}$ & .190 & .239 \\
\hline Violencia verbal/agresor & $\begin{array}{l}\text { Local } \\
\text { Extranjera }\end{array}$ & $\begin{array}{l}32 \\
38\end{array}$ & $\begin{array}{l}1.84 \\
2.34\end{array}$ & $\begin{array}{l}1.05 \\
1.43\end{array}$ & .008 & .108 \\
\hline Violencia sexual/agresor & $\begin{array}{l}\text { Local } \\
\text { Extranjera }\end{array}$ & $\begin{array}{l}32 \\
38\end{array}$ & $\begin{array}{l}1.28 \\
1.32\end{array}$ & $\begin{array}{l}.772 \\
1.01\end{array}$ & .171 & .875 \\
\hline
\end{tabular}

En el caso de la variable de la violencia siendo el personaje inmigrante víctima de esta se encontraron diferencias significativas en las medias que se puede ver en la tabla 10. Los datos hallados nos dicen que en las series de producción local el personaje inmigrante se percibe más como víctima de violencia fisica, intimidación y violencia verbal. 
TABLA 10

Percepción de violencia como víctima en función al origen de producción de la serie

\begin{tabular}{|l|l|c|c|c|c|c|}
\hline \multicolumn{1}{|c|}{ Variable } & \multicolumn{1}{|c|}{ Producción } & $\mathrm{N}$ & Media & $\mathrm{DT}$ & $\mathrm{t}$ & $\mathrm{p}$ \\
\hline \multirow{2}{*}{ Violencia física/víctima } & Local & 32 & 2.44 & 1.29 & \multirow{2}{*}{.002} & \multirow{2}{*}{.041} \\
& Extranjera & 38 & 1.87 & .906 & & \\
\hline \multirow{2}{*}{ Intimidación/víctima } & Local & 32 & 3.28 & 1.32 & \multirow{2}{*}{.062} & \multirow{2}{*}{.000} \\
\hline \multirow{2}{*}{ Daño a la propiedad/víctima } & Extranjera & 38 & 2.03 & 1.02 & & \\
& Local & 32 & 1.97 & 1.15 & \multirow{2}{*}{.002} & .013 \\
\hline \multirow{2}{*}{ Violencia verbal/víctima } & Extranjera & 38 & 1.39 & .718 & & \\
& Local & 32 & 3.84 & 1.24 & \multirow{2}{*}{.566} & .000 \\
\hline \multirow{2}{*}{ Violencia sexual/víctima } & Extranjera & 38 & 1.92 & 1.05 & & \\
& Local & 32 & 1.50 & 1.01 & \multirow{2}{*}{.000} & .118 \\
\hline
\end{tabular}

En cuanto a la variable hábitos nocivos se encontraron diferencias significativas en las medias del ítem de alcoholismo a favor de la producción extranjera como se observa en la tabla 11. En los demás apartados que componen esta variable como son fumador, adición a fármacos y adicción a sustancias ilegales no se encontraron diferencias significativas.

TABLA 11

Hábitos nocivos percibidos en función del origen de producción

\begin{tabular}{|l|l|c|c|c|c|c|}
\hline \multicolumn{1}{|c|}{ Variable } & \multicolumn{1}{|c|}{ Producción } & N & Media & DT & T & p \\
\hline \multirow{2}{*}{ Fumador } & Local & 32 & 1.31 & .859 & -.498 & .620 \\
& Extranjera & 38 & 1.42 & .948 & & \\
\hline \multirow{2}{*}{ Alcoholismo } & Local & 32 & 1.34 & .937 & -2.84 & .005 \\
& Extranjera & 38 & 2.05 & 1.14 & & \\
\hline \multirow{2}{*}{ Adicción a fármacos } & Local & 32 & 1.16 & .515 & \multirow{2}{*}{-1.54} & .108 \\
\hline \multirow{2}{*}{ Adicción a sustancias ilegales } & Extranjera & 38 & 1.47 & 1.05 & & \\
& Local & 32 & 1.19 & .471 & \multirow{2}{*}{-.900} & .371 \\
\hline
\end{tabular}

En la variable de temas conversación utilizada por el personaje inmigrante expuesto en la tabla 12, no se encontraron diferencias significativas en los siguientes temas: amor, violencia, sexo, trabajo, medio ambiente, salud, educación, familia, racismo e inmigración. En cambio se encontraron diferencias significativas en temas 
como la amistad, dinero, diferencias sociales y deporte. Por lo que se puede observar según este resultado es que en las series de producción extranjera la muestra percibe que el personaje inmigrante habla más sobre la amistad y deportes que sobre cualquier otro tema. Mientras que en las series local se percibe que hablan más de diferencias sociales y dinero.

TABLA 12

Temas de conversación recurrentes en función al origen de producción

\begin{tabular}{|l|l|c|c|c|c|c|}
\hline \multicolumn{1}{|c|}{ Variable } & \multicolumn{1}{|c|}{ Formato } & N & Media & DT & \multicolumn{1}{c|}{ t } & P \\
\hline \multirow{2}{*}{ Amistad } & Local & 31 & 3.03 & .933 & \multirow{2}{*}{.02} & \multirow{2}{*}{.000} \\
& Extranjera & 39 & 3.92 & .912 & & \\
\hline \multirow{2}{*}{ Dinero } & Local & 31 & 3.28 & 1.19 & \multirow{2}{*}{2.06} & .043 \\
& Extranjera & 39 & 2.68 & 1.21 & & \\
\hline \multirow{2}{*}{ Diferencias sociales } & Local & 31 & 3.22 & 1.33 & \multirow{2}{*}{2.22} & \multirow{2}{*}{.030} \\
& Extranjera & 39 & 2.53 & 1.26 & & \\
\hline \multirow{2}{*}{ Deporte } & Local & 31 & 1.38 & .660 & \multirow{2}{*}{-2.56} & .009 \\
& Extranjera & 39 & 2.03 & 1.30 & & \\
\hline
\end{tabular}

\section{Conclusiones y discusión}

Este estudio piloto es el punto de partida de una investigación más amplia que tiene como finalidad dar respuesta, a cómo perciben los jóvenes al inmigrante en las series de televisión. Cabe agregar que por naturaleza de los resultados y el tamaño de la muestra los datos de este estudio deben tomarse con cautela, ya que éstos no permiten que se pueda generalizar en estas variables. Con una metodología enteramente cuantitativa, se trata de analizar la percepción del sujeto de la muestra acerca de las características del inmigrante en las series de ficción.

El objetivo principal de este trabajo comprende varios objetivos específicos, respecto al primer objetivo, se ha hallado que el alumnado del grado educación infantil tiene una percepción mayor del hábito nocivo de fumar en el personaje inmigrante que el alumnado de comunicación. Asimismo los estudiantes de comunicación perciben al personaje inmigrante más como secundario no protagónico que es el menos importante dentro de una trama. Lo que tiene congruencia con lo hallado por Ruiz et al. (2007) ya que ellos explican que la figura del inmigrante en la ficción aparece de forma esporádica y marginada. Asimismo esto no corresponde con los hallazgos de Harwood y Anderson (2002) donde no se encontraron diferencias significativas respecto al rol de los personajes inmigrantes. Esto confirma que este fenó- 
meno debe continuar siendo estudiado, porque, aunque los estudios previos arrojen conclusiones similares en muchos aspectos difieren entre sí.

Sin embargo, cuando la serie tiene formato de drama la percepción de prejuicios del alumnado universitario es mayor que cuando es comedia. Aun así, este trabajo corrobora en un aspecto y difiere en otro con lo que concluyó Galán (2006). Aquel aspecto que difiere con la autora se refiere a las series dramáticas que ella analizó, donde se encontró a que los inmigrantes son utilizados en roles episódicos y ni siquiera secundarios. Mientras que en este estudio se ha encontrado que en las series dramáticas el personaje inmigrante fue percibido con roles de notoria importancia como protagonistas y antagonistas. Esta diferencia puede darse en cuanto al formato debido al mundo cambiante de la ficción televisiva que se va renovando rápidamente respecto a roles, tramas e inclusión (Bornaetxea, 2015). En este aspecto también es congruente con el trabajo de Lacalle (2008) en el cual la autora explica en su análisis que los inmigrantes tienen una representación positiva en las series dramáticas.

En cuanto a los datos en consonancia con Galán (2006; 2009), que de igual forma congruentes con Van Dijk (2007), se trata de que el personaje inmigrante es percibido más violento como agresor en todos los tipos de violencia excepto en la agresión sexual. En cambio en nuestro estudio solo se percibió al inmigrante como víctima en el caso de la violencia física. Por lo que el personaje ha sido percibido como agresor, y concuerda con que los temas de conversación recurrentes que más se percibe en el personaje inmigrante esté la violencia. De acuerdo con Mastro y Greenberg (2000) en el aspecto de enmarcar al personaje inmigrante en temas relativos a la violencia.

En esta línea Oliver y Raney (2011) especifican en su investigación que las series dramáticas estimulan la reflexión del espectador, pero lo que se refleja en este estudio es lo contrario, debido a que en las comedias el personaje inmigrante es percibido con temas de conversación recurrentes que evocan más a la reflexión como son el amor, el medio ambiente y la inmigración. Mientras que en el drama se reitera la percepción del personaje relacionado con la violencia por lo que el tema de conversación al que más recurre es la violencia como hemos dicho anteriormente.

En cuanto al origen de la producción se observa que los jóvenes de esta muestra prefieren ver series extranjeras en lugar de series locales no siendo congruentes estos datos con lo que establece Martínez-Serrano (2014). En cuanto rol narrativo del personaje, cuando la serie es extranjera se percibió que se le concedía más importancia al personaje inmigrante que en las series de producción local debido a los roles, ya que fueron percibidos como protagonistas y secundarios protagónicos. Esta percepción de los jóvenes en series de ficción de producción extranjera que son más consumidas, no coincide con el estudio de Igartua et al. (2013) y Ramos (2014), donde sitúan al inmigrante con tendencia a aparecer como villano/antagonista en el 
contenido. Aunque el rol de antagonista tiene su importancia dentro de la trama, el protagonista y el secundario protagónico muestran una mejor imagen que este rol y en la mayoría de casos se le da más importancia. Esta diferencia puede indicar un cambio respecto a la producción de las series y el tratamiento de la figura del inmigrante en las mismas, por lo que se podría profundizar en estudios posteriores.

Igualmente cuando la serie es de producción local el personaje inmigrante se percibe más como víctima de violencia siendo marginado como expone Galán (2006), exceptuando la violencia sexual. Mientras que en las series extranjeras fueron percibidos como agresores y no como víctimas. Asimismo, otro aspecto que llama la atención es que en series extranjeras se percibe al inmigrante como alcohólico. Es decir, que tanto en las series locales como extranjeras se percibe una espiral de violencia en torno al personaje inmigrante, acompañado en las producciones extranjeras por el alcoholismo lo que coincide en ciertos aspectos con las investigaciones realizadas por: Galán, (2009), Igartua, Barrios y Ortega, (2012), Mastro y Behm-Morawitz (2005), Ramos, Igartua, Frutos, Barrios, Mohedano y Naval (2014), Ramos (2014) que manifiestan que la figura del inmigrante está construida con prejuicios en las series de TV. Por lo cual, en este estudio los jóvenes han percibido actitudes de prejuicios en el personaje inmigrante en la mayoría de los casos.

Los temas de conversación recurrentes percibidos por la muestra en el personaje inmigrante, en las series locales fueron las diferencias sociales y el dinero, mientras que en las series extranjeras fueron percibidos en los inmigrantes temas como los deportes y la amistad. Se puede deducir que en cada pareja de temas tiene relación entre uno y otro lo que significa que lo que percibieron tiene una misma relación temática. Lo que evidencia que la producción de la serie se adapta al contexto social donde se emite; por lo que las series extranjeras pueden transmitir una realidad diferente respecto al contexto y por ello la realidad en cuanto a la inmigración estaría sesgada la mayor parte de las veces, por el consumo de estas producciones que tendrían prejuicios diferentes según el escenario donde se desarrolle la acción principal.

Es importante, señalar alguna limitación de este trabajo, recogido a través del auto informe, lo que implica la deseabilidad social que pueden tener las personas al momento de la cumplimentación de un cuestionario de esta naturaleza. Este tema puede abordarse de diferentes maneras en un futuro, según la popularidad de las series, así como con los formatos de las mismas, incluso como el enfoque de Adams (2018) y Arellano (2017), con un tipo etnia específica en el mundo de la ficción. También mezclando metodologías y técnicas como el análisis de contenido y los cuestionarios donde se podrían cruzar los datos para enriquecer más la investigación y de esta forma tener más claro el discurso mediático de la ficción televisiva sobre la inmigración en un determinado momento social, lo que ayudaría en la perspectiva de la educación mediática sobre temas como éste de gran relevancia social. 


\section{Agradecimientos}

Este estudio ha sido financiado por la Universidad del País Vasco (UPV/EHU). Referencia GIU 16/44.

\section{Referencias}

Adams, A. (2018). The Case of Rewards and Punishments: Analyzing Televisual Representations of Race and Gender in Two 21st-Century Criminal Drama Series.

Arellano, G. (2017). Latino Representation on Primetime Television in English and Spanish Media: A Framing Analysis.

Allport, G.W., Malfé, R., y Verón, E. (1968): «La naturaleza del prejuicio». Argentina: Eudeba.

Benavides, J.L., y Retis, J. (2005): «Miradas hacia Latinoamérica: La representación discursiva de los inmigrantes latinoamericanos en la prensa española y estadounidense». Palabra Clave, (13), 93-114.

Bermejo, J., y Núñez, M. (2008): «Valores y actitudes de los espectadores de series de ficción televisiva». Presentado en actas de I Congreso De La AE-IC Investigar La Comunicación. Santiago De Compostela, 35-55.

Bornaetxea, A.R. (2015): «Experiencias asociativas y colaborativas de diseño televisual. La televisión como herramienta de inclusión social». Obra Digital: Revista De Comunicación, (9), 12-27.

Carrasco Campos, A., y Universidad Miguel Hernández de Elche. (2010): «Teleseries: Géneros y formatos. Ensayo de definiciones». Miguel Hernández Communication Journal, (1), 174-200.

Cohen, J. (2001): «Defining identification: A theoretical look at the identification of audiences with media characters». Mass Communication \& Society, 4(3), 245-264.

Díaz, R.R. (2004): "Teoría de la Agenda-Setting aplicación a la enseñanza universitaria» (R.R. Díaz, Ed.) Alicante: OBETS Editorial.

Eberl, J., Meltzer, C.E., Heidenreich, T., Herrero, B., Theorin, N., Lind, F., Berganza. R., Boomgaarden. H. G., Schemer. C. y Strömbäck, J. (2018). The European media discourse on immigration and its effects: A literature review. Annals of the International Communication Association, 1-17.

Galán, E. (2006): «La representación de los inmigrantes en la ficción televisiva en España. Propuesta para un análisis de contenido. El comisario y Hospital Central». Revista Latina de Comunicación Social, 61. Recuperado el 13/01/2016 de http://www.ull.es/ publicaciones/latina/200608galan.htm

Galán, E. (2009): «Personajes, estereotipos y representaciones sociales. Una propuesta de estudio y análisis de la ficción televisiva». Revista ECO-Pós, 9(1), 58-81.

Gálvez, J.Á. (2009): «La representación mediática de la inmigración. Entre el encuadre y el estigma». Revista Del Ministerio De Trabajo e Inmigración, (80), 61-80. 
García de Castro, M. (2002): «La ficción televisiva popular: Una evolución de las series de televisión en España» (1st ed.) Barcelona: Gedisa.

Gerbner, G. (1996): «Fred Rogers and the significance of story». En M. Collins, y M.M. Kimmel, Mister Rogers Neighborhood (pp. 3-15). Pittsburgh, PA: University of Pittsburgh Press.

Giró, X., y Jarque, J.M. (2006). Prensa escrita e inmigración: Estudio sobre la opinión de los diarios sobre la inmigración procedente de fuera de la unión europea y sobre la cobertura informativa de conflictos destacados que tienen relación con ella (octubre 1999junio 2002). Zer-Revista De Estudios De Comunicación, 11(20)

Harwood, J., y Anderson, K. (2002). The presence and portrayal of social groups on primetime television. Communication Reports, 15(2), 81-97.

Hoekstra, S.J., Stos, A.N., Swendson, J.R., y Hoekstra, A.E. (2012): «Racial bias in dream content». Dreaming, 22(1), 10-17.

Igartua, J. (2013): «Attitudinal impact and cognitive channelling of immigration stereotypes through the news». Revista Latina De Comunicación Social, 68, 599-621.

Igartua, J.J. (2007): «Persuasión Narrativa». Alicante: Editorial Club Universitario.

Igartua, J.J. (2008): «Identificación con los personajes y persuasión incidental a través de la ficción cinematográfica». Escritos De Psicología, 2(1), 42-53.

Igartua, J.J., Barrios, Isabel M. y Ortega, Félix (2012): «Analysis of the image of immigration in prime time television fiction». Comunicación y Sociedad, XXV(2), 5-28.

Igartua, J.J., y Frutos, F.J. (2016). Procesos de recepción y efectos socio-cognitivos de películas sobre inmigración. El papel moderador del prejuicio hacia inmigrantes. Migraciones. Publicación Del Instituto Universitario De Estudios Sobre Migraciones, (40), 33-61.

Igartua, J.J., y Ramos, M.M. (2013): «Creación de personajes para la ficción televisiva: Influencia del tipo de personaje y del contexto de la acción narrativa». Espacios de Comunicación. IV Congreso Internacional De La Asociación Española De Investigación En Comunicación, 1101.

Igartua, J., Marcos, M., Alvidrez, S., y Piñeiro, V. (2013): «Ficción audiovisual, inmigración y prejuicio». Las Representaciones De Las Migraciones En Los Medios De Comunicación, 157-177.

Lacalle, C. (2008). El discurso televisivo sobre la inmigración: Ficción y construcción de identidad Omega.

López Vidales, N., González Aldea, P. y Medina-de-la-Viña, E. (2011): «Jóvenes y televisión en 2010: un cambio de hábitos». Zer, 30, 97-113.

López Vidales, N., Medina de la Viña, E., y González Aldea, P. (2013): «Los jóvenes españoles demandan una televisión con más ficción y entretenimiento». Revista Ámbitos De Comunicación, (22). Recuperado el 30/03/2016 de http://institucional.us.es/ ambitos/?p=398\#more-398

Mastro, D.E., y Behm-Morawitz, E. (2005). Latino representation on primetime television. Journalism \& Mass Communication Quarterly, 82(1), 110-130. 
Mastro, D.E., y Greenberg, B.S. (2000). The portrayal of racial minorities on prime time television. Journal of Broadcasting \& Electronic Media, 44(4), 690-703.

Monk-Turner, E., Heiserman, M., Johnson, C., Cotton, V., y Jackson, M. (2010). The portrayal of racial minorities on prime time television: A replication of the Mastro and Greenberg study a decade later. Studies in Popular Culture, 32(2), 101-114.

Martínez-Serrano, M.D.M (2014): «El perfil de consumo televisivo en estudiantes de grados en Educación/The television viewing habits in university students of grades in education». Revista Latinoamericana De Tecnología Educativa-RELATEC, 13(1), 101-109.

Martín, M.B., Muntada, M.C., Busquets, C.G., Pros, R.C., y Sáez, T.D. (2015): «Videojuegos, televisión y rendimiento académico en alumnos de primaria». Pixel-Bit.Revista De Medios y Educación, (46), 25-38.

Medrano, C.M., y Palacios Navarro, S. (2008): «Los hábitos y la dieta televisiva en distintas edades: Implicaciones educativas». Pixel-Bit.Revista De Medios y Educación, 31, 59-70.

Medrano, C.M., Martínez de Morentin, J.I., y Pindado, J. (2014): «Identificación con los personajes televisivos y valores percibidos por los y las adolescentes». Revista De Estudios De Juventud, (106), 31-48.

Menéndez, M.I.M. (2014): «Ponga una mujer en su vida: Análisis desde la perspectiva de género de las ficciones de TVE» mujeres» y» con dos tacones» (2005-2006)/Put a woman in your life: An analysis of the TVE series» mujeres» and» con dos tacones» (20052006) from a gender perspective». Área Abierta, 14(3), 61.

Montero, Y. (2005): «Estudio empírico sobre serial juvenil «Al salir de clase»: sobre la transmisión de valores a los adolescentes». Comunicar(25). Recuperado el 16/11/2015 de https://www.revistacomunicar.com/verpdf.php?numero $=25 \&$ articulo $=25-2005-070$

Montero, Y. (2006): "Televisión, Valores y Adolescencia». Barcelona: Gedisa.

Moreno, A. y Rodríguez, E. (2016): «Informe de juventud en España 2012». METAMORFOSIS, 112-118. Consultado de http://revistametamorfosis.es/index.php/ metamorfosis/article/view/15

Moyer-Gusé, E. (2008): «Toward a theory of entertainment persuasion: Explaining the persuasive effects of entertainment-education messages». Communication Theory, 18(3), 407-425.

Müller, F. (2009): «Entertaining anti-racism multicultural television drama, identification and perceptions of ethnic threat». Communications, 34(3), 239-256.

Muñiz, C., Serrano, F.J., Aguilera, R.E., y Rodríguez, A. (2013): «Estereotipos mediáticos o sociales. Influencia del consumo de televisión en el prejuicio detectado hacia los indígenas mexicanos». Global Media Journal México, 7(14), 93-113.

Oliver, M.B., y Raney, A.A. (2011): «Entertainment as pleasurable and meaningful: Identifying hedonic and eudaimonic motivations for entertainment consumption». Journal of Communication, 61(5), 984-1004.

Park, S. (2012): «Mediated intergroup contact: Concept explication, synthesis, and application». Mass Communication and Society, 15(1), 136-159. 
Prats, E., de Régil, M., Lombarte, S., Higueras, E., y Santamaria (2006): »El tratamiento televisivo de la diversidad cultural según los jóvenes de secundaria». Congreso internacional de educación intercultural. Formación del profesorado y práctica escolar Madrid. Recuperado de: https://www.academia.edu/2013850/El_tratamiento_televisivo_de_la_diversidad_ cultural_seg\%C3\%BAn_los_j\%C3\%B3venes_de_secundaria

Ramos, M.M. (2014): La Imagen De Los Inmigrantes En La Ficción Televisiva De Prime Time. Análisis y recomendaciones para los profesionales.

Ramos, M.M. (2014): «Principales estudios realizados sobre la representación de las minorías en la ficción televisiva». Chasqui Revista Latinoamericana De Comunicación, (126), 97108.

Ramos, M.M., Igartua, J.J., Esteban, F.J.F., Vicente, I.M.B., Mohedano, F.O., y Naval, V.P. (2014): «La representación de los personajes inmigrantes en los programas de ficción». Vivat Academia, 17(127), 43-71

Rovira, D.P., y Igartua, J.J. (1998): «Validez y fiabilidad de una escala de empatía e identificación con los personajes». Psicothema, 10(2), 423-436.

Ruiz, X., Ferrer, J., Obradors, M., Pujadas, E., y Pérez, O. (2007): «Los roles narrativos del inmigrante en la ficción televisiva. El caso de la ficción española de producción propia». En J.J, Igartua y C. Muñiz (Eds.), Comunicación, Inmigración y Sociedad (pp. 111126) Salamanca: Universidad de Salamanca.

Signorielli, N., Morgan, M., Gross, L., y Gerbner, G. (1996): «Crecer en la televisión: Perspectiva de aculturación». En J. Bryant y D. Zillman (Eds.), Los efectos de los medios de comunicación: Investigaciones y teorías (pp. 35-66) Barcelona: Paidós Ibérica.

Ugalde, L., Medrano, C.M., y Aierbe, A. (2012): «Identificación con personajes cinematográficos discapacitados y valores percibidos: Una investigación experimental con universitarios». Zer-Revista De Estudios De Comunicación, 17(32), 187-208.

Van Dijk, T. (2005): «Nuevo racismo y noticias». En M. Nash, R. Tello y N. Benach (Eds.), Inmigración, género y espacios urbanos. Los retos de la diversidad (pp.33-55) Barcelona, España: Edicions Bellaterra.

Van Dijk, T. (2007): «Discurso Racista». En J.J. Igartua, y C. Muñiz (Eds), Medios de comunicación, inmigración y sociedad (págs. 9-17). Salamanca: Ediciones Universidad de Salamanca. 



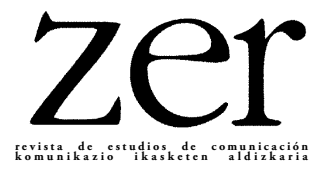

\title{
Revistas iberoamericanas sobre Comunicación
}

\author{
Komunikazioari buruzko aldizkari iberoamerikarrak \\ Latin American Journals of Communication \\ Udane Goikoetxea Bilbao* \\ Universidad del País Vasco/Euskal Herriko Unibertsitatea
}

\section{Introducción}

Las revistas sobre comunicación que publican en castellano, proponen diversos temas no siempre novedosos. Analizan tanto la comunicación como las nuevas tecnologías aplicadas a diversas situaciones y la cultura de masas. Algunas de las revistas no han publicado ningún número durante 2018. Tal es el caso de CIC Cuadernos de Información y Comunicación, de la Universidad Complutense de Madrid, Discursos Fotográficos de la Universidade Estadual de Londrina Paraná, Documentación de las Ciencias de la Información de la Universidad Complutense de Madrid, Enl@ce: Revista Venezolana de Información, Tecnología y Conocimiento de Maracaibo, Universidad del Zulia, o Transinformaçao de la Pontificia Universidade Católica de Campinas en Brasil.

^ Correspondencia a: Udane Goikoetxea Bilbao. Fac. CC. Sociales y de la Comunicación, barrio Sarriena, s/n (48940 Leioa).udane.goikoetxea@ehu.eus http://orcid.org/0000-0002-9844-5221

Cómo citar: Goikoetxea Bilbao, Udane. 2018. Revistas iberoamericanas sobre Comunicación. Zer. 23(45). 227-249.

https://doi.org/10.1387/zer.20307

Recibido: 23 octubre 2018; aceptado: 23 octubre 2018

1137-1102 y 1989-631X / C 2018 UPV/EHU

(c) (1) Esta obra está bajo una licencia Creative Commons Atribución 4.0 Internacional 
En este trabajo mencionamos los artículos publicados en el resto (28), de las 33 revistas listadas en años anteriores ordenadas alfabéticamente. Algunos de los temas desarrollados por dichos artículos aunque son conocidos, presentan nuevos o renovados puntos de vista sobre temáticas tales como las referidas a la crisis económica, Google, el consumo o los riegos que conlleva la difusión de contenidos en las redes como Instagram. Los temas estrella son diferentes aspectos sobre las redes sociales, publicidad en su relación tanto con la educación como con la comunicación, los entornos transmedia o el tratamiento de las noticias en los medios. Algunas de las revistas han publicado números monográficos. Son reseñables los publicados por Historia y Comunicación Social de la Universidad Complutense de Madrid sobre «1917. Revolución y comunicación", o el de la revista Icono 14 de Madrid que plantea como objetivo reposicionar el periodismo de datos iberoamericano dentro de las investigaciones internacionales en este campo. Por su parte Obra Digital edita un monográfico que se centra en los retos y oportunidades que las Relaciones Públicas están viviendo en nuestros días, especialmente en lo que concierne a un mundo interconectado, los nuevos medios de comunicación y los medios sociales en diferentes ámbitos de actuación. La Revista Mediterránea de Comunicación Universidad de Alicante, divulga dos monográfico. El primer monográfico es sobre Educomunicación y promoción de la salud y explora la eficiencia de los hospitales españoles en producción científica como indicador de transferencia de Conocimiento, la competencia tecnológica y habilidades relacionadas con las Tecnologías de la Información y la Comunicación (TIC) de los adultos maduros, las construcciones del género en tiempos de Internet como modos de expresión y riesgos percibidos en las redes sociales durante la niñez o la gamificación y transformación de la escuela. También se abordan temáticas prosociales e impacto de una intervención educativa Flipped Classroom relacionada con la promoción de la salud mediante la creación relatos audiovisuales y un estudio sobre la importancia de Informar y concienciar sobre cáncer basado en el caso de la Asociación Española Contra el Cáncer en Facebook. Finaliza con un artículo sobre la representación de la salud en la publicidad audiovisual de Manos Unidas mediante un análisis de contenido de las campañas institucionales de 1995 a 2017. El segundo monográfico, que versa sobre la generación LED abarca temas como la educomunicación, competencias mediáticas y smartphones o sobre el uso crítico de los medios en la formación universitaria. Las competencias parentales positivas y Smartphones; diagnóstico en el contexto familiar sobre la generación millennial, las autorrepresentaciones y rasgos comunicativos de las interacciones de jóvenes en Tinder.

El número de la revista Trípodos (Llenguatge, Pensament, Comunicació de la Universitat Ramon Llull de Barcelona) es un monográfico sobre el cine negro, «thriller» y policíaco español desde una perspectiva histórica.

El blog de la revista Comunicar publicaba en junio de 2016 los resultados para las Revistas Iberoamericanas en JCR, según los cuales «Comunicar se posiciona como la única revista iberoamericana de Ciencias Sociales en Primer Cuartil, y una 
de las 20 revistas de Comunicación con mayor impacto del mundo ${ }^{1}$ ». El resto o la mayor parte de ellas, según la misma fuente, pertenecen a la base de datos Science Citation Index. Además, se encuentran posicionadas en tercer y cuarto cuartil. Afirman también que de los países que publican, España tiene revistas mejor posicionadas y cuenta con mayor presencia de revistas de Ciencias Sociales. Posteriormente los resultados se mantienen igual en líneas generales.

\section{1. Ámbitos. REVISTA INTERNACIONAL DE COMUNICACIÓN \\ (Sevilla: Universidad de Sevilla, GREHCCO, núm. 41, 2018)}

El primer artículo toma como estudio de caso el entorno mediático malagueño para la adaptación de los periodistas y las empresas de medios al uso de la denominada "cuarta pantalla». Se presenta también la importancia de la caricatura y el grafiti como medio de comunicación en la Primavera Árabe Siria. Dos artículos nos trasladan a México: el estudio transversal de metodología mixta titulado «Persecución criminal en México y su influencia en la hipermediación: un estudio de caso» y un segundo que profundiza en la formación de profesores como esfuerzo de alfabetización digital en México. En el último abordan la turbotemporalidad y la omnipantalla que son presentados como los nuevos paradigmas de acción en el mundo actual y que es necesario comprender sus mecanismos de cara a poder potenciar el pensamiento crítico del siglo XXI.

\section{ANALES DE DOCUMENTACIÓN}

(Murcia: Universidad de Murcia, vol. 21, núm. 1, 2018)

La revista incluye artículos que presentan una propuesta sobre el copyfraude que analiza las prácticas desarrolladas por un conjunto de bibliotecas digitales españolas pertenecientes a las Administraciones públicas para divulgar sus colecciones patrimoniales en Dominio público.

Continúa con un análisis sobre el rol crucial que ocupan las bibliotecas universitarias españolas en el contexto actual como soporte para la investigación. Su objetivo es ofrecer una visión global de cuáles son los servicios de apoyo a la investigación prestados por las bibliotecas vinculadas a REBIUN. El siguiente artículo tiene como propósito presentar el estado del arte realizado para el proyecto de investigación Doctoral «La incidencia de la biblioteca en la reducción de las desigualdades sociales: el caso del Sistema de Bibliotecas Públicas de la ciudad de Medellín a partir del Acuerdo 079 de 2010». También presenta la gestión de la comunidad biblio-

\footnotetext{
1 https://revistacomunicar.wordpress.com/2016/06/14/las-revistas-iberoamericanas-en-jcr-2015/
} 
tecaria en cuanto a la información en paralelo con otros sectores profesionales del mundo web. Finaliza con un artículo cuyo objeto de estudio es indagar en las vicisitudes de la conocida biblioteca gimnástico-deportiva del Gimnasio Colón (18921906). Asimismo se analiza la trascendencia de esta biblioteca y del Catálogo del Gimnasio Colón (1935) en su época.

\section{AnÀlisi (Quaderns de Comunicació y Cultura)}

(Barcelona: Universitat Autònoma de Barcelona, núm. 58, 2018)

En su número 58, Anàlisi incluye artículos sobre la ampliación de los paisajes de la narración televisiva en el entorno de los medios digitales del siglo Xxi, la cobertura de noticias de la radio comunitaria en los medios europeos mediante un mapeo de temas populares y silencios importantes como identificar qué tipo de problemas es más probable que se informen en los medios, así como las realidades desconocidas en las que aún están inmersos. También un análisis que pretende establecer la relación entre la calidad de las noticias y el género de la información, atendiendo a los protagonistas de las noticias y a las fuentes informativas. Un artículo que aborda una nueva forma de aplicar la narración en el marketing, que lo usa para extender productos repasando la importancia general de la narración de historias como una herramienta y estrategia de comunicación. El siguiente artículo titulado «La función del pathos en el storytelling del documental publicitario» investiga el documental como formato del contenido de marca a fin de analizar sus características narrativas como estrategia de comunicación publicitaria. Un artículo que se centra en dos trabajos del italiano Igort, "Cuadernos ucranianos» y «Cuadernos rusos», que describen las atrocidades del Holodomor y la guerra ruso-chechena y reflexiona sobre el problema de la distancia respecto a sus fuentes y a la realidad misma, cuestión central en cualquier relato histórico, periodístico o documentalista. Incluye un análisis sobre las narrativas hegemónicas de la violencia. El crimen organizado y el narcotráfico entre el periodismo y las ficciones televisivas. Finaliza con un artículo que partiendo del caso mexicano que propone una revisión de las repercusiones de estas narrativas periodísticas en las series televisivas de ficción Gomorra (2014), Narcos (2015) y El Chapo (2017). También está presente Chile con un artículo que reflexiona sobre qué memorias sobre el pasado reciente de Chile construye la generación que vivió el golpe de estado (de 50 a 64 años) a partir de sus lecturas de series ficcionales y por qué estas memorias entran en conflicto en la esfera pública.

4. ÁREA ABIERTA

(Madrid: Universidad Complutense de Madrid, vol. 18, núm. 2, 2018)

Este último número de Área Abierta centra sus contenidos en las diferentes representaciones de la crisis. El primer trabajo describe las películas recientes «Los exámenes», 
«Dos días y una noche» $\mathrm{y}$ «Capital humano» que cuentan historias que revelan diversas facetas de la crisis económica y cómo el cine de autor ilumina los aspectos más oscuros del fenómeno social. Sigue con un artículo que trata de analizar en qué medida las seis producciones cinematográficas de viajes espaciales, estrenadas entre 2013 y 2018, han contribuido la renovación del concepto de sueño americano durante una de sus peores crisis. También podemos encontrar una revisión de la mirada filmica en torno a la crisis de la posmodernidad, tomando como punto de partida el análisis de sociólogos posmodernos de relieve y se repasan las tendencias filmicas dominantes de los 80 y 90 . Además, el trabajo atiende a la experimentación de un giro en esta tendencia a comienzos del milenio, expresada en el cine múltiplex como exponente de este cambio. Sigue con un artículo que propone estudiar las cinco películas que componen la franquicia La jungla de cristal (1988-2013) mediante un acercamiento multidisciplinar. También un artículo que tiene como objetivo explicar la razón por la que la película «El hijo de Saúl» volvió a reabrir una crisis sobre lo representable y no representable del Holocausto debido a lo novedoso de su planteamiento ético y estético. Continúa con un artículo sobre la descripción de las crisis (socio) políticas nacionales a las que se enfrentan los presidentes norteamericanos de ficción en ejemplos de series televisivas Kennedy (1983) y The West Wing (19992006). Incluye un trabajo sobre la representación de la crisis española en la publicidad en la campaña «Despertar» (Campofrío, 2015). Y un texto que trata de establecer unas nociones generales sobre la aplicación del Big Data a diversos ámbitos que interactúan con la disciplina de la Comunicación en el contexto de la Cuarta Revolución Industrial. Otro titulado «Imágenes en la Crisis Mediterránea: la creación de la imagen pública de Nasrallah» que propone analizar la imagen de Nasrallah como líder carismático de Hezbollah, a partir de la definición de Weber y las aportaciones de House. Finaliza con un resumen de una investigación sobre los orígenes, evolución y crisis del sistema de exhibición cinematográfica en el Teatro Principal de Zamora durante sus años de existencia como sala de cine (1897-1984) desde la etapa finisecular del XIX a su cierre.

\section{COMUNICACIÓN Y SOCIEDAD \\ (Guadalajara, México: Universidad de Guadalajara, núm. 33, 2018)}

Este número está dedicado al Alfabetismo transmedia, propuesta que abarcaba tanto la formación crítica para el consumo mediático como la creación de un periódico o radio escolar. Incluye un artículo sobre el concepto de alfabetización transmedia en el ámbito educativo mediante la revisión de la literatura. Continúa con una investigación transnacional sobre alfabetismos digitales con el objetivo de estudiar las prácticas de lectoescritura juvenil de estudiantes de colegios públicos colombianos en relación a las de narraciones transmedia. Un estudio que presenta los principales hallazgos de la investigación Transliteracy para Uruguay en relación al objetivo de identificar estrategias de aprendizaje informal de habilidades que los adolescentes 
desarrollan a través de prácticas transmedia. A continuación recoge un estudio sobre usos mediáticos y prácticas de producción con adolescentes de Portugal, España e Italia. En el siguiente artículo se analiza el proceso de creación y difusión de videos que desarrollan niños YouTubers peruanos para comprender el tipo de habilidades que se despliegan en dicho proceso a través del método de la etnografia digital. También un trabajo que revela la emergencia de nuevos alfabetismos transmediales basados en una ética Do It Yourself bajo el título «De la alfabetización a los alfabetismos: aprendizaje y participación DIY de Fans y Makers mexicanos». En este número podemos encontrar un artículo que describe y analiza la validez de «Viaje al Centro de la Radio» como propuesta de alfabetización transmedia que pretende promover la cultura radiofónica entre los jóvenes en el entorno digital. Y otro que presenta la experiencia de una narrativa transmedia en una escuela secundaria de Argentina con el objetivo de reflexionar sobre las implicaciones en el proceso educativo. Finaliza analizando la experiencia pedagógica \#Orson80, una propuesta de narrativa transmedia educativa que se inserta en la currícula escolar y que a la vez genera producciones que exceden las paredes del aula.

\section{COMUNICACIÓN Y SOCIEDAD}

(Pamplona: Universidad de Navarra, vol. 31, núm. 3, 2018)

El primer artículo aborda el tema de la comunicación política actual en un escenario de tecnologías digitales, participación ciudadana y gobernanza abierta. Pone como ejemplo la salida inesperada de los británicos de la Unión Europea, la crisis migratoria, el ascenso de Isis, los conflictos en países como Siria, el surgimiento del populismo y las reacciones ciudadanas imprevistas (el rechazo del Plan de Paz de Colombia o la elección del presidente Trump) y afirma que todos tienen en común la incertidumbre que trae consigo y que caracteriza la era actual. El segundo artículo tiene como objetivo analizar el uso de Twitter por parte de los actores políticos españoles para construir su agenda durante las campañas electorales. En el tercero también están presentes las elecciones españolas de 2016; en este caso el objetivo de la investigación es examinar qué tipo de expresión electrónica de los ciudadanos se puede encontrar al comentar los mensajes de Facebook de los líderes de los partidos políticos en el contexto de una elección. Sigue con un artículo sobre el uso del contenido viral en la comunicación de la política y aborda el caso del ex primer ministro croata, Ivo Sanader. Dos artículos tienen como tema central el populismo. Uno analiza los elementos centrales del populismo centrándose en los Partidos populistas en Europa occidental. Y el otro analiza la calidad del discurso en los tiempos del populismo mediante un análisis de los debates parlamentarios alemanes sobre la política de inmigración. Incluye un trabajo sobre tres actitudes políticas, eficacia interna, eficacia externa e interés político en el contexto de Chile. El siguiente artículo tiene como eje dos requisitos de las emisoras de servicio público en España; la participación cívica e independencia del poder político. También presenta el impacto de las 
redes sociales en la agenda parlamentaria europea con respecto a la guerra Siria. Seguidamente recoge un documento que explora el poder de la representación en el contexto del futuro incierto de los inmigrantes indocumentados en los Estados Unidos. El último artículo del especial habla sobre el uso de algoritmos de aprendizaje supervisado en comunicación política y estudios de medios.

En la miscelánea encontramos artículos sobre el tratamiento informativo de las víctimas, victimarios y demandas punitivas en la Argentina, un artículo que explora la obra del director argentino Lisandro Alonso a partir de la figura del hombre nómade, del errante contemporáneo que ya no encuentra lugar en las ciudades moderna. Otro sobre el impacto de las plataformas globales en la competencia mediática y los resultados de las empresas de comunicación europeas. Sigue con un artículo que presenta el Instituto Cervantes analizando la comunicación del mismo a través de la red Twitter durante un periodo determinado. Y entre otros un artículo que ahonda en el «Decreto Miró» y su repercusión en la producción de películas relacionadas con la violencia de ETA (1983-1989).

\section{COMUNiCAR. REVISTA CIENTÍfiCA IBEROAMERICANA DE COMUNICACIÓN Y EDUCACIÓN}

(Huelva: Grupo Comunicar, vol. XXVI , núm. 56, octubre 2018)

Con el título «Artivismo: Arte y compromiso social en un mundo digital» el dossier central de la revista tiene estudios sobre principales experiencias en artivismo para reflexionar sobre la utilidad del mismo como nuevo lenguaje social y como herramienta educativa capaz de romper los roles tradicionales de la comunicación social. El primer artículo presenta el artivismo de la mano del compromiso social para transformar la formación del profesorado desde la sensibilidad. También presenta un análisis sobre la forma, el contenido y el engagement generado por las fotografias y el uso que se hace en ellas de la figura del niño de las fotografias publicadas en Instagram a lo largo del año 2017 por las 20 ONG más relevantes a nivel internacional. Incluye un trabajo sobre la cultura del posdrama en Ecuador y España y una indagación teórica de los fundamentos del videoartivismo, con el objetivo de realizar una delimitación conceptual bajo el título «Videoartivismo: Poética del conflicto simbólico».

La sección Caleidoscopio incluye un trabajo que tiene como objetivo definir los patrones de consumo, creación y difusión de contenidos audiovisuales de Internet en los ámbitos del ocio y las fuentes de información complementarias para uso escolar de los jóvenes guipuzcoanos, atendiendo a las variables de género, curso y tipo de centro. También un artículo que presenta la relación entre preadolescentes y youtubers, con el objetivo de observar cómo los primeros integran a los youtubers como referentes de una cultura digital juvenil. Continúa con un artículo que desa- 
rrolla ideas y genera nuevas líneas de investigación sobre las vidas digitales de los niños en China y Australia. Finaliza con un trabajo sobre la formación universitaria sobre el emprendimiento en proyectos empresariales de comunicación y periodismo y otro titulado «Los estudios sobre radio: Un balance desde la academia iberoamericana» que efectúa una aproximación a la situación de los «radio studies iberoamericanos» desde la perspectiva de su comunidad científica que se centra en las trayectorias, percepciones y valoraciones en torno a la investigación radiofónica en una esfera supranacional, con características comunes pero importantes divergencias en el abordaje de la comunicación como ámbito de estudio.

\section{CUADERNOS.INFO}

(Santiago de Chile: Pontificia Universidad Católica de Chile, núm. 42, 2018)

Las investigaciones de la revista están centradas en Social media, branding y consumo. El primer artículo aborda el tema de la figura del en las redes sociales como un nuevo modelo de líder de opinión que debe combinar la gestión de su marca personal con el rol de prescriptor, incluyendo los mensajes de contenido político analizando el contenido de mensajes de diez influencers españoles con alto impacto en Twitter. El siguiente trabajo reflexiona sobre la programación de la creación mediante una exploración al campo socio-técnico de YouTube en Chile. «El uso de Twitter en las marcas de moda de lujo frente a las denominadas low-cost» es un análisis de contenido de 1.135 tuits publicados por H\&M, Zara, Ralph Lauren y Hugo Boss. Y también están presentes las estrategias de gestión de los clubs de golf públicas, privadas o comerciales de la Comunidad de Madrid en Twitter.

\section{DOXA. COMUNICACIÓN: REVISTA INTERDISCIPLINAR DE ESTUDIOS DE COMUNICACIÓN Y CIENCIAS SOCIALES}

(Madrid: Universidad San Pablo-CEU, núm. 26, 2018)

La revista publica trabajos sobre las acciones de comunicación que realizan las ONG españolas de apoyo al Sáhara, las oportunidades que brinda el uso de drones al relato informativo en España, las campañas contra el castigo físico a menores en España y propuesta de estrategias para el cambio de actitudes, la utilidad de las herramientas y métricas de audiencia surgidas en el entorno digital para desarrollar prácticas comunicativas de Inbound Marketing, el uso cuantitativo y cualitativo de Twitter por parte de los principales candidatos durante las campañas electorales españolas de 2011 y 2015 para plantear si existe una brecha digital entre los candidatos de la «vieja»y «nueva» política, La formación para la gestión de las redes sociales en los grados de comunicación en España y su adecuación a las competencias demandadas por las organizaciones, Frames de la religión en editoriales de cuatro periódicos españoles 
(2009-2010), un estudio de caso sobre las Unidades de Cultura Científica y de la Innovación $(\mathrm{UCC}+\mathrm{i})$ españolas en la prensa digital, la inmersión del espectador en el reportaje en $360^{\circ}$ mediante análisis comparativo de «En la piel de un refugiado» y «Fukushima, vidas contaminadas», y cómo afrontar las noticias falseadas (fake news) en los medios de comunicación y en las redes sociales mediante la alfabetización periodística.

\section{ESTUDIOS SOBRE EL MENSAJE PERIODÍSTICO}

(Madrid: Universidad Complutense de Madrid, vol. 24, núm. 1, 2018)

Esta publicación presenta artículos sobre el femicidio en la prensa ecuatoriana mediante un análisis de contenido de los diarios El Univers y El Comercio, la tercera edad en los contenidos informativos de la prensa digital que estudia los encuadres noticiosos sobre las personas mayores de Castilla y León, y un estudio basado en los editoriales de la prensa española El País, El Mundo y ABC (1994-2014) que afirma que tras la publicación en 1995 de la Ley de Prevención de Riesgos Laborales, la mayor cantidad de editoriales se deriva de graves accidentes en el periodo de máxima siniestralidad en España. El propósito del siguiente trabajo es saber, a través de un análisis de contenido cuantitativo, el tratamiento informativo desde el plebiscito sobre los acuerdos de paz en Colombia, hasta el día en que Juan Manuel Santos gana el premio Nobel de Paz. Continúa con el análisis del tratamiento de la información económica en los códigos éticos y deontológicos en el entorno español. Además explora la presencia de los elementos constitutivos del género negro en los textos que no pueden considerarse puramente literarios y reportajes publicados por Rosa Montero en El País sobre el atentado de Atocha, ocurrido en 1977. Continúa con un estudio que rescata la figura de Jacinto Ontañón (1845-1917), primer periodista profesional de Burgos y un análisis del periodismo de datos en la campaña electoral del 20 de diciembre de 2015 a través de las ediciones digitales de diarios generalistas. También cuenta con un estudio que afirma que la hipótesis de la comercialización periodística sostiene que la creciente presión de la prensa por rentabilizar su actividad la lleva a relegar aspectos sustanciosos de cobertura política por encuadramientos de tipo estratégico, de juego o de interés humano, particularmente durante las elecciones. Incluye una propuesta socio-crítica para investigar las culturas periodísticas a partir de la revisión de «Worlds of Journalism Study» (20122015) y un análisis sobre la televisión informativa en el entorno digital de las ediciones diarias de las cadenas generalistas líderes de audiencia en España. Se analiza la percepción profesional de la eficacia de los mecanismos tradicionales de autorregulación periodística en el nuevo contexto del periodismo y también se analiza el peso de la influencia de los gobiernos en las informaciones de la prensa de calidad. El objetivo del siguiente artículo ha sido indagar cuáles serían los criterios selectivos más apropiados para aplicar a los documentos fotoperiodísticos. En este número se incluye un trabajo de la biblioteca digital sobre Donald Trump «Fact-checking frente 
a fake news». Otra investigación analiza la biblioteca digital creada por la Fundación del Internet Archive sobre Donald Trump, incluye más de 700 discursos, entrevistas y debates del Presidente de los EEUU. A continuación se afirma que importantes transformaciones políticas, sociales y tecnológicas ocurridas durante las últimas décadas han afectado a los sistemas de medios, así como a la profesión periodística en Latinoamérica. Otro artículo parte de la hipótesis de que un bajo porcentaje de periodismo interpretativo perjudicaría la calidad de la información política y podría fomentar la apatía ciudadana hacia la política. El objetivo en otro artículo es doble: demostrar las restricciones de los procesos de integración horizontal en el sector periodístico, así como analizar los desaciertos cometidos por Vocento en su estrategia de diversificación multimedia. Otro trabajo analiza la tipología de fuentes informativas que emplean seis medios de la prensa española cuando tratan el tema de la ley de extranjería para determinar la proporción de la presencia de fuentes oficiales y de la sociedad civil. Se aborda la profesión periodística ante sus retos éticos como la autorregulación profesional y comunicativa frente a regulación en el caso español. En el siguiente trabajo de investigación se plantea la hipótesis de que los medios de comunicación generalistas no cuentan con una estrategia para informar sobre inmigración. Otro artículo analiza el nacimiento y evolución, trascendencia y situación actual de la prensa étnica, surgida en torno a los inmigrantes en España. Continúa con análisis de los factores y rasgos comunes presentes en una muestra de textos periodísticos sobre ciencia aparecidos en las ediciones online de tres diarios hispanoparlantes de referencia (La Nación de Argentina, El País de España y El Universal de México) en 2010, 2012 y 2014. Finaliza con el análisis de prensa argentina y chilena: casos José López y Caval. Esta publicación también da cuenta de Investigaciones y otros documentos.

\section{HISTORIA Y COMUNICACIÓN SOCIAL}

(Madrid: Universidad Complutense, vol. 23, núm. 1, 2018)

El Monográfico titulado «1917. Revolución y comunicación» abre este número con una investigación que parte de la invisibilidad de la mujer en la Revolución Rusa. También abarca artículos sobre el retorno de los españoles refugiados en la Unión Soviética mediante el análisis de las noticias aparecidas en los medios de la época nacional e internacional, los diferentes aspectos de la política de comunicación sobre el tópico «las mujeres y la revolución rusa», una hipótesis de que la teoría de la comunicación persuasiva de masas tiene su origen en el inicio del siglo xx, durante la I Guerra Mundial y especialmente en la Revolución Bolchevique y un trabajo sobre las relaciones entre el arte y la política en Rusia durante la revolución de 1917. También presenta el impacto de revolución rusa en el campo cordobés mediante una aproximación desde la prensa y las Actas Capitulares de los ayuntamientos, o las formas de creación visual que se generan en el período que comprende la Revolución Bolchevique atendiendo al soporte propagandístico del cartel bajo el título «La influencia del 
formalismo en el cartel bolchevique». Bajo el título «Desde Rumanía al frente soviético: los periodistas» se indaga sobre varios artículos de quiénes combatieron contra el comunismo en suelo ruso en los años cuarenta, el ejemplo más claro es la obra $\mathrm{Ru}$ manía. El siguiente artículo versa sobre las guerras de la memoria en Rusia que propone un acercamiento a las implicaciones políticas, para el presente y el futuro, de la «elección» de una determinada memoria histórica. Y un ensayo bibliográfico que propone ofrecer una panorámica histórica, política y social de la revolución de octubre de 1917. La revista también incluye artículos sobre las redes anarquistas en la Europa de posguerra, la información gubernamental en las páginas de apertura de sección en la prensa de referencia. También presenta la crónica como una tradición periodística y literaria latinoamericana. Un trabajo sobre la figura del judío en el cine franquista como El mito errante. En este número se presentan también un artículo sobre los fundamentos del concepto de desinformación como práctica manipuladora en la comunicación política y las relaciones internacionales y un artículo sobre las publicaciones sobre la organización del Frente de Juventudes (1940-1961) que hace referencia al adiestramiento de las mujeres en las actividades de la naturaleza.

\section{IBERSID \\ (Zaragoza: Universidad de Zaragoza, vol. 12, núm.1, 2018)}

Esta revista anual de gestión de la información pública investigaciones sobre «Buenas prácticas en la declaración de obras huérfanas en Europa», un análisis de los proyectos europeos de preservación y digitalización del patrimonio cultural. Incluye un trabajo sobre la percepción de las revistas científicas españolas hacia el acceso abierto, open peer review y altmetrics y otro sobre los archivos eclesiásticos como fuentes para el estudio de la beneficencia en España. Además se hace una evaluación de impacto de los recursos informativos bibliotecarios en la competitividad académica de 33 universidades públicas mexicanas acreditadas y un análisis de las noticias sobre lectura digital en cuatro periódicos portugueses Jornal de Notícias, Diário de Notícias, Correio da Manha y Público (2009-2011) utilizando la base de datos Factiva de especial relevancia. Finaliza con una contribución de la alfabetización informacional en el contexto académico a la Ciencia Abierta y una propuesta de un sistema de gestión integrado para fondos documentales patrimoniales familiares (FDPF).

\section{ICONO 14}

(Madrid: Icono14.net-Asociación Científica de Investigación de las NNTT de la Educación, vol. 16, núm. 2, 2018)

Este monográfico de la revista ICONO 14 tiene como objetivo reposicionar el periodismo de datos iberoamericano dentro de las investigaciones internacionales en este campo, para recontextualizar la contribución que realiza en los debates sobre el 
papel de esta práctica periodística. En el monográfico se publican trabajos sobre los resultados de una investigación realizada sobre la startup Politibot, un chatbot o bot conversacional especializado en contenidos políticos, surgido durante la campaña electoral de junio de 2016 en España a través de Telegram. En otro artículo se muestra la necesidad de desarrollar modelos en el uso y representación de datos aplicable a campos como la educación y el empoderamiento. El artículo «Periodismo de datos y transparencia al margen de los grandes medios, un estudio comparativo de Civio y ProPublica» hace un análisis comparativo de entrevistas con profesionales del periodismo de datos en la americana ProPublica y la española Civio. Los artículos de investigación incluidos en este número presentan la importancia del papel de las TIC, internet y redes sociales en el campo de la comunicación política electoral a través del caso de las elecciones de los diputados de ultramar de la República Dominicana del 2012 o una investigación que estudia las informaciones periodísticas sobre Google, desde la perspectiva de la teoría del encuadre (framing). También presenta la importancia del proceso colectivo basado no solamente en la acción artística como forma de conocimiento sino también como aprendizaje y comprensión de una realidad social en la que quedamos sumergidas. Otra basada en el proyecto europeo Erasmus+ Artivism: artistic practices as instruments for social transformation que se focaliza en los problemas de participación social de los jóvenes y la ciudadanía activa. Otro trabajo analiza la oferta de unas webradios que, con independencia de posibilitar la escucha de una programación más o menos regular en streaming o podcasting, que se caracterizan por compartir con su audiencia una amplia gama de contenidos complementarios multimedia. En el siguiente artículo muestra que las ONGD consideran importante la figura del Community manager y que incluyen las redes sociales Facebook y Twitter en los planes estratégicos de comunicación. Además del monográfico, la revista incluye trabajos de investigación sobre el tiempo en la fotografia mediante una revisión de conceptos forjados por autores relevantes Benjamin (1931), Barthes (1980) o Dubois (1986). Bajo el título «Prosumo, Swarming y Transmedia» se afirma que la storytelling transmedia representa hoy una auténtica revolución comunicativa, también un nuevo modelo de negocio. Finaliza con un estudio que afirma que la inmersión y emersión en los juegos digitales es importante en las últimas décadas, ya que la computación ubicua y los dispositivos geolocalizados han desdibujado el límite entre el espacio digital y el físico transformado la forma en que experimentamos ambos.

\section{INFORMAÇÃO \& SOCIEDADE: ESTUDOS}

(Brasil: Universidade Federal da Paraíba, vol. 28, núm. 2, 2018)

Recoge artículos de revisión sobre el modelo de metadatos Dublin core (19952015), uno que presenta las transformaciones que está teniendo Catálogos Online de Acceso Público (OPAC) debido al desarrollo tecnológico y por una supuesta exigencia de usuarios acostumbrados con servicios más interactivos proporcionados por la Web 2.0 y un análisis del discurso de la dimensión cultural de la ISKO, la Socie- 
dad Internacional para la organización del conocimiento. En el siguiente artículo presenta la relación mutua entre elementos de la creatividad y competencia en información y otro sobre las áreas de actuación del bibliotecario en el mundo de la publicación y las competencias técnicas y comportamentales necesarias para ello; la presencia del bibliotecario en el mercado editorial ha sido percibida, principalmente, en periódicos científicos y en editoriales comerciales y universitarias, pero de forma aún muy modesta, son pocos los bibliotecarios que actúan en la editorial, lo que puede ocurrir debido a la falta de conocimiento por parte del mercado editorial de las diversas. Finaliza con una revisión de literatura que reúne aspectos importantes para ampliar la discusión sobre los rankings, debate los indicadores más utilizados y principales críticas a los rankings universitarios league tables.

\section{InFOrmaCión, Cultura y SOCIEDAD}

(Argentina: Instituto de Investigaciones Bibliotecológicas de la Facultad de Filosofia y Letras de la Universidad de Buenos Aires, núm. 38, 2018)

Este número recoge un artículo sobre la profesionalización de la Filosofía en la Argentina a través de sus revistas: notas para la confección de un corpus hemerográfico, el estado del acceso abierto en publicaciones científicas emergentes del Ecuador. Continúa con las preferencias de investigadores y prácticas institucionales/disciplinares en la difusión y socialización de los resultados de investigación que tiene como objetivo realizar un aporte al conocimiento de las prácticas y preferencias de los docentes-investigadores de instituciones universitarias al momento de difundir y socializar sus publicaciones en repositorios institucionales de acceso abierto y en redes sociales académicas, partiendo de la premisa de que dicho fenómeno está influenciado tanto por la disciplina, como por la pertenencia institucional. Incluye un análisis de grupos de investigación de la Universidad de La Sabana sobre la visibilidad científica y académica en la web 2.0. Finaliza con un artículo sobre el estado de los repositorios institucionales venezolanos y sus revistas científicas y otro sobre el uso del archivo desde la perspectiva de los usuarios, centrado en el Archivo Nacional Histórico de Chile.

\section{OBRA DIGITAL}

(España: Universidad de Vic-Universidad Central de Cataluña, núm. 15, 2018)

El foco de este monográfico se centra en los retos y oportunidades que las Relaciones Públicas están viviendo en nuestros días, especialmente en lo que concierne a un mundo interconectado, los nuevos medios de comunicación y los medios sociales en diferentes ámbitos de actuación. En el primer artículo se hace un análisis exploratorio de las empresas vitivinícolas nacionales cuyas acciones desinteresadas en beneficio 
de su entorno, en especial vinculadas con la RSC y la filantropía, se divulgaron entre 2008 y 2015 en Twitter, Facebook, blogs, Página web o medios de comunicación social. Otro artículo expone los resultados de un análisis efectuado sobre una muestra de herramientas de comunicación que el sector inmobiliario viene desarrollando al albor del desarrollo de las TIC y en el marco de una reconfiguración estratégica de la comunicación institucional. Aborda el papel de las redes sociales en la relación con los públicos internos de las organizaciones. Continúa con una investigación de carácter exploratorio que permite diagnosticar la importancia que las organizaciones no gubernamentales para el desarrollo (ONGd) dan a la "comunicación». Y un estudio que se centra entre los años 2011-2013, período en el cual España estaba inmersa en un escenario de crisis para indagar sobre quiénes fueron los actores y los discursos que participaron del proceso de construcción de Opinión Pública respecto de los desahucios en España. Presenta un análisis de la estrategia de Responsabilidad Social Corporativa (RSC) dirigida a la comunidad local mediante el caso de una multinacional. En la miscelánea encontramos dos artículos: uno sobre la comunicación web y análisis económico financiero en el sector del transporte en el caso Busmet y un análisis del Diseño Corporativo en la moda española que analiza los logotipos de las 54 empresas españolas incluidas en la Asociación de Creadores de Moda de España (ACME) .

\section{PALABRA CLAVE}

(Bogotá: Facultad de Comunicación Social de la Universidad de La Sabana, vol. 21, núm. 3, 2018)

Este número especial de Palabra Clave busca dar cuenta del estado del campo de estudio y sus transformaciones en Iberoamérica. El primer artículo aborda el tema de las redes de citación como elemento de construcción del campo científico de la comunicación política en México. Otro titulado «Voces independientes de noticieros emprendedores: estableciendo una nueva agenda en Latinoamérica» que recoge los antecedentes y las razones por las cuales la independencia es considerada una innovación necesaria en el periodismo latinoamericano. Continúa analizando el framing político realizado por la televisión y la prensa durante la campaña electoral de Nuevo León, México en el 2015. Sigue con un estudio de caso de las elecciones generales españolas de 2015 titulado «Los debates electorales, ¿el último reducto frente la mediatización?» que tiene como objetivo observar qué temas destacaron en las intervenciones de los actores políticos y determinar si la mediatización afecta el contenido de los debates electorales, o si, por el contrario, estos espacios se mantienen como foros para la discusión detallada de diversas cuestiones de política pública. Incluye tres publicaciones sobre las redes sociales. En primer lugar habla sobre la campaña a la Alcaldía de Manizales (Colombia) en Twitter para comprender la interacción en línea entre candidatos y ciudadanos. En segundo lugar recoge un análisis de opinión pública durante las elecciones del año 2014 en Brasil con el fin de investigar los medios compartidos y la preferencia electoral de los ciudadanos en Twitter. Y en 
tercer lugar plantea un análisis de la concordancia y las estrategias temáticas del Centro Democrático en Twitter.

\section{Pensar la PUblicidad. REVISTA InTERnACIONAL DE INVESTIGACIONES PUBLICITARIAS \\ (Valladolid: Universidad de Valladolid-Universidad Complutense de Madrid, vol. 11, 2017)}

La revista divulga investigaciones sobre el origen, las propiedades y tipología del eslogan o la fórmula verbal muy empleada en la comunicación comercial y política, una aproximación historiográfica sobre el primer museo dedicado al arte publicitario creado en España, MUVAP (2001-2016). Continúa con la historia de vida, publicidad y ficción sobre Steve Jobs tratando de hacer entender cómo fue la construcción de un mito como proposición estratégica de consumo del brandscape Apple. A continuación se analiza la presencia de la técnica del Product placement y su evolución desde el comienzo del videoclip hasta la actualidad. El siguiente artículo indaga en la publicidad de los medios de comunicación que son, por definición, soportes de una publicidad consustancial a su existencia. El objetivo del siguiente artículo es conocer el alcance, dimensiones y futuro del patrocinio, así como diferenciarla del branded content. Finaliza con una aproximación a la actuación entre anunciantes y creativos en el nuevo contexto para tratar de entender las áreas formativas que se están exigiendo a los profesionales de la creatividad publicitaria.

\section{PeRspeCtiVAS EM CIÊNCIA DA INFORMAÇÃO}

(Brasil: Escola de Ciencia da Informacao da UFMG, vol. 23, núm. 3, 2018)

El número incluye artículos sobre ontología para la representación de tiempo en el contexto de indicadores de rendimiento, un estudio sobre cuál es el mejor estándar de metadatos que presenta un mapeo relacional entre los principales patrones de metadatos utilizados por los repositorios de objetos de aprendizaje y también incluye un artículo sobre la influencia de factores individuales en el uso de bibliotecas digitales centrado en el caso del Portal de Periódicos de Capes. Sigue con la evolución de la producción científica sobre la epistemología en el área de Ciencia de la Información que busca presentar autores de destaque y principales referenciales. Se analizan las prácticas innovadoras en las bibliotecas de Florianápolis en torno a las ideas de ciberativismo y de vigilancia cívica a través de las denominadas «redes sociales». Un estudio sobre la aplicabilidad de la Política archivística de preservación digital en instituciones públicas federales. El objetivo del siguiente artículo consiste en analizar el compartir y la protección del conocimiento en una empresa de innovación, del sector sucroenergético. Se presenta la etnometodología como un concepto teórico ade- 
cuado a la investigación sobre lectura, especialmente en lo que se refiere al género de los cómics de superhéroes. Y un artículo cuyo objetivó es analizar la Inteligencia Competitiva en el contexto de la Innovación en una industria global del sector automotriz de vehículos pesados.

\section{PERspeCtiVAs DE LA COMUNiCACIÓN}

(Chile: Facultad de Educación, Ciencias Sociales y Humanidades de la Universidad de La Frontera, vol. 11, núm. 1, 2018)

Este número difunde artículos sobre Comunicación y literatura desde una perspectiva transatlántica. Se reflexiona sobre si el populismo debiese ser considerado sólo como un fenómeno puramente político o si puede ser también estudiado desde una perspectiva cultural. Un ensayo enfoca en dos obras altamente representativas sobre el sur de Italia: el libro de Franco Arminio Terracarne (2011) y el filme documental de Gianfranco Rosi «Fuocoammare (2016). En «Observando a Europa observar sus fronteras» se hace autorreflexión cultural y vigilancia en filmes sobre migración. El siguiente artículo indaga en el análisis de la sociedad española que realizaron tres intelectuales republicanos, Francisco Ayala, Max Aub y Vicente Llorens, en sus primeras vueltas al país después de décadas en el exilio. A continuación se realizar una pequeña contribución al debate en relación al significado de ser europeo en el momento actual. También divulga artículos sobe la representación del rol de la mujer en el discurso gubernamental chileno (1990-2016) o la agenda política en el periodismo y los medios digitales en Chile. Otro titulado «Visualidad colonial sobre el Nuevo Mundo. Representación e imaginario del Reino de Chile en los grabados de Alonso de Ovalle (siglo XVII)» y finaliza con un análisis de la representatividad de los desahucios y de los desahuciados en la sociedad española actual tratando de identificar y determinar hasta qué punto el relato de los desahuciados y sus circunstancias sirven de epítome de los discursos de la crisis.

\section{ReVista InTERnacional de Relaciones Públicas \\ (Málaga: Universidad de Málaga, vol. 8, núm. 15, 2018)}

La revista publica trabajos referentes a la comunicación de crisis de Barcelona tras el atentado terrorista para conocer cómo gestionó Barcelona Turisme su comunicación de crisis durante y después del atentado de agosto de 2017 a través de su plataforma de Twitter. Otro sobre las enseñanzas de las relaciones públicas promovidas en el contexto de la racionalización del trabajo desde una perspectiva histórica brasileña. Continúa con un análisis bibliométrico comparativo de dos revistas con el título «Journal of Public Relations Research» que aparecen en el buscador de la WoS. También un artículo que tiene como objetivo conocer qué teorías de la comunicación organizacional influencian los estudios desarrollados en Brasil y cómo son apro- 
piados en la investigación y en la enseñanza en los cursos de Relaciones Públicas, Comunicación Organizacional, Periodismo y otros ofrecidos por instituciones de enseñanza brasileñas y un estudio comparativo de modelos de relaciones públicas en 60 organizaciones del tercer sector de México, Chile, Inglaterra y España utilizando Facebook. Incluye un documento que explora el uso de la comunicación de referencia para los proyectos de construcción en Cataluña después de la aprobación de la segunda estatua de Autonomía en 1979. Otro artículo trata de identificar y caracterizar las informaciones sobre políticas públicas de sustentabilidad ambiental disponibles en las páginas web del Sistema Ambiental Paulista, del Estado de São Paulo (Brasil), accesadas por medio de la red social Facebook. Continúa con un artículo sobre las organizaciones contra el cáncer de mama que profundiza en las características de los posts de Facebook con más engagement publicados por las organizaciones internacionales contra el cáncer de mama. Otro artículo analiza el uso de la escucha organizacional como estrategia de comunicación por parte de las organizaciones en España. Y finaliza con un artículo sobre los niveles de responsabilidad de los medios en sus relaciones con las minorías, centrado en la epilepsia y el autismo.

\section{REVISTA INVESTIGACIÓN BIBLIOTECOLÓGICA \\ (México: Universidad Nacional Autónoma de México, vol. 32, núm. 77, 2018)}

La revista científica mexicana editada por el Instituto de Investigaciones Bibliotecológicas y de la Información de la Universidad Nacional Autónoma de México, incluye un trabajo que tiene como objetivo es analizar el impacto de los artículos más citados que han sido publicados en las dos revistas españolas de Biblioteconomía y Documentación incluidas en el Journal Citation Reports (JCR), así como determinar la influencia de las autocitas en su índice h. Un artículo que presenta la actividad de Espasa-Calpe Mexicana desde su origen en 1927 hasta el final de la dictadura del general Franco en 1975, analizando las distintas fases de su desarrollo con el objetivo específico de aportar nuevos datos para la historia de la edición en ambos países. El objetivo del artículo titulado «La enseñanza por la investigación: interlocuciones con Paulo Freire en la docencia en biblioteconomía» es relatar y confirmar la propuesta freireana de enseñar aprendiendo al ser aplicada en el contexto de la Ciencia de la Información y discurre acerca de la práctica de la investigación aliada al diálogo y al intercambio de informaciones, procedimientos adoptados por un docente de Biblioteconomía en una universidad.

\section{REVISTA LATINA DE COMUNiCACIÓN SOCIAL}

(Tenerife: Universidad de La Laguna, núm. 73, 2018)

La revista aborda investigaciones sobre el fandom televisivo y construcción de identidad analizando comentarios de las fans españolas y los community managers en foros 
y redes sociales dedicados a la ficción televisiva española. Incluye un artículo sobre el individualismo como estrategia improvisada en la dispersión de vídeos yihadistas en YouTube y otro centrado en el caso de Verdeliss y las marcas bajo el título «La profesionalización de los youtubers». Continúa con un estudio que explora el papel de la homofilia en la argumentación y la interacción comunicativa en Facebook. En otro artículo se analizan las industrias culturales y la composición de los personajes en las series de animación infantil emitidas en España. También trata sobre la crisis económica y financiera de 2008, que ha sido un tema argumental recurrente en numerosos productos culturales contemporáneos, tales como ensayos, novelas, cómics, trabajos fotográficos, films documentales, películas de ficción, series de televisión, web-documentales, videojuegos, etc. bien para analizar las causas de este fenómeno o sus consecuencias en la actualidad.

Presenta además unos ítems-parámetros para el diseño de una escala de detección temprana y cribado sobre el uso problemático de Internet para actividades sexuales en los adolescentes y jóvenes, que nos informe si un individuo tiene o no un problema, o riesgo de tenerlo respecto a la actividad sexual en Internet. En otro trabajo se investiga sobre si el uso de un formato narrativo estructurado en Facebook produce un mayor impacto en el conocimiento sobre el VPH y en las actitudes y conductas más preventivas, que presentando la misma información en un formato no narrativo, más tradicional y expositivo. La revista también recoge dos artículos titulados «El uso de los medios de comunicación y la elaboración cognitiva: El papel mediador de la eficacia mediática» y «Las Industrias Culturales y Creativas (ICC) en las comunidades autónomas españolas centrado en Cataluña». Plantean además, si la cultura digital continúa las pautas de la cultura de masas difundida por medios analógicos o si inicia un nuevo modelo cultural en las redes digitales. A continuación se analiza el impacto de la televisión a la carta en las audiencias del prime time en España. También incluye un artículo sobre la representación composicional de la intermedia agenda-setting de los principales grupos de medios y partidos políticos en las elecciones generales españolas de 2015 y una investigación que analiza el uso de los recursos de la web 2.0 y el tratamiento informativo de 6 revistas sobre divulgación científica y pseudociencia. Seguidamente se analizan los contenidos del programa radiofónico «Complementarios» de la cadena pública Radio 5 como muestra de la preocupante pandemia de discursos pseudocientíficos que se distribuyen desde los medios de comunicación. Sigue con un trabajo que pretende analizar y comparar los actos de violencia emitidos en televisión española durante franjas horarias con diferente grado de protección a la infancia y otro sobre la implantación de la innovación en los cibermedios españoles analizando las percepciones de los periodistas. En otra investigación analiza el fenómeno de la discriminación de precios por género y su presencia en el ámbito de los productos de cuidado personal, poniendo en relación la construcción de la identidad de género en los medios de comunicación con la oferta de productos dirigidos a hombres y mujeres. El tratamiento que le otorga la publicidad audiovisual a la diversidad sociocultural se analiza en otro ar- 
tículo, centrándose particularmente en los rasgos fenotípicos. Las relaciones públicas y los desastres naturales se abordan describiéndose el papel que la gestión de la comunicación y las relaciones públicas cumplieron en el sismo del 19 de septiembre del 2017 en México. Continuando en ese país tratan las perspectivas de los estudiantes mexicanos sobre competencias en TIC, definidas por género. En otro trabajo y tras una base metodológica descrita a través de una viñeta se muestra un breve planteamiento teórico de la cuestión en el que se divide al mensaje periodístico en coyuntural y estructural. A continuación se abordan temas como «De los mass media a los medios sociales: reflexiones sobre la nueva ecología de los medios» o «Experiencia de usuario y medios de comunicación». Este último trabajo tiene por objetivo determinar el número óptimo de clics que los usuarios están dispuestos a hacer para llegar a la información que buscan. Una investigación aborda las estrategias del festival «Camerimage» para potenciar la fotografia cinematográfica, los estilos fotográficos impulsados y su repercusión en la carrera de los directores de fotografía. Otro estudio pretende determinar la evolución de la comunicación turística 2.0 en Ecuador desde la gestión de las empresas que ofrecen productos y servicios turísticos. También se recoge la contribución del futurólogo estadounidense Alvin Toffler al imaginario teórico y conceptual de la comunicación.

Se analiza la calidad de la infografía impresa en los diarios de información general de la Comunidad Autónoma del País Vasco a raíz del atentado yihadista del 17 de agosto de 2017 perpetrado en Barcelona. El trabajo titulado «Audiencia televisiva y memoria: estudio de caso de la ficción Los archivos del cardenal en Chile», se explica que la serie de ficción televisiva del canal público TVN en Chile; Los archivos del cardenal, causó impacto de impresión, recuerdo y dramatismo en los espectadores al revivir con sus dos temporadas en el 2011 y 2014, acontecimientos ocurridos en Chile durante la dictadura militar. Otro conflicto es el que se aborda en el trabajo «El tratamiento del postconflicto colombiano por medio de infografias y visualizaciones de datos». El análisis de los usos de la fotografía en la red social $\mathrm{Fa}$ cebook, a través de un estudio de 200 perfiles de Facebook de personas adultas, abre la opción de conocer cuáles son las fotografias más utilizadas para la conformación de la imagen del perfil y qué herramientas utilizan los usuarios que ya han dejado atrás la adolescencia. La eficacia en la comunicación de las ONGD y el uso de Facebook en campañas de emergencia explican que las redes sociales son la base de la eficacia de la comunicación de las ONGD. El objeto de estudio es determinar el papel de dichas redes y analizar las características de los mensajes en Facebook, la red social más utilizada en campañas de emergencia. Sigue con un análisis crítico de corte cuantitativo sobre la tendencia a la externalización de la producción en TVE. También presenta un estudio bibliométrico de las revistas de relaciones públicas catalogadas en las bases de datos Social Sciences Citation Index-Communication-Journal List y de las de estrategia del Social Sciences Citation Index-Management-Journal List, propiedades de Thomson Reuters. Se abordan temas como el desarrollo de las productoras audiovisuales en Extremadura en el siglo xxi o la evaluación de la reputación de 
los medios de comunicación realizado en Castellón en 2017 en el ámbito del proyecto I+D «La reputación de los medios de comunicación en España y en Europa». También el uso por los periodistas de las recomendaciones de la OMS para la prevención del suicidio. El caso del periódico $A B C$. Las claves del éxito de las adaptaciones de producciones televisivas españolas en el extranjero se abordan desde un análisis de los valores de producción de la serie española de RTVE «Los Misterios de Laura», adaptada por la NBC en Estados Unidos bajo el título «The Mysteries of Laura» (NBC, 2014-2016).

Mediante un estudio sobre los jóvenes universitarios en Colombia se explica la relación entre el consumo de medios digitales, la participación y la eficacia política. El objetivo del siguiente trabajo es contrastar puntos de vista, temáticas, influencias y publicaciones entre periodistas españoles y latinoamericanos. Otro se centra en la labor de periodistas y medios en pro de la libertad de expresión y en contra de la censura en un escenario post primavera árabe y un también un mapa de los cibermedios de España en 2018. En «El imaginario sociodemográfico de las mujeres en los 'mercados' sexuales y eróticos en la filmografia marroquí» se analiza y ofrece una primera base de datos sobre la representación de los mercados sexuales y eróticos de la filmografia marroquí, centrándose en las figuras femeninas: su caracterización sociodemográfica, roles desempeñados y carácter liminar de las prácticas de sexo transaccional representadas. Como una forma de personificación de la marca, otro trabajo analiza la presencia de la figura del portavoz en sus distintas modalidades y el uso que se hace de ellos en la publicidad radiofónica. La importancia y singularidad del movimiento de las radios libres en España durante la Transición Española. Este número incluye artículos sobre los menores influyentes en YouTube bajo el título «Un espacio para la responsabilidad», sobre la fuga de los millennials de la televisión lineal, sobre las mujeres cineastas y mujeres representadas en el cine comercial español (20012016), sobre la aplicación de la crítica de los dispositivos a la cena performativa de la ópera «El Somni» de El Celler de Can Roca y Fran Aleu y finaliza con un artículo sobre la construcción de la identidad infantil en el Mundo Disney y otro sobre la transparencia e información pública en las televisiones del Ecuador centrado en Ecuavisa y TC Televisión.

\section{REVISTA MEDITERRÁNEA DE COMUNICACIÓN}

(Alicante: Universidad de Alicante, vol. 9, núm. 2, 2018)

La revista que publica desde el 2010 divulga dos monográficos. El primer monográfico, sobre Educomunicación y promoción de la salud explora la eficiencia de los hospitales españoles en producción científica como indicador de transferencia de Conocimiento, la competencia tecnológica y habilidades relacionadas con las Tecnologías de la Información y la Comunicación (TIC) de los adultos maduros, las construcciones del género en tiempos de Internet como modos de expre- 
sión y riesgos percibidos en las redes sociales durante la niñez o la gamificación y transformación de la escuela. También se abordan temáticas prosociales e impacto de una intervención educativa Flipped Classroom relacionada con la promoción de la salud mediante la creación relatos audiovisuales y un estudio sobre la importancia de Informar y concienciar sobre cáncer basado en el caso de la Asociación Española Contra el Cáncer en Facebook. Finaliza con un artículo sobre la representación de la salud en la publicidad audiovisual de Manos Unidas mediante un análisis de contenido de las campañas institucionales de 1995 a 2017. El segundo monográfico, que versa sobre la generación LED abarca los siguientes temas: la educomunicación, competencias mediáticas y smartphones divulga el contenido sobre el uso crítico de los medios en la formación universitaria. También las competencias parentales positivas y Smartphones: Diagnóstico en el contexto familiar sobre la generación millennial. Continúa con las autorrepresentaciones y rasgos comunicativos de las interacciones de jóvenes en Tinder. Se presenta la aplicación móvil como estrategia de educomunicación orientada a la eliminación del castigo físico en menores en el caso de Hands up y también la validez de la publicidad como recurso en la Educación Ambiental. Finaliza con un análisis de la (d)Eficiencia en el uso del smartphone y las redes sociales en la acción pastoral de los agentes de la Iglesia de Aragón. Incluye otros artículos fuera de los monográficos, que describen el consumo literario como experiencia compartida en entornos transmedia basado en el club de los incomprendidos, la interacción de las audiencias con las noticias en los portales digitales de los principales diarios de Perú, la transformación de la docencia mediante los usos de las plataformas de e-learning en la educación superior presencial y la autonomía mediática del alumnado de Educación Infantil y Bachillerato en el caso español. Además presenta un artículo sobre la producción y edición del vídeo de bajo presupuesto en «Lost Ones» (Joan Thiele) de Giada Bossi y otro sobre formatos y sectores en el branded content musical (videoclip y moda, popstars de la musicidad). Finaliza con un análisis sobre la danza contemporánea y sincronía musicovisual en el videoclip musical actual.

\section{SCIRE}

(Zaragoza: Universidad de Zaragoza, vol. 24, núm. 1, 2018)

La revista que versa sobre la representación, normalización, tratamiento, recuperación y comunicación de la información y el conocimiento, aborda la representación, información, identificación y valoración del libro antiguo desde el punto de vista de bibliotecarios e investigadores ante un problema común. En segundo lugar presenta un estudio para trazar un mapa y discutir el conocimiento producido sobre análisis de contenido en la Ciencia de la Información brasileña. Continúa con la información como tema en el derecho y en la ciencia de la información, un estudio comparativo a partir de la realidad brasileña. Y también las confluencias filosóficas para la clasificación de las artes. Lo siguiente es un análisis sobre las influencias filosófi- 
cas de la clasificación bibliográfica de William Torrey Harris, reconocida por la literatura del área, como la fuente más inmediata utilizada por Dewey para la creación de su sistema. A continuación presenta un estudio que tiene como objetivo analizar las interrelaciones e interdisciplinariedad del Diseño de la Información, Ciencia de la Información y la Organización del Conocimiento. Seguidamente se analiza la evolución del Conjunto Mínimo Básico de Datos (CMBD), un sistema de información hospitalario desde sus inicios hasta su última versión denominada Registro de Atención Sanitaria Especializada (RAECMBD). Para finalizar, se presenta la trayectoria académica de Hope A. Olson, cuya producción bibliográfica se caracteriza por una marcada crítica hacia los principios de universalidad y jerarquía presentes en las clasificaciones documentales.

\section{Signo y PENSAMiento}

(Bogotá: Pontificia Universidad Javeriana, vol. 37, núm. 72, 2018)

Bajo el título «Avances» el número recoge artículos sobre algunos cruces textuales del discurso bíblico y político, producidos en el género discursivo periodístico de opinión «Columna», a partir de un hecho noticioso y político contingente como el "Caso Caval», que involucra a la familia presidencial chilena. Continúa con un estudio de la participación digital en la cultura que pretende contribuir a la comprensión de la participación digital en la cultura del entorno cubano. En tercer lugar, se analiza de manera crítica un conjunto de discursos, en los cuales, el concepto de diversidad cultural ha sido valorado positivamente. Para finalizar, un artículo titulado «Bibliotecas, internacionalismo y paz» en el que se explica el surgimiento de los movimientos internacionalistas y pacifistas en el siglo XIX y su relación con la llegada moderna de la bibliotecología y la ciencia de la documentación. También se discute el rol de las bibliotecas en la consolidación de la paz.

\section{Telos: Cuadernos de Comunicación e InNOVACiÓN (Madrid: Fundación Telefónica, núm. 109, 2018)}

En la entrevista que contiene el número el reconocido inventor Jaron Lanier expone su visión sobre la capacidad de la realidad virtual para iluminar y ampliar nuestra comprensión del momento y urge a revisar el universo digital que estamos construyendo. Su cuaderno central está dedicado a las cuestiones éticas que plantea el progreso, a las motivaciones y a los objetivos por los que el humano busca constantemente el mejoramiento de sí mismo y de su entorno. Y desde diferentes perspectivas se reflexiona sobre las razones por las que nos esforzamos en idear, investigar, desarrollar e innovar si no la búsqueda de la felicidad y el bienestar; el logro de la equidad y el bien común. Los autores apuestan por un desarrollo que ponga los valores de la humanidad por encima de todo. 


\section{Trípodos: Llenguatge, Pensament, Comunicació}

(Barcelona: Universitat Ramon Llull, núm. 41, 2017)

El número sobre la revista es un monográfico sobre el cine negro, thriller y policíaco español desde una perspectiva histórica.

En primer lugar propone una aproximación al estudio de la evolución del género en España desde sus albores hasta la actualidad, enlazándolo con la progresión histórico-política del país y de la cinematografia autóctona. A continuación se descubre cómo una parte muy importante de estas producciones tendrán su origen en las productoras barcelonesas. En el siguiente texto se expone cómo en el universo cinematográfico del thriller "Angustia» dirigido por José Antonio Nieves Conde se logra hacer copartícipe al espectador de la inquietud y la desazón experimentada por una subjetividad alienada. Además se explican las singularidades y rupturas del cine criminal español a través de «Los ojos dejan huellas» (1952). En el siguiente artículo se analiza el tratamiento y promoción del filme «El cebo» (1958), desde una perspectiva aleccionadora. También un análisis sobre el cine de temática policíaca de la Transición española o una investigación sobre el acercamiento formal de Antonio Drove al cine negro en "La verdad sobre el caso Savolta» (1978) que choca con prácticamente todo lo visto anteriormente en el cine español según la crítica de la época. «Asesinato en el Comité Central», de Vicente Aranda (1982) es un thriller político que en su momento no tuvo ni fortuna crítica ni éxito de taquilla y que, en parte, fue repudiado por su propio director que con el tiempo nos permite proceder a una relectura que valore su clara raíz esperpéntica.

En un estudio comparativo entre «Plenilunio» y «Caníbal» se analiza el psicohorror en el cine español del nuevo milenio. Este número también incluye artículos sobre la polivalencia periodística en las agencias de noticias AFP, EFE, ANSA y ACN con el objetivo de hallar los límites que no deben traspasarse para evitar que la sobrecarga de trabajo reduzca la capacidad de informar y un trabajo que estudia la estrategia digital con audiencia social desarrollada por las principales formaciones políticas durante el debate electoral del 13 de junio de 2016 retransmitido por $17 \mathrm{ca}-$ denas de televisión, fue el quinto debate más visto en la historia de España y alcanzó 1,8 millones de tuits. 

Reseñas

Liburu aipamenak

Book Reviews

\section{zer}





\section{Media and Global Climate Knowledge. Journalism and the IPCC}

\section{Risto Kunelius, Elisabeth Eide, Matthew Tegelberg y Dmitry Yagodin}

(Editores)

Nueva York: Palgrave Macmillan, 2017

Este libro es un estudio de caso amplio y detallado sobre cómo los periodistas de más de 20 países del mundo, cubrieron los informes de la Quinta Evaluación (AR5) del Panel Intergubernamental sobre el Cambio Climático (IPCC), en el que se debatía sobre el estado del conocimiento científico más relevante en el área. Es una lectura necesaria para cualquier persona interesada en lo que se debe y no se debe hacer respecto a la comunicación científica de esta temática.

La obra está dividida en 13 capítulos en los que se destaca la importancia del periodismo como elemento clave para la divulgación trasnacional de la política climática, que debe a su vez aceptar, el nuevo reto de una dinámica cambiante en la comunicación de un mundo cada vez más interconectado. Donde se están renegociando términos como el de los valores individuales, el acceso al conocimiento presente y futuro, o el trabajo del periodista y su relación con las fuentes y los estados. En la AR5, se instó a los periodistas a ir más allá de centrarse en la evidencia de que el cambio climático está ocurriendo, y a enfocar sus esfuerzos en describir cómo está ocurriendo ese cambio. Debemos pasar de una preocupación de alarma global, que ha sido importante y útil, a una concienciación general sobre los desafios que se presentan actualmente para la mitigación y adaptación a este cambio.

El buen periodismo climático, como plantea el texto, requiere estímulo y apoyo. Especialmente a nivel local, en donde deben generarse de manera activa las preguntas más críticas que fomenten políticas reales, con consecuencias reales para las personas. Las nuevas alianzas trasnacionales en pro de una comunicación global entre, medios de comunicación, periodistas, redes sociales y demás actores, están ayudando a los periodistas a producir espacios más diversificados de interpretación pública.

En la lectura de los diferentes capítulos se examinan las variaciones de cobertura periodística en distintos países y ubicaciones y se promueve que el periodismo de aquellos estados que prestan poca atención a la comunicación del cambio climático, exploren, cultiven y aprendan a vincular el tratamiento del clima con temas que son de interés local. A su vez, en el documento se analiza cómo los científicos del IPCC revisan el papel de los medios de comunicación y su relación con los periodistas de la ciencia, y se sugiere un mayor diálogo entre ambos, dentro de una atmósfera de reconocimiento mutuo y confianza.

Se muestra la necesidad urgente de que se realicen más estudios de comunicación climática entre países, que abarquen los diversos modos de tratamiento en el panorama actual de los medios. En particular, se necesita más investigación sobre las redes sociales y la comunicación científica, especialmente sobre cómo los científicos que estudian el clima pueden participar directamente en los diálogos 
con otras partes interesadas, a través de las redes sociales, mejorando la comprensión de estos agentes y de la política climática. Del mismo modo, abogan por centrar las investigaciones en mejorar la divulgación de los diferentes tipos de ciencias del clima (desde física y geología hasta economía y sociología), para así beneficiaríamos de un análisis más detallado sobre casos en los que la comunicación científica ha sido parte exitosa de la producción de políticas públicas informadas (lluvia ácida, gases de efecto invernadero, tabaco, etc.). Esto haría que mejorásemos nuestra comprensión de cómo enfrentarnos a los desafios de políticas diferenciadas que mitiguen los efectos adversos del clima.

Los informes completos de la Quinta Evaluación del Panel Intergubernamental sobre el Cambio Climático, aproximadamente 7.000 páginas, no están destinados para ser comprendidos por un público general. Este es uno de los temas que se debatieron durante la cumbre. Los científicos deben comprometerse a destilar y hacer accesibles sus investigaciones a los miembros de los diferentes estados, periodistas y ONG, superando el desafio que supone desarrollar y lanzar mensajes coherentes que sirvan para tomar decisiones en políticas públicas.

Muchos periodistas, por su parte, poseen una formación menos que adecuada sobre cambio climático y tienden a dar una perspectiva de fatalidad y alarma a estas noticias, que genera una sensación de miedo muy perjudicial. Otra de las preguntas que generó mucho debate, tiene que ver con la prioridad que tienen los medios de comunicación en informar de manera global sobre estas cuestiones, en una época en donde existe mucha presión comercial y se recorta en corresponsales y periodistas especializados.
La comunicación del cambio climático a menudo se deja a estos periodistas sin la experiencia necesaria para interpretar los informes del IPCC. En términos generales, podemos afirmar que el IPCC ha puesto la comunicación del cambio climático en su agenda con mucho más interés que en el pasado, lo que atestigua la urgencia del asunto. Una forma de optimizar esta situación sería mejorando la capacitación de estos profesionales, tanto la de los periodistas en general como la de los especializados. De este modo podrían representar los intereses de los ciudadanos y desempeñar el papel de intermediarios.

Desde la década de 1960 los periodistas evaluaban los sucesos según criterios de proximidad y relevancia cultural, política o económica. Esta manera de hacer, mantuvo su validez hasta principios de la década de 1990. Ahora, para que una noticia llame nuestra atención es imprescindible apoyarse en rasgos culturales y narrativas locales, es decir, en fuentes y actores capaces de traducir los temas internacionales a versiones localizadas. Con esta práctica, en la que los actores de las noticias locales se convierten, en participantes y agentes activos, el debate público que se crea reconstruye el discurso global y abre espacios nacionales de interpretación. También hay similitudes y patrones transnacionales que se extienden más ampliamente entre determinadas naciones pero que no se comparten globalmente. Esto puede deberse al papel que han ejercido las agencias internacionales de noticias, la cultura periodística transnacional, las afinidades ideológicas, el legado de la Guerra Fría o las alianzas entre gobiernos.

Son muchos los factores que se analizan en este libro para comprender cómo se produce hoy en día la comunicación del cambio climático, pero debemos ir 
más allá. Como afirman los autores, el mundo ya se ha comprometido con el cambio climático, ahora es el turno de científicos y periodistas. No hay otra opción más que comprometerse a encontrar «formas de hacer» frente a los desafios que esto conlleva.

Norberto Fabián Díaz Duarte

\section{La estética televisiva en las series contemporáneas}

\author{
Miguel Ángel Huerta Floriano \\ y Pedro Sangro Colón (ed.), 2018 \\ (226 páginas) \\ Valencia, Tirant Humanidades
}

A pesar de que la ficción (sus tramas, estilo visual, retórica) ha motivado la eclosión de una edad de oro en la televisión, la estética de sus series es uno de los aspectos que los estudiosos del medio no se han atrevido a abordar en profundidad y cuando lo han hecho ha sido de manera tangencial. Huerta Floriano y Sangro Colón, como editores, han decidió rellenar este vacío con valentía ya que el trabajo que el volumen titulado La estética televisiva en las series contemporáneas supone enfrentarse a miles de horas de visionado y a géneros y estilos múltiples y diversos. La declaración de intenciones que se manifiesta en la introducción pone de relieve el problema de la inabarcabilidad del objeto de estudio al afirmar que «el presente libro tiene la vocación de ser una humilde contribución en español a las reflexiones sobre las cualidades formales de la serialidad audiovisual. Lo hace sin pretender un alcance fundacional, pues el volumen se construye a partir de la fragmentación propia de la autoría colectiva», que se puede desmembrar en once colaboraciones de diferentes universidades tanto estatales como fuera de nuestras fronteras desatacando las firmadas por Jordi Ballò y Concepción Cascajosa.

El objetivo del estudio coordinado por Huerta y Sangro es el de sacar a la luz las estrategias formales que se encuentran en la base de esas miles de horas de visionado que han generado uno de los fenómenos culturales definitorios del ocio. En este sentido, los autores implicados se empeñan en desentrañar los motivos visuales, construcción de los personajes, estrategias de montaje, o la utilización del punto de vista, en series de tanta influencia como Twin Peaks, Juego de Tronos, The Wire, Fargo, Narcos, The Night Of, Girls, Hannibal o Boardwalk Empire.

Una investigación de este calibre no podría comenzar de otra manera que eligiendo a Twin Peaks como ejercicio de análisis aplicado ya que es la serie que lo cambió todo, revolucionando primero el mundo televisivo en sus dos primeras entregas a principio de la década de los noventa para trascenderlo en 2017 en su tercera temporada. El acertado estudio firmado por Jordi Ballò y Xavier Pérez expone las transgresiones de Lynch ante la idea del hogar como espacio de la estabilidad, el mito de Orfeo y la culpa edípica. Ballò y Pérez rastrean la influencia de la serie seminal de Lynch en ficciones televisivas posteriores.

El siguiente capítulo, firmado por M. A. Huerta, bucea en la presentación audiovisual del protagonista de once series 
de prestigio descubriendo parámetros similares en muchas de ellas. Un elemento recurrente consiste en la presentación del personaje de espaldas a la cámara, signo visual que nos revela una identidad conflictiva.

Twin Peaks también es la elegida como punto de partida para que Iván Pintor desarrolle las líneas generales de una estética de la negatividad en la ficción contemporánea. El capítulo amplia la investigación sobre el espacio de la maldad en otras ficciones, como es el caso de True Detective, para llegar a la conclusión de que nace como consecuencia de la ausencia de pasión.

Muchas de las ficciones contemporáneas utilizan como táctica de atracción la representación de lo repugnante. La aportación de A.N. García Martínez responde a la pregunta de a qué se debe la atracción por relatos que visualmente nos incomodan y emocionalmente rechazamos, utilizando ejemplos de series como Dead Wood y Hannibal.

A partir del quinto capítulo este punto de vista comparativo se pierde a favor del análisis de series concretas: Fargo (P. Sangro Colón), Narcos y El Patrón del Mal (E. Pérez Morán), Girls (A. Tous- Rovirosa), Hannibal (J. Medina Contreras) o Boardwak Empire (R. Gelado Marcos). De este gran bloque destaca el capítulo firmado por Concepción Cascajosa, una de las académicas más reputadas en la investigación de la ficción televisiva, que centra su análisis en el estudio de The Night Of y de cómo los atentados del once de septiembre cambiaron el panorama cultural estadounidense y, por supuesto, afectaron a la producción audiovisual al reflejar la realidad de un espectador marcado por el miedo, poniendo en marcha una estética de la vigilancia que utilizará motivos visuales reiterativos, como es el caso de las sombras.

Es evidente que resulta imposible abarcar todos los títulos televisivos y que muchas series de culto no aparecen mencionadas en el presente volumen pero también lo es que el trabajo coordinado por Miguel A. Huerta y Pedro Sangro pone la primera y fundamental piedra en el estudio de la estética televisiva de las series contemporáneas tal y como pretendían.

Carmen Arocena

\section{Periodistas (in)formados}

\author{
Pilar Sánchez-García (2017) \\ Madrid: Editorial Universitas, S.A.
}

El presente libro se marca el objetivo de analizar cómo ha sido, es y será la formación de los periodistas en España. Constituye un excelente manual para estudiantes y profesorado de Periodismo y Comunicación, y para el público en general interesado en la evolución de la Historia del Periodismo en España desde la perspectiva de la enseñanza periodística. Ofrece un repaso pormenorizado de la evolución formativa desde las primeras escuelas privadas y el control dictatorial de la Escuela Oficial de Periodismo, a las primeras universidades y hasta las actuales facultades con Grados en Periodismo que tratan de adaptarse a las tendencias tecnológicas innovadoras que provocan transformaciones constantes en las redacciones de los medios. 
Esta monografía nace no sólo de la pasión que su autora Pilar Sánchez-García procesa por la profesión periodística, sino también de su vocación docente y de la responsabilidad académica que le inspiran las aulas. Pero además es el resultado de las reflexiones personales y profesionales de los últimos veinte años de su vida.

Una interesante contribución que también responde al interés académico de recoger en una única obra la evolución de la enseñanza del Periodismo en nuestro país desde principios del siglo xx para acabar dejando constancia de las tendencias y las necesidades más acuciantes en la formación del periodista del siglo XXI, con el dificil empeño de buscar el equilibrio adecuado entre la enseñanza práctica y teórica multidisciplinar.

Y es que Sánchez-García es una ferviente defensora de una formación en técnicas y prácticas innovadoras cada vez más rigurosa de los periodistas para que sean capaces de adaptarse a un entorno comunicativo cambiante, pero también con refuerzo teórico y humanístico que contribuya a formar para ser mejores periodistas. Alegar en favor de llevar a las aulas de nuestras facultades la tecnología más actual tiene que ser compatible con la labor tradicional del periodista de servicio público, de informar interpretar, contrastar y contar las mejores historias posibles que ayuden a comprender la realidad de cada momento. Y puntualiza «necesitamos periodistas polivalentes, innovadores, que conozcan y conecten con sus audiencias, pero también periodistas muy formados intelectualmente, mucho más, para interpretar la realidad social, política, cultural, económica y religiosa cada vez más compleja, propia de un mundo global e hipercomunicado».
La discusión en torno a la enseñanza del Periodismo, sobre su historia, sobre la transformación acontecida en las redacciones y la consideración social de la propia profesión que mira a un futuro en constante cambio, se presenta en esta monografia a través de cinco capítulos organizados en dos partes: la perspectiva histórica y evolución de la enseñanza periodística; y el presente y futuro de una titulación en plena fase de rediseño de sus planes de estudio para adaptarse a un entorno comunicativo mutante.

La primera parte abarca tres capítulos claramente diferenciados en los que se aborda el debate en sí de la formación de los periodistas, las claves más relevantes y la propia evolución de los planes de estudio. Así, el capítulo uno posibilita contextualizar la propia evolución del debate sobre la enseñanza del Periodismo mediante un paralelismo entre los argumentos y discusiones de principios del siglo xx y los del siglo xxI. Un debate que, según la propia autora, «discurre ligado a la concepción que la sociedad tiene del Periodismo y de la labor del periodista en diferentes épocas, como oficio o como profesión con base científica». El segundo capítulo ofrece la revisión histórica de la enseñanza del Periodismo en España que abarca casi un siglo de cambio y evolución con distintas etapas en las que los poderes fácticos de cada momento muestran su interés por influir en la formación ideológica de los periodistas. Por último, el tercer capítulo se centra en la evolución de los planes de estudio de Periodismo desde los primeros programas y asignaturas concretas que se impartían en las escuelas hasta oferta universitaria en el siglo XXI. La principal transformación que Sánchez-García detecta en este periodo es el salto de una formación instrumen- 
tal y técnica propia de las primeras escuelas, hacia los programas más completos y multidisciplinares de las Universidades.

La segunda parte del libro se centra en el presente y el futuro de la titulación, desde los nuevos Grados surgidos del Plan de Bolonia (2010) hasta las tendencias universitarias de la Comunicación, en general, y del Periodismo, en particular. Así, el cuarto capítulo aborda las consecuencias de la doble convergencia educativa y tecnológica de los estudios de Periodismo con la transformación de criterios educativos como motivo de su adaptación a la normativa del Espacio Europeo de Educación Superior (EEES) y la modificación de tecnológica que ha alterado el entorno comunicativo de una manera profunda y permanente. Esta doble convergencia, en palabras de la propia autora, "provoca una revisión de los programas formativos de la titulación con algunas consecuencias constatables: el progresivo recorte de los conocimientos teóricos de otras áreas de las Ciencias Sociales y el aumento del contenido práctico enfocado a los nuevos roles multimedia del periodista». Como no podía ser de otra manera, el quinto y último capítulo de este libro deja entreabierta una ventana de discusión académica con la mirada puesta en el futuro más a corto plazo de la enseñanza del Periodismo que atraviesa una de las etapas de mayores transformaciones y que pasa por ayudar a aumentar la calidad periodística disponiendo al alumnado en los nuevos lenguajes, con formatos innovadores y modelos comunicativos emergentes.

Por último, se incluyen, en forma de anexos, una amplia recopilación de la normativa relaciona con la enseñanza del Periodismo en España (1938-2013), así como una detallada base de datos de las cuarenta universidades que cuentan con estudios de Grado en Periodismo, de las que se facilitan enlaces a sus planes de Licenciatura y Grado publicados en el BOE y en sus respectivas webs.

En definitiva, este libro constituye una excelente clase magistral de Periodismo que muestra el recorrido de la formación de los periodistas a través de la historia acercando al lector ante el abismo de lo que está por llegar; un debate el formativo que no sólo sigue adherido a la profesión desde sus inicios sino que se ha avivado en estas primeras décadas del siglo XxI. Sánchez-García concluye: «la formación profunda y permanente constituye la única respuesta para ejercer un Periodismo de calidad que se proteja a sí mismo como profesión en el presente y en el futuro».

Koldobika Meso Aierdi

\section{Una televisión con dos cadenas. La programación en España (1956-1990)}

\author{
Julio Montero Díaz (dir.) (2018) \\ Madrid: Ed. Cátedra (Grupo Anaya)
}

«Una televisión con dos cadenas. La programación en España (1956-1990)» es un libro que nace para paliar un hueco respecto a los inicios de la televisión en España. El equipo liderado por Julio Montero Díaz no acomete el proyecto con capítulos independientes con un paraguas común, sino que lo aborda como un todo, como un análisis cronológico de 
los 34 primeros años de TVE, estructurado en base a su programación. La acotación del período a investigar y su posterior forma de análisis resulta novedoso e interesante. Umberto Eco distinguía entre la paleotelevisión y la neotelevisión, la primera dedicada a promocionar unos valores educativos, ideológicos, que contribuyen a la cohesión nacional; y la segunda, en cambio, se rige por la lógica del mercado y el beneficio. El tránsito de uno a otra tiene lugar en la década de los 80 , pero ésta no es la línea divisoria del libro; el grupo de investigación autor de «Una televisión con dos cadenas» opta por un límite temporal comprendido entre su aparición hasta el surgimiento de las cadenas privadas. Es esta frontera la que les permite investigar los cambios producidos durante ese periodo basándose en su programación.

Frente a historiadores anteriores que asentaban sus estudios en los recuerdos de los agentes implicados o que extrapolaban conclusiones desde el visionado de uno o dos programas, los autores de este libro deciden analizar el contenido televisivo desde su conjunto, mediante el visionado y la reconstrucción de la programación del periodo a investigar. Utilizan la definición de flow, el fluir de los distintos programas, postulada por Raymond Williams (1992) por la que la unidad televisiva de análisis es la programación. Es válida aquí la analogía cinematográfica por la que la programación sería la película y los programas sus secuencias, esto es, unidades más pequeñas que las componen. Hay que analizar la programación para entender bien cada programa. «El estudio del flow conforma el primer escalón en la investigación académica sobre televisión y, desde luego, sobre la historia de la televisión» escribe Julio Montero en la introducción.
El libro distingue tres tipos de programación : la que tuvo lugar durante el franquismo, desde los inicios, octubre 1956, hasta diciembre 1975; la de la transición democrática (desde el 19 de diciembre de 1975 hasta el 7 de diciembre de 1982) y, por último, la programación televisiva en la era socialista, (desde el 8 de diciembre de 1982 hasta el 31 de diciembre de 1990).

Un capítulo introductorio a cada parte describe la parrilla, contextualiza el periodo y explicita los objetivos de la misma para desmenuzar, en contundentes capítulos, los distintos géneros: informativos, ficción nacional, extranjera, cine, concursos y programas de variedades, deportes, toros, programas infantiles y juveniles y de divulgación científica y cultural. Es indispensable analizar, junto al contenido televisivo, dos elementos constituyentes de la televisión: la publicidad de aquel periodo y las audiencias y consumo televisivo. A lo largo de las tres partes la estructura se repite, así como los autores del análisis de cada género, reforzando la continuidad del fenómeno a estudio.

Es un libro que, gracias a su planteamiento como a su unificación de estilo, es atractivo tanto para el especialista como para el telespectador de aquellos años, quien, atraído por la nostalgia de sus recuerdos, observa ahora esos programas bajo otra luz al conocer las decisiones estratégicas que el momento imponía al medio.

Tal y como mantiene "Una televisión con dos cadenas», el propósito principal en los comienzos de la televisión era el entretenimiento basado en la ficción $(60 \%)$, frente a una presencia menor de programas informativos (25\%) y divulgativos $(21 \%$ en el segundo canal, $14 \%$ en 
la Primera). El segundo canal, desde su aparición en 1966, se caracteriza por dedicarse a la divulgación y la educación, y como campo de pruebas de programas que pasaban a la Primera si tenían éxito. Esta primera fase de la televisión no es homogénea y comprende, a su vez, otros tres subtipos de parrilla: la experimental, entre 1956-1963, la puzzle, desde 1964 hasta 1969 y consolidación de la la parrilla moderna entre 1970 y 1975.

En la época experimental, las escasa horas de emisión se iban llenando con contenidos cuya aceptación intentaban medir con las cartas, llamadas de teléfono o cuestionarios de sus telespectadores, a quienes pedían participación mediante la revista Tele-Radio. La táctica de prueba-error funciona y la parrilla comienza a asentarse y a planificarse de forma estratégica, inaugurando técnicas de captación como el lead-in, el hammock o la tent-poling, elementos que culminan en una forma moderna de programar. Es una televisión que trata más de agradar que de adoctrinar y los pasos que toma en su evolución es muy similar a sus vecinas europeas.

Es la Transición (1975-1982), sin embargo, quien hace un uso más doctrinal de TVE. A través de este medio se mantiene informada a la ciudadanía de los pasos políticos y, a su vez, se socializan las prácticas democráticas, educando en nuevas formas de comportamiento social del nuevo periodo de libertades. El Estado realizó una potente campaña de comunicación, convirtiendo la TV en un instrumento político para influir en la opinión pública. Es el momento en el que aparecen los debates y los programas de entrevistas, promocionando a los protagonistas de la política y la cultura del momento. Eran una forma de presentar al público a los protagonistas del cambio político, rescatados del olvido y la ignominia a la que les había destinado el régimen.

La era socialista (1982 - 1990) inaugura una TV comercial, preocupada en recaudar, vía publicidad y no mediante los Presupuestos, los recursos que la innovación tecnológica (color, cámaras ligeras,...) requiere. Los contenidos se espectacularizan y los tres directores de este periodo efectúan cambios importantes en el organigrama y gestión del medio. Es un periodo de grandes programas tanto en ficción como en entretenimiento y, simultáneamente, la consolidación de una televisión controlada por el Gobierno, sin un contrapeso que pudiera dotarla de mayor imparcialidad y margen de maniobra.

«Una televisión con dos cadenas. La programación en España (1956-1990)» es un libro riguroso y entretenido, con una perspectiva que va de lo global a lo concreto y que incluye los elementos fundamentales en el carácter del medio como son las audiencias y la publicidad. Entre el ramillete de recuerdos que despliega su lectura, quizás los lectores de las Comunidades Autónomas con cadenas propias, añoren referencias y explicaciones sobre aquellos contenidos compartidos por la FORTA que, aunque no alcanzaron a todo el Estado, crearon un conjunto de nostalgias compartidas en muchos telespectadores alejados geográficamente entre sí.

Itxaso del Castillo Aira 


\section{Fashion Branding and Communication: Core Strategies of European Luxury Brands}

Byoungho Jin y Elena Cedrola

(editores)

Nueva York: Palgrave Macmillan, 2017

Este libro es el segundo volumen que las editoras Jin y Cedrola han publicado en los dos últimos años. El primero, Fashion Brand Internationalization: Opportunities and Challenges (2016) ofrece una visión completa de cómo las marcas de moda construyen y gestionan sus negocios en otros países. En esta segunda entrega se centran en enumerar las estrategias básicas e innovadoras de las marcas como activos, e identifican las diferentes herramientas de comunicación que utilizan las marcas de lujo en el mundo de la moda para consolidar su identidad.

El volumen comienza con un capítulo introductorio que resume la esencia de la gestión de las empresas de moda, con un énfasis particular en las prácticas de marca emergentes, los desafios y las tendencias en la industria. En los siguientes cinco casos que describen en los capítulos, se muestra cómo un taller familiar de una pequeña ciudad puede convertirse en una marca global de lujo o de primera calidad en un período de tiempo relativamente corto. Nos hablan también de los académicos y los profesionales de la moda, del comercio minorista, la marca y de cómo se efectúan los negocios a nivel internacional.

Centrándonos en las nuevas tendencias y desafios del branding en el negocio de la moda, especialmente en lo que las autoras han tratado respecto al tema de la comunicación, nos hablan de cómo las empresas combinan técnicas tradicionales de difusión con otras más innovadoras como las redes sociales, los blogs, la venta por Internet, las ediciones limitadas de colecciones de ropa, el marketing de guerrilla o el nuevo concepto de las tiendas Pop-Up que refuerzan el valor de la marca al ofrecer espacios experienciales de compra, entre otras.

La publicidad siempre ha ocupado un lugar destacado en las estrategias de comunicación de la industria de la moda, especialmente entre las marcas de lujo. Las autoras recogen que las revistas de moda especializadas, como Vogue, Elle y GQ, emplean esta herramienta tradicional, no solo para vender, sino también para inspirar al consumidor a identificarse con ellas. Por esta razón aproximadamente el $75 \%$ de una revista de moda se compone de anuncios. Con la llegada de la era digital las revistas desarrollaron dos innovaciones para aumentar el número de ventas. En 1993 Salvatore Ferragamo fue el primero en introducir las página plegables de las portadas. La otra innovación consistió en incorporar las muestras de cosméticos y perfumes que se han ido ampliando con el regalo de otros accesorios como pulseras y bolsos.

En el texto se señala cómo los famosos pueden ayudar a destacar a las marcas e ingresar en nuevos mercados al atraer la atención de los consumidores, pero para ello la imagen transmitida por la marca debe ser coherente con el personaje seleccionado. Hoy en día, actores famosos, atletas o estrellas del pop están reemplazando a las modelos. Algunos ejemplos incluyen a Sofia Coppola para Marc Jacobs, Keira Knightley para Asprey y AdamBrody para Ermenegildo Zegna. 
En la industria de la moda y el lujo, las relaciones públicas son una estrategia cada vez más común y de mayor impacto que atrae la atención de los medios. De igual manera, eventos como los desfiles en los que los diseñadores presentan sus creaciones durante las semanas de la moda, dirigiéndose a los compradores y la prensa internacional y las grandes inauguraciones de tiendas en lugares estratégicos, también están proliferando.

También se señala en el libro, que el patrocinio de eventos es otra manera de que las marcas se den a conocer. Un ejemplo es el Gran Premio de Hermès en París, considerada una de las competiciones ecuestres más prestigiosas a nivel internacional. Lo que permitió a Hermès aumentar su asociación con la tradición y la aristocracia británica. El último tipo de eventos que se describe, es el que se realiza en ceremonias exclusivas. Son ocasiones en las que la marca está vinculada a celebridades a través de eventos como los Grammy. AwardMTV, los Oscar y el Cine. Richard Gere usó trajes de Armani en la película "American Gigolo», imprimiéndole prestigio a la marca, lo que culminó en un fuerte aumento en las ventas de marca después del lanzamiento de la película.

En el sector del lujo, los productos los suele vender el propio diseñador o bien especialistas. Con la venta personal se pueden adaptar a las necesidades individuales de los consumidores. En este sentido, en el libro se especifica que la distancia entre vendedores y consumidores es más cercana en Occidente, mientras que en Asia es más distante y jerárquica.

La difusión de las redes sociales también ha cambiado la moda y el lujo. Las redes sociales más habituales incluyen $\mathrm{Fa}-$ cebook, Twitter, YouTube, Instagram y MySpace. Para las editoras, Facebook se utiliza principalmente para lanzar nuevos productos y establecer relaciones con clientes y fans. Twitter es una herramienta de relaciones públicas que permite a las empresas evaluar la satisfacción de los consumidores a través de chats virtuales. YouTube representa la narración de cuentos en forma de cortometrajes. Instagram es una de las aplicaciones sociales más conocidas para las marcas, que les permite mejorar sus valores fundamentales a través de imágenes. Es por eso que Burberry no solo publica fotos relacionadas con sus campañas publicitarias, sino también imágenes de rincones característicos en Londres, que la relacionan con la cultura británica. Instagram también sirve como una plataforma virtual donde las personas pueden proponer diferentes estilos y combinaciones utilizando un hashtag (\#). También se utilizan Tumblr, Flickr, Pinterest, Foursquare y eBay FashionGallery. Además, las marcas han desarrollado cada vez más aplicaciones para teléfonos inteligentes como Chanel, Gucci, Ralph Lauren, Donna Karan.

Los blogs de moda están hechos, o bien por expertos que han trabajado en el mundo de la moda o para los medios de la moda tradicional, o bien por blogeros independientes que son expertos en moda y consumidores frecuentes, cuyas opiniones tienen mucha repercusión. Las empresas ya no ignoran este fenómeno. Dolce \& Gabbana decidió colocar por primera vez a blogeros famosos en la primera fila de sus desfiles, que realizaban sus comentarios a tiempo real, mientras que antes los diseñadores tenían que esperar al menos una semana para conocer las críticas. La inmediatez está cambiando la comunicación de la moda. 
Otro fenómeno que está transformando el mercado de la moda es que, desde 2006 las principales marcas de lujo están empezando a vender productos directamente desde sus páginas corporativas. Se espera que las ventas digitales de la moda de lujo para mujeres, aumenten a un $17 \%$ en 2018 y lleguen hasta un $40 \%$ en 2020 .

Una tendencia creciente tanto en marcas de diseñadores como en marcas masivas es la introducción de productos de edición limitada al restringir la cantidad producida y la cantidad de tiempo en que está disponible para los consumidores. Se hizo popular después de la exitosa colección de H\&M con Karl Lagerfeld en 2004. Desde entonces, H\&M ha seguido creando colecciones limitadas con muchos diseñadores líderes, como Stella McCartney en 2005, Jimmy Choo en 2009 y Versace en 2011 y 2012, y celebridades, Madonna en 2007 y Beyoncé en 2013. Proporciona un canal para que los diseñadores y marcas de alto nivel aumenten su exposición a mercados masivos, algunos de los cuales pueden convertirse en potenciales consumidores en el futuro. Además aumentan las ventas porque crean un sentido de urgencia y exclusividad, y las protege, porque el producto tiene una disponibilidad limitada.

Las autoras describen el término marketing de guerrilla, como aquellas actividades de comunicación que vienen a sorprender al público. Se trata de acciones o eventos que provocan un gran revuelo entre los consumidores y que les hace ganar visibilidad entre los principales medios de comunicación, aunque ocurren durante un período de tiempo corto y tienen presupuestos limitados. La marca española Desigual puso en marcha la gira Kiss en París, Londres, Berlín y Madrid en 2010, con un evento abierto a todos los que quisieron intercambiar un beso. El beso sirvió como un símbolo de afecto que se corresponde con la filosofía de la empresa para difundir mensajes positivos, identificaron el beso como sinónimo de amor.

Otra herramienta de marketing son las tiendas Pop-Up, que permanecen abiertas en períodos que van desde una semana hasta un año y que están ubicadas en lugares estratégicos y sorprendentes como museos, iglesias, antiguos almacenes u otras estructuras no convencionales. $\mathrm{Mu}-$ chas marcas de la industria también han elegido ubicaciones móviles como autobuses o furgonetas para permitir que la marca llegue a muchos lugares. Otra estrategia utilizada por las tiendas Pop-Up es la sincronización. Muchas marcas abren durante una semana de la moda o en ocasiones especiales como la Navidad. Chanel, por ejemplo, abrió una tienda Pop-Up en Cannes junto con el Festival de Cine. Pueden considerarse como una forma de marketing de guerrilla porque su apariencia puede sorprender a los consumidores, pero que las autoras definen como una actividad diferente. Estas tiendas pueden proporcionar una salida para que los consumidores adquieran una experiencia diferente con la marca y entiendan sus valores.

Las últimas tendencias para reforzar la imagen de las marcas de moda, según Jin y Cedrola, pasan por ofrecer las experiencias como productos. Los consumidores acuden a las tiendas insignia no solo para comprar productos, van a experimentar la marca, la compañía y los productos en un entorno exclusivo. Hoteles, restaurantes y cafés refuerzan la imagen de marca y crean una visión más holística para las empresas, creando espacios como el Ho- 
tel Armani en Milán y Dubai o el restaurante que ofrece Polo Ralph en su tienda principal de Chicago. En estos espacios, los logotipos de las marcas de moda se colocan estratégicamente en elementos como la decoración de las habitaciones, la ropa de cama, las toallas, el jabón, los platos y los cubiertos, creando un vínculo emocional con las marcas.

Está claro que las marcas evolucionan como los seres humanos, pero si saben gestionar estratégicamente su imagen y la comunicación con sus consumidores, perdurarán en el tiempo y conseguirán mayores beneficios.

\section{Carolina Raigosa Díaz}

\section{Irresistible: The Rise of Addictive Technology and the Business of Keeping Us Hooked}

\author{
Alter, Adam (2017) \\ Penguin Press
}

Hubo un tiempo en donde las pantallas que nos rodeaban eran limitadas, casi inexistentes. La tele al llegar a casa o una visita esporádica al cine era el único contacto que teníamos con aquel resplandeciente objeto cristalino. Pero desde aquellos días mucho ha cambiado; hoy en día, en casi cualquier lugar y a todas horas estamos al frente de una pantalla. Cuando sumas una superautopista de la información disponible 24/7 y la erupción del smartphone, te encuentras entonces a millones de personas pegadas empedernida- mente a una pantalla negra en un ciclo infinito de uso.

Con la nueva era de la información también han llegado nuevos problemas y hábitos de consumo. Y es que cada vez estamos más enganchados a nuestros dispositivos móviles y se nos hace más dificil desprendernos de estos irresistibles aparatos. Irresistible, con ese leitmotiv nos presenta Adam Alter, profesor asociado en la Stern School of Business de la Universidad de Nueva York e investigador de psicología y marketing, su último trabajo investigativo. A través de 368 páginas nos advierte de las terribles consecuencias y de los efectos negativos que las nuevas tecnologías de la información, los videojuegos y las aplicaciones móviles están teniendo en nuestra sociedad actual, bienestar emocional y psicológico.

El libro comienza con una impactante revelación: ni Steve Jobs, ni el fundador de Twitter, Evan Williams, así como muchos otros líderes del sector tecnológico, permiten que sus hijos usen a rienda suelta ninguno de los productos y servicios que éstos crean; de hecho, Jobs no tenía ningún ejemplar en casa de uno de sus productos estrella: el iPad. Pero, ¿por qué uno de los genios del diseño informático no dejaba que sus vástagos utilizaran una de sus mayores creaciones? Alter cree tener la respuesta: así como los grandes narcotraficantes, los jefes de Silicon Valley se rigen bajo la misma regla fundamental de la distribución de estupefacientes: nunca te drogues con tu propio suministro.

Mediante un análisis inteligente y fascinante, el autor, capítulo a capítulo, va describiendo de forma crítica y cruda (junto a testimonios de titanes de la industria) cómo las redes sociales, los sitios 
de apuesta online y los videojuegos de ordenador están diseñados deliberadamente para enganchar a sus usuarios y explotar cada una de sus vulnerabilidades psicológicas. No es casualidad por lo tanto que muchos inventos digitales tengan características adictivas incrustadas dentro de sus principales funciones. El autor nos revela, caso tras caso, cómo las compañías que diseñan estos productos los van modificando constantemente con el tiempo hasta que se vuelven casi imposibles de resistir; ahí es dónde recae su extraordinario magnetismo.

En capítulos siguientes se explica de forma detallada y precisa cada una de estas funciones, todas patentadas, entre las que se encuentran: Facebook, con su interminable timeline, Twitter e Instagram con sus despliegues de contenido en bucle; YouTube y Netflix con la reproducción automática de vídeos y Tinder con el deslice del dedo hacía la derecha para acceder ilimitadamente a su interminable catálogo de solteros/as.

Resulta particularmente reseñable el número de experimentos, investigaciones de vanguardia y hallazgos científicos mencionados dentro del libro que el autor utiliza regularmente para ilustrar, en un lenguaje próximo al lector, cada una de las razones por las que nos sentimos atraídos evolutivamente hacía las aplicaciones digitales y los dispositivos móviles.

El autor nos revela que a través de la historia de la humanidad los comportamientos adictivos han existido durante mucho tiempo, pero que en las últimas décadas se han vuelto más comunes y más dificiles de resistir desde la creación de internet, el lanzamiento de los ordenadores de bolsillo y la incorporación de las pantallas táctiles. De manera cercana y amena
Adam nos desgrana elocuentemente cada uno de los aspectos adictivos biológicos y psíquicos del comportamiento humano y pone en evidencia el peligro oculto del abuso de las pantallas que amenaza con socavar nuestra salud mental y cambiar drásticamente la manera en cómo nos relacionamos unos con otros.

También es importante mencionar el extenso análisis que el autor dedica en la tercera parte del libro sobre las motivaciones sociales que han llevado a las nuevas generaciones de la información a sumergirse dentro de dichas tecnologías y cómo éstas han llegado a colarse en los espacios más íntimos de nuestras vidas diarias: Llenándola de notificaciones cargadas de monodosis de dopamina y recompensas intermitentes.

Alter cierra la obra con una esmerada síntesis sobre éste fenómeno cultural y social que representan las tecnologías de información y nos invita a pensar con tajante autocrítica el papel que desempeña en nuestras relaciones interpersonales la tecnología y cómo en general en los últimos años se ha ido acortando la capacidad de atención y la empatía de los usuarios/as.

El autor también aporta soluciones pormenorizadas a los problemas que plantean los dispositivos móviles en el futuro y nos habla sobre la creación de una «arquitectura de comportamiento» donde se controlen y limiten la exposición a los tiempos que se pasan enfrente de la pantalla, incluida la prevención a partir de posibles situaciones tentadoras. Todo esto en aras de mantener una relación saludable con nuestros dispositivos digitales.

Definitivamente, Irresistible no es un libro alarmista, pero tampoco utópico en su enfoque, ya que el objetivo final de 
Alter es reorientar la relación que tenemos con las tecnologías y servir como un llamado de atención para quienes están detrás del diseño adictivo de las aplicaciones digitales. En suma, se trata de un libro de lectura imprescindible puesto que nos hace reflexionar, e incluso, sentir un poco culpables también sobre el excesivo e inadecuado uso que hacemos de nuestros dispositivos móviles. Si alguna vez el lector se ha preguntado por qué hay algunas experiencias digitales que son tan adictivas o en algún momento se ha visto incapaz de salir de éstas, entonces este libro le proporcionará una serie de respuestas detalladas y claras sobre su inherente relación con la tecnología. Internet, la conectividad y las TICs han llegado para quedarse y seguirán formando una parte substancial de nuestra existencia, todo siempre dependerá del uso y la moderación que hagamos de ellas.

Orge Castellano

\section{Museum Thresholds: The Design and Media of Arrival}

\author{
Ross Parry, Ruth Page \\ $y$ Alex Moseley (editores) \\ Routledge: Nueva York, 2018
}

Los 12 capítulos de esta obra ofrecen, desde diferentes perspectivas, la forma sobre cómo se accede hoy en día a los museos. El libro muestra los resultados de la investigación "Accesos transformadores» (2012-2014), dirigida por la Universidad de Leicester, en colaboración con otras universidades del Reino Unido y Dinamarca, junto con el apoyo de instituciones como el Consejo de Investigación de Artes y Humanidades del Reino Unido (AHRC).

Los museos nunca han tenido una única forma de acceso, siempre ha habido muchas maneras de conectar con ellos y comenzar nuevas experiencias, construyendo una relación cada vez más estrecha con ellos. De hecho lo que se ha venido haciendo, según los autores del libro, es multiplicar esos puntos de entrada, que van desde la publicación de catálogos y libros, hasta el patrocinio de grupos y sociedades de interés especializado, las exposiciones itinerantes y el préstamo de objetos, hasta la programación de servicios de divulgación y su recorrido en línea, lo que ha aumentado las conexiones que pueden establecer con la sociedad.

En el texto se constata que las rutas de acceso a los museos son cada vez más creativas, a través del contenido móvil, datos abiertos y redes sociales. El museo continúa desarrollando modos a través de los cuales los visitantes pueden (re) encontrarse y (re) ingresar en él. Hoy en día, ya no hay restricciones de tiempo o para visitar determinadas colecciones, el museo va a estar siempre disponible bajo demanda. Estas nuevas experiencias pueden ser más fugaces y fragmentadas: el titular de una noticia, el resultado de la de búsqueda de unas imágenes, la recomendación de un "amigo» o un «tweet», entre otros. Lo que hacen estas audiencias en tránsito, en medio de lo cotidiano, es atraer visitantes, y para ello, los museos están enviando contenido a los lugares donde van los usuarios.

A pesar de todo ello, el acceso físico a los museos sigue predominando. Los au- 
tores describen como un museo en hora punta puede ser todo un torbellino de actividad, que hace que las entradas a los edificios sean lugares muy concurridos, animados y ruidosos. Los visitantes, ya empiezan a interactuar en los vestíbulos, se reúnen, saludan a familiares y amigos, de pie o, a veces, se sientan y conversan, esperan a otros, utilizan sus teléfonos móviles o tabletas y se van involucrando con el lugar y sus contenidos. Es comprensible, como se recoge en el texto, que los museos quieran presentar todo esto como parte de la experiencia de la visita. Pero también hay otras actividades que tienen lugar en las puertas de los museos que no son tan fáciles de ver. Si uno observa durante un período prolongado de tiempo verá cómo la gente ingresa y mira a su alrededor con ansiedad, se ponen de pie y estudian los avisos y las listas de precios con atención, observan los carteles, leen los folletos y pantallas de información digital y buscan las señales de dirección para comenzar la visita.

Aunque, como puntualizan los investigadores, la visita a los museos no comienza en la entrada de los edificios. Los museos que se mencionan en las redes sociales o que se anuncian en sitios web de viajes y aplicaciones móviles, se ofrecen junto con una gran cantidad de actividades alternativas. Uno tiene que descubrir el museo y tomar la decisión de ir antes de llegar, entrar y comenzar la visita. Esto rara vez ocurre de manera instantánea y casi siempre implica un proceso con diferentes tipos de esfuerzo físico y cognitivo. Los visitantes pueden estar buscando una experiencia social, ya que a menudo vienen en parejas o en grupos pequeños, o experiencias de aprendizaje y descubrimiento, así como también de disfrute o relajación.
Los autores proponen interesantes perspectivas, sobre cómo los medios deberían jugar un papel crucial en la redefinición de cómo los visitantes encuentran la información sobre los museos a visitar y la manera de vivir la experiencia. Y de cómo pueden entretejerse medios digitales y espacio físico, para redirigir el flujo de visitantes y para crear un nuevo tipo de espacios de información.

La entrada al museo es un espacio que está cargado de simbolismo, que facilita la transición de la experiencia externa (previsita) a la experiencia de aprendizaje de la visita presencial al museo, para promover la transición experiencial, de ser un viajero a ser un visitante. Los investigadores del estudio abogan por reinventar los espacios en las entradas de los edificios y en sus salas. Esto requiere descubrir las necesidades y deseos latentes en los visitantes, y responder con soluciones innovadoras que deben identificar, moldear y respaldar las nuevas experiencias que se produzcan en estos puntos.

El Design thinking, entre especialistas de diferentes disciplinas, es uno de los métodos que se promueven en este proyecto para diseñar servicios que se ajusten a las necesidades de las personas, viendo las cosas desde la perspectiva de los usuarios. La satisfacción de las necesidades, emociones y expectativas de los visitantes, son los impulsores más importantes de la innovación que se busca en los museos del siglo xxI, aunque, teniendo en cuenta la creciente adopción de la tecnología digital es solo un medio para lograr este objetivo.

Ya lo decía Stein, el museo es como una ventana al mundo que debe ofrecer espacios de transición y conexión. La obra de arte permite al museo enrique- 
cer la experiencia del visitante. En el libro se explora cómo el lenguaje creativo de las obras de arte puede contribuir a la narrativa que experimenta el visitante del museo. A través de una serie de ejemplos que van desde una proyección de sombras en una pared blanca, la madera recuperada de un viejo velero y una mesa de granito donde los visitantes pueden quitar una flor, se da a entender que al pensar que la obra de arte tiene cualidades metafóricas, podemos creer que tienen una función que va más allá de su papel material y estético.

El concepto de obra de arte es en sí mismo muy amplio. En el volumen se demuestra la importancia y el potencial de incorporar obras de arte en museos no artísticos. Los museos han utilizado las artes como un medio para demostrar que existen muchos enfoques para comprender lo que constituye conocimiento. Se ha utilizado a los artistas para ofrecer formas de interpretar y relacionarse con información empírica, han explorado la noción de memoria colectiva y personal y se han utilizado para facilitar la interacción pública y permitir que las voces de las comunidades locales o marginadas estén representadas en el museo.

En otro de los capítulos se constata que los museos han sido vistos tradicionalmente como lugares de silencio. La presencia de la actividad humana siempre está acompañada por sonidos, como lo demuestran los sonidos que se encuentran con frecuencia en los museos. Sin embargo, el sonido suele ser más aceptable en las instituciones que no aspiran tener un aura de cultura elevada. Los zoológicos y los museos de ciencia e historia natural son ruidosos y enérgicos, y se enriquecen notablemente con los registros superiores de la escala auditiva.
Parece que recientemente, los museos han comenzado a adoptar la dimensión del audio, implementando activamente los sonidos como parte de la experiencia, especialmente con el uso de audioguías. Por tanto, dicen los autores, el sonido ya no se considera por defecto un problema para los museos, sino que se ve cada vez más como una oportunidad para comunicar. Existe una relación similar y recíproca entre el sonido y el ambiente del museo. El sonido influye en nuestra experiencia del entorno del museo y, a su vez, el entorno del museo influye en la forma en que escuchamos.

Estos significados influyen en la percepción del entorno y, a su vez, el entorno influye tanto en lo que se escucha, como en el significado. El individuo puede manipular el entorno, por ejemplo, abriendo una ventana, afectando directamente a lo que se escucha. Luego el sonido es a menudo, señalan los autores, el desencadenante de diferentes emociones. Por ejemplo, el paisaje sonoro de la playa de un día de verano probablemente provocaría emociones positivas en la mayoría de las personas, mientras que un paisaje sonoro en una funeraria daría lugar emociones negativas como la tristeza y el miedo.

Los significados atribuidos a los sonidos a menudo están divididos en bueno (me gusta) frente a malo (no me gusta). Sin embargo, el sonido es solo un aspecto y una forma de estimular las sensaciones que recibimos cuando nos movemos a través del espacio multidimensional y, por lo tanto, todas las visitas a los museos son multisensoriales. Las atmósferas están constituidas por diferentes variables sensoriales (visuales, auditivas, olfativas, táctiles) y establecen un cierto estado de ánimo frente al ambiente, que hay que tener muy presentes en las salas de los museos. 
Esta obra es sin duda una lectura muy recomendable, esencial y reciente para académicos, investigadores y estudiantes de posgrado que trabajan en estudios sobre museos, patrimonio, arquitectura, diseño y medios

Antonia Moreno Cano

\section{Pantallas electorales. El discurso de partidos, medios y ciudadanos en la campaña de 2015}

\author{
López García, Guillermo; \\ Valera Ordaz, Lidia (eds.). (2017) \\ Barcelona: Editorial UOC.
}

La campaña electoral para las elecciones generales de 2015 tuvo lugar en un momento de cambio del panorama político, mediático y social: la aparición de dos nuevos partidos con opciones a alcanzar representación terminó con el modelo bipartidista tradicional; la gran prensa de referencia aparecía debilitada en términos de audiencia y de credibilidad, mientras que la televisión veía reforzado su papel como centro del debate público, muchas veces con formatos derivados de propuestas de entretenimiento e incluso de ficción; el auge de las redes sociales como espacios de debate entre ciudadanos otorgó a estos una mayor capacidad de selección informativa y un papel más activo y autónomo frente a los tradicionales emisores de los mensajes.

Con este escenario como telón de fondo, los autores de este libro analizan los flujos de comunicación que se generaron entre partidos políticos, medios de comunicación y ciudadanos con motivo de la citada campaña electoral. Una campaña que acabó plasmándose en unos resultados electorales inéditos hasta ese momento. El PP, el partido más votado (28\%), obtuvo 123 escaños, su peor resultado desde 1989. El PSOE, con 90 diputados y un $22 \%$, cosechó el peor resultado de su historia. La coalición de Podemos con diversas formaciones autonómicas, globalmente, alcanzó 69 diputados y el $20 \%$ de los votos. El partido Ciudadanos logró 40 escaños y en torno al 14\% de los sufragios.

Estructurado en nueve capítulos, amén de una introducción contextualizadora, este libro pretende ofrecer una visión panorámica de la campaña electoral, deteniéndose en sus puntos neurálgicos y abordando el discurso de los tres actores mencionados - partidos políticos, medios de comunicación y ciudadanos- y su plasmación en el conjunto de medios de comunicación tradicionales (televisión y prensa) y digitales (webs, blogs y redes sociales).

La construcción de la agenda temática en la campaña centra la atención del primer capítulo, desarrollado por Guillermo López, Emma Gómez y Carmen Torreblanca. Los autores buscan encontrar coincidencias y discrepancias en la cobertura electoral efectuada por parte de los partidos políticos en sus sitios web, de los medios de comunicación y de los líderes de opinión, representados mediante una muestra de blogs de temática política particularmente relevantes.

En el segundo capítulo, firmado por José Gamir, Lorena Cano y Dafne Calvo, se presenta un análisis cuantitativo com- 
parado de la presencia y actividad en blogs, Facebook y Twitter de los candidatos a la presidencia del Gobierno por parte de PP, PSOE, Podemos y Ciudadanos, así como de los cabezas de lista de las 52 circunscripciones electorales.

Lidia Valera, Adolfo Carratalá y Dolors Palau ofrecen en el capítulo tres un análisis cualitativo del discurso político durante la campaña, centrado en conocer cuáles son los marcos de acción colectiva desplegados por las cuatro fuerzas políticas citadas para persuadir y movilizar al electorado. Se trata de un análisis realizado desde el punto de vista del framing.

El cuarto capítulo, de Eva Campos y Miguel Vicente, analiza las noticias publicadas en una muestra de cuatro cibermedios (elpais.com, elmundo.es, eldiario. es y elconfidencial.com) con el objetivo de conocer si las piezas informativas mantienen un discurso basado en temas de agenda de campaña y centrado en actores y fuentes de información partidarias o si el papel de los colectivos, movimientos sociales y nuevos partidos ha conseguido reorientar la agenda mediática y atraer la atención de los cuatro medios analizados.

Los capítulos cinco y seis, firmados por Àlvar Peris, Germán Llorca, Sebastián Sánchez y Carmen M. López, evalúan el papel de la televisión en la campaña electoral, tanto en lo que se refiere a los informativos y los debates electorales como en lo relativo a los programas de infoentretenimiento, muy presentes a lo largo de la campaña y de la precampaña, y cuya lógica discursiva impregnó muchas de las piezas informativas de formato clásico emitidas por televisión.

Manuel de la Fuente y Salvador Enguix exploran, en el séptimo capítulo, cuál es la visión de la campaña de los ac- tores involucrados en ella. Para ello, llevan a cabo entrevistas a los responsables de campaña de los principales partidos políticos y a periodistas políticos de algunos de los medios de comunicación más relevantes.

Los dos últimos capítulos centran su atención en la utilización de las redes sociales por parte de la ciudadanía. Tomás Baviera, Francisco José García y Lorena Cano analizan las conversaciones surgidas a propósito de la campaña electoral en Twitter, con el objetivo de dilucidar en qué medida el papel de esta red social puede ser considerado como algo autónomo en el escenario mediático o si le corresponde un protagonismo vicario supeditado a la televisión, que puede considerarse como el actor principal. Por su parte, Lidia Valera, Agnese Sampietro y Vicente Fenoll estudian la calidad democrática de las conversaciones que se despliegan en los muros de Facebook de los cuatro principales partidos políticos, para establecer si en tales espacios prevalece la libertad discursiva o si, por el contrario, los participantes en estas conversaciones no exhiben respeto hacia el resto de individuos.

En definitiva, se trata de una obra que ofrece una visión a un tiempo global y pormenorizada de la campaña para las elecciones generales del 20 de diciembre de 2015, que dieron paso a la XI legislatura -a la postre la más corta de la democracia, ya que apenas seis meses después (el 26 de junio de 2016) se celebraron de nuevo elecciones generales-. Si bien podría considerarse que los comicios de 2015 carecieron de relevancia, puesto que sus resultados caducaron en pocos meses, desde el punto de vista de la comunicación política el escenario y el contexto concreto en los que tuvieron lugar hicieron que los flujos comunicativos surgidos 
entre partidos, medios y ciudadanos generasen interesantes aportaciones para la investigación en este ámbito, tal y como se demuestra en este libro.

Idoia Camacho Markina

\section{Diversidad e industria audiovisual. El desafio cultural del siglo XXI}

\author{
Luis A. Albornoz $y$ \\ M. ${ }^{a}$ Trinidad García-Leiva (editores) \\ (2017) (331 páginas) \\ Ciudad de México, Editorial Fondo de \\ Cultura Económica
}

Los editores de esta obra dan un valor incuestionable a la diversidad como valor dentro del nuevo ecosistema comunicativo digital, donde subyacen culturas diversas e innovaciones en la industria audiovisual. Luis Albornoz y Trinidad García-Leiva han coordinado nueve capítulos de especialistas e investigadores e investigadoras que reflexionan sobre la diversidad cultural y la cooperación en el sector audiovisual.

El libro está prologado por el profesor catedrático de Comunicación Audiovisual de la Universidad Complutense de Madrid y presidente de la Asociación Española de Investigación de la Comunicación, Enrique Bustamante, quien se refiere a la visión economicista de la cultura como enemiga de la diversidad que disuelve o anula su dimensión social. También diagnostica consecuencias irremediables en la extinción de las políticas públicas nacionales y de cooperación en cultura y comunicación amenazadas por las negociaciones para el tratado de libre comercio entre los Estados Unidos y la Unión Europea. Por ello, Bustamante señala que «se hace indispensable una visión integral de la diversidad de la comunicación y la cultura tanto de su producción (grandes corporaciones, pequeñas y medianas empresas, servicio público, tercer sector) como de su distribución (oligopolios, distribuidoras locales...), su comercialización y visibilidad (cadenas de puntos de venta, estrategias de superventas o best-sellers) y, finalmente y sobre todo, de su demanda y consumo efectivo» (p. 18).

El capítulo uno está dedicado a la diversidad cultural, industria audiovisual y gobernanza, en el que Albornoz y GarcíaLeiva ponen el énfasis en las políticas púbicas y llegan a la conclusión de que en un contexto de desmaterialización y creciente digitalización de contenidos audiovisuales urge ampliar las actuaciones en defensa de la diversidad de las expresiones culturales y su estimulación en el paisaje digital, con el objetivo de combatir la asimetría de los flujos audiovisuales.

Beatriz Barreiro Carril se adentra en la industria audiovisual como campo de aplicación de la Convención sobre Diversidad de las Expresiones Culturales (UNESCO 2005) y sostiene que junto con la promoción también se puede exigir protección donde las expresiones culturales vean amenazada su subsistencia.

La implementación de la Convención sobre la diversidad cultural y el compromiso estatal está analizada en el capítulo tres por Alejandra Val Cubero, quien propone aunar esfuerzos para mejorar la comunicación, la transparencia y el intercambio de información con respecto a la gobernanza de 
la cultura a nivel nacional e internacional, y fomentar la participación de la sociedad civil en la aplicación de la Convención.

Luis Albornoz, se encarga del capítulo cuatro que versa sobre el Fondo Internacional como nueva herramienta para la cooperación en el audiovisual, sin embargo señala: "A pesar de las aparentes buenas intenciones que hay detrás de la concepción de esta nueva herramienta de cooperación internacional en el ámbito de las industrias culturales y del compromiso demostrado por un puñado de países, hoy en día es impensable que el FIDC se encargará de cambiar la realidad de las organizaciones internacionales y/o el comercio regional de bienes y servicios culturales. Esto debe ser una prioridad para la cooperación internacional en el ámbito de las industrias culturales cuya prioridad es proteger y promover la diversidad de las expresiones culturales» (p. 143)

M. ${ }^{a}$ Trinidad García-Leiva y Ana I. Segovia exploran los conceptos de buenas prácticas y mejores prácticas en la industria audiovisual, remarcando el carácter de esta acción como eficaz, perdurable, transformadora y transparente. Las autoras consideran que «la acción podría ser ejemplar sirviendo a otros como fuente de inspiración, y reflexiva, dando lugar a repensar la propia experiencia al generar retroalimentación» (p. 160)

Por su parte, Ignacio Gallego aborda distintos estudios de caso en la industria cultural (cine, televisión, radio, música grabada y videojuegos) a través de los que quiere visibilizar cómo desde la Convención pueden desarrollarse políticas de protección y promoción de la diversidad. Además, pone de manifiesto cómo los esfuerzos desarrollados por diferentes actores de la sociedad civil deben contar con soporte legislativo y económico para que sus acciones se visibilicen y favorezcan su difusión.

El siguiente capítulo está destinado a analizar el trabajo promovido por la UNESCO para medir la diversidad en la industria audiovisual, donde Albornoz recoge las iniciativas multidimensionales y las relaciones entre variedad, balance, disparidad y diversidad, remarcando los indicadores y los índices de diversidad.

Continuando en el mismo contexto, Patricia Marenghi, aborda algunos apuntes metodológicos para un modelo de medición de la diversidad en televisión. Este capítulo propone una herramienta integrada para el diagnóstico de la diversidad en televisión, aunque este modelo presenta múltiples desafios.

Finalmente, Asier Aranzubia, explora la diversidad audiovisual en el paisaje digital como nuevas vías de distribución y exhibición cinematográficas, refiriéndose a nuevas políticas culturales para un nuevo escenario y las oportunidades que ofrece la tecnología digital.

Los autores y autoras de esta obra han participado en dos proyectos financiados por el Ministerio de Economía y Competitividad durante los trienios 2012-2014 y 2015-2017, siendo el embrión de este compendio de artículos.

La obra es todo un desafio con distintas aportaciones e ingredientes para plantear un debate público sobre la concentración mediática y llevar a discusión las reivindicaciones sobre la diversidad en el sector audiovisual. Teniendo en cuenta que la comunicación, en general, y la industria del audiovisual, en particular, son campos estratégicos en el siglo XXI, en los que las redes sociales y los dispositivos digitales juegan un importante papel en el 
nuevo ecosistema comunicativo. La diversidad cultural es una demanda social y un objetivo de cooperación a nivel internacional. Recordemos que «la principal fuente de esperanza en la posible armonía en el mundo contemporáneo radica en la pluralidad de nuestras identidades» Sen y Kliksberg (2007, p.36) Así, esta obra llega en un momento en el que el concepto de diversidad cultural sigue teniendo un gran protagonismo en el debate mundial sobre la cultura en la sociedad del conocimiento. Sin olvidar que las políticas públicas de comunicación constituyen un importante reto en el nuevo milenio.

Diversidad e industria audiovisual. El desafio cultural del siglo XXI es un libro recomendado para profesionales e investigadores/as del ámbito de la Comunicación, expertos/ as del sector audiovisual, para docentes y discentes de las universidades y para la ciudadanía en general, a la que está destinada cualquier obra científica y divulgativa.

Carmen Peñafiel Saiz

\section{Periodismo Slow. O cómo se cuecen las historias en los fogones de Anfibia, Narratively y FronteraD}

José María Albalad Aiguabella (2018)

Madrid: Editorial Fragua

Vivimos tiempos de vértigo. Se percibe una ansiedad generalizada a todos los niveles. Los fenómenos sociales se precipitan. Los sociólogos carecen de herramientas de análisis para anticipar lo que puede ocurrir dentro de cinco años. Los liderazgos sociales cada vez son más efimeros. El movimiento fast se ha extendido a los ámbitos sociales, políticos, económicos y culturales. Es parte de la $l i$ gereza o de la sociedad líquida que nos anticiparon Guilles Lipovetsky o Zygmunt Bauman. El mundo de la comunicación es vivo reflejo de todo ello. Al igual que los ciclos sociales, las noticias también se acortan, se adelgazan. Medios que hace diez años se consideraban firmes pilares del sistema comunicativo hoy atraviesan graves problemas económicos o, simplemente, han desaparecido. En ese contexto, prima el pulso por la instantaneidad, la pugna por exclusivas (en muchos casos de dudosa procedencia), la optimización de los sitios webs y la presencia en las redes sociales. Vivimos una saturación informativa sin precedentes; existe excesivo ruido a nuestro alrededor. Pero, en el mundo de la comunicación también existe un movimiento slow que se contrapone al fast. Cada vez son más les sectores sociales que demandan una pausa en el camino, una lectura reposada, deleitante y gratificante de textos analíticos que nos aporten claves para entender el mundo.

La obra Periodismo Slow. O cómo se cuecen las historias en los fogones de Anfibia, Narratively $y$ FronteraD de José María Albalad Aiguabella, profesor de la Universidad San Jorge de Zaragoza, es otra historia. Su autor ha indagado en los fogones de la cocina del periodismo narrativo o slow de tres revistas - Anfibia, $\mathrm{Na}$ rratively y FronteraD - que entre 2009 y 2012 decidieron en Argentina, EEUU y España respectivamente huir de esa vorágine impuesta por la «trepidante ac- 
tualidad» para producir textos de largo formato, ya sean crónicas, ensayos, reportajes, perfiles o entrevistas. El libro es una versión divulgativa de su tesis doctoral leída en 2016 y que obtuvo el premio extraordinario de doctorado.

El autor denota que es reportero y académico. Se aprecia en la redacción del libro y en la forma en que cuenta la intrahistoria de las redacciones de estos medios que visitó personalmente para llevar a cabo su investigación. Ha realizado un análisis etnográfico y en profundidad de los tres proyectos al objeto de conocer sus detalles, orígenes, características y viabilidad. Su mirada bascula entre una visión optimista (casi romántica) y la versión prudente que ofrecen sus conclusiones. El libro tiene una introducción, cuatro capítulos bien definidos seguidos de las conclusiones y un voluminoso apartado de anexos que ofrecen mucha e interesante información sobre el estado del Periodismo Slow a nivel mundial.

En la introducción del libro se ofrecen las primeras reflexiones sobre el Periodismo lento frente a la urgencia informativa. En la misma línea sigue el capítulo I: Apuntes sobre el periodismo literario en América Latina, Estados Unidos y España. Existe un debate no resuelto sobre la denominación que se debe dar a este tipo de periodismo. En general, tanto académicos como profesionales coinciden en referirse al periodismo narrativo o reposado como a esa práctica periodística que huye de la inmediatez y la primicia y produce textos de formato más o menos largos que inducen a la reflexión y el análisis, sin traspasar los límites de la no ficción, tratando siempre de ofrecer información rigurosa, creativa y de calidad. José María Albalad en su libro, contabiliza hasta siete denominaciones diferentes para un mismo fenómeno aunque quizás las que más se estén imponiendo son Slow journalism y literary journalism en inglés y periodismo reposado o narrativo en castellano.

El capítulo II está íntegramente dedicado a Anfibia. Ofrece numerosos datos sobre la génesis de este proyecto surgido en mayo de 2012 al amparo de la UNSAM Universidad Nacional San Martín de Buenos Aires. Tal y como apunta el autor (pp. 115) es precisamente ese apoyo económico el que estabiliza el proyecto, hasta el punto de proyectar Anfibia como una de las revistas de no ficción más importantes en español. Es fundamental tanto el papel de su carismático director (Cristián Alarcón) como el de su equipo de editores que trabajan para internet como lo hacen las publicaciones analógicas de referencia.

Coetánea en el tiempo es la revista neoyorkina Narratively, propuesta destacada dentro de los medios digitales norteamericanos que practican literary journalism. Tal y como señala J. M. Albalad en su capítulo II (pp. 163) esta revista «trata de fusionar la esencia de los modelos analógicos de referencia (The New Yorker, The Atlantic, Esquire, etc.) con las potencialidades de internet». Este proyecto tampoco se entendería sin la figura de su director Noah Rosenberg ni sin la monetización que aporta al proyecto Narratively Creative Group.

El capítulo IV cierra el círculo de su investigación con la revista FronteraD que es, curiosamente, la más temprana de las analizadas, ya que surgió en 2009. En este caso, destaca igualmente la impronta de su director, Alfonso Armada, auténtica alma mater del proyecto. Según apunta el autor (pp.208), esta revista «desafía la hegemonía del articulismo en 
la práctica del periodismo literario en España, al tiempo que abre un camino similar al iniciado en la región latinoamericana, en 1996, por la revista colombiana El Malpensante».

El apartado de conclusiones no deja lugar a dudas. Según el autor este tipo de periodismo (pp. 217 y 218) atraviesa "una etapa de florecimiento gracias a internet, aunque "no hay una base científica y/o estadística que lo demuestre», ya que, en su opinión, queda pendiente de conocer la aceptación real del fenómeno. Lo que sí está claro, en opinión del autor, es que este tipo de proyectos deben cumplir cinco aspectos esenciales como son (pp. 219 y 220): confeccionar estructuras ligeras pero no profesionales, aportar valor añadido a audiencias de nicho, adaptar los formatos al lenguaje de cada plataforma, crear comunidades de lectores y diversificar sus ingresos.

Sea Slow, narrativo, literario o reposado, este tipo de periodismo necesita ser estudiado, explorado y practicado. La obra de J.M. Albalad va en ese sentido.

Txema Ramírez de la Piscina 

Guía para la preparación de colaboraciones Kolaborazioak prestatzeko gida Guidance to prepare originals

\section{zer}





\section{- Guía para la preparación de originales •}

\section{Descripción y política editorial}

La revista ZER tiene como objetivo promover la investigación y difundir los trabajos científicos que se realizan en el área de Comunicación social. Es una publicación semestral cuyos números se publican en los meses de mayo y noviembre de cada año. De forma excepcional, el Consejo Editorial podrá aprobar la publicación de números especiales, a propuesta de la Dirección de la revista.

Se publica en versión impresa y en versión electrónica. Cada artículo publicado se identifica con un DOI (Digital Object Identifier System).

La revista ZER acepta artículos del campo de la Comunicación social, siempre y cuando sean considerados de interés por la Dirección de la revista, con la supervisión del Consejo Editorial.

Los artículos enviados deben ser originales e inéditos y no estar en proceso de publicación en ningún otro medio. Cualquier artículo que no sea inédito, por haber sido publicado o difundido on-line en todo o en parte, será rechazado automáticamente. Cada autor/a presentará una declaración responsable de autoría y originalidad, así como las responsabilidades éticas contraídas y en caso necesario, una declaración de conflictos de interés. Los autores y autoras que no respeten esta norma serán penalizados con la no publicación de ningún otro artículo hasta pasados, al menos, dos años (cuatro números) desde que se descubrió la difusión del artículo en otro medio o soporte.

La publicación de artículos en la revista ZER requiere la previa evaluación ciega por pares (peer review) a cargo de miembros del Comité Científico de la revista, formado por investigadores/as y expertos/as del área de Comunicación social externos a la Universidad del País Vasco/Euskal Herriko Unibertsitatea.

Cada autor/a no podrá publicar más de un artículo por número, tanto de forma individual como colectiva. Además, entre la publicación de un artículo y otro tienen que transcurrir, al menos, dos números.

Los artículos publicados por ZER pueden ser citados siempre y cuando se indique la procedencia y autoría. Los autores y autoras son los responsables únicos de los artículos y sus contenidos. La revista ZER no publicará correcciones de los errores cometidos por los autores/as en sus citas, atribuciones o cualquier otro dato contenido en los artículos publicados.

\section{Proceso de evaluación}

Los artículos se pueden enviar en cualquier fecha a través de la plataforma OJS de la revista ZER, en la dirección http://www.ehu.eus/ojs/index.php/Zer ("Acerca de" / "Envíos en línea").

La Dirección de la revista realiza una primera revisión de cada artículo recibido y valora su interés y ajuste al perfil de la revista. La Dirección podrá desestimar, de forma razonada, las contribuciones que sean ajenas al área de la Comunicación social, no cumplan con el carácter inédito y científico exigido por la revista o no respeten los requisitos formales para la presentación de los originales.

En el período máximo de 30 días a partir de la recepción de cada artículo-excluyendo los periodos vacacionales, si los hubiera- los autores y autoras recibirán acuse de recibo del mismo, comunicando si se desestima el trabajo o si se estima para su evaluación por los miembros del Comité Científico.

La fecha de publicación de los artículos estará condicionada al orden de recepción de los mismos y al tiempo de respuesta de los evaluadores/as. Estos tendrán un plazo no superior 
a los 30 días para evaluar. Pasado ese tiempo, la revista se reserva el derecho de retirarle el artículo y enviárselo a un nuevo/a evaluador/a.

Cada artículo será remitido a dos miembros del Comité Científico para que procedan a su evaluación. Durante el proceso de revisión se mantiene el anonimato del autor/a y de los evaluadores/ as. En el caso de que las dos evaluaciones recibidas no resulten coincidentes, se recabará un tercer informe de evaluación. En última instancia, la Dirección de la revista adoptará la decisión final.

Tras la recepción de los informes, la revista comunicará a los autores/as la decisión positiva o negativa sobre la publicación de sus originales, acompañada del contenido de los informes. En el caso de que, a instancias del Comité Científico, se requiera a los autores/as realizar modificaciones sobre el original enviado, estos lo devolverán debidamente revisado en el plazo que se les establezca en el escrito de remisión.

\section{Normas para los artículos}

Los originales se enviarán escritos en un procesador de textos. Por cada trabajo, se enviarán dos archivos:

1. Presentación: incluye los datos de cada autor/a (nombre, apellidos, universidad a la que pertenece, dirección postal, correo electrónico institucional e identificador digital ORCID) y una declaración firmada por cada autor/a en la que certifican su autoría y la originalidad del artículo enviado, así como las responsabilidades éticas contraídas y, en caso necesario, una declaración de conflictos de interés. Los trabajos procedentes de investigaciones financiadas deberán indicar el organismo financiador.

2. Artículo: conforme a las normas de este epígrafe, sin ninguna referencia a la identidad de los autores/as.

En archivo aparte se enviarán los gráficos realizados en Excel y las imágenes (en formato jpg o tiff).

La extensión de los artículos será de entre 5.000 y 8.000 palabras, incluidas las referencias bibliográficas.

El número máximo de autores/as por artículo será de tres. Si se trata de una investigación en la que han intervenido más personas, a partir del tercer firmante podrán aparecer en nota al pie de página.

Los artículos pueden presentarse en euskara, español e inglés. Su estructura será la siguiente:

- Título en español (Arial 14, negrita, centrado).

- $\quad$ Título en inglés (Arial 14, centrado).

- Resumen en español (Times New Roman 12, negrita, justificado): máximo de 100 palabras (Times New Roman 12, justificado).

- Palabras clave en español (Times New Roman 12, negrita, justificado): entre 4 y 6 palabras, separadas por un punto y coma (Times New Roman 12, justificado). Serán elegidas entre las que forman el Thesaurus de la revista ZER. Los autores/ as podrán proponer a la Dirección de la revista la inclusión en el mismo de términos nuevos.

- $\quad$ Resumen y Palabras clave en inglés (Abstract, Keywords), en el mismo formato que en español.

- $\quad$ 0. Introducción (epígrafe principal: Arial 12, negrita, justificada, sin sangrado).

- $\quad$ Cuerpo de texto (Times New Roman 12, justificado).

- $\quad$ 1.1. Epígrafe secundario (Arial 12, cursiva, justificado, sin sangrado).

- 1.1.1. Epígrafe secundario (Times New Roman 12, cursiva, justificado, sin sangrado). 
- Los artículos finalizarán con el epígrafe Referencias bibliográficas, sin numerar

(Times New Roman 12, negrita, sin sangrado).

ZER recomienda utilizar referencias bibliográficas de publicaciones científicas nacionales e internacionales del área de Comunicación social. Con el fin de mantener la coherencia de la revista, se recomienda la inclusión de referencias a los artículos publicados en números anteriores de ZER, aunque debe limitarse el uso de autocitas a aquellas que estén justificadas. Se indicarán únicamente las obras citadas en el artículo, ordenadas alfabéticamente por autores/ as, con sangría francesa de $0,5 \mathrm{~cm}$. y siguiendo las normas del estilo APA 6th edition versión 2015 (http://blog.apastyle.org/apastyle/):

- Libros

- Un autor/a:

Cebrián, M. (2008). La radio en Internet. Buenos Aires: La Crujía.

- Hasta 7 autores/as:

Caridad, M., Hernández, T., Rodríguez, D., y Pérez, B. (2011). Documentación audiovisual. Madrid: Síntesis.

- Capítulos de libros

García, J. (2014). El discurso publicitario como productor de sentidos: algo más que anuncios. En M. Catalá, y O. Díaz (coords.), Publicidad $360^{\circ}$ (pp. 267-277). Zaragoza: Universidad San Jorge.

- Artículos de revistas

Agirre, A., Aiestaran, A., y Zabalondo, B. (2015). Periodistas y lectores vascos y europeos contestan sobre el futuro de la profesión. Una colección de acuerdos y desacuerdos. ZER Revista de Estudios de Comunicación, 20(39), 101-125. doi: 10.1387/zer.15525

- Revistas y libros electrónicos

Heshmati, A., y Lee, M. (2009). Information and communications technology. Princeton: Princeton University Press. Recuperado de http://search. proquest.com/docview/189251427?accountid=14475

El sistema de citas bibliográficas en el texto se hará siguiendo el estilo Harvard. Las letras (a, b, c...) sirven para distinguir varios trabajos del mismo autor/a y año.

- Un autor/a:

Aldaiturriaga (2013: 347), (Aldaiturriaga, 2013: 347).

- Dos autores/as:

Berger y Luckmann (2013: 132), (Berger \& Luckmann, 2003: 132).

- Tres o más autores/as:

La primera vez que se les cite se escribirán los apellidos de todos los autores/ as (Moore, Estrich \& Spelman, 2012: 33), en las citas posteriores se utilizará et al. (Moore et al., 2012: 33).

Las citas literales de menos de 40 palabras irán entrecomilladas e integradas en el texto. Las citas de 40 palabras o más irán en párrafo aparte con una sangría izquierda de $2,5 \mathrm{~cm}$, sin entrecomillar y precedidas por dos puntos.

Los artículos podrán incorporar notas para aclaraciones, siempre las imprescindibles. Se situarán a pie de página para su mejor legibilidad.

Se escribirán en cursivas los nombres de publicaciones periódicas, así como los términos procedentes de otro idioma y las expresiones latinas de uso común. Los nombres de programas radiofónicos o televisivos irán entrecomillados.

Las tablas, gráficos e ilustraciones irán precedidas por títulos cortos y descriptivos y se numerarán correlativamente. Se incluirán sólo aquellos que sean imprescindibles y al pie de cada uno se indicará la fuente de procedencia. Se presentarán incorporados en el texto en Word. Los gráficos realizados en Excel se enviarán también en su formato original aparte del 
documento Word. Las imágenes se enviarán también en su formato original (jpg o tiff). Su calidad técnica ha de respetar los estándares de imprenta (300 ppp).

4. Reseñas de libros

La revista ZER acepta reseñas de libros relacionados con su área de conocimiento, siempre y cuando hayan sido solicitadas o aprobadas previamente por la Dirección. Entre la edición del libro y la publicación de la reseña no mediará más de 12 meses.

Los autores/as pueden enviar a la revista sus obras para que sean reseñadas.

La extensión de las reseñas será de entre 800 y 1.000 palabras, se encabezarán con una referencia completa del libro - Título; Apellidos y nombre del autor/a (año); ciudad: editorial-y se firmarán al final. En las reseñas tendrán cabida la descripción y la crítica. 


\section{- Originalak prestatzeko gida}

\section{Deskribapena eta argitaratze politika}

ZER aldizkariaren xedea ikerketa sustatzea eta gizarte komunikazioaren arloan egindako lan zientifikoak zabaltzea da. Sei hilean behingo argitalpen bat da, eta urtero ale bana argitaratzen da maiatzean eta azaroan. Salbuespen gisa, Kontseilu Editorialak ale bereziak argitaratzea onar dezake, aldizkariko Zuzendaritzak hala proposatuta.

Paperezko bertsioa eta bertsio elektronikoa argitaratzen dira. Argitaratutako artikulu bakoitza DOI (Digital Object Identifier System) batez identifikatzen da.

ZER aldizkariak gizarte komunikazioaren arloko artikuluak onartzen ditu, aldizkariko Zuzendaritzak interesgarritzat jotzen dituenean eta Kontseilu Editorialak gainbegiratu ondoren.

Bidalitako artikuluek originalak eta argitaragabeak izan behar dute, eta ezin dira egon argitaratze prozesuan beste hedabideren batean. Argitaragabea ez den artikulu oro, bai argitaratu delako bai on-line zabaldu delako, berehala baztertuko da. Egile bakoitzak autoretzari eta originaltasunari buruzko erantzukizun adierazpen bat aurkeztuko du, baita hartutako erantzukizun etikoei buruzkoa ere, eta, beharrezkoa bada, interes gatazken adierazpen bat. Arau hori errespetatzen ez duten egileei gutxienez bi urte (lau ale) igaro arte beste artikulurik ez argitaratzeko zigorra jarriko zaie, artikulua beste hedabide edo euskarri batean argitaratu dela jakiten den unetik zenbatzen hasita.

ZER aldizkarian artikuluak argitaratzeko, aldizkariko Batzorde Zientifikoko kideek parekoen ebaluazio (peer review) itsua egingo dute. Batzorde hori Universidad del País Vasco/Euskal Herriko Unibertsitatekoak ez diren gizarte komunikazioaren arloko ikertzaileek eta adituek osatzen dute.

Egile bakoitzak, bakarka nahiz taldean, ezin izango du argitaratu artikulu bat baino gehiago ale berean. Horrez gain, artikulu baten eta bestearen artean, gutxienez, bi ale argitaratuko dira.

ZER aldizkariak argitaratutako artikuluak aipa daitezke, betiere haien jatorria eta autoretza adierazita. Egileak izango dira artikuluen eta haien edukien arduradun bakarrak. ZER aldizkariak ez du argitaratuko egileek aipuetan, atribuzioetan edo argitaratutako artikuluen beste edozein datutan egindako akatsen zuzenketarik.

\section{Ebaluazio prozesua}

Artikuluak edozein datatan bidal daitezke ZER aldizkariko OJS plataformaren bidez, honako helbide honetan: http://www.ehu.eus/ojs/index.php/Zer (“Guri buruz" / "Lineako bidalketak").

Aldizkariko Zuzendaritzak jasotako artikulu bakoitzaren lehenengo azterketa egin, haren interesa baloratu eta aldizkariaren profilari egokitzen ote den aztertuko du. Zuzendariak ezetsi ditzake, modu arrazoituan, gizarte komunikazioaren arlokoak ez diren ekarpenak, aldizkariak eskatutako izaera argitaragabea eta zientifikoa betetzen ez dituztenak, edo originalak aurkezteko eskakizun formalak errespetatzen ez dituztenak.

Artikulua jaso eta gehienez 30 eguneko epean -oporraldiak salbuetsita-, egileek hartu izanaren agiria jasoko dute, eta bertan adieraziko zaie lana ezetsi den edo Batzorde Zientifikoko kideek ebalua dezaten onartu den.

Artikuluak argitaratzeko data jasotze ordenaren eta ebaluatzaileek erantzuteko behar duten denborak baldintzatuko dute. Ebaluatzaileek, gehienez, 30 eguneko epea izango dute ebaluatzeko. Denbora hori igarota, aldizkariak beretzat gordetzen du artikulua ebaluatzaile bati kentzeko eta beste bati bidaltzeko eskubidea. 
Artikulu bakoitza Batzorde Zientifikoko bi kideri bidaliko zaie, ebalua dezaten. Berrikuspen prozesuan, egileen eta ebaluatzaileen anonimotasuna bermatuko da. Jasotako bi ebaluazioak bat etorri ezean, hirugarren ebaluazio txosten bat eskatuko da. Azkenean, aldizkariko Zuzendaritzak erabakiko du.

Txostenak jaso ondoren, aldizkariak egileei jakinaraziko die beren originalak argitaratzeari buruzko erabakia positiboa edo negatiboa den, txostenen edukiarekin batera. Batzorde Zientifikoak hala eskatuta, egileei originalean aldaketak egiteko eskatzen bazaie, egileek beharrezkoak diren aldaketak eginda bidaliko dute berriro originala, idatzian ezarriko zaien epearen barruan.

\section{Artikuluetarako arauak}

Originalak testu prozesadore batez idatzita igorriko dira. Lan bakoitzeko, bi fitxategi bidaliko dira:

1. Aurkezpena: egile bakoitzaren datuak (izena, abizenak, unibertsitatea, posta helbidea, posta elektroniko instituzionala eta ORCID identifikatzaile digitala) eta egileak sinatutako adierazpen bat, non beren autoretza eta bidalitako lanaren originaltasuna egiaztatuko duten, baita hartutako erantzukizun etikoak ere, eta, hala behar bada, interes gatazken adierazpen bat. Finantzatutako ikerketetan oinarritutako lanetan, finantzatzen duen erakundea aipatu beharko da.

2. Artikulua: epigrafe honen arauen arabera, egileen identitateari inolako erreferentziarik egin gabe.

Beste fitxategi batean, Excelen egindako grafikoak eta irudiak (jpg edo tiff formatuan) bidaliko dira.

Artikuluek 5.000 eta 8.000 hitzen arteko luzera izango dute, erreferentzia bibliografikoak barne.

Artikulu bakoitzeko hiru egile onartuko dira, gehienez. Ikerketan pertsona gehiagok parte hartu badute, hirugarren sinatzailearen ondorengoak oin ohar batean aipatu ahal izango dira.

Artikuluak euskaraz, gaztelaniaz edo ingelesez aurkez daitezke. Haien egitura hau izango da:

- $\quad$ Izenburua gaztelaniaz (Arial 14, letra lodiz, zentratua).

- $\quad$ Izenburua ingelesez (Arial 14, zentratua).

- Laburpena gaztelaniaz (Times New Roman 12, letra lodiz, justifikatuta): Gehienez 100 hitz (Times New Roman 12, justifikatuta).

- $\quad$ Gako hitzak gaztelaniaz (Times New Roman 12, letra lodiz, justifikatuta): 4 eta 6 hitz artean, punto eta komaz bereizita (Times New Roman 12, justifikatua). ZER aldizkariaren Thesaurusa osatzen dutenen artean hautatuko dira. Egileek zuzendari-tzari termino berriak sartzea proposatu ahal izango diote.

- $\quad$ Laburpena eta gako hitzak ingelesez (Abstract, Keywords), gaztelaniazkoen formatu berean.

- $\quad$ 0. Sarrera (epigrafe nagusia: Arial 12, Letra lodiz, justifikatuta, koskarik gabe).

- $\quad$ Testu gorputza (Times New Roman 12, justifikatua).

- $\quad$ 1.1. Bigarren mailako epigrafea (Arial 12, etzana, justifikatua, koskarik gabe).

- 1.1.1. Bigarren mailako epigrafea (Times New Roman, 12, etzana, justifikatua, koskarik gabe).

- $\quad$ Artikuluen amaieran, erreferentzia bibliografikoen epigrafea agertuko da, zenbakitu gabe (Times New Roman 12, koskarik gabe).

ZER aldizkariak gizarte komunikazioaren arloko estatuko eta nazioarteko argitalpen zientifikoen erreferentzia bibliografikoak erabiltzea gomendatzen du. Aldizkariaren koherentzia zaintze aldera, ZER aldizkariaren aurreko aleetan argitaratutako artikuluen erreferentziak txertatzea gomendatzen da; dena den, justifikatutko auto-aipamenak baino ez dira erabiliko. 
Artikuluan aipatutako lanak bakarrik adieraziko dira, egileen araberako hurrenkera alfabetikoan, 0,5 cm-ko koska frantsesa utzita eta 2015eko bertsioaren APA 6th editionen estilo arauei jarraituta (http://blog.apastyle.org/apastyle/):

\section{- Liburuak}

- Egile bat:

Cebrián, M. (2008). La radio en Internet. Buenos Aires: La Crujía.

- Zazpi egile arte:

Caridad, M., Hernández, T., Rodríguez, D., eta Pérez, B. (2011). Documentación audiovisual. Madril: Síntesis.

\section{- Liburuen kapituluak}

García, J. (2014). El discurso publicitario como productor de sentidos: algo más que anuncios. In M. Catalá, eta O. Díaz (koord.), Publicidad 360 (67-277 or.). Zaragoza: San Jorge Unibertsitatea.

\section{- Aldizkarietako artikuluak}

Agirre, A., Aiestaran, A., eta Zabalondo, B. (2015). Periodistas y lectores vascos y europeos contestan sobre el futuro de la profesión. Una colección de acuerdos y desacuerdos. ZER Komunikazio Ikasketen Aldizkaria, 20(39), 101-125. doi: 10.1387/zer.15525

\section{- Aldizkari eta liburu elektronikoak}

Heshmati, A., eta Lee, M. (2009). Information and communications technology. Princeton: Princeton University Press. Hemen berreskuratua: http://search.proquest.com/docview/189251427?accountid=14475

Testuan aipu bibliografikoen sistema Harvard estiloaren arabera egingo da. Letrak (a, b, c...) egile eta urte bereko lanak bereizteko erabiltzen dira.

- Egile bat:

Aldaiturriaga (2013: 347), (Aldaiturriaga, 2013: 347).

- Bi egile:

Berger eta Luckmann (2013: 132), (Berger \& Luckmann, 2003: 132).

- Hiru egile edo gehiago:

Lehen aipamenean egile guztien abizenak idatziko dira (Moore, Estrich \& Spelman, 2012: 33), eta ondorengo aipuetan et al. erabiliko da (Moore, Estrich \& Spelman, 2012: 33).

Berrogei hitz baino gutxiagoko hitzez hitzeko aipamenak komatxo artean jarriko dira, testuaren barruan. Berrogei hitzeko edo gehiagoko aipamenak, berriz, aparteko paragrafo batean jarriko dira 2,5 cm-ko koska batez ezkerrean, komatxorik gabe eta bi punturen ondoren.

Artikuluetan argibideetarako oharrak sar daitezke, baina soilik ezinbestekoak direnean. Orrialdearen oinean kokatuko dira, irakurketa errazteko.

Aldizkako argitalpenen izenak letra etzanez idatziko dira, baita beste hizkuntza bateko terminoak eta erabilera arrunteko adierazpen latinoak ere. Irrati eta telebista saioen izenak komatxo artean idatziko dira.

Taula, grafiko eta ilustrazioen aurretik izenburu laburrak eta deskriptiboak jarriko dira, eta elkarren segidan zenbakituko dira. Soilik ezinbestean jarri beharrekoak sartuko dira, eta bakoitzaren oinean iturria adieraziko da. Testuan txertatuta aurkeztuko dira Word batean. Excelen egindako grafikoak jatorrizko formatuan ere bidaliko dira, Word dokumentutik bereizita. Irudiak ere jatorrizko formatuan bidaliko dira (jpg edo tiff). Haien kalitate teknikoak inprimatze estandarrak errespetatuko ditu (300 ppp). 


\section{Liburuen aipamenak}

ZER aldizkariak bere jakintza arloaren inguruko liburuen aipamenak onartzen ditu, baldin eta Zuzendaritzak aldez aurretik eskatu edo onartu baditu. Liburuaren eta aipamenaren argitalpenen artean ez dira egongo 12 hilabete baino gehiago.

Egileek beren lanak aldizkarira bidal ditzakete, horien aipamena egin dadin.

Aipamenek 800 eta 1.000 hitzen arteko luzera izango dute, eta goiburuan liburuaren erreferentzia osoa egingo da -izenburua; egilearen izen-abizenak (urtea); hiria: argitaletxea-; amaieran sinatu egingo dira. Aipamenetan liburuen deskribapena eta kritika egin daitezke. 


\section{- Guide for the preparation of articles •}

\section{Description and editorial policy}

The journal ZER aims to promote research and disseminate scientific work carried out in the area of social communication. It is a biannual publication whose numbers are published in May and November each year. Exceptionally, the Editorial Board may approve the publication of special issues, at the proposal of the journal management.

It is published in print and electronically. Each article is identified with a DOI (Digital Object Identifier System).

ZER accepts articles from the field of social communication, as long as they are considered of interest by the management of the journal, with the supervision of the Editorial Board.

The submitted articles must be original and unpublished, and not in the process of being published in any other medium. Any article that is not unpublished, because of having been published or broadcast online in whole or in part, will be automatically rejected. Each author is to present a responsible authorship and originality statement, which is to include ethical responsibilities assumed and if necessary any declaration of conflicts of interest. The authors who do not respect this rule will be penalised with the non-publication of any other article for a period of at least a two year (four issues) period since the discovery of the diffusion of the article in another medium.

The publication of articles in the ZER requires prior peer reviews by members of the Scientific Committee of the journal, composed of researchers and experts in the area of social communication, external to the University of the Basque Country.

Each author may not publish more than one article per issue, both individually and / or collectively. In addition, between the publication of an article and another there must pass at least two issues.

Articles published by ZER can always be cited as long as the origin and authorship is indicated. The authors are solely responsible for the articles and their contents. ZER does not publish corrections of errors made by the authors in their citations, claims or statements or any other information contained in the published articles.

\section{Evaluation Process}

The submission procedure is performed only through the OJS platform of the journal: http:// www.ehu.eus/ojs/index.php/Zer ("About" / "Online Submissions").

The management of the journal carries out a first review of each article received and values whether this fits the profile of the journal. The management may dismiss in a reasoned way contributions that are outside the area of social communication; which do not meet the scientific nature of the journal, do not meet the originality criteria or do not meet the formal requirements for the submission of originals.

In the maximum period of 30 days from receipt of each article, excluding holiday periods, if there were any, authors will receive an acknowledgment, stating whether the article is rejected or it is considered for evaluation by members of the Scientific Committee.

The date for publication of articles is conditioned by the date the article is received and the response time of referees. The referees have a period of 30 days for evaluation. After that time, the journal reserves the right to redirect the article and send it to a new referee.

Each article will be sent to two members of the Scientific Committee for the evaluation. During the review process the anonymity of the author and referees is maintained. In the event that 
the two reports do not agree, a third referee report shall be sought. Ultimately, the management of the journal will take the final decision.

Upon receipt of the reports, the journal will notify authors of the positive or negative decision on the publication of its original article, accompanied by the content of the reports. In the event that, at the request of the Scientific Committee, authors are required to modify the original version, they will return it duly revised in the period which is set-out in the letter of referral.

\section{Standards for articles}

The original article will be sent word processed. For each job, two files will be sent:

1. Presentation: includes data for each author (name, surname, affiliation, postal address, institutional e-mail and ORCID digital identifier) and a statement signed by each author wherein they will certify their authorship and originality of the article sent and the contracted ethical responsibilities and, if necessary, a declaration of conflicts of interest. Manuscripts originated from funded research should indicate the funding agencies.

2. Article: conforms according to the rules of this section, without any reference to the identity of the author(s).

Excel charts and images will be sent in a separate file (in JPEG or TIFF format).

The length of the article will be between 5,000 and 8,000 words, including bibliographical references.

The maximum number of authors per article shall be three. If it is an investigation in which more people have been involved, after the third signature the name of the authors will appear as a footnote.

Articles may be submitted in Basque, Spanish and English. Its structure is as follows:

- $\quad$ Title in Spanish (Arial 14, bold, centred).

- $\quad$ Title in English (Arial 14, centred).

- $\quad$ Summary in Spanish (Times New Roman 12, bold, justified): maximum of 100 words Times New Roman 12, justified).

- $\quad$ Keywords in Spanish (Times New Roman 12, bold, justified) 4 to 6 words separated with a semi-colon (Times New Roman 12, justified). They will be chosen from those that form the Thesaurus of ZER. The author may request to the management of the journal the inclusion of new terms in the thesaurus.

- $\quad$ Summary and Key Words in English (Abstract, Keywords), in the same format as in Spanish.

- $\quad$ 0. Introduction (main section: Arial 12, bold, justified, without indents).

- $\quad$ Body of text (Times New Roman 12, justified).

- $\quad$ 1.1. secondary epigraph (Arial 12 , italic, justified, without indents).

- 1.1.1. secondary epigraph (Times New Roman 12, italic, justified, without indents).

- $\quad$ The Articles will end with the heading References, unnumbered (Times New Roman 12, bold, without indents).

ZER recommends using national and international references from scientific publications from the area of social communication. In order to maintain consistency in the journal, it is recommended to include references from articles previously published in ZER, but the use of selfcitations should be limited to those which are justified. Only cited works should be indicated in the article and should be ordered alphabetically by author, with hanging indent of $0.5 \mathrm{~cm}$ and following the rules of APA style 6th Edition 2015 (http:// blog.apastyle.org/apastyle/): 


\section{- Books}

- An author:

Cebrián, M. (2008). La radio en Internet. Buenos Aires: La Crujía.

- Up to 7 aut hors:

Caridad, M., Hernández, T., Rodríguez, D., and Pérez, B. (2011). Documentación audiovisual. Madrid: Síntesis.

\section{- Book chapters}

García, J. (2014). El discurso publicitario como productor de sentidos: algo más que anuncios. In M. Catalá, and O. Díaz (coords.), Publicidad 360o (pp. 267-277). Zaragoza: Universidad San Jorge.

\section{- Journal articles}

Agirre, A., Aiestaran, A., and Zabalondo, B. (2015). Periodistas and lectores vascos y europeos contestan sobre el futuro de la profesión. Una colección de acuerdos y desacuerdos. ZER Revista de Estudios de Comunicación, 20(39), 101-125. doi: $10.1387 /$ zer. 15525

- Journal and eBooks

Heshmati, A., and Lee, M. (2009). Information and communications technology. Princeton: Princeton University Press. From http://search.proquest.com/docview/ 189251427 ? accountid $=14475$

The system bibliographic citations in the text will follow the Harvard style. The letters $(a, b, c$ ...) serve to distinguish several works by the same author / year.

- An author: ZER

Aldaiturriaga (2013: 347), (Aldaiturriaga, 2013: 347).

- Two authors:

Berger and Luckmann (2013: 132), (Berger \& Luckmann, 2003: 132).

- Three or more authors:

The first time all author names are written (Moore, Estrich \& Spelman, 2012: 33), in subsequent citations et al will be used (Moore et al, 2012. 33).

The quotations of less than 40 words will be written in inverted commas and integrated into the text. The quotations of 40 words or more will go in a separate paragraph with a left indent $2.5 \mathrm{~cm}$, unquoted and preceded by a colon.

Articles may include notes for clarification, especially those deemed essential. They will be placed in a footnote for better readability.

Periodical names will be written in italics, as well as the terms from another language and Latin expressions in common use. The names of radio or television programs will be in quotation marks.

Tables, graphs and illustrations will be preceded by short, descriptive titles and be numbered consecutively. Only essential tables, graphs and illustrations will be included, along with the source of origin placed at the foot of each one. They will be presented and incorporated into the text in Word. The graphics which are made in Excel will be sent both within the word document and also in their original format. Images will also be sent in their original format (JPEG or TIFF). Its technical quality has to respect press standards (300 dpi).

\section{Book Reviews}

ZER accepts reviews of books related to its field of knowledge, always and as long as they have been requested or previously approved by management. Between the publishing of the book and the publication of the review there will not be more than 12 months.

The authors can send their work to the journal to be reviewed.

The extension of the reviews will be between 800 and 1,000 words and will begin with a complete reference of the book - Title; Surname and name of the author (year); City: editorial - and will be signed at the end. The reviews can accommodate both a description and a critical analysis. 



\title{
zer
}

revista de estudios de comunicación

komunikazio ikasketen aldizkaria

journal of communication studies

\section{SUSCRIPCIÓN / HARPIDETZA / SUBSCRIPTION}

Para 2016 / 2016n / For 2016

Servicio Editorial de la Universidad del País Vasco

Euskal Herriko Unibertsitateko Argitalpen Zerbitzua

University of the Basque Country Press

Apdo. / Posta kutxatila / Mailbox 1.397 - 48080 Bilbao

santiago.delahoz@ehu.eus - Tel.: (+34) 946012 226; Fax: (+34) 946012333

\begin{abstract}
Formas de pago: Contra reembolso (suplemento de 4 Euros), transferencia bancaria, cheque talón, o tarjeta de crédito (VISA o MASTERCARD).

Ordainketa-mota: Jasotzean ordaintzekoa (4 eurotako gehigarria), banku-transferentzia, txekea edo kreditu-txartela (VISA edo MASTERCARD).
\end{abstract}

Payment options: Cash on delivery (additional cost 4 euros), bank transfer, bank check, or credit card (VISA or MASTERCARD).

\begin{tabular}{r|r|} 
Anual Subscription Rate & $20 €$ \\
Suscripción para estudiantes / Ikasleentzako & $17 €$ \\
harpidetza / Student Rate & \\
Suscripción para instituciones / Erakundeko & $35 €$ \\
harpidetza / Institutional Rate & \\
\hline Precio del ejemplar / Alearen salneurria / Price & $15 €$ \\
Per Issue & \\
\hline
\end{tabular}

\begin{tabular}{|l|l|}
\hline $\begin{array}{l}\text { Nombre y apellidos / Institución: } \\
\text { Izen-abizenak / Erakundea: } \\
\text { Name / Institution: }\end{array}$ \\
\hline DNI / NIF: \\
NAN / IFZ: \\
VAT Number: \\
\hline $\begin{array}{l}\text { Dirección completa: } \\
\text { Helbidea: }\end{array}$ \\
$\begin{array}{l}\text { Address: } \\
\text { Correo electrónico: }\end{array}$ \\
\hline e-posta: & \\
\hline e-mail: & Teléfono: \\
\hline $\begin{array}{l}\text { Modalidad de suscripción: } \\
\text { Harpidetza mota: }\end{array}$ & Telefonoa: \\
Subscription Rate: & Phone Number: \\
\hline
\end{tabular}


